Ricardo Alexandro de Andrade Queiroz

\title{
Processo de Design Baseado no Projeto Axiomático para Domínios Próximos: Estudo de Caso na Análise e Reconhecimento de Textura
}

Texto apresentado à Escola Politécnica da Universidade de São Paulo para obtenção do Título de Doutor em Engenharia Mecânica. 
Ricardo Alexandro de Andrade Queiroz

\section{Processo de Design Baseado no Projeto Axiomático para Domínios Próximos: Estudo de Caso na Análise e Reconhecimento de Textura}

Texto apresentado à Escola Politécnica da Universidade de São Paulo para obtenção do Título de Doutor em Engenharia Mecânica.

Área de concentração:

Engenharia de Controle e Automação Mecatrônica

Orientador:

Prof. Dr. José Reinaldo Silva 


\section{Ficha Catalográfica}

Queiroz, Ricardo Alexandro de Andrade

Processo de Design Baseado no Projeto Axiomático para Domínios Próximos: Estudo de Caso na Análise e Reconhecimento de Textura. São Paulo, 2011. 167 p.

Tese (Doutorado) - Escola Politécnica da Universidade de São Paulo. Departamento de Engenharia Mecatrônica e de Sistemas Mecânicos.

1. Redes neurais 2. Textura (Análise) 3. Inteligência artificial 4. Reconhecimento de imagem 4. Linguagens formais 5. Engenharia de requisitos I. Universidade de São Paulo. Escola Politécnica. Departamento de Engenharia Mecatrônica e de Sistemas Mecânicos. II. t. 
Aos meus pais e irmão, com amor, admiração e gratidão pela compreensão, carinho, presença e incansável apoio ao longo do período de elaboração deste trabalho. 


\section{Agradecimentos}

A DEUS, responsável por orientar todos os passos da minha vida.

Aos amigos e avós (José Calazans de Andrade e Maria de Lourdes Monteiro Andrade) (in memoriam) que me fazem falta.

A minha mãe, Maria de Lourdes Monteiro Andrade Queiroz, e ao meu pai, Alberto Andiracê de Araújo Queiroz, que sempre me apoiaram em todos os momentos de alegria e tristeza, com amor, dedicação, força e muita paciência.

Agradecimentos especiais a meu irmão, Alberto Alexandro de Andrade Queiroz, que acredita e incentiva a busca dos meus sonhos e ideais.

Ao Prof. Dr. José Reinaldo Silva, amigo e orientador, pelo apoio, compreensão, incentivo e ensino, contribuindo para meu crescimento intelectual e científico.

Ao amigo Prof. Dr. Paulo Victor Fleming, coordenador do Curso de Engenharia Mecânica e Mecatrônica da Universidade Salvador, pelo incentivo e apoio.

Ao Prof. Dr. Francisco Javier Ropero Pelaez da Universidade Federal do ABC São Paulo, pelo incentivo. 


\section{Resumo}

$\mathrm{O}$ avanço tecnológico recente tem atraído tanto a comunidade acadêmica quanto o mercado para a investigação de novos métodos, técnicas e linguagens formais para a área de Projeto de Engenharia. A principal motivação é o atendimento à demanda para desenvolver produtos e sistemas cada vez mais completos e que satisfaçam as necessidades do usuário final. Necessidades estas que podem estar ligadas, por exemplo, à análise e reconhecimento de objetos que compõe uma imagem pela sua textura, um processo essencial na automação de uma enorme gama de aplicações como: visão robótica, monitoração industrial, sensoriamento remoto, segurança e diagnóstico médico assistido.

Em vista da relevância das inúmeras aplicações envolvidas e pelo fato do domínio de aplicação ser muito próximo do contexto do desenvolvedor, é apresentada uma proposta de um processo de design baseado no Projeto Axiomático como sendo o mais indicado para esta situação. Especificamente, se espera que no estudo de caso da análise de textura haja uma convergência mais rápida para a solução - se esta existir. No estudo de caso, se desenvolve uma nova concepção de arquitetura de rede neural artificial (RNA), auto-organizável, com a estrutura espacial bidimensional da imagem de entrada preservada, tendo a extração e reconhecimento/classificação de textura em uma única fase de aprendizado. Um novo conceito para o paradigma da competição entre os neurônios também é estabelecida. O processo é original por permitir que o desenvolvedor assuma concomitantemente o papel do cliente no projeto, e especificamente por estabelecer o processo de sistematização e estruturação do raciocínio lógico do projetista para a solução do problema a ser desenvolvido e implementado em RNA. 


\section{Abstract}

The recent technological advance has attracted the industry and the academic community to research and propose methods, seek for new techniques, and formal languages for engineering design in order to respond to the growing demand for sophisticated product and systems that fully satisfy customers needs. It can be associated, for instance, with an application of object recognition using texture features, essential to a variety of applications domains, such as robotic vision, industrial inspection, remote sensing, security and medical image diagnosis.

Considering the importance of the large number of applications mentioned before, and due to their characteristic where both application and developer domain are very close to each other, this work aims to present a design process based on ideas extracted from axiomatic design to accelerate the development for the classical approach to texture analysis. Thus, a case study is accomplished where a new conception of neural network architecture is specially designed for the following proposal: preserving the two-dimensional spatial structure of the input image, and performing texture feature extraction and classification within the same architecture. As a result, a new mechanism for neuronal competition is also developed as specific knowledge for the domain. In fact, the process proposed has some originality because it does take into account that the developer assumes also the customer's role on the project, and establishes the systematization process and structure of logical reasoning of the developer in order to develop and implement the solution in neural network domain. 


\section{Lista de Figuras}

1.1 Representação sucinta da proposta desenvolvida para análise de eliciação e comunicação de requisitos em domínios disjuntos - análise por parte da engenharia e medicina (QUEIROZ; SILVA, 2009). . . . . . . . . 3

1.2 Comparação entre as diferentes distâncias do domínio da aplicação e do processo/domínio da engenharia. . . . . . . . . . . . 4

1.3 Característica do Projeto Axiomático em relação aos requisitos dos domínios próximos e das áreas de Projeto de Engenharia e Rede Neural. 8

1.4 Representação gráfica do contexto da proposta envolvida neste trabalho. 9

2.1 Domínios envolvidos no Projeto Axiomático . . . . . . . . . . . 16

2.2 Exemplo de hierarquia simplificada do domínio funcional de um suposto sistema de transporte pessoal (bicicleta). . . . . . . . . . 19

2.3 Ziguezague entre os domínios funcional e físico. . . . . . . . . . 20

2.4 Exemplo da matriz de projeto e a respectiva representação gráfica hierárquica dos domínios. . . . . . . . . . . . . . . 22

2.5 Esquemático gráfico das equações de projeto - exemplo bidimensional (adaptado: $($ GYUNG-JIN, 2007)) . . . . . . . . . . . . . 29

2.6 Representação gráfica da probabilidade de sucesso (adaptado: (ELHANIK, 2005)) . . . . . . . . . . . . . 32

2.7 Representação gráfica para o cálculo do conteúdo de informação . . . 35

2.8 Fluxograma de aplicação da abordagem axiomática (HOU; WEN; HAN,

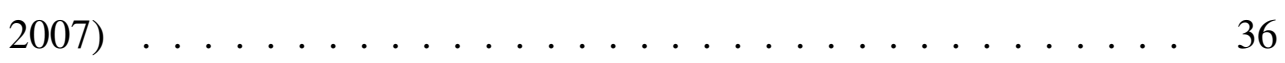

2.9 Exemplo de diagrama em árvore para a hierarquia $\{F R\}$ e $\{D P\}$ (adaptado: $($ SUH, 1998)). . . . . . . . . . . . . 37

2.10 Diagrama de junção de módulo do projeto descrito pela equação 2.16 (adaptado: $($ SUH, 1998)) . . . . . . . . . . . . . 38 
2.11 Diagrama de fluxo do projeto do sistema fornecido pela equação 2.16 $(\mathrm{SUH}, 1998) \ldots \ldots \ldots \ldots \ldots \ldots$

2.12 Representação matricial de uma imagem (adaptado: (GONZALES; WOODS, 2002) $\ldots \ldots \ldots \ldots \ldots \ldots \ldots$

2.13 Espectro da textura com base na regularidade de sua variação estrutural (adaptado:(MIRMEHDI; XIE; SURI, 2009)) . . . . . . . . . . . . . .

2.14 Possíveis direções entre o elemento de refêrencia e seus oito vizinhos. Resolução da célula $d=1$. O elemento central em relação aos vizinhos 1 e 5 possui direção $a=0^{0}$ (horizontal), enquanto que os vizinhos $7 \mathrm{e}$ 3 possui direção $a=90^{\circ}$ (vertical). Já a relação entre os vizinhos $2 \mathrm{e}$ 6 possui direção $a=135^{\circ}$ (diagonal 1), enquanto que a dos vizinhos 8 e 4 possui direção $a=45^{\circ}$ (diagonal 2) (adaptado: (HARALICK; SHANMUGAM; DINSTEIN, 1973)). . . . . . . . . . . . .

2.15 Representação da matriz de co-ocorrência em uma imagem 4 x 4, com quatro tons de cinza (adaptado: (HARALICK; SHANMUGAM; DINSTEIN, 1973)) . . . . . . . . . . . .

2.16 Ângulos utilizados para construção das matrizes de comprimento de corrida de cinza (ALBREGTSEN, 1995) . . . . . . . . . . .

2.17 Representação da matriz de corridas de tons de cinza em uma imagem

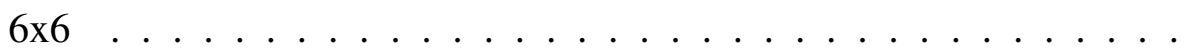

2.18 Função de autocorrelação computada de quatro texturas de Brodatz (BRODATZ, 2009), de acordo com Sebe e Lew (2001). . . . . . . . .

2.19 Representação da construção da matriz NGTDM (adaptado: (AMADASUN; KING, 1989))

2.20 Funções $S(r)$ e $S(q)$ determinadas a partir do espectro de Fourier de texturas periódicas, apresentadas em (a) e (e). (adaptado: (GONZALES; WOODS, 2002)). . . . . . . . . . . . . . . . .

2.21 Extração da característica de textura através do espectro de potencia de Fourier. (a) Energia computada com base na informação radial, caracterizando a aspereza/rugosidade da textura, e (b) energia computada com base na informação da direcionalidade, em que $\tan ^{-1}(v / u)$ denota

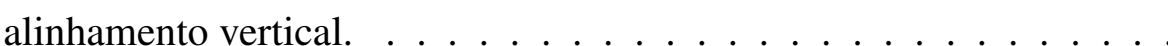


2.22 Exemplificação do uso do filtro de Gabor (frequência fixa). (a) imagem de referência (b) filtros com orientação $\theta^{0}, \theta^{45}, \theta^{90}, \theta^{135}$, e variações de escala $\sigma$; (c) resultados obtidos sobre a imagem de referência. (adaptado: $($ SAMPAIO, 2007)) . . . . . . . . . . . . . 70

2.23 Decomposição de um nível da imagem original utilizando os filtros L e H (adaptado: (MALLAT, 1989b)). . . . . . . . . . . . . . . .

2.24 Transformada bidimensional de uma imagem. (a) decomposição em um nível; (b) decomposição em dois níveis. . . . . . . . . . . . . . .

2.25 Exemplos de texturas (BRODATZ, 2009) (adaptado: (ZHANG; TIENIU, 2002)) . . . . . . . . . . . . . . . 75

2.26 Exemplos da distribuição e/ou formação espacial de primitivas . . . . 76

2.27 Segmentação da Textura utilizando Voronoi Tessellation (TUCERYAN; JAIN, 1999). . . . . . . . . . . . . . . 77

2.28 Resultado da Tesselagem de Voronoi (TUCERYAN; JAIN, 1999). . . 79

2.29 Fases envolvidas em todo o processo de classificação de textura. . . . 81

2.30 Redes auto-associativa e MPL empregadas no processo de análise de textura (adaptado: (KULKARNI; VERMA, 2001)). . . . . . . . 82

2.31 Diagrama esquemático de arquitetura de RNA para extração e classificação de textura (adaptado: (TIVIVE; BOUZERDOUM, 2006)). . . . . . . 83

3.1 Processo proposto para o desenvolvimento do trabalho - Fase I, II e III 89

3.2 Atividades e escopo dos critérios adotados na primeira fase do processo proposto. . . . . . . . . . . . . . . 93

3.3 Escopo das etapas a ser realizada na Fase II do processo proposto. . . 94

3.4 Modelo do neurônio artificial (HAYKIN, 1999). . . . . . . . . . . 95

3.5 Influência dos parâmetros $T$ e $\theta_{k}$ na função logística. . . . . . . . . . 96

4.1 Exemplos de texturas homogêneas . . . . . . . . . . . . . . 103

4.2 Relação/vínculo hipotético entre $\{$ restrição-restrição $\}$ e requisitos $\{$ requisitorestrição_associada $\}. \ldots \ldots \ldots \ldots \ldots 11$

4.3 Relação/vínculo hipotético entre $\{$ saída $(\downarrow)$ - restrição $\} \ldots 112$

4.4 Atividades envolvidas na FASE I - Definição do Problema . . . . . . 115 
4.5 Matriz de Projeto da solução (regra de análise à extração de característica a ser desempenhada pelo domínio complementar.) . . . . . . 116

4.6 Diagrama de fluxo da matriz de projeto fornecida pela Fase I . . . . . 119

4.7 Representação em Rede Neural da solução proposta pela Fase I. . . . 121

4.8 Arquitetura da rede neural proposta para a análise e reconhecimento de textura. . . . . . . . . . . . . . . . . 122

4.9 Pseudocódigo da RNA proposta . . . . . . . . . . . . . . . . . . 123

4.10 Textura homogênea sintética criada para a fase de aprendizado da RNA. 124

4.11 Textura sintética criada para os testes preliminares com a RNA proposta. 125

4.12 Imagem em função da resposta da RNA. A cor cinza - representa o reconhecimento exato do fundo da imagem; a cor branca - representa o reconhecimento das imagens que compõe os objetos; cor preta - representa as imagens do objeto que foram reconhecidas de forma errônea pela RNA. . . . . . . . . . . . . . . . . . . . . 126

4.13 Imagem clássica - Tijolo (LAMBERTI, 2011) . . . . . . . . . . . . 127

4.14 Imagem em função da resposta da RNA. A cor cinza escuro - representa o reconhecimento da classe B; cor cinza claro - representa a Classe A; cor preta - pontos onde ocorreram erros na classe A; cor branca - pontos onde ocorreram erros na classe B. . . . . . . . . . . . 128

4.15 Tecido com falha na fabricação (KUMAR, 2011) e as respectivas áreas de interesse para compor o conjunto de treinamento. . . . . . . . . . . 129

4.16 Imagens em função da resposta da RNA . . . . . . . . . . . . . . 130

4.17 Imagem utilizada para o treinamento da RNA. (adaptado: (VTT; OULU,

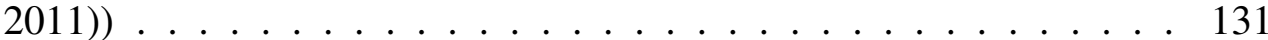

4.18 Imagem teste - tamanho 1710x395 pixels (adaptado: (VTT; OULU,

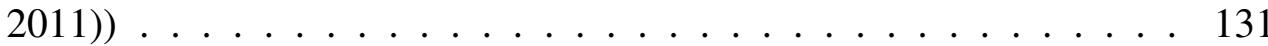

4.19 Imagem gerada em função da resposta da RNA - tamanho 1710x395 pixels

4.20 Imagem de câncer de pele (LCC, 2011) e as respectivas áreas/texturas consideradas no conjunto de treinamento à RNA. . . . . . . . . . . . 133

4.21 Imagens em função da resposta da RNA . . . . . . . . . . . . . . 134

4.22 Imagem utilizada do globo ocular $\ldots \ldots$. . . . . . . . . . 135 
4.23 Imagens em função da resposta da RNA . . . . . . . . . . . . . 136

5.1 Fases envolvidas na validação da solução. . . . . . . . . . . . . . . . 142

5.2 Histograma da imagem utilizada na simulação 03. . . . . . . . . . . . 144

5.3 Histograma do conjunto de dados utilizados para o treinamento da RNA (áreas:1,2,3 - Classe A; áreas 4,5 - Classe B). . . . . . . . . . . 145

5.4 Histograma da imagem utilizada na simulação 04. . . . . . . . . . . . 146

5.5 Histograma do conjunto de dados utilizado na RNA - Câncer de pele (áreas 1, 2, 3 e 4 - textura de câncer; áreas 5, 6 e 7 textura da pele normal). . . . . . . . . . . . . . . . . . 147

5.6 Histograma da imagem utilizada na simulação 06. . . . . . . . . . . . 148

5.7 Histograma do conjunto de dados utilizado no treinamento da na RNA - simulação 06. . . . . . . . . . . . . . . . . . . . . . . . . . . . . 149 


\section{Lista de Tabelas}

2.1 Características dos domínios envolvidos no Projeto Axiomático nas áreas de manufatura, materiais, software, organização, sistema, negócios. 18

2.2 Relação $\{\mathrm{FR}\}-\{\mathrm{DP}\}$ de acordo com a matriz de projeto. Adaptado (GYUNG-JIN, 2007). . . . . . . . . . . . . . 23

2.3 Definição dos $\{$ DPs $\}$ e equação do projeto para uma torneira (misturador) de água quente/fria - solução 1. . . . . . . . . . . . . . 26

2.4 Definição dos $\{$ DPs $\}$ e equação do projeto para uma torneira (mistura-

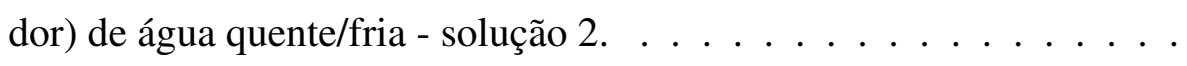

2.5 Parâmetros $\{\mathrm{DPs}\}$ e equação do projeto de refrigerador vertical e ho-

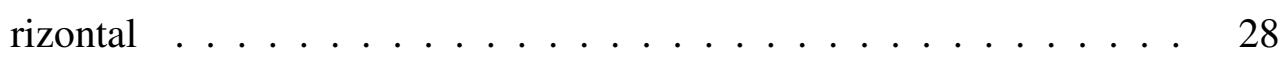

2.6 Valor de $R$ e $S$ para cada tipo de projeto. . . . . . . . . . 31

2.7 Condições das cidades A e B . . . . . . . . . . . . . . . . 34

2.8 Avaliação de alternativas . . . . . . . . . . . . . . . 34

2.9 Tipos de junções $(\mathrm{SUH}, 1998) \ldots \ldots$

2.10 Relação de descritores de Haralick com suas respectivas características. 52

2.11 Funções para extração de característica da textura, baseada no momento de área (TUCERYAN; JAIN, 1999). . . . . . . . . . . . . . 78

2.12 Trabalhos encontrados na literatura que utilizam diferentes técnicas de análise de textura . . . . . . . . . . . . . . 86

4.1 Correspondência com as atividades proposta (seção 3.2.1) e os grupos de requisitos estabelecidos para o domínio do desenvolvedor. . . . . 105

4.2 Relação/vínculo hipotético entre três requisitos quaisquer. . . . . . . 105

4.3 Levantamento dos Requisitos - Produto/Sistema . . . . . . . . . . . . 107

4.4 Levantamento dos Requisitos - Entrada - Produto/Sistema . . . . . . . 108

4.5 Levantamento dos Requisitos - Análise - Produto/Sistema . . . . . . . 109 
4.6 Levantamento dos Requisitos - Saída - Produto/Sistema . . . . . . . . 110

4.7 Restrições - Domínio Aplicação . . . . . . . . . . . . . . . . 113

4.8 Restrições - Domínio Complementar . . . . . . . . . . . . . . . . . . 114

4.9 Restrições - Domínio Complementar . . . . . . . . . . . . . . . . . 117

4.10 Taxas de acerto obtidas na fase de teste da RNA para análise e reconhecimento de textura - Simulação $01 \ldots \ldots$

4.11 Taxas de acerto obtidas na fase de teste da RNA para análise e reconhecimento de textura - Simulação 02 . . . . . . . . . . . . 128

4.12 Taxas de acerto obtidas na fase de teste da RNA para análise e reconhecimento de textura - Simulação 03. . . . . . . . . . . . . . 129

4.13 Taxas de acerto obtidas na fase de teste da RNA para análise e reconhecimento de textura - Simulação 04 . . . . . . . . . . . . . 131

4.14 Taxas de acerto obtidas na fase de teste da RNA para análise e reconhecimento de textura - Simulação 05. . . . . . . . . . . . 133

4.15 Taxas de acerto obtidas na fase de teste da RNA para análise e reconhecimento de textura - Simulação 06. . . . . . . . . . . . 135

5.1 Características fornecidas pela abordagem da busca de informações explícitas em documentos. . . . . . . . . . . . . . . . . . . 139

5.2 Resumo das seis simulações da RNA em relação a texturas homogêneas sintéticas e naturais. . . . . . . . . . . . . . . . . . . . . . 143 


\section{Lista de Abreviaturas}

\begin{tabular}{|c|c|c|}
\hline ANN & Artiticial Neural Network & Rede neural artificial (RNA) \\
\hline $\mathrm{CNN}$ & Convolutional Neural Network & Rede neural convolutiva \\
\hline DFT & Discrete Fourier Transform & Transformada discreta de Fourier \\
\hline GLN & Gray level non-uniformity & Não uniformidade do tom de cinza \\
\hline GLRLM & Gray level run Length matrices & $\begin{array}{l}\text { Matriz de comprimento de corrida } \\
\text { de tons de cinza }\end{array}$ \\
\hline HGRE & High gray level runs emphasis & $\begin{array}{l}\text { Ênfase em corrida em baixo nível } \\
\text { de tom de cinza }\end{array}$ \\
\hline LGRE & Low gray level runs emphasis & $\begin{array}{l}\text { Ênfase em corrida em alto nível de } \\
\text { tom de cinza }\end{array}$ \\
\hline LMS & Least Mean Square & Mínimo quadrado médio \\
\hline LRE & Long runs emphasis & Ênfase em corridas longas \\
\hline MPL & Multi layer perceptron & Perceptron de múltiplas camadas \\
\hline MRA & Multiresolution Analysis & Análise de multiresolução \\
\hline NAE & National Academy of Engineering & Academia nacional de Engenharia \\
\hline NGTDM & $\begin{array}{l}\text { Neighborhood gray tone difference } \\
\text { matrix }\end{array}$ & $\begin{array}{l}\text { Matriz da diferença dos tons de } \\
\text { cinza da vizinhança }\end{array}$ \\
\hline $\mathrm{NN}$ & Nearest Neighbors & Vizinhos mais próximos \\
\hline PNN & Probabilistic Neural Network & Rede neural probabilística \\
\hline QMF & Quadrature Mirror Filters & Filtro de quadratura espelhado \\
\hline RLN & Run length non-uniformity & $\begin{array}{l}\text { Não uniformidade do tamanho de } \\
\text { corrida }\end{array}$ \\
\hline $\mathrm{RP}$ & Run percentage & Percentagem de corrida \\
\hline SER & Short runs emphasis & Ênfase em corrida curtas \\
\hline SGLDM & $\begin{array}{l}\text { Spacial gray level dependence ma- } \\
\text { trices }\end{array}$ & $\begin{array}{l}\text { Matriz de dependência espacial dos } \\
\text { níveis de cinza }\end{array}$ \\
\hline $\mathrm{SOM}$ & Self-Organizing Map & Mapa auto-organizável \\
\hline SVM & Support Vector Machine & Máquinas de vetor de suporte \\
\hline WTA & Winner Takes All & O ganhador leva tudo \\
\hline
\end{tabular}




\section{Sumário}

1 Introdução 1

1.1 Contextualização . . . . . . . . . . . . . . . . . . 1

1.1.1 Domínios Disjuntos ................. 1

1.1.2 Domínios Próximos ................ 2

1.2 Problemática ...................... 5

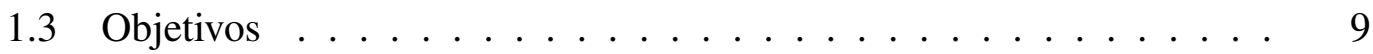

1.4 Contribuições da Tese . . . . . . . . . . . . . . . . . . . . . . . 10

1.5 Organização do trabalho . . . . . . . . . . . . . . . . 10

2 Fundamentação Teórica $\quad 13$

2.1 Projeto Axiomático . . . . . . . . . . . . . . . . . . . . 14

2.1 .1 Introdução . . . . . . . . . . . . . . . . . . . . 14

2.1 .2 Conceitos e Definições Iniciais . . . . . . . . . . . . . . 15

2.1.3 Axioma 1 - Axioma da Independência . . . . . . . . . . 21

2.1.4 Axioma 2 - Axioma da Informação . . . . . . . . . . . 31

2.1.5 Arquitetura do Sistema . . . . . . . . . . . . . 36

2.2 Análise de Textura . . . . . . . . . . . . . . . . . . 40 40

2.2.1 Representação da Imagem Digital . . . . . . . . . . . . . . . 40

2.2 .2 Textura ......................... 42

2.2.3 Métodos de Análise . . . . . . . . . . . . . . . . . . 45

2.2.3.1 Abordagem Estatística . . . . . . . . . . . . 45

2.2.3.2 Abordagem Baseada em Processamento de Sinais . 62

2.2.3.3 Abordagem Geométrica . . . . . . . . . . . 75 
2.2.4 Classificação de Textura . . . . . . . . . . . . . . . 79

3 Processo de Projeto em Domínios Próximos $\quad 87$

3.1 Introdução . . . . . . . . . . . . . . . . . . . . 87

3.2 Definição do Processo . . . . . . . . . . . . . . . . . . 87

3.2.1 Fase I - Definição do Problema . . . . . . . . . . . . . . . . 89

3.2.2 Fase II - Desenvolvimento e Implementação . . . . . . . . . . 94

3.2.3 Fase III - Avaliação e Validação . . . . . . . . . . . . . . . . 98

3.3 Resumo do Capítulo . . . . . . . . . . . . . . . . . . 99

4 Estudo de Caso $\quad 102$

4.1 Introdução . . . . . . . . . . . . . . . . . . . . . . . 102

4.2 Delimitação do Contexto de Análise . . . . . . . . . . . . . . . 102

4.3 Aplicação do Processo Proposto . . . . . . . . . . . . . . . . . . . 103

4.3.1 FASE I - Definição do Problema . . . . . . . . . . . . . . . . 104

4.3.1.1 Etapa I - Domínio do Desenvolvedor . . . . . . . . 104

4.3.1.2 Etapa II - Domínio Funcional e Físico . . . . . . . 115

4.3.2 FASE II - Desenvolvimento e Implementação . . . . . . . . . 119

4.3.3 FASE III - Avaliação e Validação . . . . . . . . . . . . . . . 122

4.3.3.1 Textura Homogênea Sintética . . . . . . . . . . . . 124

4.3.3.2 Textura Homogênea Natural . . . . . . . . . . . . 126

5 Discussões e Análise dos Resultados 137

5.1 Introdução . . . . . . . . . . . . . . . . . . . . . 137

5.2 Discussões . . . . . . . . . . . . . . . . . . . 137

5.2.1 Discussões sobre o Processo e sua Aplicação ....... . 137

5.2 .2 Validação . . . . . . . . . . . . . . . . . . . 141

5.3 Análise dos Resultados . . . . . . . . . . . . . . . . . . . . . 143

5.4 Resumo do Capítulo . . . . . . . . . . . . . . . . . . . . . . . . 149 
6 Conclusões e Trabalhos Futuros

Referências Bibliográficas 


\section{Introdução}

\subsection{Contextualização}

\subsubsection{Domínios Disjuntos}

O principal responsável pelas falhas em projetos de engenharia são erros e decisões tomadas na fase inicial do processo de aquisição dos objetivos, necessidades ou restrições estabelecidas pelos clientes e/ou usuários do sistema. Segundo Sheldon et al. (1992) tais erros podem alcançar uma taxa de $41 \%$ em um dado projeto. Steve McConnell e Weinberg Jerry (ROBERTSON; ROBERTSON, 2006) estimam que estes erros podem atingir a marca de $60 \%$ - todos eles gerados na fase de comunicação e transferência de conhecimento entre o cliente e o desenvolvedor (BEYER; HOLTZBLATT, 1995).

Queiroz (2007), Queiroz e Silva (2009) afirmam que estas taxas podem aumentar de forma exponencial em projetos que possuem domínios disjuntos ${ }^{1}$, como, por exemplo, no caso de sistemas voltados para a medicina. A terminologia domínio disjunto é baseada no fato de não existir uma intersecção substancial de termos e conceitos entre o domínio do projeto e o domínio de discurso da equipe de desenvolvimento. Este conjunto de termos comuns (chamado símile) poderia ser usados como base de descrição (QUEIROZ; SILVA, 2009) e comunicação de requisitos. Por exemplo, nos projetos de automação para a área médica, em especial na área cirúrgica, a diferença de linguagem técnica (jargões técnicos, métricas, encadeamento de processos, etc) é um entrave para a aquisição e interpretação dos requisitos (KOTONYA; SOMMERVILLE, 1998). Esta distância entre domínios pode induzir a falhas que podem inviabilizar a difusão da automação para esta e outras áreas demandantes, uma vez que o atendimento completo (ou mesmo parcial) aos requisitos tende a se tornar ainda mais crítico em áreas distantes do domínio da engenharia (QUEIROZ; SILVA, 2009).

Portanto, este é um problema de grande relevância para as áreas de automação e mecatrônica e, curiosamente, pouco discutido na literatura (FREY; DYM, 2006). Em

\footnotetext{
${ }^{1}$ Aplicação onde os usuários e especialistas (stackholders) do domínio estão distantes dos processo da engenharia e do universo dos desenvolvedores.
} 
Queiroz (2007) foi apresentado um modelo para a eliciação de requisitos em domínios disjuntos, tomando como exemplo a área médica cirúrgica (especificamente em oftalmologia), e focando prioritariamente na visualização de processos. O modelo é baseado no planejamento de ações de artefatos modelados formalmente (ou aproximadamente) a partir da análise etnográfica dos requisitos - movimentos cirúrgicos realizado numa cirurgia minimamente invasiva (catarata). Alguns conceitos da computação gráfica, em especial o de realidade virtual, foram usados para desenvolver um ambiente tridimensional, não imersivo. Este ambiente foi utilizado não só para minimizar a distância na comunicação (engenheiro e médico) entre os domínios, bem como para explorar a percepção visual do especialista ${ }^{2}$ da área médica no processo de validação dos requisitos eliciados. Os resultados foram muito promissores e efetivos para lidar com a distância entre os domínios, embora incluíssem uma etapa de eliciação baseado em técnicas etnográficas, que embora eficientes nestes casos, demandam grande esforço e dedicação. Por outro lado, o método proporcionou também a visualização clara de perspectivas/alternativas para a automação do procedimento cirúrgico.

De forma sucinta, apresenta-se na figura 1.1 o conceito do ambiente desenvolvido para criar o elo de comunicação entre os domínios disjuntos. Maiores detalhes sobre as discussões levantadas sobre a eliciação proposta, bem como suas fases, aplicação e resultados obtidos num estudo de caso em particular podem ser encontrados em Queiroz (2007), Queiroz e Silva (2009). No que se segue será resgatada a definição de domínio próximo (em contraposição ao domínio distante, usada no trabalho mencionado), que serão importantes para o presente trabalho.

\subsubsection{Domínios Próximos}

Os domínios próximos, interesse deste trabalho, são caracterizados por um contexto em que o domínio da aplicação está tão próximo do processo de engenharia que o desenvolvedor assume o papel do próprio especialista (isto é, o detentor do conhecimento e das necessidades da área da aplicação) no desenvolvimento do projeto. Ou seja, nesta abordagem é o próprio desenvolvedor o responsável pela definição do escopo do problema a ser solucionado, estabelecendo os objetivos, necessidades, restrições e as decisões a serem tomadas no decorrer do projeto.

Para melhor compreensão do distanciamento existente entre os domínios citados, apresenta-se na figura 1.2 uma ilustração que mostra a superposição de papéis entre o desenvolvedor e o especialista (stakeholder).

\footnotetext{
${ }^{2} \mathrm{O}$ termo especialista aqui é uma "tradução" de stakeholder - aquele que entende do processo a ser desenvolvido.
} 


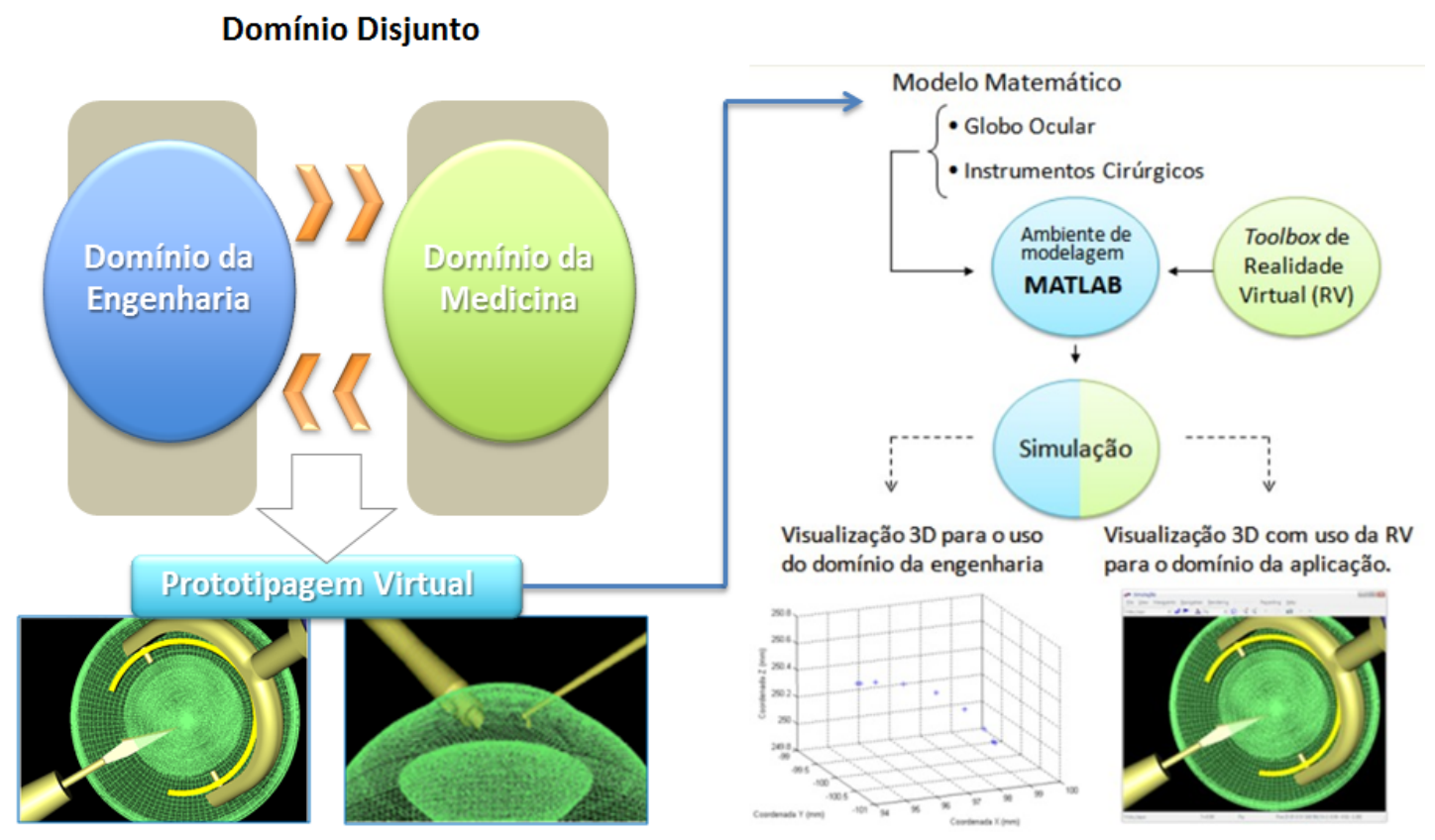

Figura 1.1: Representação sucinta da proposta desenvolvida para análise de eliciação e comunicação de requisitos em domínios disjuntos - análise por parte da engenharia e medicina (QUEIROZ; SILVA, 2009).

À primeira vista pode parecer que a proposta se resume a uma simplificação do processo de eliciação de requisitos, em especial, da comunicação e transferência de conhecimento entre o cliente/especialista e desenvolvedor, tida na literatura como uma das fases mais críticas no desenvolvimento de projeto (GOGUEN; LINDE, 1993; HICKEY; DAVIS, 2003; ROBERTSON; ROBERTSON, 2006). Entretanto, o fato do desenvolvedor se sobrepor ao papel do especialista nesta nova abordagem impõe outros problemas/dificuldades no que se refere ao projeto de engenharia.

O primeiro problema está ligado a dificuldades da própria eliciação - eminentemente informal e, na abordagem clássica, intuitivo. O fato desta vertente ser direcionada ao conhecimento explícito em documentos, pode levar o projetista/desenvolvedor a falsa sensação de conforto e crença de que todos os problemas de eliciação foram resolvidos. Além disto, a dispersão das informações contidas em vários documentos pode aumentar o volume de trabalho a ser realiazado (identificação da real relevância de um dado aspecto do problema, aquisição do potencial de volatilidade dos requisitos e a identificação das restrições) de maneira que este se sinta desestimulado a desenvolvê-lo.

Assim, o fato do desenvolvedor ser o "senhor" do projeto, isto é, o detentor da plena autonomia das decisões a serem tomadas no projeto, pode influenciá-lo, na prática, a reduzir/simplificar esta atividade. Como conseqüência, soluções pré-concebi- 


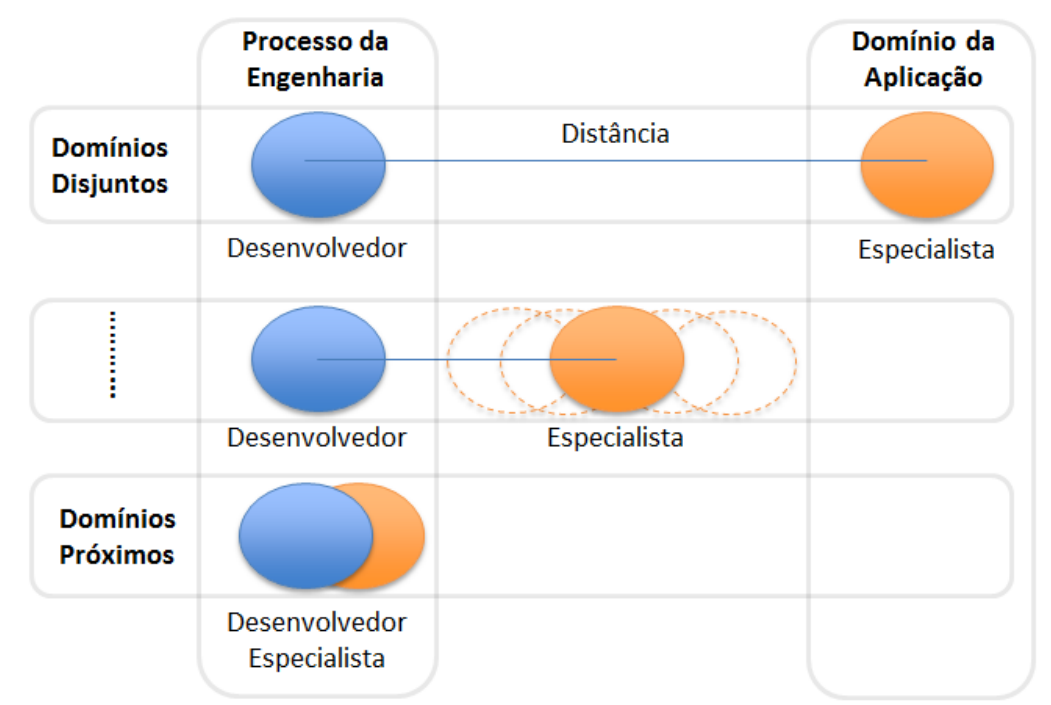

Figura 1.2: Comparação entre as diferentes distâncias do domínio da aplicação e do processo/domínio da engenharia.

das ou tendenciosas podem ser estabelecidas com base (somente) no seu conhecimento e compreensão do domínio da aplicação, optando por uma posição de autoconfiança infundada na documentação. Uma alternativa para minimizar esta postura seria acelerar a formalização e análise dos requisitos, tornando a confiança do desenvolvedor em algo realístico e bem fundamentado. Naturalmente, a exeqüibilidade desta alternativa está ligada ao método de projeto (design) adotado. Um tratamento mais adequado, baseado na Engenharia do Conhecimento pode também ser outra alternativa, não excludente com a formalização (MILTON, 2007).

O segundo problema a ser mencionado refere-se ao processo de tomada de decisão na escolha da melhor solução/alternativa na fase preliminar de projeto (design) (em específico, fase de projeto conceitual (PAHL; BEITZ, 2007)). Neste caso, a avaliação das concepções é realizada de forma subjetiva, pois se encontram em um estágio abstrato, incompleto e esquemático. Logo, os critérios estabelecidos e avaliados pela equipe de projeto levam em conta não só as necessidades do cliente/especialista, como a opinião destes em relação às alternativas propostas (PAHL; BEITZ, 2007; ULLMAN, 1997; ULRICH; EPINGER, 1995).

Como na abordagem de domínios próximos, o desenvolvedor assume o papel do próprio especialista que delega parte da responsabilidade pelo controle das decisões a serem tomadas no projeto (ou seja, o discernimento sobre as alternativas/concepções de possíveis soluções são realizada com base no conhecimento e opinião do próprio desenvolvedor), a solução a ser estabelecida está sujeita a: i) ser selecionada por atender melhor a sua conveniência, ou seja, aquela, por exemplo, que reduza o trabalho a ser realizado no desenvolvimento/implementação da solução; ii) ser escolhida por ter vários 
recursos que teoricamente venham a aumentar a produtividade do cliente, muito embora não atenda de forma satisfatória aos usuários finais; iii) ou na pior hipótese, uma alternativa que desvirtue completamente da real necessidade do cliente/especialista.

A fim de minimizar o fato descrito acima, propõe-se a intensificação no uso da técnicas de projeto (design) com critérios não só formais, independentes do domínio da aplicação mas que contemplem o acoplamento do formal e informal, e que seja aplicável em qualquer estágio (abstrato ou detalhado) na definição da concepção.

Na seção seguinte é apresentada com maiores detalhes a problemática na qual o contexto dos domínios próximos é estabelecido.

\subsection{Problemática}

A comunidade acadêmica vem sendo atraída para investigar, buscar e propor métodos, processos, técnicas e linguagens formais na área de Projeto de Engenharia com a finalidade de melhor atender a demanda por produtos e sistemas cada vez mais complexos, e que satisfaçam as necessidades do usuário/cliente. Necessidades estas que podem ser, por exemplo, a análise e reconhecimento de objetos que compõe uma imagem através de textura, essenciais para aplicações no âmbito da: visão robótica - navegação de robôs baseado na textura do ambiente (CHANDLER et al., 2003); monitoração industrial - inspeção e verificação de falhas em produtos manufaturados (FERREIRA; SANTOS, 2006; ISLAM; AKHTER; MURSALIN, 2006); sensoriamento remoto - análise de fotografias aéreas ou imagens de satélite à identificação de desmatamento/queimadas (LORETTE; DESCOMBES; ZERUBIA, 2000; COOPER, 2004), segurança - reconhecimento de face (ZHANG; GAO; LEUNG, 2006), recuperação de imagens por conteúdo - categori- zação de imagens médicas de ressonância, raio-x, tomografia computadorizada, etc (SILVA, 2009); diagnóstico médico assistido - detecção e/ou caracterização de lesões ou regiões atingidas por doenças (CASTELLANO et al., 2004; BHARATHI; VIJILIOUS; GANESAN, 2008), etc.

Em vista da relevância da gama de aplicações envolvidas, verificou-se a inexistência de um processo na área de Projeto de Engenharia, para, associado a métodos da Inteligência Artificial, como as Redes Neurais, propor solução(ões) mais rápida(s) as atividades envolvidas no contexto da análise e reconhecimento de textura. Assim, este trabalho parte de uma busca na literatura com o intuito de identificar os pontos de convergência entre as áreas de Projeto de Engenharia e Redes Neurais e que pudessem resultar em um processo de projeto para domínio próximos, aplicável por exemplo, à área de análise de textura. 
$\mathrm{Na}$ área de Projeto de Engenharia muitos modelos de desenvolvimento têm sido criados com o intuito de aumentar a qualidade dos produtos, reduzir custos e também o tempo de desenvolvimento. Atualmente vinte e um modelos de referência (JUNG et al., 2009) fornecem orientações gerais (etapas de transformação das informações sobre demandas e oportunidade em especificações técnicas) de como proceder durante o projeto, desenvolvimento e fabricação do produto, bem como atividades de gestão, marketing, comercialização e distribuição de serviço pós-venda (fora do escopo de interesse deste trabalho). Entretanto, a diferença entre esses modelos, de acordo com Jung et al. (2009), estão no detalhamento do desenvolvimento do projeto e na terminologia empregada entre eles.

$\mathrm{Na}$ literatura, o modelo mais difundido na área de projeto é fornecido por Pahl e Beitz (2007), denominado de modelo consensual, dividido em quatro fases: projeto informacional, projeto conceitual, projeto preliminar e projeto detalhado.

De forma sucinta, o projeto informacional é caracterizado pela definição do problema, estabelecimento das necessidades do cliente, usuários, especialistas (ALEXANDER; ROBERTSON, 2004), e transformações de tais informações em especificações de projeto. Estas por sua vez orientam a geração de soluções, bem como o estabelecimento dos critérios de avaliação.

A segunda fase, projeto conceitual, visa o desenvolvimento e a seleção de uma solução que atenda, ou que satisfaça mais completamente as especificações do projeto. Entretanto, por estar em uma fase inicial, abstrato e esquemático, ou seja, ainda em um estágio conceitual com poucos detalhes, com parâmetros não mensuráveis, o processo de análise, avaliação e seleção da(s) melhor(es) alternativa(s) torna-se crítico. Isto ocorre porque a avaliação ${ }^{3}$ (ponderação de pesos) dos critérios estabelecidos pela equipe de projeto (que devem refletir o desejo do cliente e não a opinião/necessidade pessoal do engenheiro) é realizada, via de regra, de forma subjetiva (não formal). Além disto, outro problema presente é o fato de que esses mesmos critérios de decisão refletem na própria característica da(s) concepção(ões) envolvidas. Tal fato dificulta ainda mais o processo sistemático de desenvolvimento de produtos, pois esses critérios tornam-se dependentes de um único domínio de análise específico (ou seja, não pode ser utilizado de forma comum/geral em outros domínios de aplicação). Assim, uma decisão realizada nesta fase de forma equivocada, traz problemas não só para as demais etapas mas compromete também o sucesso de todo o projeto.

\footnotetext{
${ }^{3} \mathrm{Na}$ literatura alguns métodos de seleção podem ser encontrados, tais como: matriz de decisão; julgamento de viabilidade, baseado nas limitações tecnológicas, atendimento dos requisito, etc; filtro tipo continua ou interrompe; prós e contras; protótipo e testes; facilidade de acesso à tecnologia; etc (OTTO; WOOD, 2001; ULLMAN, 1997; ULRICH; EPINGER, 1995; PUGH, 1990)
} 
À partir de uma melhor solução/concepção do produto, a fase de projeto preliminar tem como objetivo evoluir de uma abordagem conceitual para uma descrição fechada do produto, através de atividades como: modelagem, simulação e análise. Já a última fase, projeto detalhado, tem como resultado uma documentação completa com os detalhes de dimensões, formas, especificação de materiais e montagens, detalhamento dos componentes, etc.

Com relação à área de Redes Neurais, não possui regras formais bem estabelecidas (consensuais) para a definição/estabelecimento dos parâmetros da solução (FAUSETT, 1994; HAYKIN, 1999; RUSSELL; NORVIG, 2003; SILVA; SPATTI; FLAUZINO, 2010). Verifica-se claramente que este fato ocorre porque os parâmetros são escolhidos (por exemplo: número ótimo de camadas, número de neurônios, seleção dos pesos iniciais, quantidade de dados de entrada, entre outros) de forma empírica, isto é, baseado em resultados práticos obtidos através de simulação, como pode ser visto em vários exemplos de aplicação de Silva, Spatti e Flauzino (2010). Isto ocorre porque o processo envolvido nesta área é estocástico, não existindo garantias de que o problema a ser tratado tenha uma única solução, conforme Reed e Marks (1999).

Além do acima mencionado, verifica-se também que não existe na literatura um procedimento formal que estruture o raciocínio lógico (ou seja, a idéia) do desenvolvedor para encontrar a solução para um dado problema.

Em vista das lacunas citadas e do contexto de domínios próximos ${ }^{4}$ e sua aderência à área de análise e reconhecimento de textura, propõem-se neste trabalho a abordagem de desenvolvimento sistêmico de projeto, denominada de Projeto Axiomático (SUH, 1990, 1998, 2001), para compor o processo de projeto. Processo este que tem como objetivo orientar e auxiliar a sistematização, estruturação e formalização do raciocínio lógico do projetista ao desenvolvimento de solução(ões) mais rápida(s) para a análise de textura.

Resumidamente, a análise e reconhecimento de textura pode ser dividida em duas abordagens. A primeira, denominada clássica, onde duas fases são realizadas: a de extração de características através de técnicas estatísticas, baseadas em processamento de sinais, geométria etc (HARALICK, 1979; WECHSLER, 1980; CROSS; JAIN, 1983; LUERKENS, 1991; CHAUDHURI; SARKAR, 1995; MATERKA; STRZELECKI, 1998; ZHANG; TIENIU, 2002); e a que utiliza métodos classificatórios, tais como K vizinhos mais próximos (Knn) (TOU; TAY; LAU, 2009). A segunda, é baseada no emprego de Redes Neurais Artificiais(RNA). Esta também possui duas for-

\footnotetext{
${ }^{4}$ Contexto em que o domínio da aplicação está tão próximo do processo de engenharia que o desenvolvedor assume o papel do próprio especialista (isto é, o detentor do conhecimento e das necessidades da área da aplicação) no desenvolvimento do projeto.
} 
mas de utilização, sendo uma: com o uso de duas redes distintas, uma para cada fase da abordagem clássica (VERMA; KULKARNI, 2001; KULKARNI; VERMA, 2001); e outra, baseada em uma rede que trabalha com a extração e classificação por meio de uma única fase de aprendizado (TIVIVE; BOUZERDOUM, 2005, 2006), maximizando a atividadade envolvida como um todo (foco de interesse deste trabalho).

Com o objetivo de justificar a adoção da abordagem axiomática neste trabalho, apresenta-se na figura 1.3, de forma sucinta: i) os requisitos críticos relevantes a cada uma das áreas discutidas nesta seção, ii) os requisitos dos domínios próximos (apresentado na seção anterior) e iii) as respectivas características do projeto Axiomático que justificam direta e indiretamente a sua adoção. Na literatura também não foram encontrados relatos do uso deste método com as áreas de redes neurais e análise de textura.

Domínios Próximos

- Acelerar a formalização e solução do problema;
- Maximizar o tempo de elaboração do projeto;
- Técnica formal para processo de tomada de decisão
(em nivel abstrato ou detalhado da concepção);
Projeto de Engenharia
(Método Consensual)

- Nem sempre é possível estabelecer critérios de avaliação na fase de conceitual do projeto;

- Os critérios de decisão refletem nas próprias caracteristicas das concepções e normalmente são dependentes de um domínio de análise específico;

\section{Rede Neural}

- A criação de projetos baseia-se na experiência do projetista;

- Não existe um processo formal que estruture - raciocínio lógico do desenvolvedor para solução do problema.
Projeto Axiomático

Fornece critérios práticos na tomada de decisões e escolha da(s) melhor (res) solução(ões) sem depender do domínio da aplicação;

$\checkmark$ Formalização do processo de concepçãoé realizado através de axiomas;

Aplicável as mais diversas áreas do conhecimento humano (manufatura, materiais, software, organizações, sistemas, negócios, etc);

$\checkmark$ Natureza flexível - adaptável a outras teorias e métodos;

O processo de sistematização fornece suporte a criatividade/raciocínio do projetista;

$\checkmark$ Auxilia na redução (ou "eliminação") do processo de tentativa e erro;

$\checkmark$ Redução do processo aleatório de busca por novas soluções;

Figura 1.3: Característica do Projeto Axiomático em relação aos requisitos dos domínios próximos e das áreas de Projeto de Engenharia e Rede Neural.

A figura 1.4 ilustra graficamente o contexto da proposta deste trabalho. 


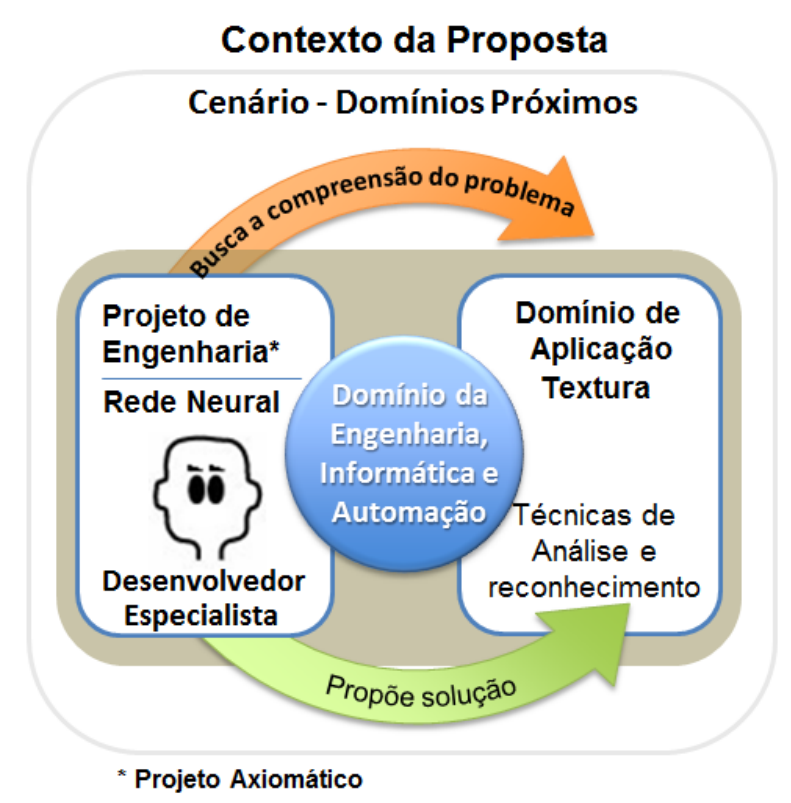

Figura 1.4: Representação gráfica do contexto da proposta envolvida neste trabalho.

\subsection{Objetivos}

O objetivo geral deste trabalho é o desenvolvimento de um processo, baseado na teoria de Projeto Axiomático, que levando em conta a proximidade dos domínios, oriente o especialista da área de projeto a desenvolver uma solução mais rápida para a abordagem clássica da análise e reconhecimento de textura. Isto implica na concepção de uma arquitetura de rede neural artificial, auto-organizável, com a estrutura espacial bi-dimensional da imagem de entrada preservada, para a extração da característica da textura, e, posteriormente, acoplar a esta uma segunda rede que desenvolva o processo classificatório. Em outras palavras, uma arquitetura que empregue ambas as atividades por meio de uma única fase de aprendizado.

O objetivo proposto pode ser desmembrado nas seguintes etapas:

- Apresentação da fundamentação teórica da Teoria de Projeto Axiomático, os princípios, técnicas, ferramentas, aplicabilidade geral em projetos e suas características, e justifica da escolha deste método neste trabalho;

- Apresentação das principais abordagens de análise e reconhecimento de textura, com a finalidade de expor um panorama geral sobre as diferentes técnicas/formas de tratar o problema, e justificar a escolha do algoritmo de solução, contribuindo para a melhoria de desempenho destes;

- Propor um processo inovador em que o desenvolvedor assuma conscientemente o papel dos clientes (stakeholders) no projeto, definindo a sistematização e estru- 
turação do raciocínio lógico do projetista para solução do problema (analise da interação /relacionamento local entre os pixels numa textura) com a fase de desenvolvimento /implementação em Rede Neural Artificial, bem como o estabelecimento da avaliação, ajuste e validação. Esta seria a contribuição principal do trabalho

- Desenvolver um estudo de caso com base na análise de texturas homogêneas, apresentando os resultados das atividades propostas;

- Apresentar as discussões e análise dos resultados, bem como a conclusão do trabalho.

\subsection{Contribuições da Tese}

Além do levantamento bibliográfico das principais técnicas de análise de textura e da abordagem de Projeto Axiomático, as contribuições científicas são:

- Proposta de um processo de projeto baseado em domínios próximos, com base na abordagem axiomática;

- O emprego de uma fundamentação teórica baseada no pensamento lógico e racional (SUH, 1990), como método de projeto para a concepção da arquitetura de uma rede neural, uma vez que não foram encontrados relatos do uso de tal metodologia na área da RNA (Rede Neural Artificial).

- Estudo e desenvolvimento de RNA com arquiteturas bidimensionais (2-D) e algoritmo de aprendizado em uma única fase;

- Definição de uma nova arquitetura de RNA para extração de características locais e não globais dos padrões de entrada, cuja atividade é realizada diretamente na representação espacial bidimensional da imagem/textura de entrada;

- Um novo conceito para o paradigma da competição entre os neurônios, denominada de competição regional;

- Redução/simplificação da abordagem clássica da análise de textura.

\subsection{Organização do trabalho}

Este trabalho de tese encontra-se estruturado em quatro capítulos: 


\section{Capítulo 1: Introdução}

Apresentação da contextulização, problemática, dos objetivos propostos, motivação e contribuição ao meio acadêmico científico.

\section{Capítulo 2: Fundamentação Teórica}

Dividida em duas partes, a primeira apresenta a abordagem de Projeto Axiomático, em que são mencionados os princípios, aplicabilidade em geral, ferramentas disponíveis e outras características que justificam o emprego/uso de tal abordagem; e a segunda trata da apresentação das principais técnicas de análise de textura (classificação) encontradas na literatura.

\section{Capítulo 3: Processo de Projeto em Domínios Próximos}

Apresentação do processo proposto na tese. Descrição das atividades a serem executadas com análise de impacto e vantagens sobre os métodos clássicos. Explanação das adequações empregadas na abordagem de projeto axiomático (ilustradas graficamente), do equacionamento matemático a ser incorporado no desenvolvimento/implementação da proposta, bem como a avaliação e validação a ser empregado.

\section{Capítulo 4: Estudo de Caso}

Explana a aplicação prática da proposta em um estudo de caso para análise e reconhecimento de textura. É dividido basicamente em três partes, em que na primeira descreve-se as atividades realizadas no levantamento das necessidades, restrições, as premissas e os resultados que propiciaram o estabelecimento de uma solução. Posteriormente, apresenta-se o desenvolvimento e a implementação desta no domínio de Redes Neurais Artificiais e, em seguida, expõe-se o desempenho da rede na extração e classificação/reconhecimento de texturas homogêneas sintéticas e naturais.

\section{Capítulo 5: Discussões e Análise dos Resultados}

Discute-se e aponta-se as vantagens, desvantagens, as fases mais onerosas e mais rápidas, a validação e alguns questionamentos sobre a aplicação prática do processo proposto. Por fim, se analisa as taxas de acerto/erro oriundas dos resultados práticos 
da Rede Neural Artificial desenvolvida/implementada neste trabalho.

\section{Capítulo 6: Conclusão e Trabalhos Futuros}

Apresenta as conclusões e algumas propostas para trabalhos futuros. 


\section{Fundamentação Teórica}

Este capítulo apresenta uma visão geral sobre a fundamentação teórica envolvida no trabalho e está dividido em duas partes, sendo a primeira, responsável por abordar um processo sistemático e formal para o desenvolvimento de projeto, denominado Projeto Axiomático (SUH, 2001), e a segunda por introduzir os conceitos referentes à Análise de Texturas.

Na primeira parte, as vantagens da teoria formal do Projeto Axiomático é apresentado. Em seguida os conceitos e definições iniciais do método são explanados, além da exemplificação das áreas de aplicações em que esta abordagem é utilizada. Postulados básicos da teoria, exemplos sucintos de utilização, bem como os diferentes tipos de medidas quantitativas utilizadas para tomadas de decisão também são descritas. Por último, apresenta-se o fluxograma de aplicação desta teoria e a representação gráfica utilizadas na definição de um projeto.

Na parte referene à Análise de Textura são levantadas as informações necessárias a compreensão de como é realizada a representação de uma imagem digital. Posteriormente, são introduzidas as definições teóricas sobre o que vem a ser o termo "textura", bem como sua importância/relevância. Por se tratar de uma fonte rica de informações esta análise é utilizada nas mais diversas áreas, mencionadas neste capítulo. Em seguida, as principais abordagens e técnicas de análise (extração de características) são apresentadas. Isto é, a formulação matemática envolvida, as características peculiares de cada uma delas, o tipo de textura que elas analisam, bem como os pontos críticos e relevantes. Para concluir a segunda parte, menciona-se também como é realizado o processo classificatório envolvido na análise de textura. 


\subsection{Projeto Axiomático}

\subsubsection{Introdução}

Projeto axiomático é uma teoria de projeto criada e popularizada pelo professor Nam P. Suh, do MIT (Massachusetts Institute of Technology), que tem como objetivo estabelecer uma base formal para a área de projetos. Para tal, utiliza-se de uma fundamentação teórica baseada em ferramentas e processos lógico e teoria da racionalidade (SUH, 2001).

O diferencial desta abordagem reside em fornecer uma estrutura teórica geral que pode ser utilizada em diversas áreas do conhecimento humano (manufatura, materiais, software, organizações, sistemas de automação, negócios, etc.) (SUH, 1995; WHITCOMB; SZATKOWSKI, 2000; ARCIDIACONO et al., 2004), além de ter uma natureza flexível, isto é, adaptável a outras teorias e metodologias utilizadas em projetos de engenharia (EL-HANIK, 2005). Segundo Suh (1998, 2001), Odom et al. (2005) e Design (2010), a mencionada abordagem também fornece importantes características, tais como:

- formalização do processo de concepção;

- auxílio à comunicação entre os especialistas nas fases iniciais do projeto;

- melhoria na qualidade do projeto, uma vez que fornece critérios práticos e precisos para tomada de decisões e escolha da(s) melhor(res) solução(ões);

- auxílio no desenvolvimento de uma documentação clara, lógica e objetiva (útil para rastrear a história do projeto, identificar causas de falhas, criar bases de conhecimento, etc);

- facilita o rastreamento explícito das necessidades do cliente para os requisitos lógicos do projeto;

- aprimora a criatividade do projetista, pois exige deste uma definição clara dos objetivos do projeto;

- reduz aleatoriedade de busca por novas soluções;

- "elimina" o processo de tentativa e erro, etc.

Suh (2001) teve como premissa para a formulação desta teoria a busca pela existência de similaridades entre projetos. O autor acreditava que existia um conjunto de princípios que determinavam as boas práticas de design e que estes não dependiam 
do domínio específico de aplicação e sim dos princípios básicos inerentes à atividade. Assim, analisou vários projetos desenvolvidos nas indústrias e em universidades, identificando elementos comuns, que permitiu a definição de um conjunto de axiomas ${ }^{1}$, corolários $^{2}$ e teoremas ${ }^{3}$. Estes por sua vez representam os princípios, critérios e regras presentes na Teoria de Projeto Axiomático.

A seguir apresentam-se os principais conceitos e definições que envolvem a abordagem axiomática na área de projetos, seja ela dedicada a produto, processos, sistemas, organizações, etc.

\subsubsection{Conceitos e Definições Iniciais}

A abordagem axiomática de projeto possui quatro conceitos principais que definem as atividades e regras do processo: domínios, hierarquia, "ziguezague" e axiomas de projeto, abaixo descritas.

\section{Domínios}

Segundo a Academia Nacional de Engenharia (National Academy of Engineering - NAE) (NAE, 2010) o termo projeto (design) é definido como o processo pelo qual o intelecto humano, a criatividade e desejo são traduzidos em artefatos úteis. De acordo com a proposta de Nam P. Suh (SUH, 1998), este é composto e realizado através de quatro domínios, denominados de: domínio do cliente, domínio funcional, domínio físico e domínio de processo, como mostra a estrutura da figura 2.1.

Para cada par de domínios adjacentes, o domínio da esquerda representa "o que se deseja realizar", enquanto que o domínio do lado direito representa a solução do projeto indicado "como alcançar tal propósito", ou seja, como satisfazer os requisitos especificados no domínio da esquerda (SUH, 1995). Para ir do "o que" para "como" faz-se necessário um mapeamento que relaciona um elemento de um domínio com um ou mais elementos do outro domínio. Esta relação de dependência é representada através de uma matriz denominada de matriz de projeto, discutida na seção seguinte.

\footnotetext{
${ }^{1}$ Axioma são conhecimentos fundamentais que não podem ser deduzidos e nem testados, mas aceitos como verdade, uma vez que não existem contra-exemplos e exceções. Um axioma não pode ser derivado de outra lei ou princípio da natureza (SUH, 1998; EL-HANIK, 2005)

${ }^{2}$ Corolário são proposições originadas dos axiomas ou de outras proposições que já foram aprovadas (SUH, 1998)

${ }^{3}$ Proposição não evidente que pode ser comprovada através de premissas ou axiomas, estabelecendo uma lei ou um princípio.
} 


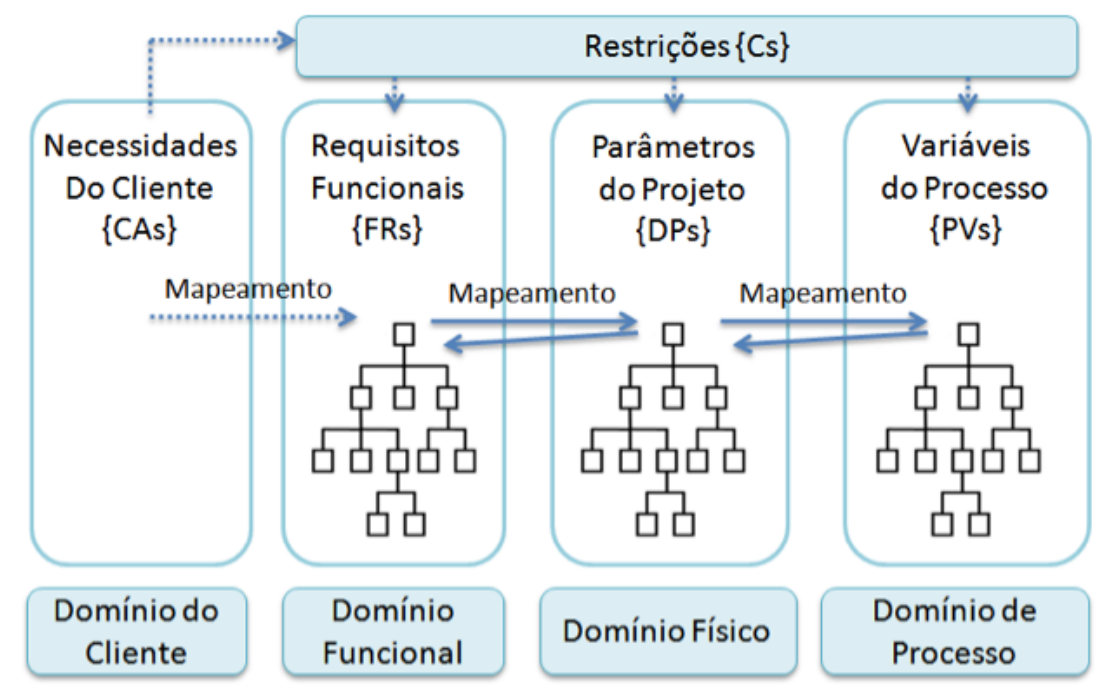

Figura 2.1: Domínios envolvidos no Projeto Axiomático

O mapeamento entre os domínios ocorre de maneira sequenciada, sendo o domínio do cliente e funcional, os primeiros. O segundo e terceiro mapeamento ocorrem entre o domínio funcional e o físico e, entre o domínio físico e do processo, respectivamente. A representação em matriz de projeto é realizada somente nos dois últimos (TATE, 1999; SUH, 2001).

Os elementos do primeiro domínio (Fig. 2.1) expressam as necessidades ou atributos do cliente $\{\mathrm{CAs}\}$ para um determinado produto. Normalmente estes abributos são genéricos e não organizados e surgem de um problema ou da percepção do cliente sobre um determinado problema. Técnicas de auxilio à eliciação de requisitos (QUEIROZ, 2007; QUEIROZ; SILVA, 2009) e priorização (EL-HANIK, 2005) podem ser utilizadas para a identificação destes atributos, que formam a base para a composição do conjunto dos requisitos funcionais.

Já os elementos do domínio do funcional, denominados de requisitos funcionais $\{$ FRs $\}$, são definidos como o conjunto minimal de requisitos (e maximamente desacoplados) que caracterizam as necessidades funcionais da solução de projeto. Os $\{$ FRs $\}$ também são chamados de especificação de engenharia, segundo (SUH, 1995).

As restrições $\{\mathrm{Cs}\}$ são derivadas das $\{\mathrm{CAs}\}$, constituintes do domínio funcional e representam os limites para soluções aceitáveis. São classificadas em dois tipos: restrições de entrada e restrições de sistema, em que o primeiro bloco refere-se às restrições impostas como parte da especificação do projeto enquanto que, o segundo, é imposto pelo sistema na qual a solução do projeto irá funcionar.

As $\{\mathrm{Cs}\}$ podem causar diferentes impactos no projeto e no processo de desenvolvimento. Por exemplo, estas podem afetar todos os parâmetros do processo $\{\mathrm{DFs}\}$ 
de acordo com as suas limitações. Entretanto, podem ser utilizadas como filtro para selecionar a(s) melhor(es) solução(ões), auxiliar na definição dos próprios requisitos funcionais $\{$ FRs $\}$ e sub $\{$ FRs $\}$. Pode existir durante o processo de decomposição dos $\{$ FRs $\}$ e $\{$ PVs $\}$.

$\mathrm{Na}$ abordagem axiomática, requisitos não funcionais, isto é, requisitos relacionados com a qualidade, que quantificam aspectos de desempenho, integridade, disponibilidade, segurança, economia, qualidade, etc (ROBERTSON; ROBERTSON, 2006), são considerados como restrições.

Segundo Suh (2001) a restrição se diferencia de um $\{F R\}$ de duas maneiras: primeiro, elas não são independentes uma das outras, nem independentes dos requisitos funcionais; e segundo, não possuem tolerância associadas, diferentemente do $\{$ FRs $\}$.

Os elementos do domínio do físico, denominados de parâmetros do processo $\{\mathrm{DPs}\}$, são os elementos da solução do projeto no domínio físico escolhido para satisfazer aos requisitos funcionais $\{\mathrm{FRs}\}$ especificados. Estes também são estabelecidos de forma independente da solução. Por fim, os elementos do domínio $\{$ PVs $\}$, chamado de variáveis do processo, caracterizam como o atividade de produção pode gerar, ou realizar, os parâmetros de projeto $\{$ DPs $\}$ especificados.

A tabela 2.1 exemplifica como vários projetos de diferentes campos (manufatura (COCHRAN; REYNAL, 1996; BABIC, 1999; BLAXTER et al., 2002; HOU; WEN; HAN, 2007; AULAKH; GILL, 2009), materiais (GIL, 2006), software (DO; SUH, 2000; SUH, 2001; DO; PARK, 2001; TOGAY; DOGRU; TANIK, 2008), organização (DURMUSOGLUA; KULAKB, 2008), sistema (HEO; LEE, 2007; BANG; HEO, 2009) e negócios (NORDLUND, 1996)) podem ser descritos nos quatro domínios mencionados. De acordo com Suh (2001), projetos que se enquadram nesses domínios possuem todas as atividades de projeto generalizadas em termos do mesmo princípio e podem ser desenvolvidas de forma sistemática.

Na literatura também são encontrados projetos de produtos (BAEA; LEEB; CHUB, 2002; HOUSHMAND; JAMSHIDNEZHAD, 2002; ARCIDIACONO et al., 2004), sistema de controle (LEEA; SUHA; OHB, 2001), sistema de qualidade (CALARGE, 2000) que utilizam a abordagem axiomática. Outros trabalhos podem ser encontrados em (DESIGN, 2010), inclusive alguns que propagam o uso do projeto axiomático como técnica para tomada de decisão. Nota-se que, apesar desta abordagem utilizar quatro domínios a atividade principal é estabelecida entre o domínio funcional e físico (COCHRAN; REYNAL, 1996; BABIC, 1999; HOU; WEN; HAN, 2007; AULAKH; GILL, 2009) 
Tabela 2.1: Características dos domínios envolvidos no Projeto Axiomático nas áreas de manufatura, materiais, software, organização, sistema, negócios.

\begin{tabular}{|c|c|c|c|c|}
\hline & $\begin{array}{l}\text { Domínio do } \\
\text { Cliente } \\
\{\mathrm{CAs}\}\end{array}$ & $\begin{array}{c}\text { Domínio } \\
\text { Funcional } \\
\{\text { FRs }\}\end{array}$ & $\begin{array}{l}\text { Domínio } \\
\text { Físico } \\
\{\text { DPs }\}\end{array}$ & $\begin{array}{c}\text { Domínio do } \\
\text { Processo } \\
\{\text { PVs }\}\end{array}$ \\
\hline "Manufatura & $\begin{array}{c}\text { Atributos que } \\
\text { os clientes } \\
\text { desejam }\end{array}$ & $\begin{array}{c}\text { Requisitos } \\
\text { funcionais } \\
\text { especificados } \\
\text { para o produto }\end{array}$ & $\begin{array}{c}\text { Variáveis } \\
\text { físicas que } \\
\text { podem } \\
\text { satisfazer os } \\
\text { requisitos } \\
\text { funcionais }\end{array}$ & $\begin{array}{c}\text { Variáveis de } \\
\text { processo que } \\
\text { podem } \\
\text { controlar os } \\
\text { parâmetros de } \\
\text { projeto }\end{array}$ \\
\hline Materiais & $\begin{array}{c}\text { Performance } \\
\text { desejada }\end{array}$ & $\begin{array}{c}\text { Propriedades } \\
\text { desejada }\end{array}$ & Microestruturas & Processo \\
\hline Software & $\begin{array}{l}\text { Atributos } \\
\text { desejados no } \\
\text { software }\end{array}$ & $\begin{array}{l}\text { Especificação } \\
\text { de saída do } \\
\text { código do } \\
\text { programa }\end{array}$ & $\begin{array}{l}\text { Variáveis de } \\
\text { entrada, } \\
\text { algoritmos, } \\
\text { módulos, sub- } \\
\text { programas }\end{array}$ & $\begin{array}{l}\text { Sub-rotinas, } \\
\text { códigos de } \\
\text { máquina, } \\
\text { compiladores, } \\
\text { módulos }\end{array}$ \\
\hline Organização & $\begin{array}{l}\text { Satisfação do } \\
\text { cliente }\end{array}$ & $\begin{array}{c}\text { Função de } \\
\text { organização }\end{array}$ & $\begin{array}{l}\text { Programas, } \\
\text { escritórios, } \\
\text { atividades } \\
\text { empresariais }\end{array}$ & $\begin{array}{c}\text { Pessoas e } \\
\text { outros recursos } \\
\text { para suporte } \\
\text { aos programas }\end{array}$ \\
\hline Sistema & $\begin{array}{c}\text { Atributos } \\
\text { desejados para } \\
\text { o sitema }\end{array}$ & $\begin{array}{c}\text { Requisitos } \\
\text { funcionais do } \\
\text { sistema }\end{array}$ & $\begin{array}{c}\text { Máquinas, } \\
\text { componentes e } \\
\text { sub-componentes }\end{array}$ & $\begin{array}{l}\text { Recursos } \\
\text { (humanos, } \\
\text { financeiros, } \\
\text { materiais,etc) }\end{array}$ \\
\hline Negócios & $\begin{array}{c}\text { Retorno sobre } \\
\text { o investimento } \\
\text { (ROI) }\end{array}$ & Metas do negócio & $\begin{array}{c}\text { Estrutura do } \\
\text { negócio }\end{array}$ & $\begin{array}{c}\text { Fontes humanas } \\
\text { e financeiras }\end{array}$ \\
\hline
\end{tabular}

\section{Hierarquia}

O segundo conceito é o de hierarquia, responsável por representar a decomposição do projeto do nível mais alto de abstração para o nível de maior detalhamento. Tal decomposição é realizada nos domínios funcional, físico e de processo e resulta na hierarquia dos $\{\mathrm{FRs}\},\{\mathrm{DPs}\}$ e $\{\mathrm{PVs}\}$, respectivamente (SUH, 2001). O domínio do cliente não possui tal representação, pois segundo (TATE, 1999) as informações contidas nos $\{\mathrm{CAs}\}$ não são rigorosamente estruturadas.

A estrutura hierárquica representa a arquitetura do sistema (produto, organização, etc) e é desenvolvida através da decomposição em árvore, seguindo camada a camada até o nível mais baixo, denominado folha. Desta forma, um sistema, por exemplo, pode ser decomposto em elementos com funcionalidades menores e especificas utilizandose de sub-requisitos. A figura 2.2 mostra um exemplo simplificado de como cada elemento no domínio funcional está hierarquicamente associado com o seu superior. 


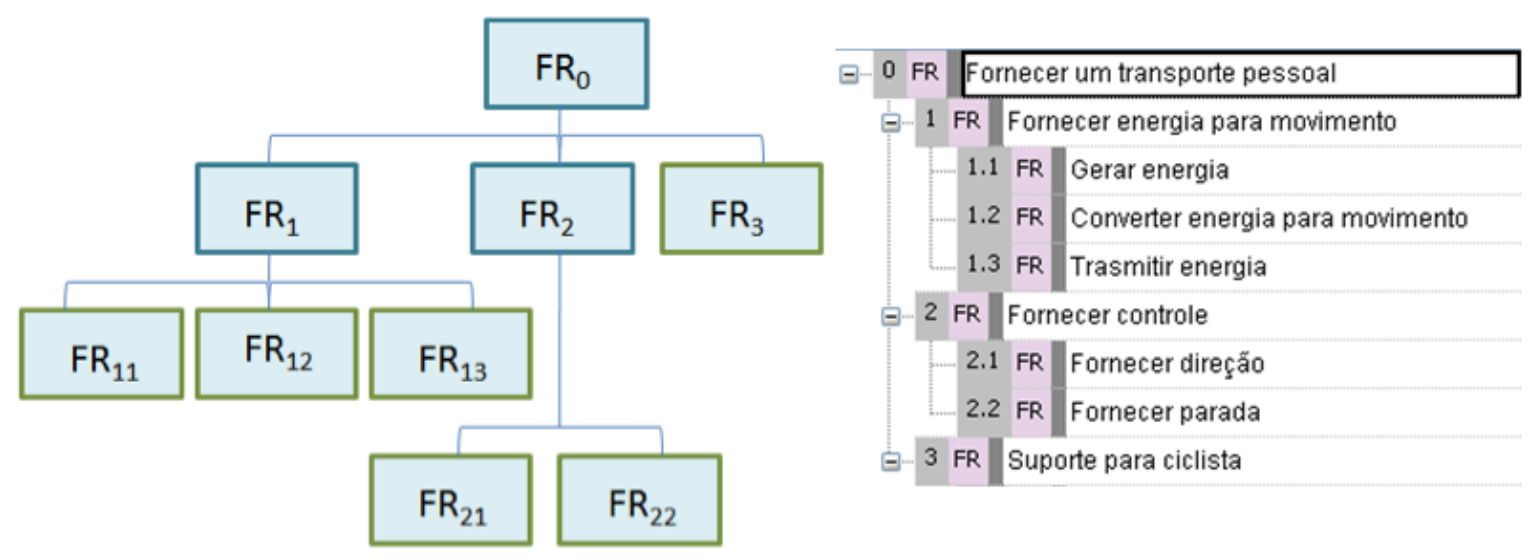

Domínio Funcional

Figura 2.2: Exemplo de hierarquia simplificada do domínio funcional de um suposto sistema de transporte pessoal (bicicleta).

Segundo Nam P. Suh, essa decomposição deve ser realizada até que as necessidades de representação do projetista para o projeto sejam suficientes. Este também está associado a um terceiro conceito denominado de "ziguezague", apresentado a seguir.

\section{"ZigueZague"}

O "ziguezague" descreve o processo de decomposição do projeto hierárquico de forma alternada entre os pares dos domínios (funcional-físico; físico-processo), interligando cada elemento de um nível hierárquico do domínio da esquerda com o elemento do domínio da direita.

Desta forma, por exemplo, para cada requisito funcional $\{\mathrm{FR}\}$ (domínio da esquerda) identificado em um determinado nível de decomposição, um dado parâmetro de projeto $\{\mathrm{DP}\}$ deve ser estabelecido (domínio da direita). Após a identificação de todos os $\{$ DPs $\}$ de tal nível, a decomposição de cada $\{F R\}$ em sub-requisitos $\{$ sub - FR $\}$ deve ser realizada e apresentada em um novo nível hierárquico. Segundo Suh (1998), a decomposição em nível subseqüente só pode ser estabelecida após a definição de todos os parâmetros $\{\mathrm{DPs}\}$ correspondentes.

Esse procedimento de ida do domínio da esquerda para o da direta é chamado de "zigue", enquanto que o procedimento de volta é denominado de "zague". Deve ser realizado até o momento que o projeto esteja completo, isto é, que seja definido todo o mapeamento entre os elementos $\{F R\}$ e $\{D P\}$. A figura 2.3 apresenta um exemplo do procedimento de "ziguezague" entre o domínio funcional e físico. 


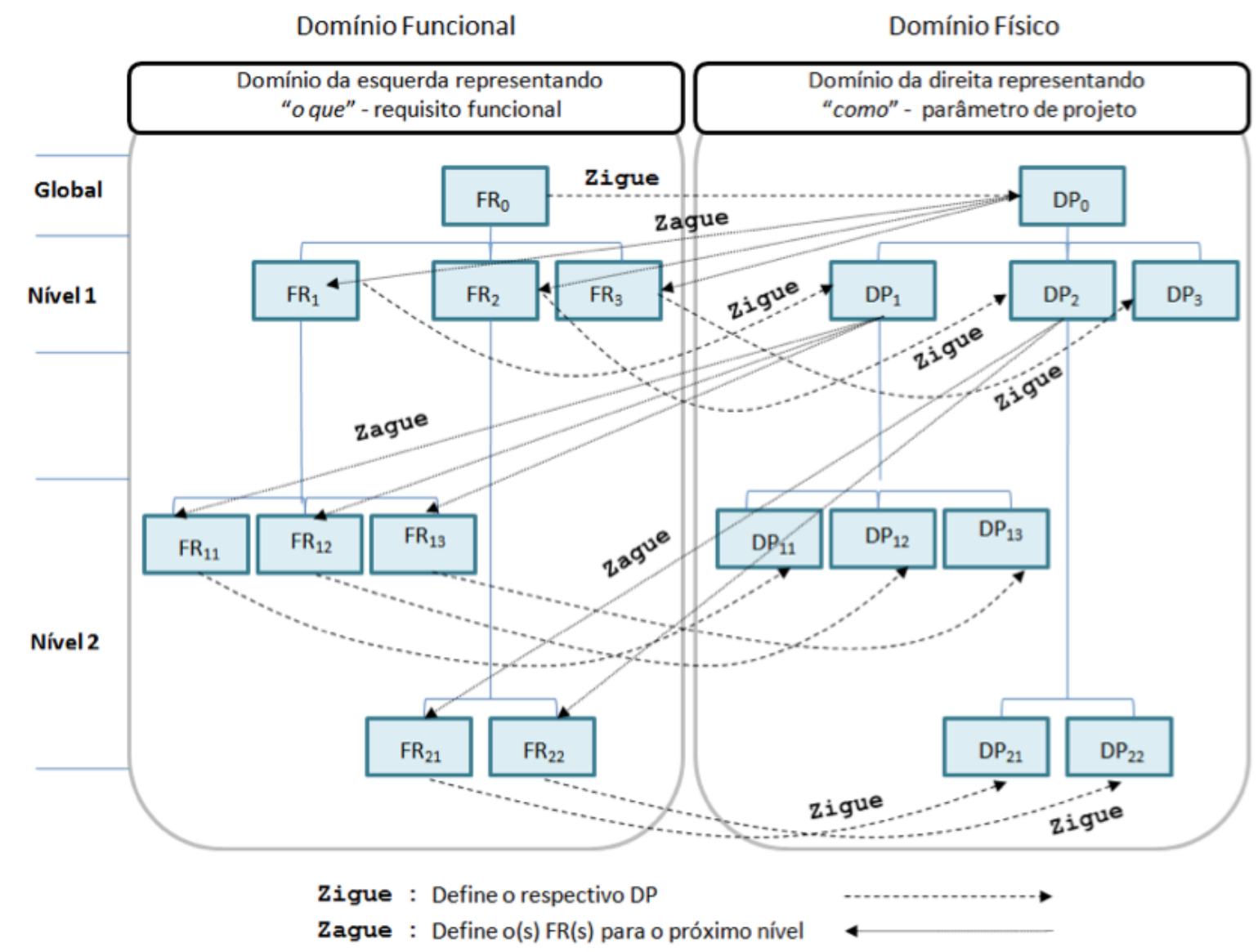

Figura 2.3: Ziguezague entre os domínios funcional e físico.

O término deste processo fornece à equipe de projeto às seguintes características: compreensão clara do impacto das mudanças sobre o nível hierárquico, isto é, como modificações em níveis mais elevados afetam os níveis inferiores e vice versa; rastreamento das tomadas de decisões realizadas no projeto; lista dos componentes do domínio físico e as funções que devem ser satisfeitas, etc (BROWN, 2010).

\section{Axiomas de Projeto}

O postulado básico da abordagem axiomática é composto de dois axiomas fundamentais que governam o processo do projeto, sendo eles:

\section{Axioma 1 - Axioma da Independência}

O enunciado deste axioma enfatiza que: "a independência dos requisitos funcionais $\{F R\}$ deve ser sempre mantida" (SUH, 1995). Ou seja, as decisões de projeto devem sempre ser realizadas de forma a não violar a independência 
de cada requisito funcional. Em um projeto aceitável, os $\{$ DPs $\}$ e os $\{$ FRs $\}$ são relacionadas de maneira que um dado $\{D P\}$ pode ser modificado/ajustado para satisfazer um correspondente $\{F R\}$ sem afetar outro $\{F R\}$. Desta forma soluções ótimas podem ser obtidas (SUH, 2001)

\section{Axioma 2 - Axioma da Informação}

O segundo axioma estabelece o enunciado: "minimize o conteúdo da informação do projeto" (SUH, 1995). Em outras palavras isto quer dizer que: dentre todos os projetos que satisfaçam o primeiro axioma, aquele que tiver o mínimo de conteúdo da informação (menor número de requisitos funcionais e restrições), possui a mais alta probabilidade de sucesso, ou seja, é tido como o melhor projeto. Portanto a quantidade de informação é considerada como uma medida quantitativa que auxilia na escolha da melhor solução.

A seguir são apresentados em maiores detalhes os mencionados axiomas.

\subsubsection{Axioma 1 - Axioma da Independência}

O axioma de independência determina que os requisitos funcionais devem ser mantidos independentes, implicando que o mapeamento entre domínios deve ser pelo menos injetor. Como a atividade principal da abordagem axiomática (no sentido da realização do processo de design) está associada ao mapeamento entre o domínio funcional e físico, a relação entre os $\{F R\}$ e os $\{\mathrm{DP}\}$ deve ser também uma relação injetora, ou seja, os $\{$ DPs $\}$ e $\{F R s\}$ se relacionam de tal forma que caso seja necessário ajustar um dado $\{\mathrm{DP}\}$ para satisfazer a mudanças em um correspondente $\{\mathrm{FR}\}$, estas mudanças não devem se propagar para outros $\{$ FRs $\}$.

Matematicamente, o relacionamento entre os mencionados elementos é expresso através de uma matriz denominada de Matriz de Projeto. Esta utiliza notação de vetores para $\{$ FRs $\}$ e $\{$ DPs $\}$ e é expressa como mostra a equação 2.1 e 2.2

$$
\left\{F R_{i}\right\}=\left[A_{i j}\right]\left\{D P_{j}\right\}
$$




$$
\left\{\begin{array}{c}
F R_{1} \\
F R_{2} \\
\cdots \\
F R_{n}
\end{array}\right\}=\left\{\begin{array}{ccc}
A_{11} & A_{12} & A_{13} \\
A_{21} & A_{22} & A_{23} \\
\ldots & \ldots & \cdots \\
A_{n 1} & A_{n 2} & A_{n 3}
\end{array}\right\}\left\{\begin{array}{c}
D P_{1} \\
D P_{2} \\
\cdots \\
D P_{n}
\end{array}\right\}
$$

em que:

- $F R_{i}$ e $D P_{j}$ referem-se aos vetores de requisitos funcionais e parâmetros de projeto respectivamente;

- $A_{i j}$ é denominada de matriz de projeto.

$\mathrm{Na}$ abordagem axiomática, os vetores de requisitos funcionais, pertencentes ao domínio funcional, representam os objetivos do projeto, enquanto que os vetores de parâmetros de projeto, pertencentes ao domínio físico, representam a definição da solução. Assim, com base na equação apresentada, o produto de $A_{i j}$ e $D P_{j}$ indica como se espera satisfazer os requisitos funcionais $\left\{F R_{i}\right\}$ do projeto.

De acordo com Suh (1995), os elementos da matriz $A_{i j}$ podem assumir valores constantes (modelam matematicamente os relacionamentos físicos), representando um projeto linear, enquanto que para projeto não linear o elemento $A_{i j}$ pode ser representado por funções dos $\{\mathrm{DPs}\}$. Quando a representação literal é utilizada, esta expressa apenas a existência de uma relação não especificada, como mostra a figura 2.4 (a).

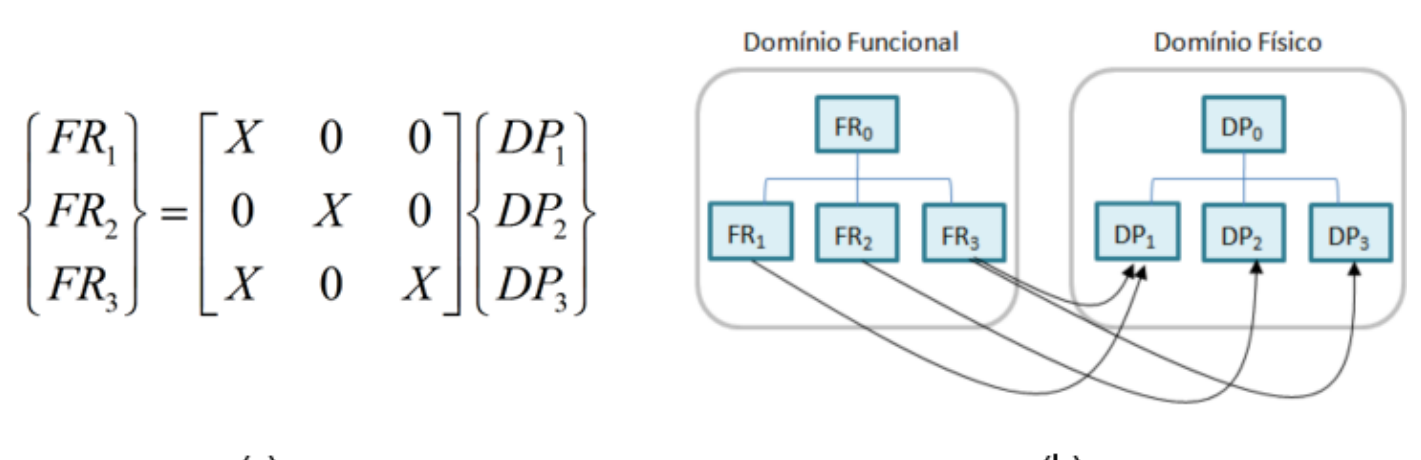

(a)

(b)

Figura 2.4: Exemplo da matriz de projeto e a respectiva representação gráfica hierárquica dos domínios.

Cada linha do sistema (linear) da equação 2.2 representa um requisito funcional (independente como uma combinação (linear) dos parâmetros de design), bem como o 
módulo do sistema (conceito empregado na seção 2.1.5) projetado.

$$
F R_{i}=\sum A_{i j} D P_{j}
$$

Atendendo às restrições do axioma da independência, o relacionamento entre os $\{$ FRs $\}$ e os $\{$ DPs $\}$ de acordo com a matriz de projeto pode ser de três tipos como apresenta a tabela 2.2

Tabela 2.2: Relação $\{F R\}-\{D P\}$ de acordo com a matriz de projeto. Adaptado (GYUNG-JIN, 2007).

\begin{tabular}{c|ll}
\hline Projeto & Equação do Projeto & Processo do Projeto \\
\hline Desacoplado & $\left\{\begin{array}{l}F R_{1} \\
F R_{2} \\
F R_{3}\end{array}\right\}=\left[\begin{array}{ccc}A_{11} & 0 & 0 \\
0 & A_{22} & 0 \\
0 & 0 & A_{33}\end{array}\right]\left\{\begin{array}{l}D P_{1} \\
D P_{2} \\
D P_{3}\end{array}\right\}$ & $\begin{array}{l}F R_{1}=A_{11} \times D P_{1} \\
F R_{2}=A_{22} \times D P_{2} \\
F R_{3}=A_{33} \times D P_{3}\end{array}$ \\
Semi-acoplado & $\left\{\begin{array}{l}F R_{1} \\
F R_{2} \\
F R_{3}\end{array}\right\}=\left[\begin{array}{lll}A_{11} & 0 & 0 \\
A_{21} & A_{22} & 0 \\
A_{31} & A_{32} & A_{33}\end{array}\right]\left\{\begin{array}{l}D P_{1} \\
D P_{2} \\
D P_{3}\end{array}\right\}$ & $\begin{array}{l}F R_{1}=A_{11} \times D P_{1} \\
F R_{2}=A_{21} \times D P_{1}+A_{22} \times D P_{2} \\
F R_{3}=A_{31} \times D P_{1}+A_{32} \times D P_{2}+A_{33} D P_{3}\end{array}$ \\
$\left\{\begin{array}{ll}F R_{1} \\
F R_{2} \\
F R_{3}\end{array}\right\}=\left[\begin{array}{lll}A_{11} & A_{12} & A_{13} \\
0 & A_{22} & A_{23} \\
0 & 0 & A_{33}\end{array}\right]\left\{\begin{array}{l}D P_{1} \\
D P_{2} \\
D P_{3}\end{array}\right\}$ & $\begin{array}{l}F R_{1}=A_{11} \times D P_{1}+A_{12} \times D P_{2}+A_{13} D P_{3} \\
F R_{2}=A_{22} \times D P_{2}+A_{23} D P_{3} \\
F R_{3}=A_{33} D P_{3}\end{array}$ \\
$\left\{\begin{array}{l}F R_{1} \\
F R_{2} \\
F R_{3}\end{array}\right\}=\left[\begin{array}{lll}A_{11} & A_{12} & A_{13} \\
A_{21} & A_{22} & A_{23} \\
A_{31} & A_{32} & A_{33}\end{array}\right]\left\{\begin{array}{l}D P_{1} \\
D P_{2} \\
D P_{3}\end{array}\right\} \begin{array}{l}F R_{1}=A_{11} \times D P_{1}+A_{12} \times D P_{2}+A_{13} D P_{3} \\
F R_{2}=A_{21} \times D P_{1}+A_{22} \times D P_{2}+A_{23} D P_{3} \\
F R_{3}=A_{31} \times D P_{1}+A_{32} \times D P_{2}+A_{33} D P_{3}\end{array}$ \\
\hline
\end{tabular}

Se a matriz de projeto for diagonal, então cada parâmetro de projeto é usado para satisfazer um único requisito funcional. Este é chamado de o projeto desacoplado (uncoupled design), pois satisfaz perfeitamente o Axioma de Independência. Em outras palavras, os $\{$ DPs $\}$ e $\{$ FRs $\}$ se relacionam de tal forma que caso seja necessário ajustar um dado $\{\mathrm{DP}\}$ para satisfazer seu correspondente $\{\mathrm{FR}\}$, este não afeta outros \{FRs\}. Segundo Suh (1998), este é considerado o melhor tipo de projeto.

Quando a matriz de projeto é triangular, como apresentado na tabela 2.2, o pro- 
jeto é dito semi-acoplado (decoupled design). Neste caso, um requisito funcional é satisfeito por mais de um parâmetro de projeto. Ou seja, mesmo não sendo os $\{$ FRs $\}$ inteiramente independentes (como recomenda o Axioma 1) existe uma forma única de modificação dos parâmetros de design.

Segundo Gyung-jin (2007), a definição da matriz de projeto $[A]$ triangular inferior, por exemplo, deve ser feita da seguinte maneira: primeiro estabelece-se o $\left\{D P_{1}\right\}$ que satisfaça o $\left\{F R_{1}\right\}$, e toma-se este parâmetro como valor fixo. Em seguida $\left\{F R_{2}\right\}$ deve ser satisfeito pela escolha do $\left\{D P_{2}\right\}$ e do $\left\{D P_{1}\right\}$, que está fixo. Por ultimo $\left\{D P_{3}\right\}$ é determinado da mesma maneira, sendo que $\left\{D P_{1}\right\}$ e $\left\{D P_{2}\right\}$ permanecem fixos.

Entretanto, tal matriz pode assumir outras formas além da triangular inferior e superior (HOU; WEN; HAN, 2007). Quando isto ocorre, a recomendação é fazer modificações na ordem dos requisitos e parâmetros de projeto de modo que matriz se torne triangular. As mudanças devem ser tais que se mantenha a relação entre os $\{$ FRs $\}$ e os $\{$ DPs $\}$, e entre os primeiros e as restrições $\{\mathrm{Cs}\}$.

Finalmente, o terceiro e último caso mostra um sistema acoplado (coupled design), em que a matriz não é nem diagonal e nem triangular. Neste tipo de projeto, pode-se verificar com base na equação apresentada na tabela 2.2 , que ao modificar $\left\{D P_{1}\right\}$ para satisfazer $\left\{F R_{1}\right\}$, este afeta os demais requisitos funcionais $\left\{F R_{2}\right\}$ e $\left\{F R_{3}\right\}$. Se o mesmo for realizado para $\left\{D P_{2}\right\}$ em função de $\left\{F R_{2}\right\}$, os requisitos $\left\{F R_{1}\right\}$ e $\left\{F R_{3}\right\}$ seriam afetados também e, assim por diante. Portanto, independentemente da ordem de alteração dos $\{\mathrm{DPs}\}$, esse tipo de projeto viola o Axioma de Independência. Ou seja, fornece consequiências não desejadas, como dificuldade não só controle, bem como no ajuste do projeto. Segundo Suh (1998) e Gyung-jin (2007) tal hipótese deve ser desconsiderada. Novos parâmetros $\{$ DPs $\}$ devem ser estabelecidos, isto é, novas soluções devem ser criadas de modo a atender um projeto desacoplado ou semiacoplado. Operações de multiplicação e adição são permitidas nesse tipo de matriz, muito embora transformações de coordenadas não sejam permitidas (GYUNG-JIN, 2007).

De acordo com os teoremas da abordagem axiomática, a matriz de projeto também pode apresentar-se de forma não-singular (SUH, 1998; EL-HANIK, 2005). Isso ocorre quando a quantidade de $\{\mathrm{RFs}\}$ é diferente dos números de $\{\mathrm{DPs}\}$, ou vice versa.

Desta forma, quando o número de $\{\mathrm{FRs}\}$ for maior do que $\{\mathrm{DPs}\}$, este projeto é dito acoplado ou um projeto em que os $\{$ FRs $\}$ não podem ser satisfeitos de forma independente. Tal exemplificação pode ser ilustrada pela equação 2.4. 


$$
\left\{\begin{array}{l}
F R_{1} \\
F R_{2} \\
F R_{3}
\end{array}\right\}=\left[\begin{array}{ll}
A_{11} & A_{12} \\
A_{21} & A_{22} \\
A_{31} & A_{32}
\end{array}\right]\left\{\begin{array}{l}
D P_{1} \\
D P_{2}
\end{array}\right\} ; \quad \begin{aligned}
& F R_{1}=A_{11} D P_{1}+A_{12} D P_{2} \\
& F R_{2}=A_{21} D P_{1}+A_{22} D P_{2} \\
& F R_{3}=A_{31} D P_{1}+A_{32} D P_{2}
\end{aligned}
$$

Neste caso, o acoplamento pode ser reduzido pela adição de novos parâmetros de projeto, fazendo com que o número de $\{\mathrm{FRs}\}$ e $\{$ DPs $\}$ sejam iguais e possam constituir uma matriz triangular. Ou seja, se tornar um projeto semi-acoplado.

No caso inverso, isto é, quando o projeto possuir uma número maior de $\{\mathrm{DPs}\}$ do que $\{\mathrm{FRs}\}$, este será caracterizado como um projeto redundante ou um projeto acoplado, ilustrado pela equação 2.5 .

$$
\left\{\begin{array}{l}
F R_{1} \\
F R_{2}
\end{array}\right\}=\left\{\begin{array}{lll}
A_{11} & A_{12} & A_{13} \\
A_{21} & A_{22} & A_{23}
\end{array}\right\}\left\{\begin{array}{l}
D P_{1} \\
D P_{2} \\
D P_{3}
\end{array}\right\} \begin{aligned}
& F R_{1}=A_{11} D P_{1}+A_{12} D P_{2}+A_{13} D P_{3} \\
& F R_{2}=A_{21} D P_{1}+A_{22} D P_{2}+A_{13} D P_{3}
\end{aligned}
$$

A seguir são apresentadas dois exemplos que ilustram a aplicação dos conceitos mencionados nesta seção. O primeiro exemplo apresenta a situação de um projeto acoplado e uma possível alternativa para torná-lo um projeto desacoplado. O segundo, apresenta a importância das restrições na tomada de decisão durante a síntese de uma solução.

Exemplo 1 - Projeto da torneira de água quente/fria (SUH, 2001; GYUNG-JIN, 2007)

Para o projeto de uma torneira que mistura água quente/fria para pia de banheiro, os seguintes requisitos funcionais podem ser definidos:

$\left\{F R_{1}\right\}:$ Controlar a temperatura da água $(\mathrm{T})$

$\left\{F R_{2}\right\}$ : Controlar a vazão da água $(\mathrm{Q})$

A definição dos $\{$ DPs $\}$ que satisfazem os $\{F R s\}$ e a equação do projeto são apresentados na Tabela 2.3. 
Tabela 2.3: Definição dos $\{$ DPs $\}$ e equação do projeto para uma torneira (misturador) de água quente/fria - solução 1.

\begin{tabular}{|c|l}
$\begin{array}{c}\text { Parâmetros de } \\
\text { projeto }\end{array}$ & $\begin{array}{l}\left\{D P_{1}\right\}: \text { Controle da válvula } \phi_{1} \text { - Agua fria (ângulo) } \\
\left\{D P_{2}\right\}: \text { Controle da válvula } \phi_{2} \text { - Agua quente (ângulo) }\end{array}$ \\
\hline $\begin{array}{c}\text { Equação do } \\
\text { projeto }\end{array}$ & $\left\{\begin{array}{l}F R_{1} \\
F R_{2}\end{array}\right\}=\left[\begin{array}{ll}X & X \\
X & X\end{array}\right]\left\{\begin{array}{l}D P_{1}\left(\phi_{1}\right) \\
D P_{2}\left(\phi_{2}\right)\end{array}\right\}$ \\
\hline Torneira
\end{tabular}

Verifica-se neste exemplo que a mudança das condições $D P_{1}\left(\phi_{1}\right)$ e $D P_{2}\left(\phi_{2}\right)$, responsáveis no controle da temperatura e vazão de água, modifica simultaneamente não só $\left\{F R_{1}\right\}$, como $\left\{F R_{2}\right\}$. Tal fato viola o primeiro axioma em discussão. O projeto é dito acoplado e, segundo a abordagem axiomática, deve-se buscar uma solução desacoplada, ou pelo menos semi-acoplada.

A tabela 2.4 apresenta uma nova solução para o projeto em questão

A nova solução é um projeto desacoplado, cuja matriz é diagonal. Os parâmetros de projeto $D P_{1}$ e $D P_{2}$ agem independentemente sobre os respectivos requisitos funcionais $F R_{1}$ (Controlar a temperatura da água) e $F R_{2}$ (Controlar a vazão da água), que é o caso ideal previsto pelo primeiro axioma. Neste exemplo não são considerados requisitos relacionados a aspectos estéticos, que podem ser estabelecidos como restrições $(\{\mathrm{Cs}\})$. Um exemplo envolvendo $\{\mathrm{Cs}\}$ é apresentado a seguir.

Exemplo 2 - Projeto da porta de um refrigerador (NSF, 1998 apud GYUNG-JIN, 2007)(SUH, 2001).

Do ponto de vista da abordagem axiomática ( $\{$ FRs $\}$ e $\{$ DPs $\}$ estabelecidos a seguir), o melhor projeto entre a porta de um refrigerador horizontal e vertical pode ser ilustrado da seguinte forma: 
Tabela 2.4: Definição dos $\{$ DPs $\}$ e equação do projeto para uma torneira (misturador) de água quente/fria - solução 2.

\begin{tabular}{|c|c|}
\hline $\begin{array}{c}\text { Parâmetros de } \\
\text { projeto }\end{array}$ & $\left\{D P_{1}\right\}:$ Controle da válvula de temperatura $\gamma$ (deslocamento) \\
\hline $\begin{array}{c}\text { Equação do } \\
\text { projeto }\end{array}$ & $\left\{\begin{array}{l}\left.F P_{2}\right\}: \text { Controle da válvula de vazão de água } \phi_{2} \text { (ângulo)/ } \\
F R_{2}\end{array}\right\}=\left[\begin{array}{ll}X & 0 \\
0 & X\end{array}\right]\left\{\begin{array}{l}D P_{1}(\gamma) \\
D P_{2}\left(\phi_{2}\right)\end{array}\right\}$ \\
\hline Torneira &
\end{tabular}

Requisitos funcionais:

$\left\{F R_{1}\right\}$ : Fornecer acesso para itens armazenados no refrigerador

$\left\{F R_{2}\right\}$ : Minimizar a perda de energia

Os parâmetros de projeto e o equacionamento são apresentados de acordo com a Tabela 2.5.

A equação de projeto do refrigerador com porta vertical o define como um sistema semi-acoplado. Ou seja $\left\{F R_{2}\right\}$ é dependente não só do $\left\{D P_{2}\right\}$ como do $\left\{D P_{1}\right\}$. Em outras palavras, a minimização da perda de energia está associada não só ao isolamento térmico da porta, como também do sistema de abertura realizada na posição vertical.

Tal fato não ocorre no refrigerador horizontal, pois o sistema de abertura permanece em localização privilegiada. Ou seja, todo o ar frio tende a permanecer embaixo por causa da sua maior densidade. Este fato naturalmente minimiza de forma acentuada a perda de energia quando comparado ao sistema vertical. Por isto $\left\{F R_{2}\right\}$ fica restrito somente ao isolamento da porta, tornando a equação do projeto desacoplada.

De acordo com a abordagem de projeto axiomático, o congelador de porta horizontal seria a melhor solução, pois é tida como ideal - desacoplado. No entanto, restrições $\{\mathrm{Cs}\}$ como a redução de área ocupada, a conveniência em acessar e organizar melhor 
Tabela 2.5: Parâmetros $\{$ DPs $\}$ e equação do projeto de refrigerador vertical e horizontal

\begin{tabular}{|c|c|c|}
\hline & Vertical & Horizontal \\
\hline Refrigerador & . & \\
\hline $\begin{array}{c}\text { Parâmetros } \\
\text { de projeto }\end{array}$ & $\begin{array}{l}\left\{D P_{1}\right\}: \text { Sistema de porta vertical } \\
\left\{D P_{2}\right\}: \text { Isolamento térmico na porta }\end{array}$ & $\begin{array}{l}\left\{D P_{1}\right\}: \text { Sistema de porta horizontal } \\
\left\{D P_{2}\right\}: \text { Isolamento térmico na porta }\end{array}$ \\
\hline $\begin{array}{l}\text { Equação do } \\
\text { projeto }\end{array}$ & $\left\{\begin{array}{l}F R_{1} \\
F R_{2}\end{array}\right\}=\left[\begin{array}{ll}X & 0 \\
X & X\end{array}\right]\left\{\begin{array}{l}D P_{1} \\
D P_{2}\end{array}\right\}$ & $\left\{\begin{array}{l}F R_{1} \\
F R_{2}\end{array}\right\}=\left[\begin{array}{ll}X & 0 \\
0 & X\end{array}\right]\left\{\begin{array}{l}D P_{1} \\
D P_{2}\end{array}\right\}$ \\
\hline
\end{tabular}

os itens, etc, provocaria uma tomada de decisão diferente da mencionada. Ou seja, a porta vertical seria a melhor solução considerando tais restrições, mesmo comparando um projeto semi-desacoplado com um desacoplado. Tal exemplo mostra claramente que as restrições são importantes e possuem influencia na decisão das equações de projeto obtidas, isto é, na escolha da melhor solução.

No caso de existirem diferentes soluções semi-acopladas (projeto aceitável) que atendam as mais diversas restrições, a abordagem axiomática fornece medidas quantitativas que auxiliam a tomada de decisão. Estas são denominadas de Reangularidade (R) Semangularidade (S), definidas matematicamente no decorrer desta seção.

Para a seleção de alternativas que envolvem projetos desacoplados (projeto ideal), o segundo axioma (Axioma da Informação) é utilizado como critério para escolha da melhor solução. Já no caso de projetos acoplados, a abordagem axiomática advoga que não há necessidade de haver métricas para avaliação uma vez que esse tipo de projeto em princípio deve ser descartado. Entretanto, alguns autores não concordam com esta posição e fornecem alternativas de critérios para sistemas acoplados (FREY; JAHANGIR; ENGELHARDT, 2000).

No decorrer deste capítulo são apresentadas os critérios utilizados no processo de avaliação da melhor alternativa.

\section{Cálculo da Independência Funcional}


Segundo Suh (1990), o cálculo da Independência Funcional está associado à relação existente entre as coordenadas $\{F R\}-\{D P\}$, apresentadas de forma sucinta na figura 2.5
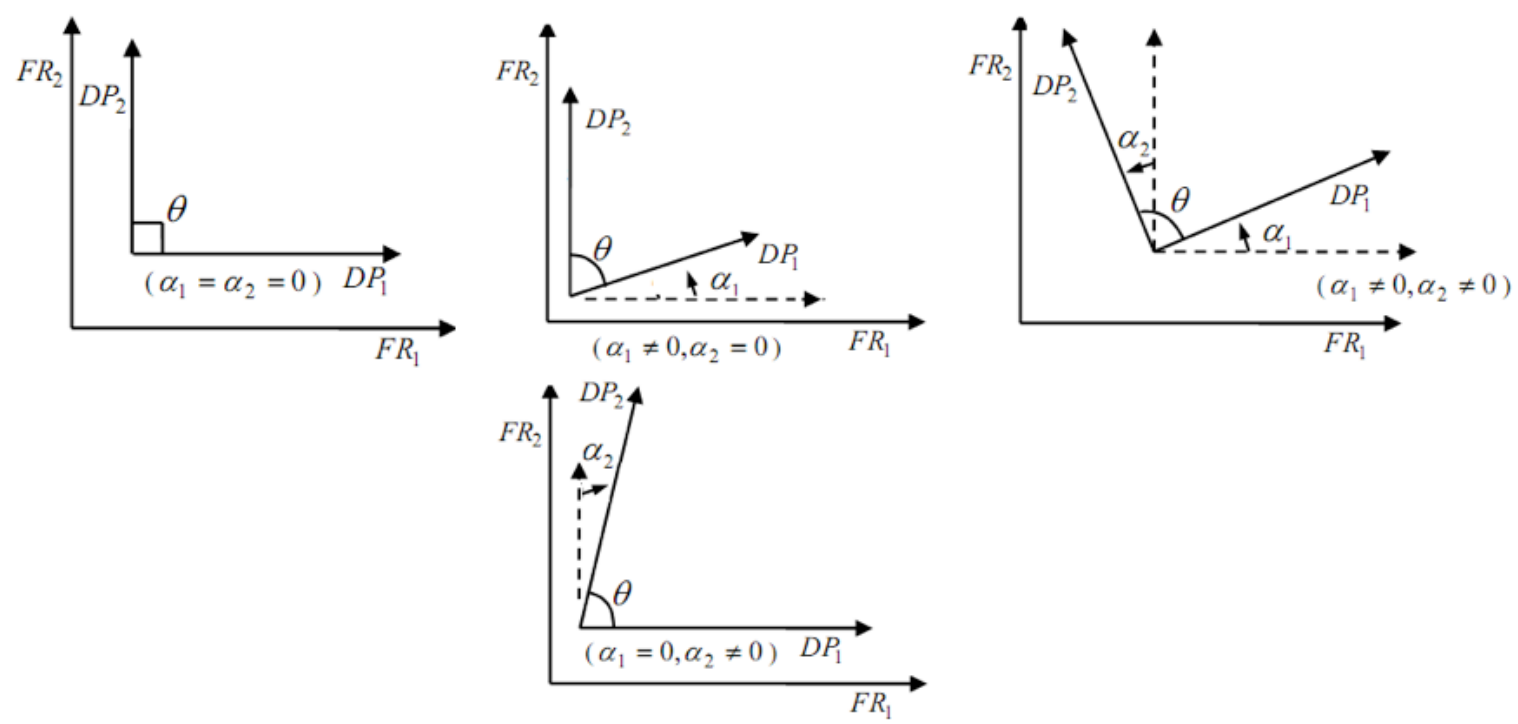

Projeto desacoplado

Projeto semi-acoplado

Projeto acoplado

$\left\{\begin{array}{l}F R_{1} \\ F R_{2}\end{array}\right\}=\left[\begin{array}{cc}X & 0 \\ 0 & X\end{array}\right]\left\{\begin{array}{l}D P_{1} \\ D P_{2}\end{array}\right\}$

$\left\{\begin{array}{l}F R_{1} \\ F R_{2}\end{array}\right\}=\left[\begin{array}{ll}X & 0 \\ X & X\end{array}\right]\left\{\begin{array}{l}D P_{1} \\ D P_{2}\end{array}\right\}$

$\left\{\begin{array}{l}F R_{1} \\ F R_{2}\end{array}\right\}=\left[\begin{array}{ll}X & X \\ X & X\end{array}\right]\left\{\begin{array}{l}D P_{1} \\ D P_{2}\end{array}\right\}$ $\left\{\begin{array}{l}F R_{1} \\ F R_{2}\end{array}\right\}=\left[\begin{array}{ll}X & X \\ 0 & X\end{array}\right]\left\{\begin{array}{l}D P_{1} \\ D P_{2}\end{array}\right\}$

(a)

(b)

(c)

Figura 2.5: Esquemático gráfico das equações de projeto - exemplo bidimensional (adaptado: (GYUNG-JIN, 2007))

A figura 2.5 mostra que os requisitos funcionais e os parâmetros de projeto devem ser ortogonais para não violar o Axioma da Independência. Os parâmetros de design $\{$ DPs $\}$ devem ser paralelos aos respectivos eixos dos $\{$ FRs $\}$ e os coeficientes nas equações de projeto estão associados aos ângulos $\alpha_{1}, \alpha_{2}$ e $\theta$. Maiores detalhes sobre as deduções desenvolvidas pelo autor podem ser encontradas em (SUH, 1990; GYUNG-JIN, 2007).

Com base nos parâmetros mencionados, Suh (1990) criou duas medidas quantitativas que mensuram o grau de independência funcional, denominadas de Reangularidade (R) (Reangularity) e Semangularidade (S) (Semangularity), A primeira é responsável por medir o grau de ortogonalidade entre os parâmetros de projeto $\{$ DPs $\}$ e é expressa pela equação 2.6 para caso bidimensional. 


$$
R=\operatorname{sen} \theta=\left(1-\cos ^{2} \theta\right)^{1 / 2}
$$

Para casos com n-dimensões, a equação 2.7 é fornecida.

$$
R=\prod_{\substack{i=1, n-1 \\ j=1+i, n}}\left(1-\frac{\left(\sum_{k=1}^{n} A_{k i} A_{k j}\right)^{2}}{\left(\sum_{k=1}^{n} A_{k i}^{2}\right)\left(\sum_{k=1}^{n} A_{k j}^{2}\right)}\right)^{1 / 2}
$$

em que:

- A apresenta os elementos da matriz de projeto;

- $R=1$ indica que os parâmetros de projeto são mutuamente ortogonais;

- $n$ é o número de $\{F R s\}$ e $\{D P s\}$.

Entretanto, a medida R não é suficiente para apresentar por completo o grau de independência funcional. A medida da semangularidade é um critério auxiliar que mede o relacionamento angular entre os eixos correspondentes de parâmetros de projeto $\{$ DPs $\}$ e dos requisitos funcionais $\{$ FRs $\}$, definido pela equação 2.8

$$
S=\prod_{j=1}^{n}\left(\frac{\left|A_{j j}\right|}{\left(\sum_{k=1}^{n} A_{k j}^{2}\right)^{1 / 2}}\right)
$$

em que:

- A apresenta os elementos da matriz de projeto;

- $S=1$ indica que a equação do projeto é diagonal;

Portanto, quanto maior a tendência a unidade nas medidas $R$ e $S$ maior será a inde- 
pendência funcional. A tabela 2.6 mostra o comportamento de tais medidas de acordo com cada projeto.

Tabela 2.6: Valor de $R$ e $S$ para cada tipo de projeto.

\begin{tabular}{l|ccl}
\hline & Projeto desacoplado & Projeto semi-acoplado & Projeto acoplado \\
\hline Reangularidade $(R)$ & 1 & $R=S<1$ & $R \neq S<1$ \\
Semangularidade $(S)$ & 1 & $S=R<1$ & $S \neq R<1$ \\
\hline
\end{tabular}

\subsubsection{Axioma 2 - Axioma da Informação}

O segundo axioma estabelece que dentre os projetos que satisfazem o primeiro axioma (especificamente os desacoplados), aquele que tiver o mínimo conteúdo da informação é tido como o melhor projeto.

De acordo com Suh (SUH, 1990, 1998), o conteúdo da informação é a medida do conhecimento necessário para satisfazer um dado $\{\mathrm{FR}\}$ em um dado nível da estrutura. Assim, quanto menor o número de informações em relação a um $\{\mathrm{FR}\}$, menor é o seu conteúdo, menor a complexidade da tarefa e, conseqüentemente, maior a probabilidade de sucesso.

O conteúdo da informação é definido em termos da probabilidade do parâmetro $\left\{D P_{i}\right\}$ satisfazer o requisito $\left\{F R_{i}\right\}$. Logo, se a probabilidade de sucesso deste parâmetro for $p$, o conteúdo da informação $I$ pode ser calculado de acordo com a equação 2.9.

$$
I=\log _{2}\left(\frac{1}{p}\right)
$$

em que a base 2 do logaritmo expressa o conteúdo da informação em unidades de bit;

A função logaritmo é escolhida porque caso existam vários requisitos funcionais que precisem ser satisfeitos ao mesmo tempo, o conteúdo da informação passa a ser o somatório de todos eles. Assim, supondo $p_{1}, p_{2}$ e $p_{3}$ como probabilidades dos $\left\{D P_{1}\right\}$, $\left\{D P_{2}\right\}$ e $\left\{D P_{3}\right\}$ satisfazerem os respectivos $\left\{F R_{1}\right\},\left\{F R_{2}\right\}$ e $\left\{F R_{3}\right\}$ de um projeto desacoplado (equação apresentada na Tabela 2.2), o conteúdo da informação total seria 
expressa pela equação 2.10. Isto é, a informação total de uma solução de projeto é fornecida pelo somatório das informações associadas a cada requisito funcional.

$$
I_{\text {total }}=\sum_{i=1}^{n} \log _{2}\left(\frac{1}{p_{i}}\right)
$$

em que:

- $p_{1}$ é a probabilidade de $\left\{D P_{i}\right\}$ satisfazer o requisito $\left\{F R_{i}\right\}$;

- $n$ representa o número total de $\{F R s\}$;

Quando todas as probabilidades são iguais a um, o conteúdo da informação é zero (não havendo chance de falha), e inversamente, a informação necessária é infinita quando um ou mais probabilidades são iguais a zero. Ou seja, se a probabilidade for baixa, mais informações devem ser fornecidas para satisfazer os requisitos funcionais.

De acordo com Suh (1998), no mundo real, a probabilidade de sucesso é governada pela interseção entre o intervalo de projeto (design range) (definido como o intervalo determinado para satisfazer o $\{\mathrm{FR}\}$ ) e o intervalo de sistema (system range), isto é, o intervalo determinado para produzir o artefato. A interseção é denominada de intervalo comum (common range) e representa a região em que os requisitos funcionais são satisfeitos, como mostra a figura 2.6.

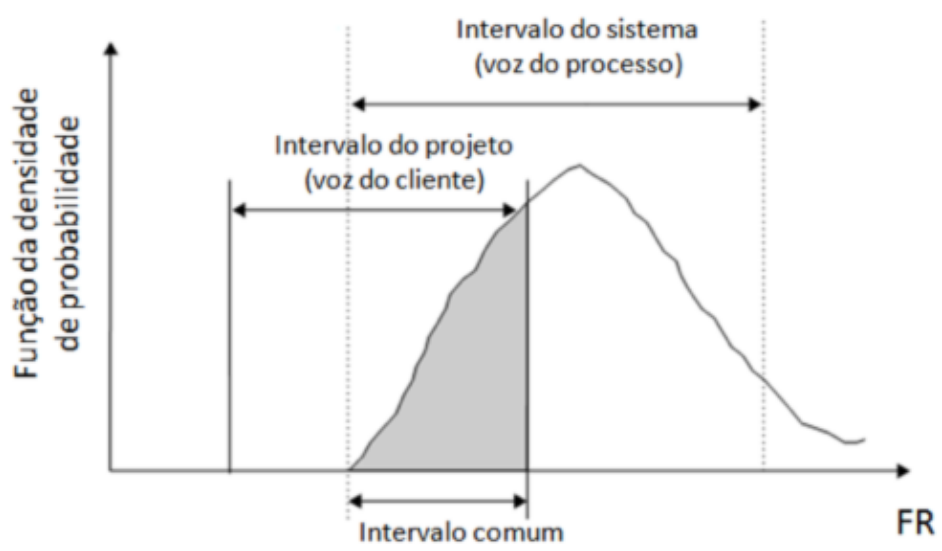

Figura 2.6: Representação gráfica da probabilidade de sucesso (adaptado:

(EL-HANIK, 2005)) 
Um mapeamento pode ser realizado entre o domínio funcional e o domínio físico, e nesse caso a abscissa passa a ser $\{F R\}$, mapeado as informações sobre os $\{$ DPs $\}$. Similarmente, um mapeamento pode ser feito entre o domínio físico e domínio do processo e nesse caso a abscissa passa a ser $\{D P\}$, mapeando informação sobre as variáveis de processo $\{\mathrm{PV}\}$. Evidentemente o primeiro mapeamento é exógeno e mapeia a informação que é inserida no domínio do projeto como um todo, enquanto as demais são internas ao projeto propriamente dito.

Como a medida da probabilidade de sucesso pode ser expressa pelo intervalo comum, apresentado na figura 2.6, o conteúdo da informação $I$ pode ser rescrito como:

$$
I=\log _{2}\left(\frac{A_{s r}}{A_{c r}}\right)
$$

onde:

- $A_{s r}$ é a área do intervalo de sistema;

- $A_{c r}$ é a área do intervalo comum.

Um exemplo do cálculo do conteúdo da informação através do uso da função da densidade de probabilidade é mostrado a seguir.

Exemplo - Compra de uma casa (GYUNG-JIN, 2007)

Seja um indivíduo que deseja efetuar a compra de uma casa. De acordo com suas necessidades, os seguintes requisitos funcionais foram estabelecidos:

$\left\{F R_{1}\right\}$ : Selecionar faixa de preço entre $\mathrm{R} \$ 50.000$ a $\mathrm{R} \$ 80.000$

$\left\{F R_{2}\right\}$ : Selecionar tempo gasto no deslocamento casa-trabalho: 40 minutos.

Com base nas alternativas presentes na tabela 2.7 e na abordagem axiomática, deseja-se saber qual das alternativas (A ou B) minimiza o conteúdo da informação. 
Tabela 2.7: Condições das cidades A e B

\begin{tabular}{l|cc}
\hline & Cidade A & Cidade B \\
\hline$\left\{D P_{1}\right\}:$ Preço & $\mathrm{R} \$ 45.000-\mathrm{R} \$ 60.000$ & $\mathrm{R} \$ 70.000-\mathrm{R} \$ 90.000$ \\
$\left\{D P_{1}\right\}:$ Tempo de deslocamento & $35-50 \mathrm{~min}$ & $20-30 \mathrm{~min}$ \\
\hline
\end{tabular}

Assumindo a probabilidade uniforme, avaliam-se ambas as alternativas (Tab. 2.8) de acordo com a equação 2.11 .

Tabela 2.8: Avaliação de alternativas

\begin{tabular}{|c|c|c|c|c|}
\hline & \multicolumn{2}{|c|}{$F R_{1}$} & \multicolumn{2}{c|}{$F R_{2}$} \\
\cline { 2 - 5 } Meta - Projeto & $\min$ & $\max$ & $\min$ & $\max$ \\
Alternativa A & 50 & 80 & 0 & 40 \\
Alternativa B & 75 & 60 & 35 & 50 \\
\hline
\end{tabular}

Os valores da métrica $I A_{\text {total }}$ e $I B_{\text {total }}$ são apresentados conforme as equações (Eq. 2.12), (Eq. 2.13), (Eq. 2.14), (Eq. 2.15) abaixo. Como auxílio, a figura 2.7 mostra a representação gráfica envolvida nos cálculos do conteúdo da informação.

$$
\begin{gathered}
I A_{1}=\log _{2}\left(\frac{60-45}{10}\right)=0.58496 ; I A_{2}=\log _{2}\left(\frac{50-35}{5}\right)=1.58496 \\
I_{\text {A.total }}=I A_{1}+I A_{2}=2.17(\text { bits }) \\
I B_{1}=\log _{2}\left(\frac{90-70}{10}\right)=1 ; I B_{2}=\log _{2}\left(\frac{30-20}{10}\right)=0 \\
I_{\text {B.total }}=I B_{1}+I B_{2}=1.0(\text { bits })
\end{gathered}
$$

De posse dos resultados, verifica-se que o conteúdo $I_{A}$ para a cidade $A$ é 2.18 e para cidade $B I_{B}$ é 1.0. Ou seja, a cidade $B$ tem a melhor opção do ponto de vista da abordagem axiomática do que a cidade $A$.

No exemplo apresentado, a escolha da melhor solução parece óbvia porque a quan- 


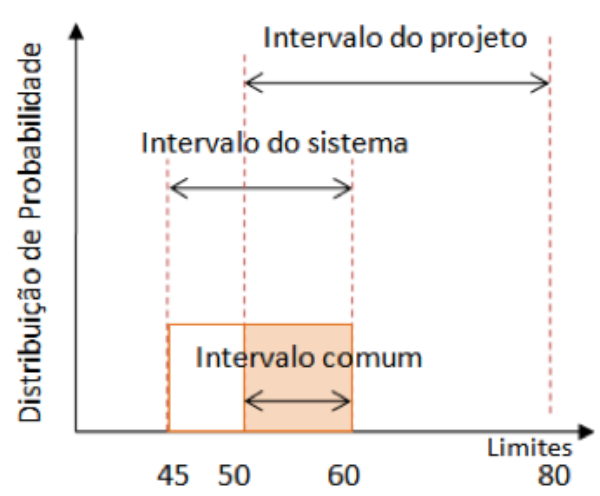

(a) $I A_{1}$

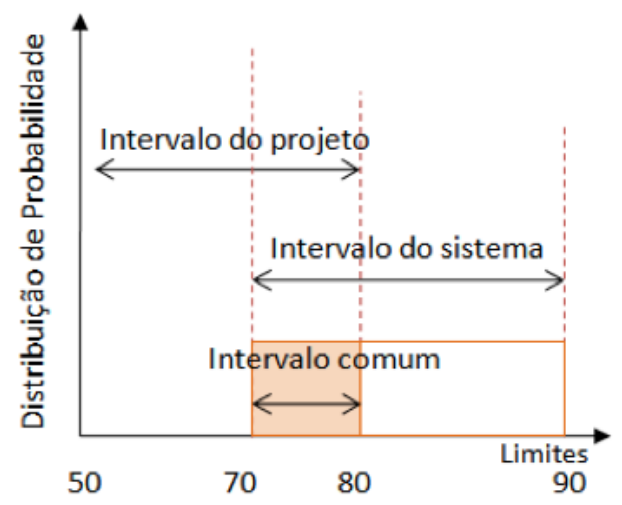

(c) $I B_{1}$

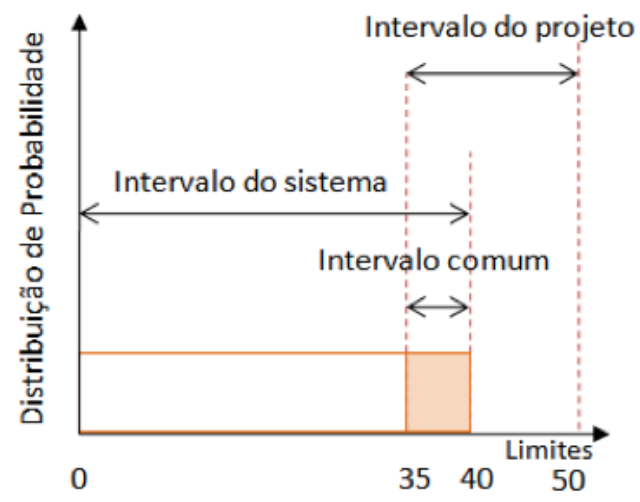

(b) $I A_{2}$

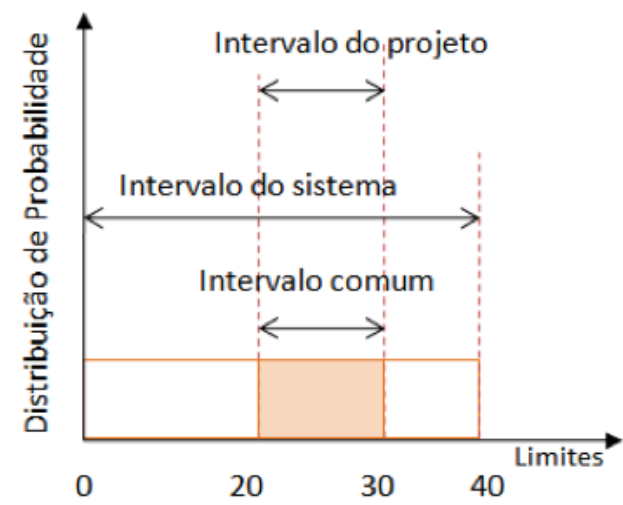

(d) $I B_{2}$

Figura 2.7: Representação gráfica para o cálculo do conteúdo de informação

tidade de parâmetros $\{\mathrm{DP}\}$ é artificialmente pequena. O mesmo não ocorre para projetos reais, pois o numero de parâmetros é muito superior.

Resumindo os conceitos abordados nesta e nas seções anteriores - dentro da perspectiva do Projeto Axiomático - um fluxograma do processo de projeto é apresentado na figura 2.8 .

Como pode ser visto na figura acima mencionada, cada axioma tem um papel e uma utilização diferente na abordagem axiomática. Entretanto, Kulaka, Cebib e Kahramanc (2010) mostram que existe uma forte tendência por parte dos pesquisadores enfatizar o primeiro axioma em projetos. Esta afirmação é baseada na análise de vários artigos encontrados nas bases de dados da Siencedirect, Taylor \& Francis e Web of Science, entre 1990 a 2009, em que $71,4 \%$ dos 63 trabalhos consultados fazem uso exclusivo do Axioma da Independência. Este fato deve-se principalmente ao papel deste axioma no auxílio na redução de busca aleatória de soluções, no fornecimento de infra-estrutura científica para o mundo do design, na minimização das atividades repetidas de tentativa e erro, e no suporte à criatividade do projetista.

A próxima seção introduz uma representação esquemática para alguns conceitos mencionados nas seções anteriores que traduzem o que se chama de arquitetura do 


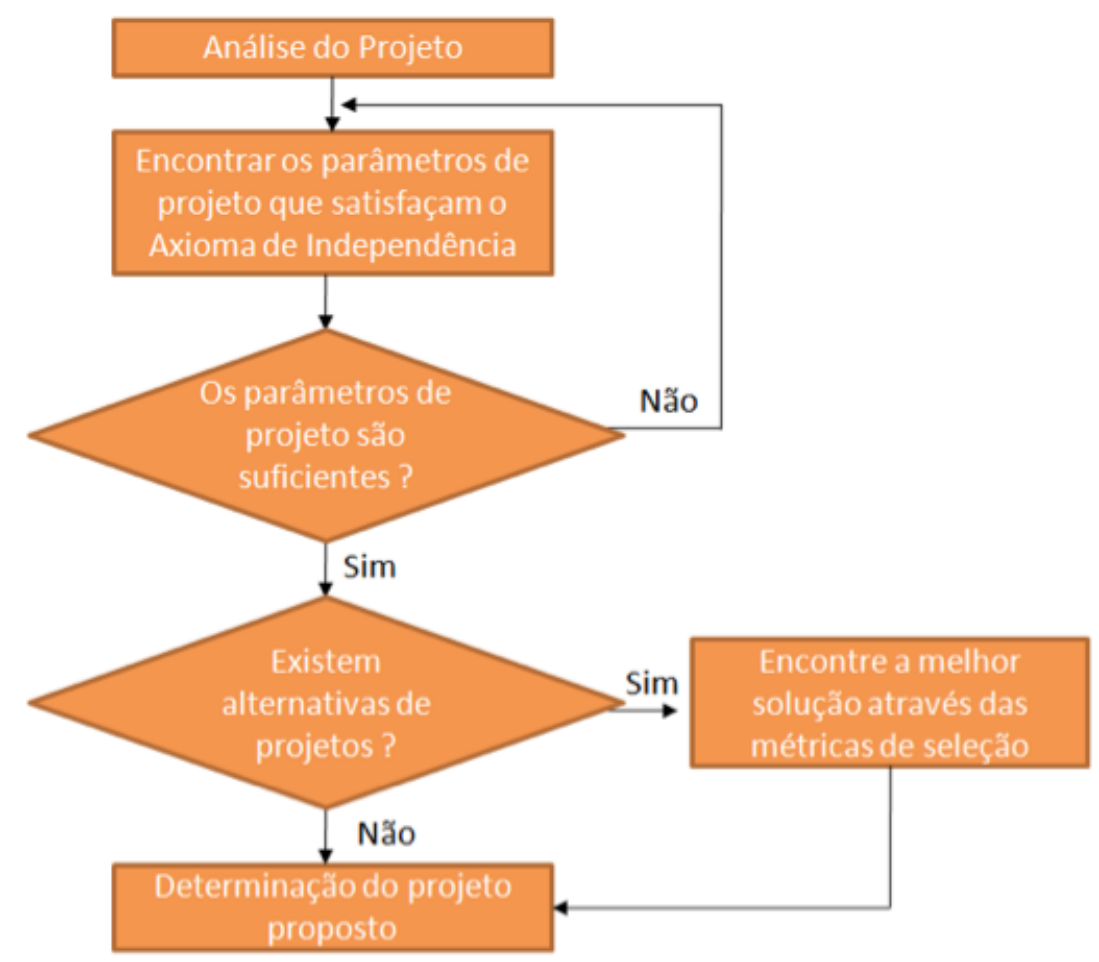

Figura 2.8: Fluxograma de aplicação da abordagem axiomática (HOU; WEN; HAN, 2007)

sistema.

\subsubsection{Arquitetura do Sistema}

A arquitetura do sistema é uma representação gráfica concisa do projeto e possui três modos de visualização: diagrama em árvore; diagrama de junção de módulo e de fluxo. Todos eles apresentam a mesma informação, muito embora enfatizem diferentes aspectos do sistema (SUH, 2001).

Estas representações podem ser utilizadas para diversos fins, tais como: i) avaliar o impacto de mudanças no projeto, bem como as alterações dos requisitos funcionais e restrições; ii) analisar como as alterações em níveis mais elevados afetam os níveis mais baixos, ou seja, como o desenvolvedor pode tomar decisões mais conscientes e informadas a respeito das modificações propostas; iii) facilitar a identificação de erros, isto é, auxiliar o diagnóstico de falhas do sistema; iv) ajudar na comunicação entre os próprios projetistas/especialistas; v) prover uma boa técnica de documentação de projeto, facilitando a compreensão das tomadas de decisão, bem como o raciocínio envolvido por traz delas (rationale); vi) avaliar como o impacto da alteração em parte 
do sistema pode afetar outra parte; etc.

A primeira versão da representação gráfica esquemática é o diagrama em árvore, apresenta justamente a estrutura hierárquica do sistema em termos de $\{$ FRs $\},\{$ DPs $\}$ e $\{\mathrm{PVs}\}$, o que corresponde ao projeto e a suas equações matriciais. A figura 2.9 ilustra este digrama.

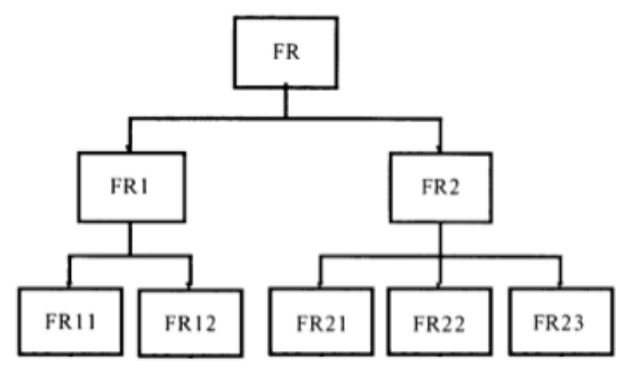

Domínio funcional

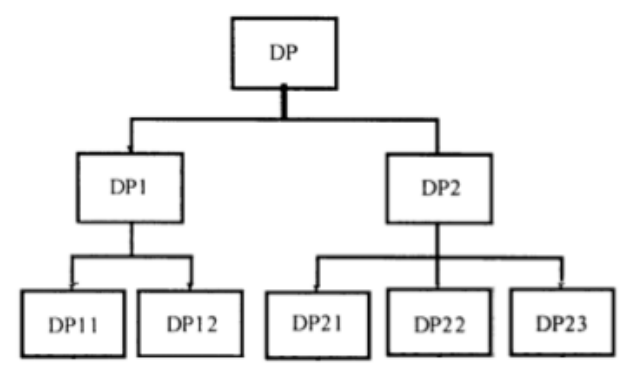

Domínio fisico

Figura 2.9: Exemplo de diagrama em árvore para a hierarquia $\{F R\}$ e $\{D P\}$ (adaptado: (SUH, 1998)).

O diagrama de junção de módulo é criado para representar a arquitetura do sistema de forma mais detalhada que o anterior. Para isso será introduzido o conceito de módulo. Entretanto deve ser sublinhado que o conceito de módulo na abordagem axiomática não está associado a elementos estruturados do sistema ou à sua composicionalidade.

Segundo a abordagem axiomática, um módulo é definido como uma expressão extraída da matriz de projeto que retorna um requisito funcional $\{F R\}$ quando um correspondente parâmetro de projeto $\{\mathrm{DP}\}$ é colocado como entrada (input). Com base neste conceito, o diagrama de junção de módulo auxilia a criação de uma representação gráfica que engloba/encapsula não só as árvores $\{F R\}$ e $\{D P\}$, como também a matriz de projeto.

Desta forma, três representações de junção são fornecidas, sendo a primeira, o conectivo $\mathbf{S}$. Esta enfatiza um relacionamento independente entre os módulos e representa uma matriz de projeto desacoplada. O segundo, o conectivo $\mathbf{C}$, indica que os módulos possuem uma dependência de controle entre eles, o que corresponde a uma matriz semi-acoplada. Por último, o conectivo $\mathbf{F}$ enfatiza uma retroalimentação, violando o Axioma da Independência.

Um exemplo de diagrama de junção de módulos é apresentado na figura 2.10 que tem como base as equações de projeto (Eq. 2.16). 


$$
\begin{aligned}
& \left\{\begin{array}{l}
F R_{1} \\
F R_{2}
\end{array}\right\}=\left[\begin{array}{ll}
X & 0 \\
0 & X
\end{array}\right]\left\{\begin{array}{l}
D P_{1} \\
D P_{2}
\end{array}\right\} \\
& \left\{\begin{array}{l}
F R_{11} \\
F R_{12}
\end{array}\right\}=\left[\begin{array}{ll}
X & 0 \\
X & X
\end{array}\right]\left\{\begin{array}{l}
D P_{11} \\
D P_{12}
\end{array}\right\} \\
& \left\{\begin{array}{l}
F R_{21} \\
F R_{22} \\
F R_{23}
\end{array}\right\}=\left[\begin{array}{lll}
X & 0 & 0 \\
X & X & 0 \\
X & 0 & X
\end{array}\right]\left\{\begin{array}{l}
D P_{21} \\
D P_{22} \\
D P_{23}
\end{array}\right\}
\end{aligned}
$$

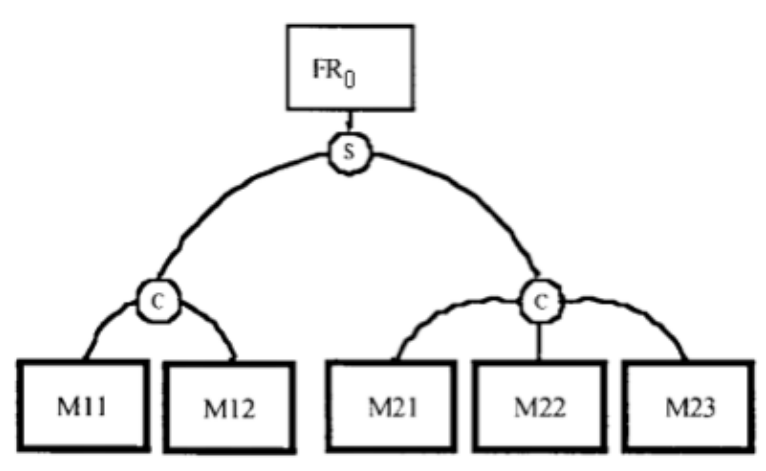

Figura 2.10: Diagrama de junção de módulo do projeto descrito pela equação 2.16 (adaptado: (SUH, 1998))

Por fim, o diagrama de fluxo é uma representação que mostra a interação entre os módulos e deve ser criado após a definição do diagrama de estrutura de junção de módulo. Esse tipo de representação enfatiza como a informação deve fluir através do sistema. A classificação do fluxo da informação em paralelo, seqüencial ou com retroalimentação é determinada pelos tipos de junções mencionadas anteriormente e apresentadas de acordo com a tabela 2.9.

De acordo com o diagrama de junção de módulo do projeto ilustrado anteriormente, tal representação é mostrada na figura 2.11 .

Baseado no trabalho de Melvin e Suh (2002), o diagrama de fluxo pode representar um link entre a abordagem axiomática e uma possível simulação dos elementos da matriz de projeto. 
Tabela 2.9: Tipos de junções (SUH, 1998)

\begin{tabular}{cccc}
\hline Símbolo & Tipo & $\begin{array}{c}\text { Tipo do } \\
\text { Projeto }\end{array}$ & Representação no diagrama de fluxo \\
\hline S & Soma & Desacoplado & Soma dos módulos em paralelo \\
C & Controle & $\begin{array}{c}\text { Semi- } \\
\text { acoplado }\end{array}$ & Processamento dos módulos em sequência \\
F & $\begin{array}{c}\text { Retroalime } \\
\text { ntação }\end{array}$ & Acoplado & Processo sequencial de retroalimentação \\
& &
\end{tabular}

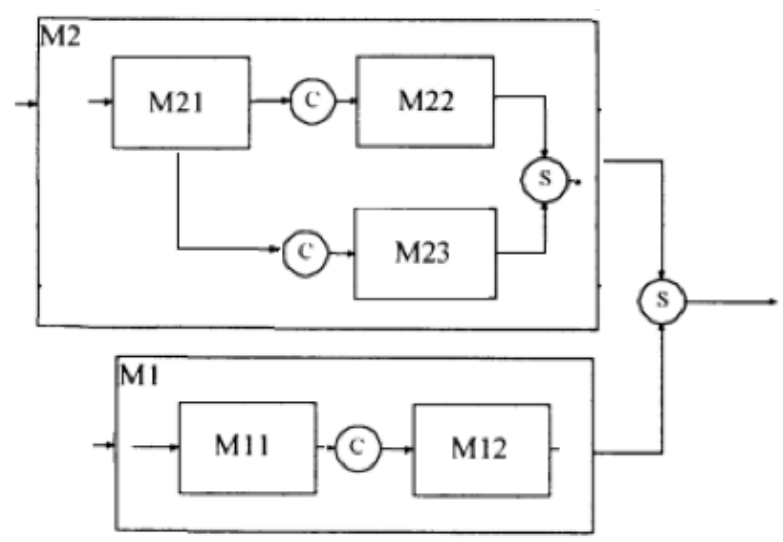

Figura 2.11: Diagrama de fluxo do projeto do sistema fornecido pela equação 2.16 (SUH, 1998). 


\subsection{Análise de Textura}

A análise ou interpretação de imagens digitais tem sido foco em várias áreas de pesquisa. O crescente avanço da tecnologia digital tem permitido o desenvolvimento e a implementação de algoritmos capazes de analisar e reconhecer padrões em imagens digitais. Para tal, pesquisadores buscam empregar as características utilizadas pelo ser humano na interpretação de informações visuais.

A textura pode ser considerada como um elemento de extrema relevância para o desempenho do processo de reconhecimento de padrões, uma vez que este é uma fonte rica de informações sobre a distribuição espacial de uma superfície. Variação de luminosidade, descrição do arranjo estrutural e as relações entre regiões vizinhas das superfícies, são características necessárias a discriminação e, conseqüentemente, constituem suporte para o processo de classificação de regiões ou objetos de interesse numa imagem. No entanto, uma textura possui uma quantidade elevada de variações, isto é, um espectro que se inicia desde o regular (padrões periódicos simples, com forma dos elementos da textura repetidos em intervalos iguais) até o estocástico (imagem com aparência de ruído, em que seus elementos são espalhados aleatoriamente).

A utilização do mencionado elemento no reconhecimento de padrões se dá através de dois processos: o primeiro, composto por diferentes técnicas de análise capazes de mensurar o relacionamento, local ou global, entre os elementos que compõem a textura/imagem (ou seja, cada uma com sua respectiva aplicação no espectro de textura) (MATERKA; STRZELECKI, 1998; GONZALES; WOODS, 2002); e a segunda, através de um processo classificatório, em que são agrupadas características semelhantes, determinando a formação de classes ou grupos.

Assim, esta seção tem como objetivo apresentar de forma gradativa os aspectos envolvidos na análise de textura, desde a representação digital de uma imagem, até a análise e classificação de textura.

\subsubsection{Representação da Imagem Digital}

Uma imagem monocromática pode ser definida como uma função bidimensional $f(x, y)$ onde $x$ e $y$ são coordenadas espaciais (plano), e a amplitude da função $f$, em qualquer ponto $(x, y)$, é denominada de intensidade ou níveis de cinza neste ponto (GONZALES; WOODS, 2002).

Assim, representação de uma imagem digital pode ser feita através de uma matriz 
bidimensional (Eq. 2.17) em que os índices de linha e coluna identificam um ponto na imagem (chamado de elemento da imagem ou pixel) e o valor do elemento da matriz identifica o nível de cinza (discretizado computacionalmente em um intervalo de 0 a 255 , em que o valor zero é associado ao preto (ausência de cor) e o valor 255, à cor branca) naquele ponto. A figura 2.12 exemplifica esquematicamente esta representação para os níveis de cinza correspondentes a uma pequena região destacada.

$$
f(x, y)=\left[\begin{array}{cccc}
f(0,0) & f(0,1) & \ldots & f(0, N-1) \\
f(1,0) & f(1,1) & \ldots & f(1, N-1) \\
: & : & \ldots & : \\
f(M-1,0) & f(M-1,1) & \ldots & f(M-1, N-1)
\end{array}\right]
$$

onde $N$ e $M$ correspondem, respectivamente, aos números de elementos (pixels) da imagem na horizontal e vertical.

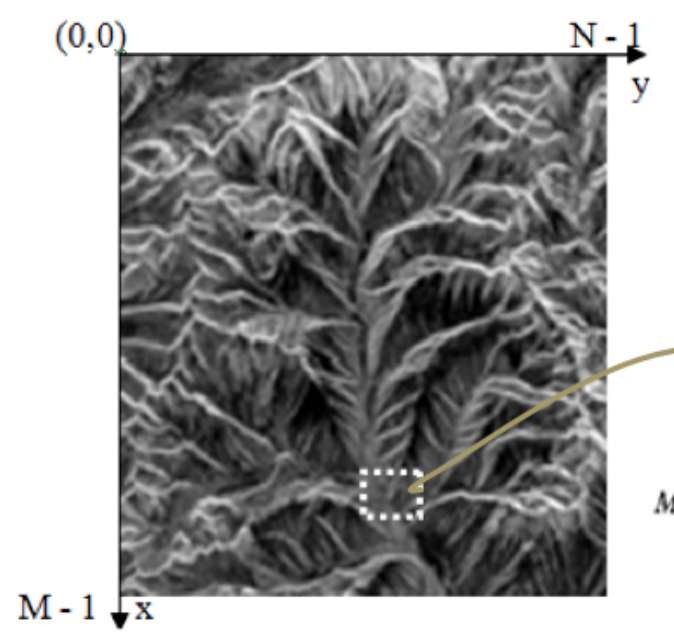

(a) Imagem (b) Exemplificação da intensidade dos elementos da área destacada.

Figura 2.12: Representação matricial de uma imagem (adaptado: (GONZALES; WOODS, 2002))

Os pixels de uma imagem possuem uma determinada região de adjacência em relação aos seus vizinhos. Um elemento pode ter até oito pixels adjacentes, isto é, para um elemento $p(x, y)$, seus vizinhos horizontais e verticais são: $f(x+1, y), f(x-$ $1, y), f(x, y+1)$ e $f(x, y-1)$, enquanto que seus vizinhos diagonais são: $f(x+1, y+$ $1), f(x-1, y-1), f(x+1, y-1)$ e $f(x-1, y+1)$. Na literatura encontram-se duas 
terminologias referentes a esta região de adjacência: vizinhança de 4 - referente aos vizinhos horizontais e verticais, e vizinhança de 8 - referente aos vizinhos horizontais, verticais e diagonais (GONZALES; WOODS, 2002).

Com relação à imagem, esta pode conter informações em intervalos ou bandas distintas de frequência. Portanto, faz-se necessário uma função $f(x, y)$ para cada uma das bandas. A imagem colorida, por exemplo, denominada de multibanda ou multiespectral, faz parte desse grupo, pois a cor em cada ponto $(x, y)$ da imagem é definida pela combinação de três bandas distintas: vermelho, verde e azul (as cores primárias utilizadas pela percepção visual do ser humano, denominada de RGB).

Existem também imagens utilizadas em sensoriamento remoto que são multiespectrais, isto é, em que os sensores operam em diferentes faixas do espectro eletromagnético (infravermelho e/ou ultravioleta).

Já a imagem binária, que só possui uma banda, tem elementos da imagem com dois valores: 0, associado a componentes de fundo, sem interesse, e 1, associados a objetos de frente, de interesse. Esse tipo de imagem é utilizada para medição de características morfológicas de objetos desejados na imagem.

Visto os conceitos relevantes para a compreensão da imagem digital, apresentamse nas seguintes seções as definições referentes à textura, bem como os métodos e técnicas envolvidas na realização do processo de extração de suas característica.

\subsubsection{Textura}

A análise ou interpretação de imagens tem por objetivo obter informações satisfatórias para distinguir objetos ou regiões de interesse em uma imagem. Entretanto, definir um conjunto de características capazes de descrever de forma efetiva cada região e/ou objeto não é uma tarefa simples. Uma tentativa de abordagem eficiente baseia-se na compreensão e emprego das características utilizadas pelo ser humano na interpretação de informações visuais, tais como: análise da forma, níveis de cinza, cores e textura dos objetos.

A textura é uma fonte rica de informações que possui dados/elementos significativos sobre a distribuição espacial de uma superfície, variação de luminosidade, descrição de arranjo estrutural e as relações das superfícies entre regiões vizinhas. Características almejadas na área da análise de textura para extração de características, discriminação e classificação de regiões ou objetos de interesse numa imagem.

Genericamente falando, segundo os autores Materka e Strzelecki (1998), texturas 
são padrões visuais complexos compostos por entidades ou sub-padrões que possuem brilho, cor, profundidade, tamanho, etc. Podem exibir uma variedade de efeitos perceptivos, como: luminosidade, uniformidade, densidade, aspereza, regularidade, suavidade, granulação, etc. Matematicamente, uma textura pode ser observada como um espectro que vai desde um padrão regular (padrões periódicos simples, com a cor/identidade e a forma dos elementos da textura repetidos em intervalos iguais), até o estocástico (imagem com aparência de ruído, em que seus elementos são espalhados aleatoriamente), como ilustrado na figura 2.13 (MIRMEHDI; XIE; SURI, 2009).

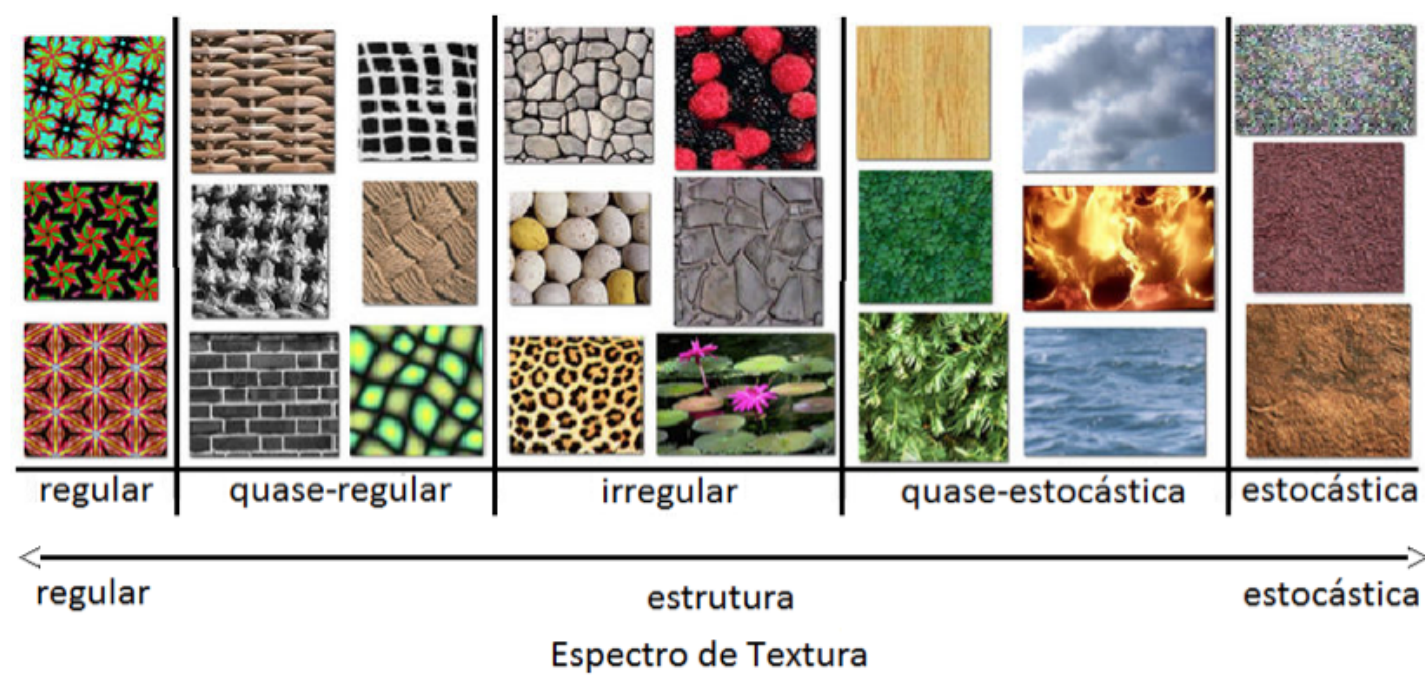

Figura 2.13: Espectro da textura com base na regularidade de sua variação estrutural (adaptado:(MIRMEHDI; XIE; SURI, 2009))

Na literatura não há um consenso em relação à definição formal de textura, dificultando o desenvolvimento de um conjunto de descritores ou medidas a ser (re)utilizado genericamente em uma avaliação de textura em diferentes domínios de aplicação (RUSS, 1998; PRATT, 2001; GONZALES; WOODS, 2002; JAHNE, 2002). A constatação deste fato pode ser baseada na variedade de técnicas de análise e/ou métodos encontrados (HARALICK, 1979; WECHSLER, 1980; CROSS; JAIN, 1983; LUERKENS, 1991; CHAUDHURI; SARKAR, 1995; MATERKA; STRZELECKI, 1998; ZHANG; TIENIU, 2002) e discutidos brevemente na seção seguinte deste capítulo. A seguir, são apresentados exemplos de definição de textura, descritas por alguns autores:

1. "Uma região macroscópica em que a estrutura é formada pela repetição de padrões, nos quais os elementos ou primitivas encontram-se arranjados conforme uma regra de composição" (TAMURA H.; YAMAWAKI, 1978 apud TUCERYAN; JAIN, 1999);

2. "Um arranjo repetitivo de padrões sobre uma área, em que se tenta medir sua 
aspereza, observando fatores como a dependência de níveis de cinza e a autocorrelação" (TUCERYAN; JAIN, 1999);

3. "A textura pode ser descrita pela iteração entre suas primitivas tonais ou propriedades locais e sua organização espacial. Elementos da imagem (pixels) próximos que apresentam propriedades semelhantes formam as primitivas, que podem ocorrer de forma aleatória ou com certo grau de dependência. A ocorrência de interações aleatórias e grandes variações nos níveis de cinza forma texturas finas, enquanto que a ocorrência de interações melhor definidas e com presença de regiões mais homogêneas (grupo de elementos da imagem com níveis de cinza semelhantes), formam texturas ásperas" (HARALICK, 1979);

4. "A noção de textura parece depender de três componentes: $(i)$ uma "ordem" local é repetida ao longo de uma região, grande em comparação com o tamanho da ordem; (ii) a ordem consiste de um arranjo não aleatório de partes elementares; e (iii) as partes são entidades praticamente uniformes tendo aproximadamente a mesma dimensão em todos os lugares dentro da região da textura" (HAWKINS, 1970 apud PRATT, 2001);

5. "Uma região de uma imagem tem textura constante se o conjunto de estatísticas locais ou outras propriedades locais da função da imagem são constantes, variando lentamente ou de forma aproximadamente periódica" (SKLANSKY, 1978 apud TUCERYAN; JAIN, 1999);

Como ilustrado, uma variedade de definições pode ser encontrada. Ainda não existe uma definição universal (precisa e formal) sobre o que seja textura. Ela é fortemente dependente da área de aplicação em análise.

Várias áreas de aplicação utilizam-se desse artifício, sendo algumas delas destacadas a seguir:

1. Automação industrial: Controle de qualidade - inspeção e verificação de falhas em circuitos impressos, defeitos em soldas, separação de peças, etc (WESZKA; ROSENFELD, 1976; HANDMANN; KALINKE, 1997; CHO; CHUNG; PARK, 2005; FERREIRA; SANTOS, 2006; ISLAM; AKHTER; MURSALIN, 2006);

2. Medicina: Interpretação e identificação de prováveis lesões ou regiões atingidas por doenças (FREEBOROUGH; FOX, 1998; KRAMER; AGHDASI, 1999; JI; ENGEL; CRAINE, 1999; MUDIGONDA; RANGAYYAN; DESAUTELS, 2000; CASTELLANO et al., 2004; BHARATHI; VIJILIOUS; GANESAN, 2008); 
busca de imagens médicas por similares e recuperação baseada em conteúdo (GLATARD; MONTAGNAT; MAGNIN, 2004);

3. Biologia: Identificação e contagem de células sanguíneas capturadas por microscópio óptico (MURATA; HERMANAND; LAKOWICZ, 2001; USHIZIMA et al., 2004);

4. Sensoriamento remoto: Análise de fotografias aéreas ou de satélites para análise de áreas de desmatamento, análise do solo, áreas urbanas e etc (HE; WANG, 1990; LORETTE; DESCOMBES; ZERUBIA, 2000; COOPER, 2004);

5. Segurança e Vigilância: Identificação e/ou reconhecimento de faces (BEYMER, 1994; LIU; WECHSLER, 2001; ZHANG; GAO; LEUNG, 2006).

A seção seguinte deste capítulo descreve os principais métodos de extração dos atributos de textura.

\subsubsection{Métodos de Análise}

Embora não haja também um consenso a respeito de uma taxonomia para os métodos de análise de textura, estes podem ser divididos em três classes principais (MATERKA; STRZELECKI, 1998; TUCERYAN; JAIN, 1999): métodos estatísticos, métodos baseados em processamento de sinais e métodos geométricos. A seguir, uma breve abordagem sobre eles.

\subsubsection{Abordagem Estatística}

A abordagem estatística não busca compreender explicitamente a estrutura hierárquica da textura. Ao invés disso, ela representa a estrutura indiretamente por propriedades não determinísticas que governam a distribuição e relação entre os níveis de cinza presentes em uma imagem (MATERKA; STRZELECKI, 1998). Essas propriedades são utilizadas apenas para representar/categorizar os atributos da textura, não podendo ser utilizada para a reconstrução da mesma.

Segundo Zhang e Tieniu (2002), os métodos estatísticos podem ser divididos em três classes: Estatística de Primeira Ordem, Segunda Ordem e/ou Ordem superior. Os métodos estatísticos de primeira ordem estimam propriedades dos valores individuais de intensidade dos elementos da imagem, ignorando a interação espacial entre eles, 
enquanto que os métodos de segunda e/ou ordem Superior estimam as propriedades da textura com base na interação espacial entre dois ou mais elementos da imagem. A seguir são apresentadas algumas técnicas computacionais que utilizam esses conceitos.

\section{I - ESTATÍSTICA DE PRIMEIRA ORDEM}

\section{Distribuição da intensidade dos Níveis de Cinza}

A discriminação da intensidade de cada elemento da imagem de maneira isolada é um dos métodos utilizados pela estatística de primeira ordem para estimar parâmetros de uma imagem. Média (Eq. 2.18), variância (Eq. 2.19), desvio padrão (Eq. 2.20), medida da assimetria da distribuição (Skewness) (Eq. 2.21) e a curtose (Eq. 2.22) dos elementos da imagem são medidas utilizadas para atingir tal objetivo (HARALICK; SHAPIRO, 1992). Esse tipo de técnicas requer um baixo custo computacional, característica relevante para alguns sistemas.

$$
\bar{X}=\frac{1}{N} \sum_{j=1}^{N} x_{j}
$$

em que:

- $N$ é o número de elementos da imagem;

- $\bar{X}$ denota o valor esperado da distribuição dos níveis de cinza;

- $x_{j}=f(x, y)$ é a intensidade do elemento da imagem;

$$
\sigma^{2}=\frac{1}{N} \sum_{j=1}^{N}\left(x_{j}-\bar{X}\right)^{2}
$$

em que:

- $\sigma^{2}$ refere-se ao desvio quadrático médio de tons de cinza em termos da média $\bar{X}$.

$$
\sigma=\sqrt{\frac{1}{N} \sum_{j=1}^{N}\left(x_{j}-\bar{X}\right)^{2}}
$$

em que: 
- $\sigma$ refere-se ao desvio médio de tons de cinza em termos da média $\bar{X}$.

$$
s=\frac{1}{N} \sum_{j=1}^{N}\left[\frac{x_{j}-\bar{X}}{\sigma}\right]^{3}
$$

em que:

- $S$ é um indicador da concentração de valores em relação à mediana, sendo negativa, quando a distribuição concentra-se à esquerda; positiva, a direita; e nula se o histograma é simétrico em torno da média. Em outras palavras, é um indicador de simetria.

$$
k=\left\{\frac{1}{N} \sum_{j=1}^{N}\left[\frac{x_{j}-\bar{X}}{\sigma}\right]^{4}\right\}-3
$$

em que:

- $k$ é um indicador do grau de achatamento da função de distribuição. Outra abordagem que utiliza a distribuição de níveis de cinza, sem caracterizar a relação espacial entre os elementos da imagem é o Histograma. Este utiliza uma função de densidade de probabilidade (Eq. 2.23) para discriminar o número total de elementos da imagem em relação a cada um dos níveis de intensidade de cinza.

$$
p(i)=\frac{h(i)}{N}, i=0,1, \ldots, G-1
$$

em que:

- $h(i)$ representa o número de ocorrências do nível de cinza;

- $N$ corresponde o número total de elementos da imagem;

- $p(i)$ função densidade de probabilidade dos níveis de cinza;

- $G$ denota o último nível de cinza.

Segundo Materka e Strzelecki (1998) essa abordagem é concisa e possui um simples resumo dos dados estatísticos contidos em uma imagem. Algumas medidas também podem ser obtidas através dele, tais como: valor mínimo e máximo, valor médio, energia (Eq. 2.24) e entropia (Eq. 2.25). A energia tem a função de medir a presença de valores altos, em relação aos demais presentes no histograma, enquanto que a en- 
tropia denota a uniformidade do histograma.

$$
\begin{gathered}
E=\sum_{i=0}^{G-1}\left[p(i)^{2}\right] \\
H=-\sum_{i=0}^{G-1} p_{i}(i) \log _{2}[p(i)]
\end{gathered}
$$

Esse método também exibe um baixo custo computacional, uma vez que estima somente propriedades individuais dos elementos da imagem. Entretanto, pelo fato de não considerar uma distribuição espacial, texturas com diferentes arranjos, mas com o mesmo valor de distribuição de níveis de cinza, podem não ser distinguidas (GONZALES; WOODS, 2002; JAHNE, 2002). Em vista deste fato, a técnica possui um baixo poder discriminativo. Na literatura encontram-se alguns trabalhos que utilizam esse tipo de abordagem (SIEW; HODGSON; WOOD, 1988; CHANDRARATNE et al., 2006).

\section{II - ESTATÍSTICA DE SEGUNDA ORDEM}

\section{Matrizes de depência espacial dos tons de cinza}

A quantificação de textura por métodos estatísticos que consideram relações espaciais entre pixels na imagem têm demonstrado um alto poder discriminatório segundo Partio, Cramarius e Visa (2002). Quando essa análise espacial é realizada entre dois elementos da imagem, estes métodos são denominados de segunda ordem. Os métodos que analisam a interação espacial entre três ou mais elementos da imagem são denominados de ordem superior.

A matriz de dependência espacial dos níveis de cinza (Spacial Gray Level Dependence Matrices - GLDM), conhecida também como matriz de co-ocorrência, é uma abordagem de segunda ordem que expressa em matriz a parte significativa da organização dos pixels de uma região (HARALICK; SHANMUGAM; DINSTEIN, 1973). Ou seja, uma matriz em que cada elemento é composto do número de transições 
que ocorrem entre dois níveis de cinza específicos, na qual a resolução da célula entre o pixel vizinho e o pixel de referência é separada por uma determinada distância e uma direção. Para tal, assume-se que cada elemento da textura possui uma relação de vizinhança de 8 (seção 2.2.1).

Matematicamente a matriz de co-ocorrência tem seu elemento definido como: $P(i, j ; d, a)$, em que o pixel tem seu nível de cinza representado por $i$ e o seu vizinho por $j$, relacionados através da distancia $d$ e da direção $a$. Tipicamente, a direção pode assumir quatro valores $0^{0}, 45^{0}, 90^{0}$ e $135^{\circ}$, como mostra figura 2.14 .

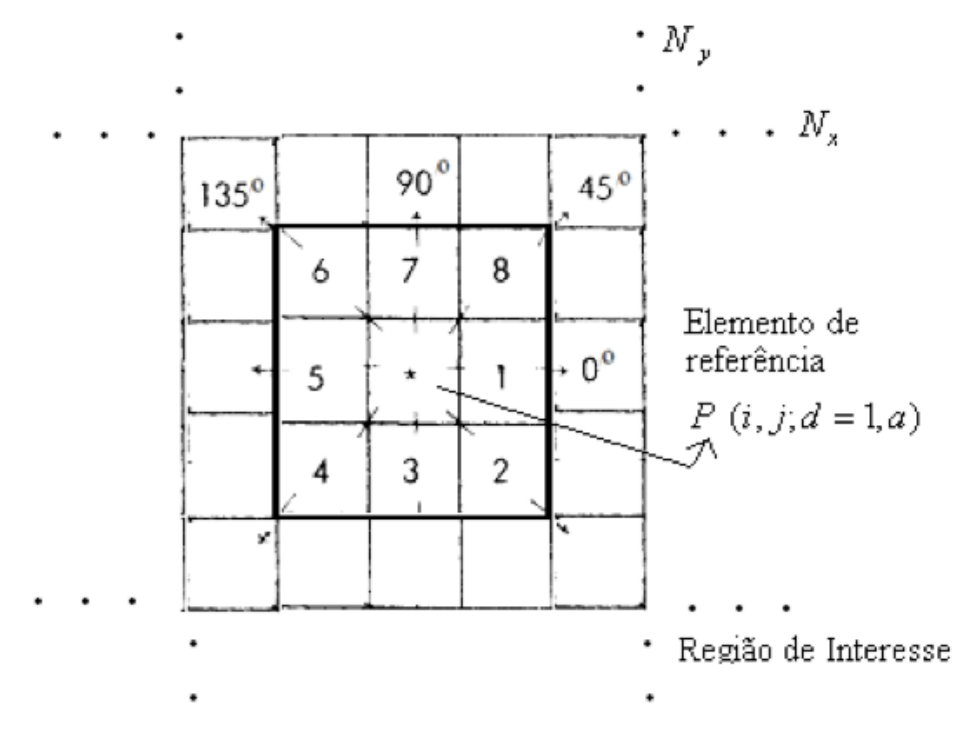

Figura 2.14: Possíveis direções entre o elemento de refêrencia e seus oito vizinhos. Resolução da célula $d=1$. O elemento central em relação aos vizinhos 1 e 5 possui direção $a=0^{0}$ (horizontal), enquanto que os vizinhos 7 e 3 possui direção $a=90^{\circ}$ (vertical). Já a relação entre os vizinhos 2 e 6 possui direção $a=135^{0}$ (diagonal 1), enquanto que a dos vizinhos 8 e 4 possui direção $a=45^{0}$ (diagonal 2) (adaptado:

(HARALICK; SHANMUGAM; DINSTEIN, 1973)).

Com base nos possíveis valores das direções, a função da densidade de probabilidade na matriz de co-ocorrência pode ser representada pelas seguintes equações 2.26 , 2.27, 2.28 e 2.29 .

$$
\begin{gathered}
P\left(i, j ; d, 0^{0}\right)=\#\{((k, l),(m, n) \in(L y \times L x) \times(L y \times L x) \\
|k-m=0,| l-n \mid=d, f(k, l)=i, f(m, n)=j\} \\
P\left(i, j ; d, 45^{0}\right)=\#\{((k, l),(m, n) \in(L y \times L x) \times(L y \times L x) \\
\mid(k-m=d, l-n=-d) \text { ou }(k-m=-d, l-n=d), \\
f(k, l)=i, f(m, n)=j\}
\end{gathered}
$$




$$
\begin{gathered}
P\left(i, j ; d, 90^{0}\right)=\#\{((k, l),(m, n) \in(L y \times L x) \times(L y \times L x) \\
|| k-m \mid=d, l-n=0, f(k, l)=i, f(m, n)=j\} \\
P\left(i, j ; d, 135^{0}\right)=\#\{((k, l),(m, n) \in(L y \times L x) \times(L y \times L x) \\
\mid(k-m=d, l-n=d) \mathrm{ou}(k-m=-d, l-n=-d), \\
f(k, l)=i, f(m, n)=j\}
\end{gathered}
$$

em que:

- \# denota o número de transições que ocorrem entre níveis de cinza;

- $k, l, m, n$ representam os índices da matriz de co-ocorrência;

- $d$, distância entre os elementos;

- $(\operatorname{Lyx} L x), L y=\left\{1,2, \ldots, N_{y}\right\}, L x=\left\{1,2, \ldots, N_{x}\right\}$, denota o conjunto da resolução da célula da imagem, ordenados por suas designadas linhas e colunas.

O tamanho da matriz está intrinsecamente associado ao número de tons de cinza presente na imagem. Isto é, se a imagem possuir $k$ níveis de cinza, a matriz de coocorrência possuirá $k$ linhas e $k$ colunas, ou seja, uma matriz $k x k$ quadrada. Além disto, segundo Haralick, Shanmugam e Dinstein (1973), essa matriz é simétrica, isto é, $P(i, j ; d, a)=P(j, i ; d, a)$.

A figura 2.15 apresenta um exemplo de representação/construção desta matriz em uma imagem $4 x 4$, com quatro níveis de tons de cinza.

A variação dos parâmetros de distância $d$ e direção $a$ permite a criação de várias matrizes de co-ocorrência, o que pode refletir em um maior número de características da textura em análise. Porém, para extrair tais atributos/características faz-se necessário o cálculo de medidas estatísticas através dos descritores de Haralick (HARALICK; SHANMUGAM; DINSTEIN, 1973) (COSSU, 1998 apud BARALDI; PARMIGGIANI, 1995). Estes por sua vez conseguem descrever/especificar propriedades da textura, tais como uniformidade, densidade, aspereza, regularidade e intensidade.

Para efetuar o cálculo dos descritores é necessário realizar a normalização dessas matrizes, isto é, dividir cada posição da matriz pela soma total de todos os seus valores não nulos. A definição do cálculo da normalização pode ser expressa pela equação 2.30 . 


\begin{tabular}{|l|l|l|l|}
\hline 0 & 0 & 1 & 1 \\
\hline 0 & 0 & 1 & 1 \\
\hline 0 & 2 & 2 & 2 \\
\hline 2 & 2 & 3 & 3 \\
\hline
\end{tabular}

(a) Imagem com apenas quatro tons de cinza

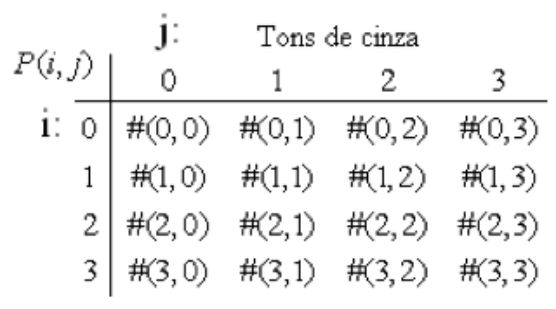

(b) Composição da matriz de co-ocorrência

$$
\begin{gathered}
P_{H}=\left[\begin{array}{llll}
4 & 2 & 1 & 0 \\
2 & 4 & 0 & 0 \\
1 & 0 & 6 & 1 \\
0 & 0 & 1 & 2
\end{array}\right], \\
d=1, a=0^{0}
\end{gathered}
$$

(c) Matriz de co-ocorrência resultante, $\operatorname{com} d=1, a=0^{0}$

Figura 2.15: Representação da matriz de co-ocorrência em uma imagem 4 x 4, com quatro tons de cinza (adaptado: (HARALICK; SHANMUGAM; DINSTEIN, 1973))

$$
p_{(i, j)}=\frac{P(i, j)}{\sum_{i, j=0}^{N-1}(P(i, j))}
$$

em que:

- $p_{(i, j)}$ denota a probabilidade da célula $(i, j)$ normalizada;

- $i$ é o número de linha e $j$ o número da coluna da matriz;

- $P_{(i, j)}$ denota o conteúdo da célula ;

- $\quad N$ representa o número de linhas e colunas;

Os descritores de Haralick possuem 14 medidas estatísticas que avaliam os atributos da textura presentes em uma imagem. A tabela 2.10 apresenta a definição matemática e característica de alguns dos mais relevantes descritores, segundo (COSSU, 1998 apud BARALDI; PARMIGGIANI, 1995). Demais métricas podem ser encontradas em (HARALICK; SHANMUGAM; DINSTEIN, 1973). 
Tabela 2.10: Relação de descritores de Haralick com suas respectivas características.

\section{Descritor}

Fórmula

1. Segundo Momento Angular

- Fornece a medida da uniformidade de uma textura;

- É também conhecido como medida de energia;

$$
f_{1(d, a)}=\sum_{i, j=0}^{N-1}\left[p_{(i, j)}\right]^{2}
$$

2. Contraste

- Reflete a quantidade de variação local de níveis de cinza. Pequena variação referese a baixo contraste;

$$
f_{2(d, a)}=\sum_{i, j=0}^{N-1}(i-j)^{2} p_{(i, j)}
$$

3. Entropia

- Quantifica o nível de dispersão dos níveis de cinza, isto é, expressa a desordem contida na textura;

$$
f_{3(d, a)}=-\sum_{i, j=0}^{N-1} p_{(i, j)} \log \left(p_{(i, j)}\right)
$$

4. Correlação

- A correlação mede a dependência linear de pixels entre os tons de cinza;

$$
f_{4(d, a)}=\sum_{i, j=0}^{N-1} p_{(i, j)}\left[\frac{\left(i-\mu_{i}\right)\left(j-\mu_{j}\right)}{\sigma_{i} \sigma_{j}}\right]
$$

em que:

$\mu_{i}, \mu_{j} ; \sigma_{i}, \sigma_{j}$ correspondem a média da distribuição marginale desvio padrão, respectivamente.

continuação da tabela na próxima página ... 


\section{Descritor}

Fórmula

5. Média

- Expressa valores em termos da matriz de co-ocorrencia dos niveis de cinza;

- Denota a heterogeneidade da matriz de co-ocorrência. Seu valor está relacionado com a combinação do pixel vizinho e o pixel de referencia. Apresenta valores altos quando os tons de cinza desviam do nível de cinza médio;

6. Variância e desvio padrão

7. Momento da diferença inversa (Homogeneidade)

- Denota a homogeneidade da matriz, refletindo a correlação inversa da medida de contraste. Ou seja, valores altos de homogeneidade indicam que a textura apresenta pequenas variações de níveis de cinza entre pares de pixels; $f_{5(d, a)}:$

$$
\begin{aligned}
& \mu_{i}=\sum_{i, j=0}^{N-1} i\left(p_{(i, j)}\right) \\
& \mu_{j}=\sum_{i, j=0}^{N-1} j\left(p_{(i, j)}\right)
\end{aligned}
$$

$$
\begin{aligned}
f_{6(d, a)}: & \\
\sigma_{i}^{2} & =\sum_{i, j=0}^{N-1}\left(i-\mu_{i}\right)^{2} p_{(i, j)} ; \\
\sigma_{j}^{2} & =\sum_{i, j=0}^{N-1}\left(j-\mu_{j}\right)^{2} p_{(i, j)} ; \\
\sigma_{i} & =\sqrt{\sigma_{i}^{2}} ; \sigma_{j}=\sqrt{\sigma_{j}^{2}}
\end{aligned}
$$

$$
f_{7(d, a)}=\sum_{i, j=0}^{N-1} \frac{1}{1+(i-j)^{2}} p_{(i, j)}
$$

A técnica para análise de textura baseada em matrizes de dependência dos tons de cinza tem demonstrado bons resultados na discriminação de texturas naturais (PARTIO; CRAMARIUS; VISA, 2002). Todavia, alguns inconvenientes podem ser mencionados. O primeiro deles refere-se à inexistência de uma definição formal para o tamanho ideal da distância $d$ entre o pixel vizinho e o pixel de referência. Qualquer desvio nesta variável do valor "ótimo" provável pode tornar o processo computacionalmente proibitivo.

O segundo deles refere-se às matrizes de co-ocorrência, que podem possuir grandes quantidades de níveis de cinza, por exemplo: 256x256. Estas exigem não só uma matriz muito mais esparsa, como maior custo computacional para a realização da extração dos atributos. Para minimizar tal efeito, pode-se reduzir o número de níveis de cinza da imagem, muito embora se deva observar que esse processo pode ocasionar 
perda na qualidade das características de textura presentes na imagem.

Por último, na tentativa de capturar todas as estruturas significantes de uma textura, pode-se criar um vetor maior de atributos. Ou seja, extrair um maior número de características através dos descritores de Haralick, considerando não só diferentes medidas de distância, como as diferentes orientações $(d=1, d=2, d=3, \ldots$, em que $a$ varia $0^{0}, 45^{0}, 90^{0}$ e $\left.135^{0}\right)$ Mas, nem sempre uma maior quantidade de característica expressa melhor qualidade.

Na literatura é possível encontrar vários trabalhos que utilizam este método na área de sensoriamento remoto (HE; WANG, 1990; ANYS; HE, 1995; SHABAN; DIKSHIT, 1998; HANN; SMITH; POWELL, 2003; COBURN; ROBERTS, 2004; PEARLSTINE; PORTIER; SMITH, 2005).

\section{III - ESTATÍSTICA DE ORDEM SUPERIOR}

\section{Matrizes de comprimento de corrida de tons de cinza}

A matriz de comprimento de corrida de tons de cinza (Gray Level Run Length Matrices - GLRLM) é uma abordagem estatística de ordem superior utilizada para obter informações relevantes sobre a regularidade de uma textura. Para tal, Galloway (apud ALBREGTSEN, 1995), propôs uma matriz, em que cada elemento representa o número de vezes que um certo nível de cinza ocorre consecutivamente em um dado comprimento da textura. A essa ocorrência consecutiva do nível de cinza é denominada de corrida e pode ser computada ao longo de diferentes orientações. Assim, de forma análoga a matriz de co-ocorrência (HARALICK, 1979), mencionada anteriormente, utiliza-se de medidas estatísticas ("descritores”) para extrair os atributos/propriedades da textura.

Matematicamente, cada elemento da matriz de Galloway (GALLOWAY, 1975 apud ALBREGTSEN, 1995) é representado por $P(i, j \mid \theta)$ em que $j$, representa o número de corridas, $i$ o nível de cinza dos elementos da imagem e $\theta$ orientação do segmento da reta formado pelos pixels.

Para uma dada imagem, pode-se calcular um conjunto de matrizes para corridas em quaisquer direções. Geralmente calculam-se as direções $0^{0}, 45^{0}, 90^{0}$ e $135^{\circ}$, apresentadas na figura 2.16 .

Um exemplo da representação/construção de uma matriz de corridas de tons de cinza em uma imagem 6 x 6 é ilustrado na figura 2.17 . 


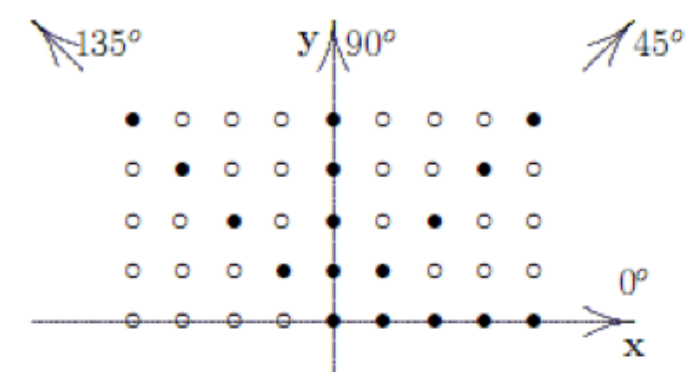

Figura 2.16: Ângulos utilizados para construção das matrizes de comprimento de corrida de cinza (ALBREGTSEN, 1995)

\begin{tabular}{|llllll|}
\hline 1 & 1 & 2 & 2 & 1 & 1 \\
3 & 3 & 1 & 1 & 2 & 2 \\
1 & 1 & 2 & 3 & 1 & 1 \\
3 & 1 & 2 & 2 & 1 & 1 \\
1 & 1 & 3 & 2 & 2 & 2 \\
2 & 3 & 1 & 1 & 2 & 2 \\
\hline
\end{tabular}

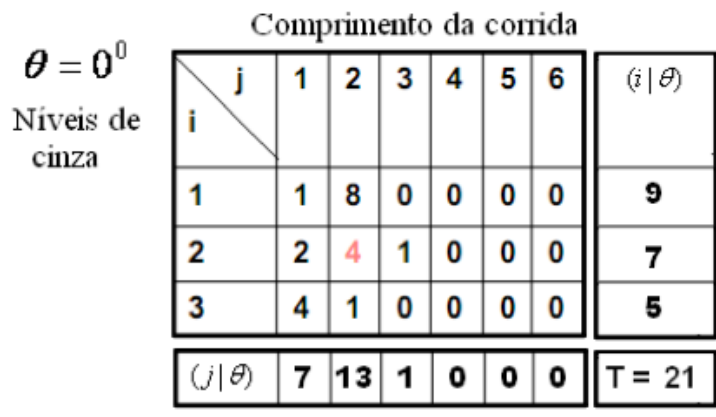

(a) imagem com três tons de cinza.

(b) matriz de corridas de cinza

Figura 2.17: Representação da matriz de corridas de tons de cinza em uma imagem $6 \mathrm{x} 6$

Segundo Galloway (apud HARALICK, 1979), Albregtsen (1995), Chu, Sehgal e Greenleaf (1990) e Tang (1998), sete medidas estatísticas podem ser utilizadas nas matrizes GLRL para extrair os atributos da textura, sendo elas:

1. Ênfase em corrida curtas (SER - Short Runs Emphasis)

$$
S R E=\sum_{i=0}^{G} \sum_{j=1}^{R} \frac{P(i, j \mid \theta)}{j^{2}} / \sum_{i=0}^{G} \sum_{j=1}^{R} P(i, j \mid \theta)
$$

2. Ênfase em corridas longas (LRE - Long Runs Emphasis)

$$
L R E=\sum_{i=0}^{G} \sum_{j=1}^{R} j^{2} P(i, j \mid \theta) / \sum_{i=0}^{G} \sum_{j=1}^{R} P(i, j \mid \theta)
$$


3. Não uniformidade do tom de cinza (GLN - Gray Level Non-Uniformity)

$$
G L N=\sum_{i=0}^{G}\left(\sum_{j=1}^{R} P(i, j \mid \theta)\right)^{2} / \sum_{i=0}^{G} \sum_{j=1}^{R} P(i, j \mid \theta)
$$

4. Não uniformidade do tamanho de corrida (RLN - Run Length Non-Uniformity)

$$
R L N=\sum_{j=1}^{R}\left(\sum_{i=0}^{G} P(i, j \mid \theta)\right)^{2} / \sum_{i=0}^{G} \sum_{j=1}^{R} P(i, j \mid \theta)
$$

5. Percentagem de corrida (RP - Run Percentage)

$$
R P=\frac{1}{n} \sum_{i=0}^{G} \sum_{j=1}^{R} P(i, j \mid \theta)
$$

6. Ênfase em corrida em baixo nível de tom de cinza(LGRE - Low Gray level runs emphasis)

$$
L G R E=\sum_{i=0}^{G} \sum_{j=1}^{R} \frac{P(i, j \mid \theta)}{i^{2}} / \sum_{i=0}^{G} \sum_{j=1}^{R} P(i, j \mid \theta)
$$

7. Ênfase em corrida em alto nível de tom de cinza (HGRE - High Gray level runs emphasis)

$$
H G R E=\sum_{i=0}^{G} \sum_{j=1}^{R} i^{2} P(i, j \mid \theta) / \sum_{i=0}^{G} \sum_{j=1}^{R} P(i, j \mid \theta)
$$

em que:

- $P(i, j \mid \theta)$ é o elemento $(i, j)$ da matriz de corridas para a direção $\theta$;

- $G$ é o número de tons de cinza;

- $R$ é o tamanho da corrida mais longa;

- $n$ é o número de pixels da imagem. 
As medidas 1 (Eq. 2.31 ) e 2 (Eq. 2.32) resultantes têm como principal objetivo ressaltar as corridas curtas e longas para um específico nível de cinza. A medida 3 (Eq. 2.33) apresenta valores baixos quando a corrida é uniformemente distribuída nos tons de cinza, enquanto que a medida 4 (Eq. 2.34) apresenta valores baixos quando a corrida é uniformemente distribuída no tamanho da corrida. Já a medida 5 (Eq. 2.35) apresenta valores próximos de um, quando ocorrem corridas curtas. Por último, as medidas 6 e 7 (Eq. 2.36 e Eq. 2.37) são utilizadas para distinguir texturas que apresentam similaridade em relação aos valores característicos SER e LRE, mas diferem na distribuição das corridas dentre os níveis de cinza.

Segundo Albregtsen (1995), para minimizar a quantidade de cálculos envolvidos nessa técnica, matrizes esparsas da GLRL, ocasionadas pelo número de tons de cinza presentes numa imagem, podem ser re-quantizadas de $G=256$ níveis, por exemplo, para 64, 32 ou 16. Todavia, a performance de resposta desta técnica depende da quantidade de tons de cinza envolvidos na imagem. Uma alternativa utilizada por alguns autores é a construção destas matrizes utilizando agrupamento de tons de cinza consecutivos (WESZKA; ROSENFELD, 1976) ou particionamento logarítmico do tamanho das corridas (ALBREGTSEN; NIELSEN; DANIELSEN, 2000), em intervalos.

Na literatura encontra-se trabalhos que utilizam este método na análise de texturas naturais, imagens aéreas, etc (LOH; LEU; LUO, 1988; TANG, 1998; BORCHANI et al., 2004; FAGAN; DU; DONNEL, 2008)

\section{Função de Autocorrelação}

A função de auto-correlação é outro método estatístico que pode ser utilizado para avaliar a quantidade de regularidade na textura, isto é, se ela é suave ou áspera (KANG; HASEGAWA; NAGAHASHI, 2003). Segundo Haralick (1979), a ocorrência de interações aleatórias e grandes variações no nível de cinza entre as primitivas caracterizam texturas como finas, enquanto que interações mais definidas e a presença de regiões mais homogêneas (grupo de elementos da imagem com níveis de cinza semelhantes) caracterizam texturas ásperas. A figura 2.18 exemplifica tais texturas.

A auto-correlação de uma imagem ou a correlação da imagem com ela mesma, deslocada em linhas e colunas, pode ser utilizada para avaliar/detectar padrões repetitivos nos elementos de uma textura, descrita formalmente pela equação 2.38. 


$$
C_{f f}(p, q)=\frac{\sum_{i=1}^{M-p} \sum_{j=1}^{M-q} f(i, j) f(i+p, j+q)}{\sum_{i=1}^{M} \sum_{j=1}^{N} f^{2}(i, j)}
$$

em que:

- $M, N$ denota a dimensão da imagem;

- $p, q$ é deslocamento dos pixels no eixo no $x$ e $y$, respectivamente;

- $(i, j)$ denota as coordenadas do elemento da imagem (sem deslocamento);

Quando as primitivas de uma textura são pequenas, a função de auto-correlação diminui rapidamente (WAN et al., 2004; CHEN; PAUL; WANG, 2005), gerando um pico único acentuado de resposta como mostra a figura 2.18 (a). Quando as primitivas são grandes, a função diminui lentamente com o aumento da distância, gerando um pico mais suave, figura 2.18 (b). Com base no tamanho das primitivas e da natureza da direção da textura, a amplitude e o alongamento do pico de respostas podem ser modificados como mostra a figura 2.18 (c). Se a primitiva for periódica, então o valor da função de auto-correlação cresce e decresce periodicamente com a distância, figura $2.18(\mathrm{~d})$.

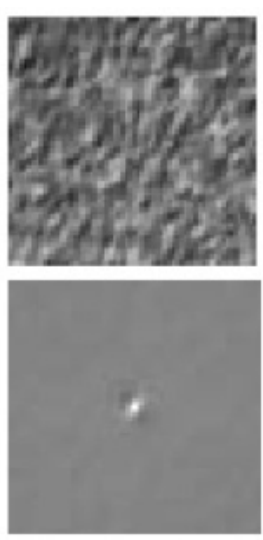

a
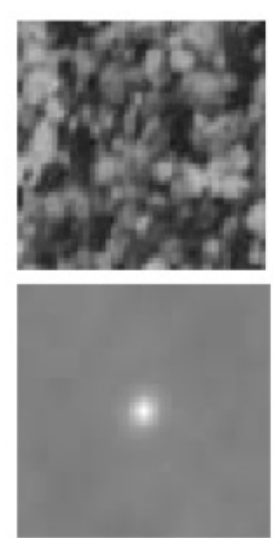

b
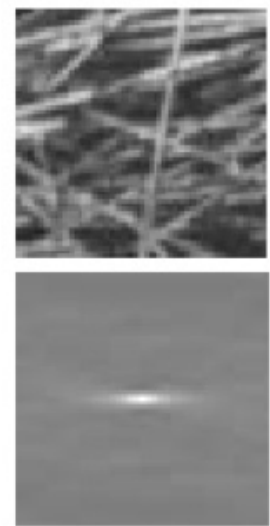

C

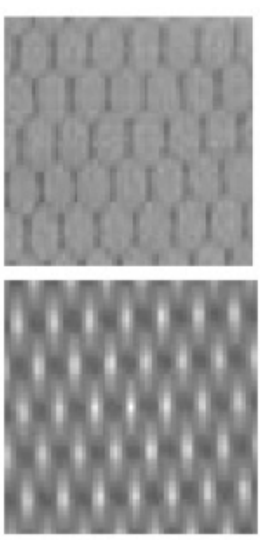

d

Figura 2.18: Função de autocorrelação computada de quatro texturas de Brodatz (BRODATZ, 2009), de acordo com Sebe e Lew (2001).

Resultados semelhantes à função de auto-correlação também podem ser obtidos a partir do espectro de potência da transformada de Fourier, método discutido em seção posterior deste capítulo.

Na literatura o uso deste tipo de técnica pode ser encontrado em (KAIZER, 1955; 
KANG; HASEGAWA; NAGAHASHI, 2003; WAN et al., 2004)

\section{Matriz da diferença dos tons de cinza da vizinhança}

De acordo com Amadasun e King (1989), o mecanismo da percepção humana possui um desempenho satisfatório na discriminação de todos os tipos de textura. A propriedade utilizada pelo ser humano para diferenciar tais padrões incluem a observação do contraste, aspereza, complexidade, fineza, forma, direcionalidade e força. Em vista deste fato, Amadasun e King (1989) desenvolveram um método que calcula cinco das características mencionadas, que segundo eles, podem ser utilizadas para analise de textura, com baixo custo computacional.

De forma análoga aos métodos anteriormente citados, cria-se uma matriz, denominada de Matriz da Diferença dos Tons de Cinza da Vizinhança (Neighborhood Gray Tone Difference Matrix - NGTDM), unidimensional, que considera a diferença entre o tom de cinza de cada pixel da imagem, com os tons de cinza dos seus vizinhos. De posse desta, aplicam-se medidas estatísticas para extrair atributos tais como: aspereza, contraste, fineza, complexidade e força da textura.

Matematicamente, a matriz de NGTDM é definida da seguinte forma:

Seja $f(k, l)$ a intensidade de qualquer pixel $(k, l)$, com valor de cinza $i$. Encontrase a média dos tons de cinza $\bar{A}(k, l)$ em torno da vizinhança do elemento central $(k, l)$ (não considerado) de acordo com a equação 2.39:

$$
\bar{A}=\bar{A}(k, l)=\frac{1}{W-1}\left[\sum_{m=-d}^{d} \sum_{n=-d}^{d} f(k+m, l+n)\right]
$$

em que:

- $(m, n) \neq(0,0), w=(2 d+1)^{2}$;

- $d$ denota o tamanho da vizinhança;

Cada elemento $s(i)$ da componente da matriz NGTDM é formado por:

$$
s(i)=\left\{\begin{array}{c}
\sum\left|i-\bar{A}_{i}\right|, \text { para } i \in N_{i} \text { if } N_{i} \neq 0 \\
0, \text { caso contrário }
\end{array}\right.
$$


em que:

- $\left\{N_{i}\right\}$ denota o conjunto de todos os pixels com tons de cinza $i$, exceto nas regiões periféricas da largura $d$;

Um exemplo da construção da matriz NGTDM é apresentado na figura 2.19

\begin{tabular}{|c|c|c|c|}
\hline 1 & 1 & 4 & 3 \\
\hline 3 & 4 & 0 & 1 \\
\hline & 4 & $22\}$ & 2 \\
\hline & 1 & 1 & 4 \\
\hline & 2 & 2 & 5 \\
\hline
\end{tabular}

(a) Imagem $5 \times 5$, com 5 tons de cinza

$$
\begin{aligned}
S(2)_{d=1} & =\left|2-\frac{17}{8}\right|+\left|2-\frac{15}{8}\right| \\
= & 0.250
\end{aligned}
$$

(b) Exemplo de cálculo do elemento $S(i)$, em específico $S(2)$, em que $d=1$.

$s(i)$
$\mathrm{i}$\begin{tabular}{|l|l|}
\hline 0 & 2.750 \\
1 & 4.125 \\
2 & 0.250 \\
3 & 0.000 \\
4 & 4.875 \\
\hline
\end{tabular}

(c) Matriz NGTDM

Figura 2.19: Representação da construção da matriz NGTDM (adaptado: (AMADASUN; KING, 1989)).

Para extrair as medidas estatísticas que caracterizam a textura algumas medidas são utilizadas, sendo elas:

1. Aspereza (indica o tamanho das primitivas da textura):

$$
f_{\cos }=\left[\varepsilon+\sum_{i=0}^{G_{h}} p_{i} s(i)\right]^{-1}
$$

em que: 
- $\varepsilon$ denota um pequeno número para evitar que $f_{\text {cos }}$ torne-se infinito;

- $G_{h}$ representa o mais alto valor de tom de cinza presente na imagem;

- $\quad p_{i}$ é a estimativa de probabilidade de ocorrência de intensidade do tom de cinza $i$. Para uma imagem $N x N$ dimensões $p_{i}$ é definido por $p_{i}=N_{i} / n^{2}$ e $n=N-2 d$.

2. Contraste (dependente da diferença de intensidade entre a vizinhança dos pixels):

$$
f_{\mathrm{co} n}=\left[\frac{1}{N_{g}\left(N_{g}-1\right)} \sum_{i=0}^{G_{h}} \sum_{j=0}^{G_{h}} p_{i} p_{j}(i-j)^{2}\right]\left[\frac{1}{n^{2}} \sum_{i=0}^{G_{h}} s(i)\right]
$$

em que:

- $N_{g}$ é o número total dos diferentes níveis de cinza presente na imagem;

3. Fineza (descrita pela alta frequência espacial das mudanças de intensidade):

$$
f_{\text {bus }}=\left[\sum_{i=0}^{G_{h}} p_{i} s(i)\right] /\left[\sum_{i=0}^{G_{h}} \sum_{j=0}^{G_{h}} i p_{i}-j p_{j}\right], p_{i} \neq 0, p_{j} \neq 0
$$

4. Complexidade (dependente do número de diferentes primitivas e intensidade médias distintas):

$$
\begin{aligned}
f_{\text {com }}= & \sum_{i=0}^{G_{h}} \sum_{j=0}^{G_{h}}\left\{(|i-j|) /\left(n^{2}\left(p_{i}+p_{j}\right)\right)\right\}\left\{p_{i} s(i)+p_{j} s(j)\right\}, \\
& p_{i} \neq 0, p_{j} \neq 0 .
\end{aligned}
$$

5. Força (indica o tão quanto as primitivas estão claramente definidas e visíveis): 


$$
\begin{aligned}
f_{\text {str }}= & {\left[\sum_{i=0}^{G_{h}} \sum_{j=0}^{G_{h}}\left(p_{i}+p_{j}\right)(i-j)^{2}\right] /\left[\varepsilon+\sum_{i=0}^{G_{h}} s(i)\right], } \\
& p_{i} \neq 0, p_{j} \neq 0 .
\end{aligned}
$$

Na literatura o uso deste tipo de técnica pode ser encontrado em (CIOCCA; SCHETTINI R., 2000; SCHETTINI. et al., 2003).

\subsubsection{Abordagem Baseada em Processamento de Sinais}

A abordagem baseada em processamento de sinais busca extrair as características de uma textura após a execução de transformações da imagem de entrada. Dentre os métodos presentes nesta abordagem estão o espectro de Fourier, responsável por identificar a periodicidade da textura através da análise dos picos de alta energia do espectro; o filtro de Gabor, que além de efetuar uma estimativa local, não global, das frequências espaciais contidas numa imagem, permite uma análise de acordo com o ajuste dos parâmetros de frequência, orientação e escala; e a transformada de wavelet, cujo método analisa a textura em diferentes escalas, resoluções e orientações.

\section{Espectro de Fourier}

A transformada de Fourier é uma ferramenta matemática que basicamente decompõe um sinal em função de uma série de senóides. Quanto aplicada a imagens digitais (função bidimensional) essa ferramenta pode fornecer informações sobre a orientação das estruturas presentes na imagem de entrada, bem como o mapeamento das variações nos tons de cinza dos pixels de uma dada região. Nesta seção é apresentado de forma sucinta o equacionamento matemático necessário para a compreensão das diferentes formas de se quantizar/caracterizar uma textura através desse método.

A primeira forma de se caracterizar uma textura, segundo Gonzales e Woods (2002), é através da identificação e análise de picos de alta energia presentes no espetro de Fourier. Estes por sua vez fornecem não só a direção dos padrões de textura, como, a sua posição no plano da frequência, indicando o período espacial fundamental dos padrões. A eliminação de quaisquer componentes periódicos através de uma filtragem pode permitir uma análise e descrição, por medidas estatísticas, dos elementos não-periódicos de uma imagem. 
A detecção e interpretação das características mencionadas acima são realizadas expressando o espectro de Fourier em coordenadas polares. Para isso, primeiro, encontra-se a Transformada de Fourier Discreta (DFT - Discrete Fourier Transform) bidimensional na textura de interesse $(M x N)$, equação 2.46, e a sua magnitude, pela equação 2.47 .

$$
F(u, v)=\frac{1}{M N} \sum_{x=0}^{M-1} \sum_{y=0}^{N-1} f(x, y) e^{-j 2 \pi\left(\frac{u x}{M}+\frac{v y}{N}\right)}
$$

em que:

- $u=0,1, \ldots M-1 ; v=0,1, \ldots N-1$;

- $F$ é também uma função discreta do mesmo tamanho de $f$;

- $(x, y)$ denota a coordenada espacial da imagem e $(u, v)$ a frequência espacial;

$$
|F(u, v)|=\left[R^{2}(u, v)+I^{2}(u, v)\right]^{1 / 2}
$$

em que:

- $|F(u, v)|$ denota o espectro de Fourier;

- $R(u, v)$ e $I(u, v)$ a parte real e imaginária, respectivamente.

Em seguida, expressa o resultado de $|F(u, v)|$ em coordenada polar, como função $S(r, \theta)$, em que $S$ é a função do espectro e $r$ e $\theta$ são as coordenadas do sistema. Para cada direção $\theta, S(r, \theta)$ pode ser considerada uma função unidimensional $S_{\theta}(r)$. O mesmo acontece para cada freqüência $r, S_{r}(\theta)$. A análise de $S_{\theta}(r)$ para um valor fixo de $\theta$ fornece o comportamento do espectro (com a presença de picos) ao longo de uma direção radial a partir da origem. A análise de $S_{r}(\theta)$ para um valor fixo de $r$ expressa o comportamento ao longo de uma circunferência centrada na origem.

Uma descrição global é obtida através das seguintes funções:

$$
S(r)=\sum_{\theta=0}^{\pi} S_{\theta}(r)
$$




$$
S(\boldsymbol{\theta})=\sum_{r=1}^{R} S_{r}(\boldsymbol{\theta})
$$

em que:

- $R$ denota o raio de uma circunferência centrada na origem e é escolhido como $N / 2$ para um espectro de $N x N$;

Variando-se as coordenadas do sistema $(r, \theta)$ é possível gerar funções unidimensionais de $S(r)$ e $S(\theta)$ que constituem descrição da energia espectral da textura para diferentes regiões. A caracterização da característica da textura pode ser realizada através de descritores estatísticos, tais como: amplitude máxima, média, variância da amplitude, variações do eixo e a distância entre a média e o maior valor da função.

A figura 2.20 (c), (d) e (f) ilustra o resultado do uso das equações 2.48 e 2.49, que fornecem a descrição global de textura da 2.20 (a) e (e). O gráfico de $S(r)$, figura 2.20 (c), mostra que a textura analisada possui alta energia próxima da origem e, progressivamente menor, para as altas freqüências. Essa característica ilustra uma das propriedades do espectro de Fourier, em que: para texturas ásperas, o espectro apresenta concentração de energia no centro do plano; e para texturas finas, a energia do espectro encontra-se espalhada no plano de frequiência. Já o gráfico de $S(\theta)$ da figura 2.20 (d), mostra picos proeminentes em intervalos de $45^{\circ}$, enquanto que na figura 2.20 (f), apresenta os picos ocorrendo em intervalos de $90^{\circ}$, correspondendo claramente a periodicidade e/ou orientação na repetição dos padrões de ambas as textura, 2.20 (a) e (e). 


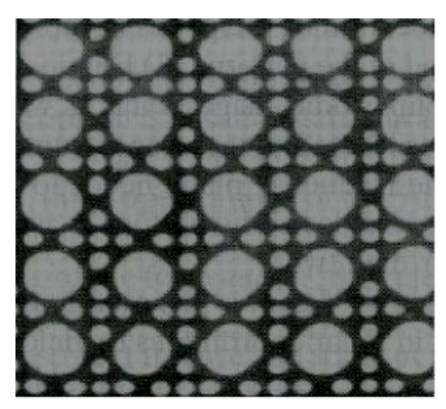

(a) Textura Periódica 01

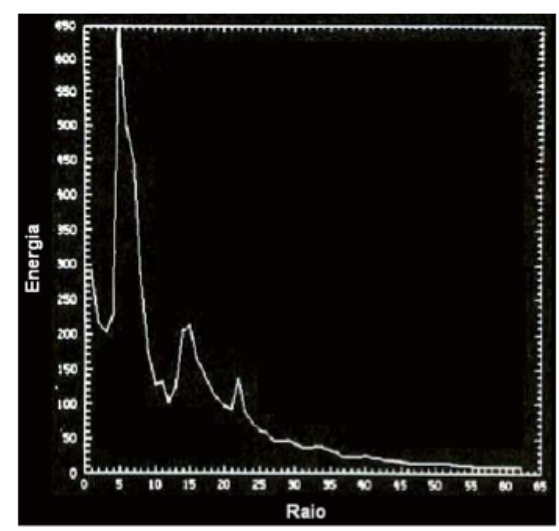

(c) Gráfico de $S(r)$ de (a)

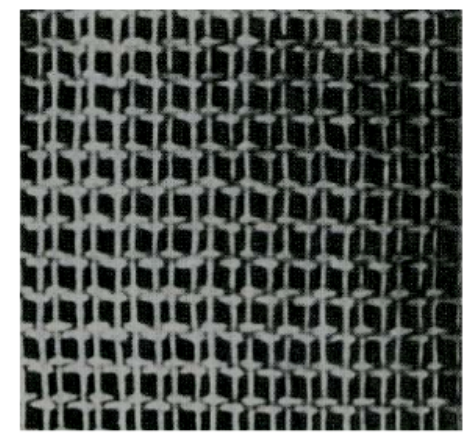

(e) Textura Periódica 02

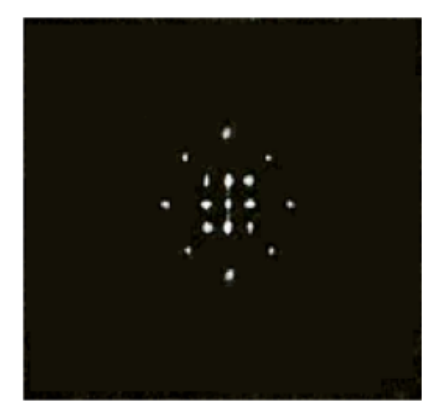

(b) Espectro de Fourier de (a)

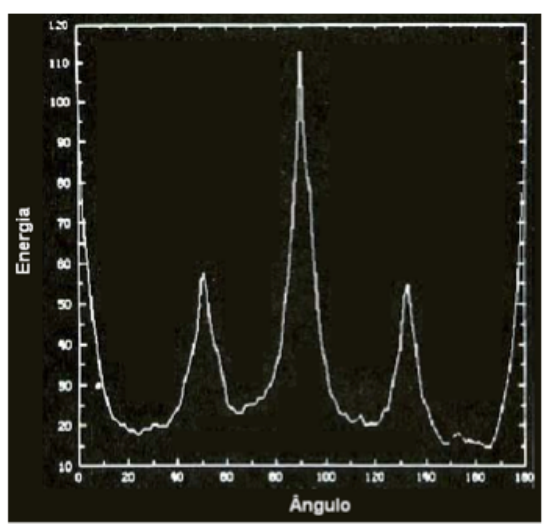

(d) Gráfico de $S(q)$ de (a)

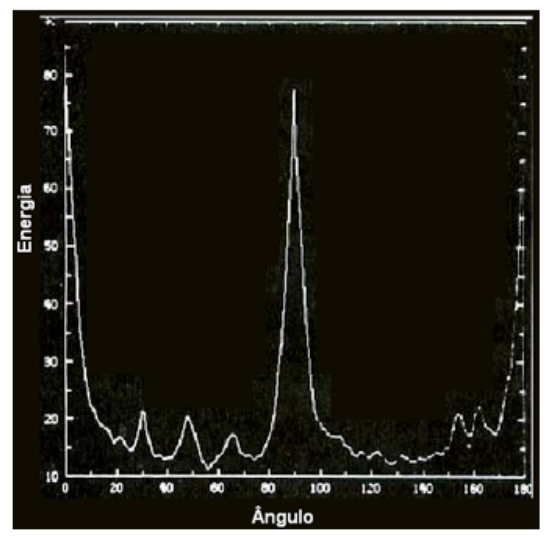

(f) Gráfico de $S(q)$ de (e)

Figura 2.20: Funções $S(r)$ e $S(q)$ determinadas a partir do espectro de Fourier de texturas periódicas, apresentadas em (a) e (e). (adaptado: (GONZALES; WOODS, 2002)).

Na literatura encontra-se outra forma de análise e/ou caracterização de uma textura utilizando o domínio de freqüência de Fourier (TUCERYAN; JAIN, 1999; BARRONS; BUTLER, 2006). Esta se baseia na interpretação das características do espectro de potência, fornecido pela equação 2.50 . 


$$
\begin{aligned}
P(u, v)= & |F(u, v)|^{2} \\
& R^{2}(u, v)+I^{2}(u, v)
\end{aligned}
$$

O espectro de potencia de Fourier também é sensível a direcionalidade e a aspereza da textura presente na estrutura $f(x, y)$ e possui as seguintes características: no primeiro caso, se $f(x, y)$ contiver linhas ou bordas com alguma direção representada por ângulo $\theta$, a distribuição angular de $P(u, v)$ irá conter concentração de altos valores em torno da direção perpendicular a $\theta$. Caso contrário, se $f(x, y)$ mostrar uma ausência na direcionalidade da estrutura, $P(u, v)$ também apresentará essa mesma ausência. Em relação à aspereza, segundo caso, se a textura for fina o resultado da distribuição radial da energia em $P(u, v)$ apresentará valores altos distantes de sua origem; e se a textura for áspera, valores altos permanecerão concentrados na origem do espectro de frequência.

Para extração dessas informações aplicam-se dois filtros W (wedge filter) e R (ring filter), respectivamente, na resposta do espectro de potencia de Fourier. A figura 2.21 ilustra a definição desses filtros.

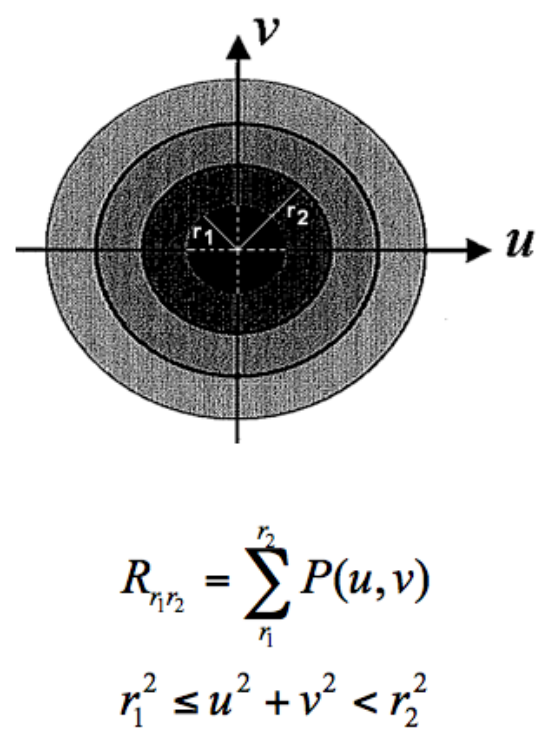

(a)

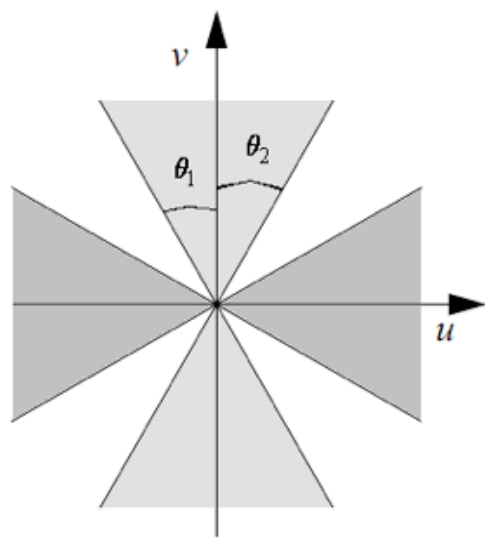

$$
\begin{aligned}
& W_{\theta_{1} \theta_{2}}=\sum_{\theta_{1}}^{\theta_{2}} P(u, v) \\
& \theta_{1} \leq \tan ^{-1}(v / u)<\theta_{2}
\end{aligned}
$$

(b)

Figura 2.21: Extração da característica de textura através do espectro de potencia de Fourier. (a) Energia computada com base na informação radial, caracterizando a aspereza/rugosidade da textura, e (b) energia computada com base na informação da direcionalidade, em que $\tan ^{-1}(v / u)$ denota alinhamento vertical.

Nesse tipo de abordagem é possível separar ou combinar as características ine- 
rentes a $P(u, v)$ em regiões e/ou áreas de forma a obter uma melhor caracterização da textura em análise.

A abordagem de Fourier para análise de textura pode ser adaptada para descrição global da orientação dos padrões periódicos ou quase periódicos de uma textura. A técnica descreve as diferentes frequências contidas numa imagem, mas não determina a localização espacial delas. É uma técnica invariante a translação dos padrões presentes na textura, muito embora seja sensível a variação de rotação. Em certas análises, esse tipo de característica pode ser um fator limitante.

Na literatura o uso desse tipo de técnica pode ser encontrado em diversas aplicações, sendo algumas delas: alimentícia (BARRONS; BUTLER, 2006), fotografias aéreas sensoriamente remoto (MAILLARD, 2001; DELENNE et al., 2006), industrial (HUYNH; KURADA; NORTH, 1991; CHAN; PAND, 2000), etc (LENDARIS; STANLEY, 1970).

\section{Filtro de Gabor}

O filtro de Gabor (FG), originalmente proposto pela Teoria da Comunicação (GABOR, 1946) e, posteriormente, estendido a problemas bi-dimensionais (DAUGMAN, 1985), é outra abordagem baseada em processamento de sinais que pode ser utilizada na extração de atributos/características da textura. Diferentemente da transformada de Fourier, o filtro de Gabor efetua uma estimativa local, não global, das frequências espaciais contidas numa imagem. Segundo Kruizinga, Petkov e Grigorescu (1999), Vyas e Rege (2006), o filtro, além de ser otimamente localizado no domínio do espaço e da frequência, pode caracterizar um sinal (imagem) simultaneamente em ambos os domínios (DAUGMAN, 1985).

A função de Gabor é constituída de senoides complexas (funções que definem a frequência e orientação - responsável pela descrição da estrutura local da textura), moduladas por uma função Gaussiana bidimensional (função que define a resolução a qual a textura é caracterizada), como mostra a equação 2.51 .

$$
g(x, y)=\exp \left[-\frac{1}{2}\left(\frac{x^{2}}{\sigma_{x}^{2}}+\frac{y^{2}}{\sigma_{y}^{2}}\right)\right] \exp \left(2 \cdot \pi \cdot j \cdot u_{0} \cdot x\right)
$$

Os parâmetros, $\sigma_{x}$ e $\sigma_{y}$, determinam o desvio padrão da distribuição Gaussiana e estão relacionados com a largura que modula o filtro nas direções $x$ e $y$; $u_{0}$ determina 
o comprimento de frequência do filtro e $g(x, y)$ denota a função de Gabor no domínio espacial.

Para aplicações práticas, o filtro de Gabor pode ser implementado utilizando somente a parte real da componente (CLAUSI; JERNIGAN, 2000), como mostra a equação 2.52 .

$$
g(x, y)=\exp \left[-\frac{1}{2}\left(\frac{x^{2}}{\sigma_{x}^{2}}+\frac{y^{2}}{\sigma_{y}^{2}}\right)\right] \cos \left(2 \pi u_{0}+\phi\right)
$$

$$
\begin{aligned}
& x=x \cos \theta_{0}+y \sin \theta_{0} \\
& y=-x \sin \theta_{0}+y \cos \theta_{0}
\end{aligned}
$$

em que a orientação do filtro é fornecida pelo parâmetro $\theta_{0}$. A rotação das coordenadas $x$ e $y$ é realizada através da equação 2.53. O parâmetro $\phi$ denota a fase, sendo $\phi=0$ relacionado a um filtro simétrico (JAIN; FARROKHNIA, 1991; PETKOV; KRUIZINGA, 1997).

Como pode ser observado na equação 2.52 e 2.53, o filtro de Gabor é ajustável à frequência, orientação e escala. A escolha desses parâmetros na função é dependente do tipo de textura que se deseja analisar (por exemplo: regular, irregular, lisa, áspera, direcional, não-direcional, fina ou grossa), ou seja, da possibilidade de se encontrar uma resolução ótima de exel $^{4}$ Segundo Raghu, Poongodi e Yegnanarayana (1995), cada textura é caracterizada por uma determinada frequência especial ou uma faixa estreita de frequências dominantemente localizadas. Estas por sua vez diferem de forma significativa entre os distintos padrões de textura.

Pelo fato de certas texturas serem caracterizadas por uma determinada faixa de frequência, como exemplo: as naturais, o filtro de Gabor é utilizado como uma abordagem de análise de textura multicanal (BOVIK; CLARK; GEISLER, 1990; JAIN; FARROKHNIA, 1991). Um esquema, composto de vários filtros ou canais, ajustados a determinadas frequências e orientações, é responsável por decompor uma imagem de referência em várias outras sub-imagens. Na literatura são encontradas algumas

\footnotetext{
${ }^{4} \mathrm{Um}$ texel é uma primitiva visual com propriedades invariantes. Ocorre repetitivamente em diferentes posições, deformações e orientações dentro de uma determinada área (BALLARD; BALLARD, 1982).
} 
abordagens utilizadas para selecionar a frequência apropriada. Bovik, Clark e Geisler (1990), por exemplo, utiliza o pico médio do espectro de potência da textura para definir tal parâmetro. Já os autores Jain e Farrokhnia (1991), Strand e Taxt (1994) utilizam uma faixa estreita de parâmetros que cobre todo o domínio da frequência.

Segundo Daugman (1988), as funções de Gabor fornecem um conjunto de base completa, mas não necessariamente ortogonais. Isto é, podem existir informações redundantes nas imagens filtradas em diferentes escalas ou canais. Algumas propostas e/ou estratégias auxiliam a redução deste problema (MANJUNATH; MA, 1996; RUBNER; TOMASI, 2001), seguindo alguns princípios: separação uniforme na orientação; separação exponencial na escala; e cobertura contínua do espaço da frequência. No trabalho de Jain e Farrokhnia (1991), por exemplo, é apresentado um conjunto de 24 filtros de Gabor, que além de cobrir de forma uniforme o domínio da frequência, são aproximadamente ortogonais.

A imagem processada por um filtro de Gabor é obtida através da convolução da imagem $I(x, y)$ com a função de Gabor $g(x, y)$, em que $r(y, y)=I(x, y) * g(x, y)$ é a imagem filtrada e $*$ denota a convolução (GONZALES; WOODS, 2002). A figura 2.22 elucida um banco de filtros (contendo dezesseis filtros) aplicado sobre uma textura de referência.

Neste exemplo é possível constatar a importância do ajuste dos parâmetros da função Gabor para a resolução ótima de Texel. Levando este fato em consideração, a melhor resposta para esta elucidação (caso isolado, em que é considerada apenas a única textura ilustrada) é o conjunto dos quatro filtros representados em $r(x, y)$ na figura 2.22 - c.

Em relação a extração de atributos da textura, esta é realizada sobre o(s) resultado(s) obtido(s) dos filtros. Para tal, um vetor característico é criado. No exemplo acima, levando em consideração o que foi mencionado anteriormente, o vetor característico pode ter dimensão quatro, no mínimo, pois cada componente representa uma medida estatística que caracteriza a imagem filtrada $\left(r(x, y)_{1}\right)$. Bovik, Clark e Geisler (1990), Manjunath e Ma (1996) utilizam a magnitude, isto é, a energia para caracterizar a textura. Manjunath e Ma (1996), Martins, Guimaraes e Fonseca (2002) utilizam a média e o desvio padrão dos valores dos coeficientes da transformada de Gabor, enquanto que Jain e Farrokhnia (1991), Strand e Taxt (1994), empregam a equação 2.54 para caracterizar a textura. 


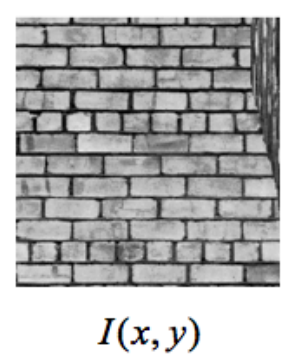

(a)

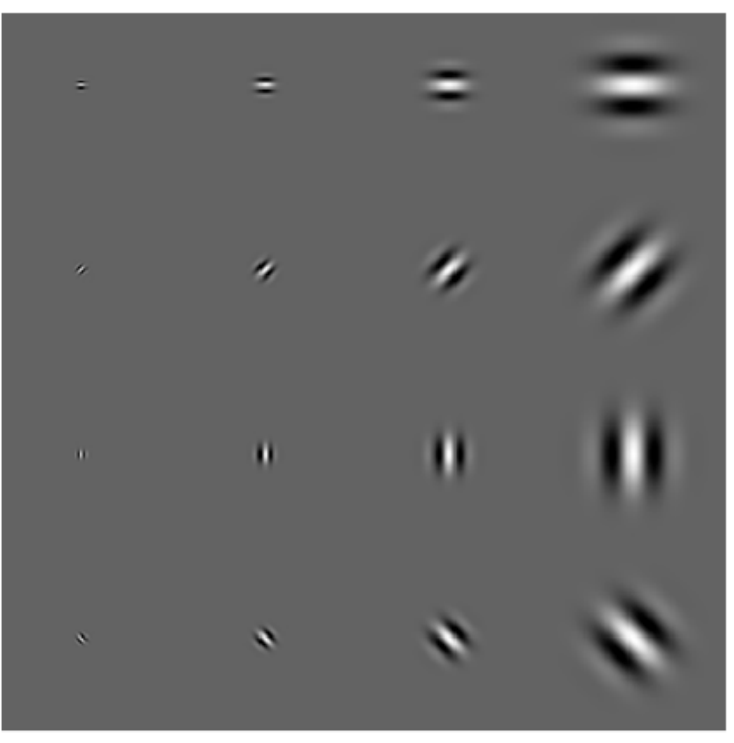

$g(x, y)_{1} g(x, y)_{2} g(x, y)_{3} g(x, y)_{4}$

(b)

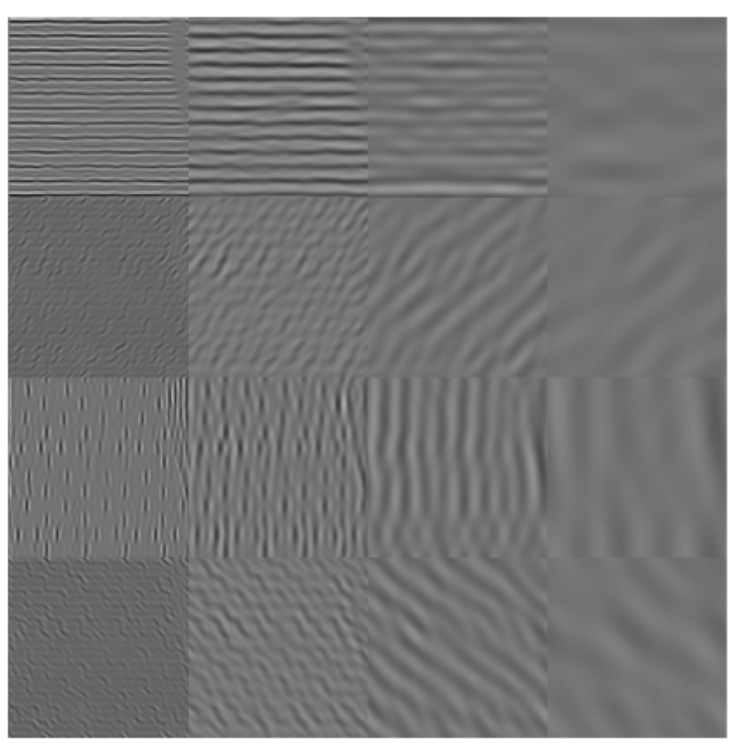

$r(x, y)_{1} r(x, y)_{2} r(x, y)_{3} r(x, y)_{4}$

(c)

Figura 2.22: Exemplificação do uso do filtro de Gabor (frequência fixa). (a) imagem de referência (b) filtros com orientação $\theta^{0}, \theta^{45}, \theta^{90}, \theta^{135}$, e variações de escala $\sigma$; (c) resultados obtidos sobre a imagem de referência. (adaptado: (SAMPAIO, 2007))

$$
e_{k}(x, y)=\frac{1}{M^{2}} \sum_{(a, b) \in W_{x, y}}\left|\psi\left(\mathrm{r}_{k}(a, b)\right)\right|
$$

em que: $\psi$ é fornecido pela equação $2.55, W_{x, y}$ é uma janela $M x M$ centrada em $(x, y)$ e $\alpha$ é uma constante.

$$
\psi(\mathrm{t})=\tanh (\alpha t)=\frac{1-e^{-2 \alpha t}}{1+e^{-2 \alpha t}}
$$

O filtro de Gabor tem sido utilizado em várias aplicações, sendo algumas delas: 
recuperação de imagens baseadas na textura (MANJUNATH; MA, 1996), sensoriamento remoto (RUIZ; FDEZ-SARRA; RECIO, 2004), discriminador de textura (FOGEL, 1989), setor coureiro (PASQUALI et al., 2007), reconhecimento de face (MANJUNATH; CHELLAPPA; MALSBURG, 1992), de impressões digitais (JAIN; ROSS; PRABHAKAR, 2001), etc.

\section{Transformada de Wavelet}

A transformada wavelet é um método que decompõe um sinal em uma série de funções elementares, ortogonais, criadas a partir de escalonamentos (processo de compressão e dilatação do sinal) e translação de uma função base, denominada wavelet mãe (DAUBECHIES, 1992).

Quanto utilizada na análise de imagens digitais, a transformada é empregada como uma técnica de multiresolução (Multiresolution Analysis - MRA) (MALLAT, 1989b, 1989a; GONZALES; WOODS, 2002), na qual uma imagem é decomposta em diferentes escalas, resoluções e orientações. Segundo Wouwer, Scheunders e Dyck (1999), Muneeswaran et al. (2005) essas características podem ser quantificadas através de descritores estatísticos e, consequentemente, utilizadas na análise e/ou discriminação de textura.

Na MRA, a transformada wavelet é constituída por duas funções base, unidimensionais: a primeira, denominada de função de escalonamento $\phi$ e, a segunda, chamada de função wavelet $\psi$. Nesse tipo de análise essas funções estão associadas a um par de filtros, $l$ (filtro passa baixa) e $h$ (filtro passa alta), denominados de filtro de quadratura (Quadrature Mirror Filters - QMF), que formam as bases para a transformada. As equações 2.56 e 2.56 apresentam tais funções.

$$
\begin{gathered}
\phi(t)=\sqrt{2} \sum_{k} l(k) \phi(2 t-k), k \in Z \\
\psi(t)=\sqrt{2} \sum_{k} h(k) \phi(2 t-k),
\end{gathered}
$$

em que:

- $k$ determina a posição da função ao longo do eixo considerado; 
Os filtros $l$ e $h$ estão relacionados por:

$$
h(k)=(-1)^{k} l(1-k)
$$

A função wavelet $\psi(x)$ se relaciona com o filtro passa alta e é responsável em produzir os coeficientes de detalhamento da imagem, enquanto que a função de escalonamento produz os coeficientes de aproximação da imagem na decomposição da wavelet. Na literatura (DAUBECHIES, 1992) diferentes conjuntos de $l(k)$ e $h(k)$ podem ser encontrados, em que cada um corresponde à base wavelet, com diferentes propriedades. Segundo Mallat (1989b), existe uma extensão da transformada 1D wavelet para análise de duas dimensões. Entretanto, uma forma simples de gerar a transformada wavelet 2D, segundo o autor, é aplicar a transformada 1D nas direções verticais e horizontais separadamente. Assim, a transformada é caracterizada pela função 2D de escalonamento, como mostra a equação 2.59 .

$$
\phi\left(t_{x}, t_{y}\right)=\phi\left(t_{x}\right) \phi\left(t_{y}\right)
$$

E três equações wavelets:

$$
\begin{aligned}
& \psi_{1}\left(t_{x}, t_{y}\right)=\phi\left(t_{x}\right), \psi\left(t_{y}\right) \\
& \psi_{2}\left(t_{x}, t_{y}\right)=\psi\left(t_{x}\right), \phi\left(t_{y}\right) \\
& \psi_{3}\left(t_{x}, t_{y}\right)=\psi\left(t_{x}\right), \psi\left(t_{y}\right)
\end{aligned}
$$

As transformadas bidimensionais obtidas pelo produto das funções unidimensionais são chamadas de separáveis, em que as funções: $\psi_{1}\left(t_{x}, t_{y}\right)$ mede variações horizontais, $\psi_{2}\left(t_{x}, t_{y}\right)$ mede variações verticais e $\psi_{3}\left(t_{x}, t_{y}\right)$ mede variações nas diagonais.

A aplicação dos filtros QMF sobre uma imagem $(N x N)$ em ambos os eixos da abscissa e ordenada, gera um nível de decomposição com fator de escala 2 e produz 
quatro sub-bandas $A_{1}, D_{1}^{1}, D_{1}^{2}, D_{1}^{3}$, como mostra as figuras 2.23 e 2.24 .

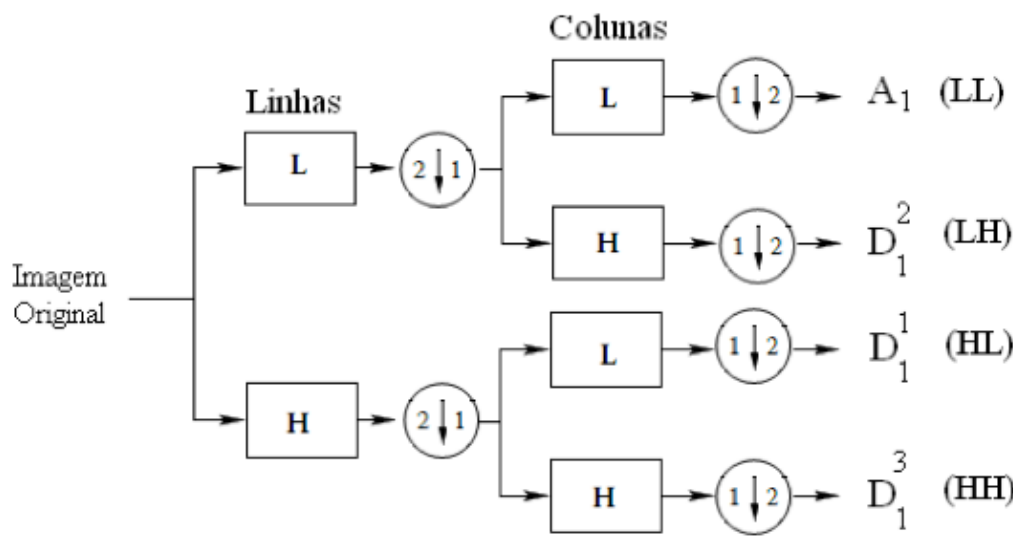

$\mathrm{X}$ : convolução (linhas e colunas) com o filtro X

(211) : mantém uma coluna de duas

(1.2) : mantém uma linha de duas

Figura 2.23: Decomposição de um nível da imagem original utilizando os filtros L e H (adaptado: (MALLAT, 1989b)).
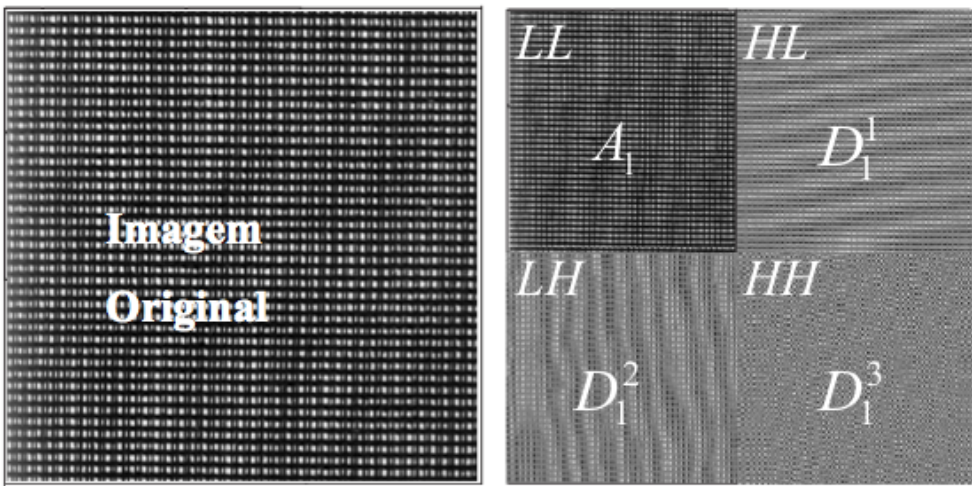

(a)

\begin{tabular}{|c|c|c|}
\hline $\mathrm{A}_{2}$ & $\mathrm{D}_{2}^{1}$ & \multirow{2}{*}{$\begin{array}{l}\mathrm{HL} \\
\qquad \mathrm{D}_{1}^{1} \\
\text { Componentes na } \\
\text { Horizontal }\end{array}$} \\
\hline $\mathrm{D}_{2}^{2}$ & $\mathrm{D}_{2}^{3}$ & \\
\hline \multirow{2}{*}{\multicolumn{2}{|c|}{$\mathrm{LH}$}} & $\mathrm{HH}$ \\
\hline & & $\mathrm{D}_{1}^{3}$ \\
\hline \multicolumn{2}{|c|}{$\begin{array}{c}\text { Componentes na } \\
\text { Vertical }\end{array}$} & $\begin{array}{c}\text { Componentes na } \\
\text { Diagonal }\end{array}$ \\
\hline
\end{tabular}

(b)

Figura 2.24: Transformada bidimensional de uma imagem. (a) decomposição em um nível; (b) decomposição em dois níveis.

De acordo com a figura 2.24 (a), a sub-imagem $A_{1}$ representa as componentes de baixa frequência da imagem original em ambas as direções, além de conter informações espaciais desta. $D_{1}^{1}$ representa a sub-imagem com a componente horizontal destacada, enquanto que $D_{1}^{2}$ destaca as componentes verticais. Já a sub-imagem $D_{1}^{3}$, caracteriza as componentes diagonais. Todas as sub-imagens geradas possuem $1 / 4$ da versão da imagem original, não aumentando o volume de dados. Segundo Mallat (1989b), essa característica é fornecida pela ortogonalização da transformada wavelet. Níveis adicionais de decomposição também podem ser obtidos, como mostra a figura 2.24 (b).

Sendo assim, na analise de textura a transformada wavelet fornece sub-images que 
concebem detalhes em diferentes resoluções e orientações das variações dos tons de cinza da imagem original. Cada uma das sub-bandas pode ser representada por medidas estatísticas extraídas dos seus coeficientes, sendo a energia, medida residual e entropia alguma delas (PORTER; CANAGARAJAH, 1996; WOUWER; SCHEUNDERS; DYCK, 1999; LIU; WU; ZHOU, 2003; MUNEESWARAN et al., 2005). As equações $2.63,2.64$ e 2.65 mostram as medidas citadas anteriormente.

$$
E_{n i}=\frac{1}{N} \sum_{j, k}\left(D_{n i}(j, k)\right)^{2}
$$

em que:

- $E_{n i}$ denota a energia;

- $D_{n i}(j, k)$ representa o coeficiente da sub-banda $D_{n i}$ na coordenada $(j, k)$

- $\quad N$ é o numero de pixel;

$$
R M_{n i}=\sum_{j, k}\left(D_{n i}(j, k)-\mu^{2}\right)
$$

em que:

- $R M_{n i}$ denota o resíduo médio;

- $\mu$ é a média amostral dos coeficientes da sub-banda $D_{n i}$

$$
E N_{n i}=-\frac{1}{N^{2}} \sum_{j, k}\left|D_{n i}(j, k)\right|^{2} \log \left|D_{n i}\right|^{2}
$$

em que:

- $E N_{n i}$ denota a entropia;

No trabalho de Wouwer, Scheunders e Dyck (1999), os autores misturam medidas estatísticas de primeira ordem (média, mediana, variância e desvio padrão) juntamente às medidas de co-occorrência, segunda ordem (com objetivo de complementar as pri- 
meiras medidas) para caracterizar a textura.

Na literatura, o uso de transformada wavelet para esse tipo de análise pode ser encontrado em diferentes áreas de aplicações, sendo algumas delas: imagens de satélites (SILVA et al,2008), recuperação de imagens baseadas em textura (LIU; WU; ZHOU, 2003), avaliação da produção de papel - industrial (REIS; BAUER, 2009), etc (CHANG; KUO, 1993).

\subsubsection{Abordagem Geométrica}

Nos métodos geométricos a textura é formada e/ou constituída por primitivas ou "elementos de texturas", denominadas de texel (seção 2.2.3.2) (ZHANG; TIENIU, 2002), que aparecem em arranjos espaciais repetitivos na imagem, como mostra a figura 2.25.
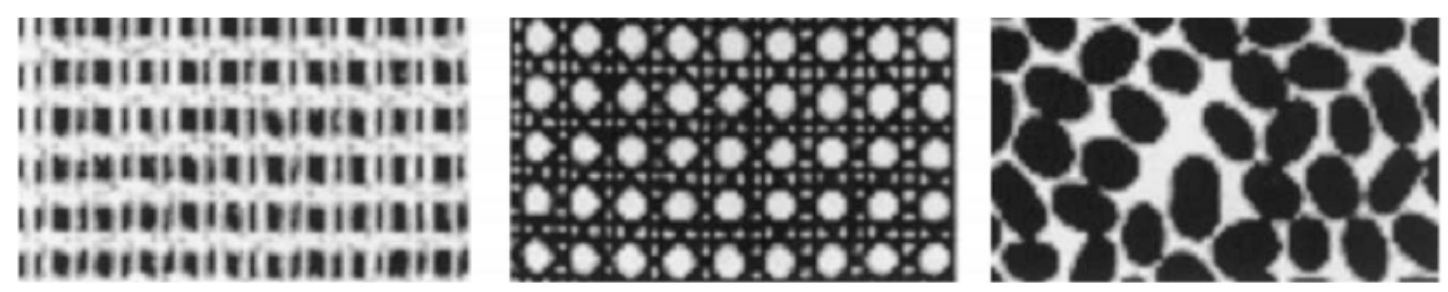

Figura 2.25: Exemplos de texturas (BRODATZ, 2009) (adaptado: (ZHANG; TIENIU, 2002))

Primeiramente, essa classe de método busca identificar as primitivas que compõe a textura da imagem. Detecção de borda através da Gaussiana de Laplace (LoG), filtros da Diferença da Gaussiana (DoG) (GONZALES; WOODS, 2002), Tesselagem de Voronoi (Voronoi Tessellation) (TUCERYAN; JAIN; LEE, 1988), etc, são algumas das técnicas utilizadas para a extração dessas primitivas. Após essa identificação, duas abordagens podem ser realizadas (TUCERYAN; JAIN, 1999). A primeira refere-se à extração de medidas estatísticas (intensidade, área, orientação, etc) desses elementos para descrever a textura, enquanto que a segunda, utiliza a inferência de regras de disposição espacial e relacionamento entre as primitivas para a caracterização da textura. Essa última abordagem, denominada de estrutural, pode utilizar descrição simbólica. Ou seja, uso de gramáticas (gramáticas de forma, árvore, gráficas e matriciais) (SONKA; HLAVAC; BOYLE, 1998), compostas por símbolos e um conjunto de regras definidas para descrever textura.

Esse tipo de abordagem possui uma boa performance para descrição de texturas regulares, isto é, bem estruturadas, como mostra a figura 2.25. Entretanto, para tex- 
turas aleatórias, comuns em imagens naturais, este tipo de abordagem possui baixa performance (ZHANG; TIENIU, 2002).

Uma técnica que abrange as diferentes fases/etapas da abordagem geométrica, mencionadas anteriormente, é a Tesselagem de Voronoi, proposta por Tuceryan, Jain e Lee (1988), descrita a seguir:

\section{Segmentação de Textura usando Polígonos de Voronoi}

Tuceryan, Jain e Lee (1988) propuseram o uso de polígonos de Voronoi para identificar e/ou caracterizar a distribuição ou formação das primitivas, denominadas de tokens, que compõe uma textura. Esse tipo de proposta possui algumas características peculiares, tais como: definição da distribuição espacial local entre as primitivas da textura, utilizando uma estrutura gráfica; caracterização do formato das primitivas a nível simbólico (útil na segmentação de textura) e compreensão da relação entre os tokens, como mostra a figura 2.26.
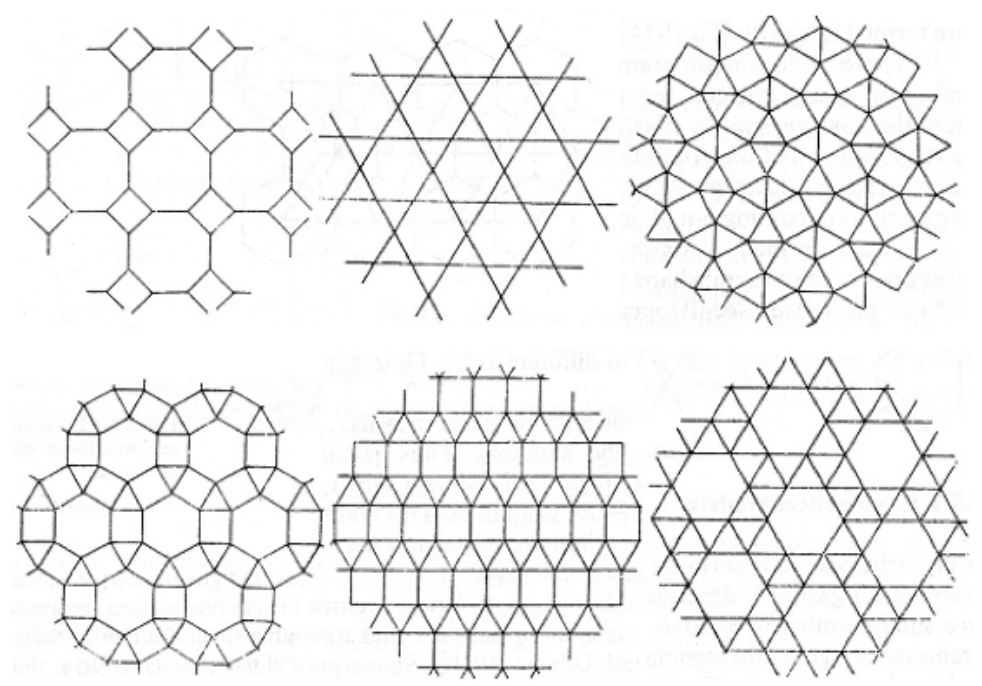

Figura 2.26: Exemplos da distribuição e/ou formação espacial de primitivas

Para extrair as primitivas, os autores propõem um algoritmo composto por três fases: primeiro, aplica-se o Laplaciano do filtro Gaussiano ( $L o G$ ou $\nabla^{2} G$ ) ou a aproximação do $\nabla^{2} G$ pela diferença do filtro Gaussiano $(D o G)$ em toda a imagem, como mostra a figura 2.27 (a) e (b); segundo, selecionam-se os pixels que se encontram em um local de intensidade máxima da imagem filtrada. Ou seja, o pixel é dito ser de um máximo local se a sua intensidade/magnitude é maior do que pelo menos seis de seus oito vizinhos mais próximos. Desta forma, o máximo local é considerado como 
um ponto de valor 1 e o restante valor 0 , gerando uma imagem binária como mostra a figura 2.27 (c); posteriormente, faz-se uma análise sobre as componentes conectadas dessa imagem através da análise dos oitos vizinhos mais próximos. Cada componente conectado define um token da textura.

Após a identificação dos tokens, a Tesselagem de Voronoi é construída. Primeiramente, extraem-se as características de cada célula de Voronoi, considerada como ponto. Grupos de pontos com atributos similares formam as regiões uniformes da textura. O momento de área é utilizado para efetuar essa tarefa, pois segundo os autores, essa medida reflete não só a distribuição espacial, como a forma que os tokens compõem a textura da imagem.

A ordem $(p+q)^{t h}$ do momento de área de uma região $R$, com relação à coordenada do token $\left(x_{0}, y_{0}\right)$, é definido matematicamente de acordo com a equação 2.66.

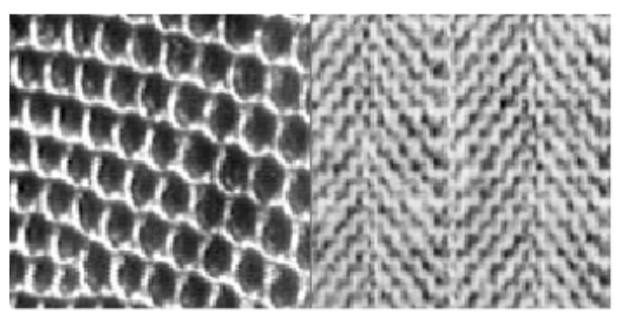

(a) Textura de album de Brodatz's

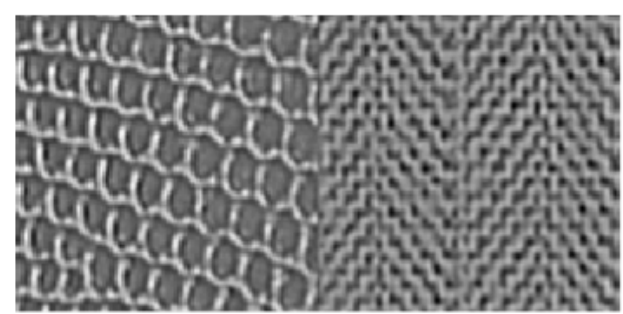

(b) Convolução da imagem após o filtro $D o G$

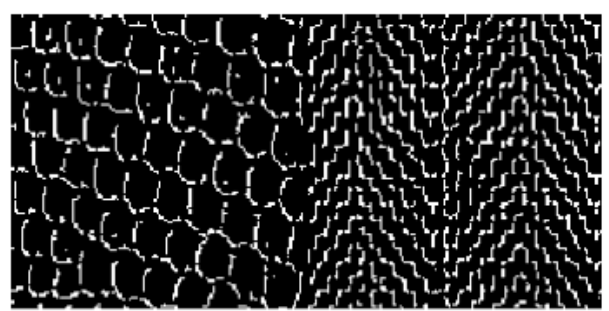

(c) Picos detectados da imagem filtrada

Figura 2.27: Segmentação da Textura utilizando Voronoi Tessellation (TUCERYAN; JAIN, 1999).

$$
m_{p q}=\iint_{(x, y) \in R}\left(x-x_{0}\right)^{p}\left(y-y_{0}\right)^{q} d x d y
$$

em que: 
- $m_{p q}$ denota o momento da área;

- $f(x, y)$ é a função de intensidade em dado ponto;

- $p, q=0,1,2, \ldots$ definem a ordem do momento de área; baixos valores fornecem melhor interpretação geométrica

A caracterização da textura, baseada no momento, é fornecida por cinco funções que definem um vetor característico $<f 1, f 2, f 3, f 4, f 5>$, apresentadas na tabela 2.11 .

Tabela 2.11: Funções para extração de característica da textura, baseada no momento de área (TUCERYAN; JAIN, 1999).

\begin{tabular}{cc}
\hline Característica & Função \\
\hline$f 1$ & $m_{00}$ \\
$f 3$ & $\sqrt{\bar{x}^{2}+\bar{y}^{2}}$ \\
$f 4$ & {$\left[\frac{\tan ^{-1}(\bar{y} / \bar{x})}{\left[\left(m_{20}-m_{02}\right)^{2}+4 m_{11}^{2}\right]^{1 / 2}+m_{20}+m_{02}}\right]^{1 / 2}$} \\
$f 5$ & $\tan ^{-1}\left(2 m_{11} /\left(m_{20}-m_{02}\right)\right)$
\end{tabular}

Com base na tabela mencionada anteriormente, a coordenada do centróide do polígono de Voronoi é representada por $(\bar{x}, \bar{y})$, em que $\bar{x}=m_{10} / m_{00}$ e $\bar{y}=m_{01} / m_{00}$ ( $m_{10} / m_{00}$ e $m_{01} / m_{00}$ fornecem o deslocamento do centróide do polígono em relação à $\left(x_{0}, y_{0}\right)$, nas direções $x$ e $y$, respectivamente).

Desta forma, $f 1$ é a área do polígono; $f 2$ fornece a intensidade do vetor do ponto da primitiva em relação ao centróide do polígono; $f 3$ indica a sua direção; $f 4$ fornece o prolongamento do polígono ( $f 4=0$ para um círculo); $f 5$ a orientação do eixo principal.

Para criar o grafo de Delaunay é preciso definir a relação de vizinhança entre os tokens, ou seja, definir as bordas que os separam. Esta etapa é realizada através de uma comparação estatística entre a vizinhança (TUCERYAN; JAIN; LEE, 1988), em que grande disparidade entre as características da textura, fornecidas pelo vetor característico, evidenciam uma borda.

A figura 2.28 mostra o resultado do uso desta técnica em um padrão de pontos que difere na regularidade, direção e média da densidade dos pontos, ou seja, dos tokens 


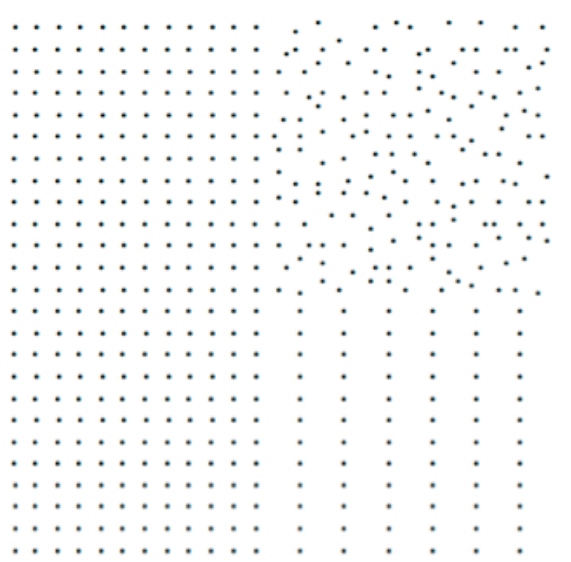

(a) Exemplo de um padrão de pontos

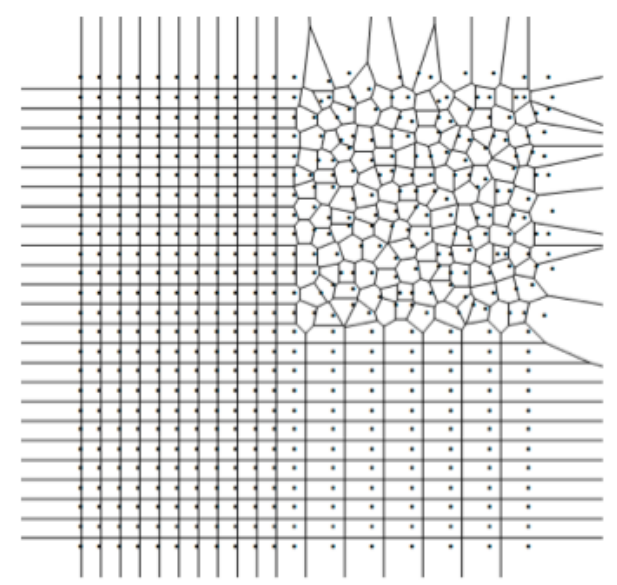

(b) Tesselagem de Voronoi

Figura 2.28: Resultado da Tesselagem de Voronoi (TUCERYAN; JAIN, 1999).

da textura.

A vantagem desta técnica está no fato de que, a priori, no algoritmo de segmentação da textura não é preciso especificar o número de regiões. Todavia, essa técnica é sensível a pequenas perturbações na localização dos tokens. Ou seja, caso uma textura seja extremamente regular e ocorra alguma perturbação em algumas regiões, o algoritmo irá caracterizá-las como diferentes texturas.

\subsubsection{Classificação de Textura}

Em geral a literatura menciona três tipos de aplicações para a análise de textura, sendo elas: segmentação (visa determinar as diferentes regiões contidas numa imagem), síntese de textura (responsável por estabelecer um modelo capaz de gerar uma dada textura) e classificação de textura (consiste em atribuir uma textura desconhecida a um conjunto de classes de imagem conhecido).

A classificação mencionada pertence ao contexto denominado de reconhecimento de padrões. Segundo Gonzales e Woods (2002), o termo padrão pode ser definido como um vetor característico (medida quantitativa fornecida através dos descritores mencionados) que descreve um objeto ou textura - contexto deste trabalho. Em outras palavras, tem-se um conjunto de valores/medidas provenientes de uma transformação ou sequência de transformações aplicadas sobre uma janela da imagem com o objetivo de descrever uma textura. Tais transformações podem ser realizadas com base nas técnicas de análise de textura descritas nas seções anteriores.

O objetivo do reconhecimento de padrões é classificar objetos de interesse em clas- 
ses ou categorias distintas. Para tal, duas fases são utilizadas: a primeira, denominada de treinamento; e a segunda, reconhecimento/classificação.

$\mathrm{Na}$ fase de treinamento, um modelo de classificador deve ser desenvolvido para identificar as peculiaridades dos padrões de interesse. Este por sua vez pode ser aplicado através de dois métodos denominados de supervisionado e não supervisionado.

De acordo com Gonzales e Woods (2002), o método supervisionado exige que o usuário colete amostras, represente-as através de vetores característicos, defina-as em classes (previamente conhecidas) e treine/ensine um algoritmo classificador a determinar a fronteira do espaço característico das amostras, isto é, fronteira que separa uma categoria de objeto da outra.

Quando não existe o conhecimento prévio das classes envolvidas no conjunto de amostras, o segundo método - treinamento não supervisionado é utilizado. Neste caso, o classificador aprende as características de cada classe diretamente dos dados de entrada sem a intervenção do usuário. Ou seja, amostras que compartilham propriedades semelhantes são agrupadas de forma "automática" em uma mesma classe. No entanto, em contraste com o método supervisionado, as classes aqui não têm uma interpretação pré-concebida.

Já a etapa de reconhecimento/classificação é a fase em que o algoritmo classificador treinado identifica qual classe ou classes pertencem ao conjunto de amostras apresentado. Ou seja, o algoritmo classificador identifica a que classe pertence o vetor característico de uma textura. A avaliação do seu desempenho pode ser realizada através de um conjunto teste de amostras pertencentes aos padrões conhecidos, mas não utilizados nas amostras contidas na fase de treinamento. Desta forma evita-se que a estimativa da taxa de erro (Eq. 2.67) obtida pelo classificador não se apresente de forma tendenciosa devido à aplicação das mesmas amostras que compõem o conjunto de treinamento.

$$
\text { erro }=e / n_{\text {total }}
$$

em que:

- $e$ denota o número de amostras classificadas de forma incorreta;

- $n_{\text {total }}$ denota o número total de amostras contidas no conjunto de treinamento;

Para facilitar a compreensão do que foi mencionado acima, apresenta-se na figura 
2.29 a sequência das etapas/fases envolvidas no processo de classificação de textura.

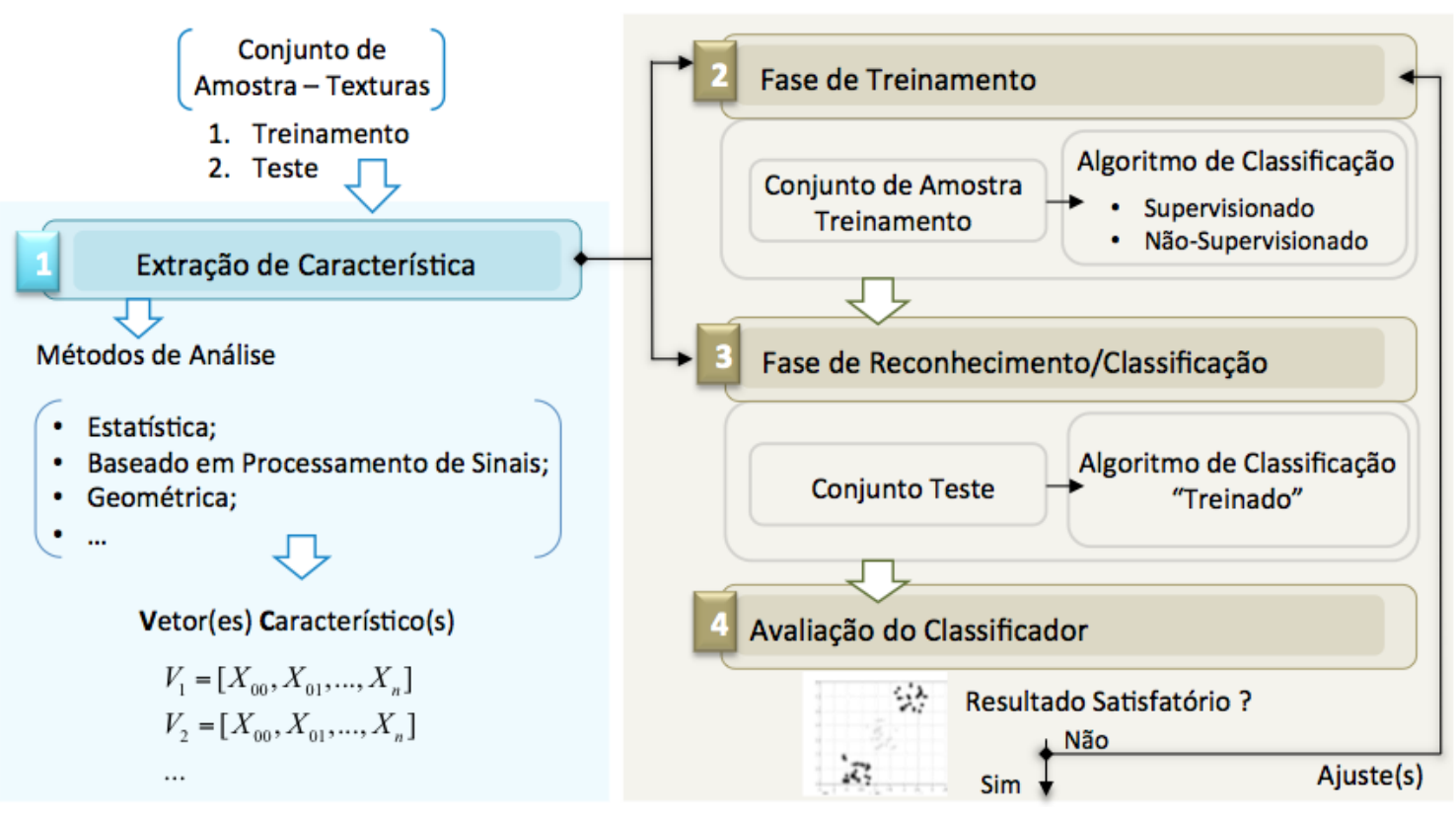

Figura 2.29: Fases envolvidas em todo o processo de classificação de textura.

Tou, Tay e Lau (2009) mencionam que existem popularmente três grandes métodos de classificação, sendo eles: Vizinhos mais Próximos (Nearest Neighbors), Rede Neural Artificial (Artificial Neural Network - ANN), Máquinas de Vetores de Suporte (Support Vector Machines - SVM) (DUDA; HART, 2001; GONZALES; WOODS, 2002; MATHER; TSO, 2009; TOU; TAY; LAU, 2009). Porém, o foco de interesse neste trabalho será na abordagem de Rede Neural Artificial (RNA) por sua capacidade de aprendizado a partir de exemplos e pela sua relação não explicita entre os dados de entrada e saída; pela boa generalização - habilidade em extrair informações que não se encontram de forma explicita nas amostras consideradas durante a etapa de treinamento; pela tolerância a falhas; pelo não estabelecimento de informações sobre a distribuição estatística dos dados de entrada; por sua habilidade de tratar problemas não-lineares; pela capacidade de treinamento supervisionado e não-supervisionado; por favorecer a velocidade e a precisão na extração e seleção de características; e pelo processamento de informações realizadas de forma paralela.

A tabela 2.12 ilustra as diferentes abordagens, por diferentes pesquisadores, em relação às técnicas de análise de textura tendo redes neurais como reconhecedor/classificador. Esta tabela tem por objetivo ilustrar de forma sucinta não só as técnicas utilizadas, mas também os tipos de redes neurais usadas na classificação de textura.

$\mathrm{Na}$ literatura encontram-se também trabalhos que englobam o uso das RNAs em todo o processo de análise de textura, isto é, não só na etapa da classificação, mas 
também na etapa da extração (apresentado na tabela 2.12). Este é o caso do trabalho de Kulkarni e Verma (2001), Verma e Kulkarni (2001), que utilizam uma rede autoassociativa composta de três camadas, em que a primeira e a última possuem o mesmo valor de entrada/saída (isto é, uma textura normalizada), enquanto que a camada intermediária/oculta é responsável por fornecer/gerar o vetor característico da textura, como ilustra o esquemático da figura 2.30.

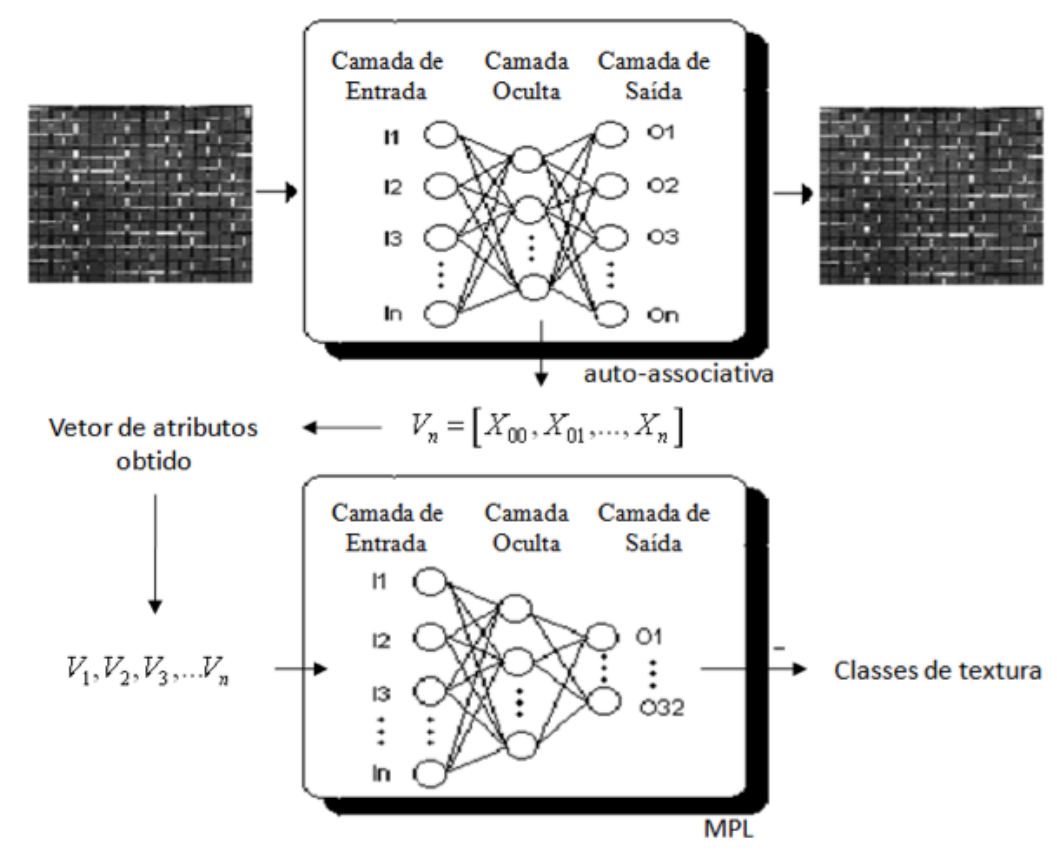

Figura 2.30: Redes auto-associativa e MPL empregadas no processo de análise de textura (adaptado: (KULKARNI; VERMA, 2001)).

Na etapa de classificação, uma rede MPL (Multi Layer Perceptron) (HAYKIN, 1999; SILVA; SPATTI; FLAUZINO, 2010) é utilizada pelos autores mencionados em que: o tamanho da entrada é definido pelo vetor característico obtido da fase anterior; a quantidade de neurônios da camada intermediária/oculta é estabelecida através dos resultados obtidos na simulação; e a camada de saída é definida pelo número de classes de texturas a serem reconhecidas/classificadas. Em ambas as redes as conexões entre as camadas são totalmente conectadas e o treinamento utilizado é supervisionado.

A abordagem utilizada por Kulkarni e Verma (2001) emprega o uso de duas fases de aprendizado distintas, sendo uma para aquisição dos atributos da textura e outra para o reconhecimento/classificação.

Já no trabalho de Tivive e Bouzerdoum (2006), os autores propuseram uma rede convolutiva (Convolutional Neural Network - CoNN) com a habilidade de extrair e classificar textura numa mesma arquitetura, isto é, através de um único processo de aprendizado. Sendo assim, a extração de características é realizada através de vários 
planos de neurônios inibitórios por derivação (shunting inhibitory neurons ${ }^{5}$ ), localizados nas camadas intermediária/oculta, enquanto que a classificação é fornecida por neurônios perceptron, localizados na camada de saída. A topologia é de propagação direta (feed forward), com conexão entre as camadas denominadas binária, como mostra a figura 2.31 .

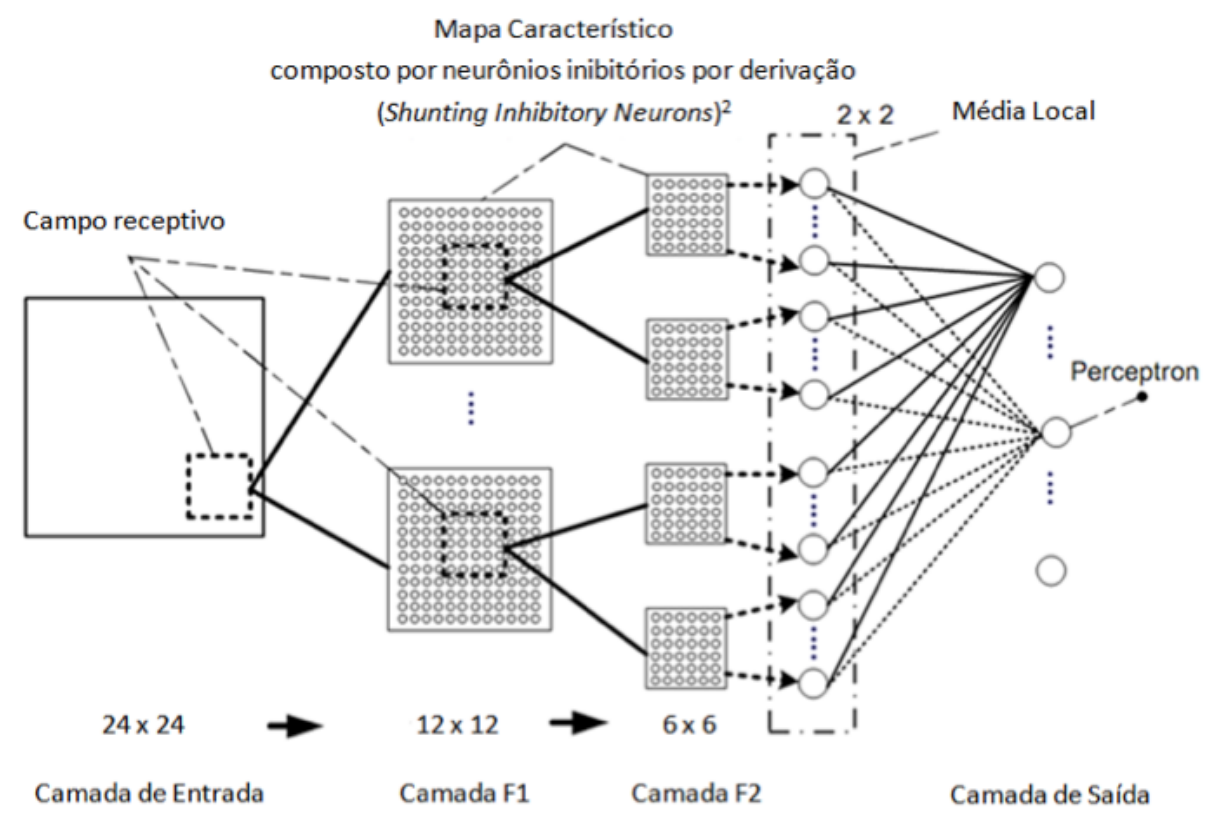

Figura 2.31: Diagrama esquemático de arquitetura de RNA para extração e classificação de textura (adaptado: (TIVIVE; BOUZERDOUM, 2006)).

Sucintamente, de acordo com Tivive e Bouzerdoum (2005), a camada de entrada é uma matriz com formato quadrado arbitrário utilizado para receber os elementos da textura. Cada camada intermediária/oculta consiste de um ou mais planos denominados de mapas característicos - composto por neurônios inibitórios por derivação (BEAR; CONNORS; PARADISO, 2008). Cada um desses neurônios do mapa é localmente conectado a uma pequena vizinhança quadrada $N x N$ (impar) da camada anterior, denominada de campo receptivo. Estes por sua vez compartilham o mesmo conjunto de peso e todos os mapas característicos utilizam o mesmo tamanho de campo $N x N$. Entretanto, diferentes mapas na mesma camada oculta utilizam diferentes conjuntos de peso, muito embora o mesmo conjunto de peso seja utilizado num único mapa. Desta forma cada neurônio de um determinado mapa possui a mesma operação em diferentes partes da imagem de entrada. Além disto, o conjunto de pesos, isto é, o conjunto $N x N$ do campo receptivo comporta-se como um filtro convolutivo, pois a saída é armazenada no neurônio correspondente do mapa característico. Logo, vários mapas podem extrair diferentes tipos de características locais, que vão desde baixa ordem,

\footnotetext{
${ }^{5}$ Traduzido com base em (BEAR; CONNORS; PARADISO, 2008)
} 
até alta ordem, a depender do número de camadas desejadas. A redução espacial de cada mapa ao longo da rede é realizada através do deslocamento do centro receptivo em duas posições, tanto horizontal como vertical da imagem de entrada, ou seja, em um quarto.

De acordo com Tivive e Bouzerdoum (2006), na camada F2 (figura 2.31) um efeito de suavização nos vetores característicos é incorporado. Para tal, utiliza-se uma mascara $2 \times 2$ para calcular a média e transformar quatro saídas em um único sinal. $\mathrm{O}$ conjunto de todos os sinais transformados alimenta o neurônio de saída, com uma conexão totalmente conectada. Uma competição competitiva do tipo "o ganhador leva tudo" (WTA - winner-take-all), proporciona a classificação da textura.

O modelo matemático da atividade (saída) do neurônio inibitório por derivação no mapa característico é fornecido pela localização $(i, j)$ no mapa $k^{\text {th }}$ na camada $L^{\text {th }}$, computado por:

$$
Z_{L, k}(i, j)=\frac{X_{L, k}(i, j)}{a_{L, k}(i, j)+Y_{L, k}(i, j)}
$$

em que:

$$
\begin{gathered}
\text { - } X_{L, k}(i, j)=f_{L}\left(\sum_{m=1}^{S_{L}-1}\left[C_{L, k} * Z_{L-1}, m\right]_{(x, y)}+b_{L, k}(i, j)\right) ; \\
\text { - } Y_{L, k}(i, j)=g_{L}\left(\sum_{m=1}^{S_{L}-1}\left[D_{L, k} * Z_{L-1}, m\right]_{(x, y)}+d_{L, k}(i, j)\right) ; \\
\text { - }(x, y)=\left\{\begin{array}{c}
(2 i, 2 j) \text { Primeiracamadaoculta }(\mathrm{L}=1) \\
(i, j) \text { Segundacamadaoculta }(\mathrm{L}=2)
\end{array}\right\} \\
\forall i, j=1, \ldots M_{L}
\end{gathered}
$$

$D_{L, k}$ e $C_{L, k}$ refere-se ao conjunto de peso excitatório e inibitório, respectivamente; $b_{L, k}$ e $d_{L, k}$ são parâmetros escalares chamado de bias do neurônio; $a_{L, k}$ é o termo de decaimento passivo, $g_{L}$ e $f_{L}$ são as funções de ativação e $M_{L}$ é o tamanho do mapa característico. A primeira camada oculta utiliza uma função linear, enquanto que a segunda camada intermediária utiliza uma função tangente hiperbólica. Para classificação, um neurônio tipo sigmóide tem sua saída computada pela equação 2.69. 


$$
y=h\left(\sum_{i=1}^{S_{N}} w_{i} z_{i}+b\right)
$$

em que:

- $h$ refere-se a função de ativação tangente hiperbólica;

- $w_{i}$ 's são as conexões dos pesos;

- $z_{i}$ os sinais de entrada do neurônio;

- $b$ termo bias;

Por fim, o treinamento utilizado nesta arquitetura é supervisionado e utiliza um algoritmo de aprendizado de retropapagação de erro (back-propagation) adaptado, descrito no apêndice do trabalho de Titive e Bouzerdoum (2006). 


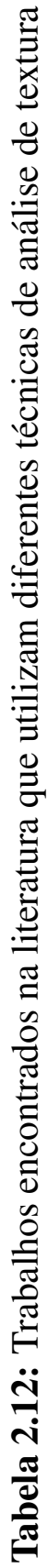
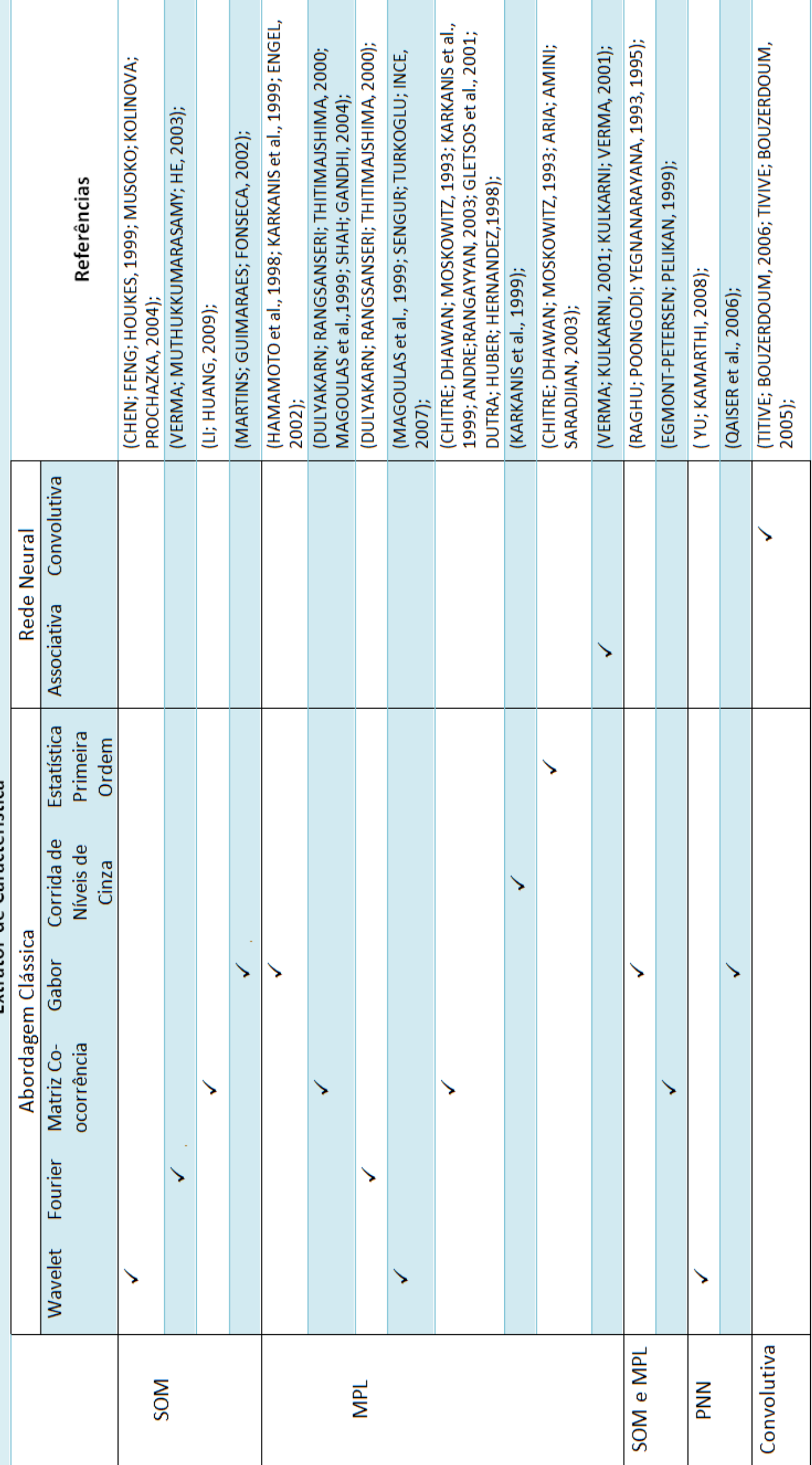

ıореכ|!!sse|ว - ןeגnan әрәу 


\section{Processo de Projeto em Domínios Próximos}

\subsection{Introdução}

Este capítulo apresenta um processo de projeto em que o domínio do cliente está relativamente próximo do domínio de desenvolvimento - definido como sendo a união do domínio funcional, domínio físico e domínio de processo (onde o caso da análise de textura se insere). Inicialmente são apresentadas as premissas adotadas, bem como as respectivas justificativas. Uma visão geral das atividades envolvidas é esboçada e, posteriormente, explanada em maiores detalhes.

A metodologia de desenvolvimento sistêmico de projeto adotado é adequada ao trabalho e um esboço gráfico é apresentado para melhor compreensão do leitor, tanto em relação ao escopo de suas atividades, quanto em relação aos critérios estabelecidos para a escolha da melhor solução. Em seguida, a descrição do equacionamento matemático a ser incorporado ao desenvolvimento/implementação da proposta de RNA é apresentado. O escopo desta atividade também é ilustrado e descrito no decorrer do capítulo, bem como a avaliação e validação a ser realizado.

\subsection{Definição do Processo}

O processo proposto para este trabalho tem duas premissas básicas: a primeira delas refere-se à importância da abordagem axiomática como método capaz de antecipar a formalização e análise de requisitos, garantindo a primeira fase de validação; a segunda é que este mesmo método axiomático pode ser considerado como a melhor opção quando se trata de projeto em que o domínio do usuário, onde estão validados os seus requisitos, é próximo do domínio de desenvolvimento. Nesse caso a imersão da equipe de desenvolvimento no domínio do usuário é simples e pode ser feita eficientemente, o que também facilita a antecipação da formalização das especificações.

Segundo Kulaka, Cebib e Kahramanc (2010), o número de trabalhos que utiliza 
o método axiomático vem crescendo, por facilitar a busca pela melhor solução para um projeto de porte médio ou grande em um curto espaço de tempo. Além disto, tal abordagem possui características como: redução da busca não-informada por novas soluções; redução de tentativa e erro; critério de eliminação de ideias ruins durante o estágio conceitual; auxílio ao rastreamento e identificação de falhas; avaliação de impacto em relação à mudança; sistematização e estruturação do raciocínio lógico do projetista de maneira organizada e de fácil compreensão; auxílio à compreensão/raciocínio envolvidos na tomada de decisão, bem como na exploração da criatividade do projetista.

Não foram encontrados na literatura caso(s) específico(s) de utilização da abordagem axiomática em projetos voltados à análise de textura em imagens digitais, ou em rede neurais (denominado neste trabalho de domínio complementar - onde ocorre o desenvolvimento e implementação da solução proposta). Acredita-se que esta lacuna ocorre por dois motivos: primeiro, por ser uma abordagem relativamente nova (onde o início de publicações e uso da teoria por parte de pesquisadores ocorre a partir de 1990); e segundo, porque o domínio mencionado não possui regras formais bem estabelecidas para a definição/ determinação de parâmetros (por exemplo: número ótimo de camadas, número de neurônios, seleção dos pesos iniciais, quantidade dos dados de entrada, entre outros). Estes por sua vez são empiricamente estabelecidos e posteriormente ajustados com base na avaliação dos resultados experimentais (mencionado anteriormente na seção 1.2).

Tendo em vista os fatos mencionados acima e de acordo com os objetivos apresentados no capitulo 1, propõe-se para o desenvolvimento deste trabalho um processo dividido em três fases. A primeira, responsável pelo estabelecimento de solução - definição e/ou orientação do projeto do produto para análise da extração de característica de textura, com base nas necessidades do desenvolvedor (utilização do Projeto Axiomático). A segunda, caracterizada pelo desenvolvimento e implementação da proposta em um domínio particular (Redes Neurais Artificiais), denominado de complementar, mencionado anteriormente. E a terceira e última, destinada a avaliação e validação da proposta, isto é, se o desenvolvimento da fase II do projeto atende corretamente as especificações das soluções delineadas na fase I.

A figura 3.1 apresenta um esboço do processo proposto, enquanto as subseções seguintes descrevem em maiores detalhes as atividades que serão executadas em cada uma delas. 


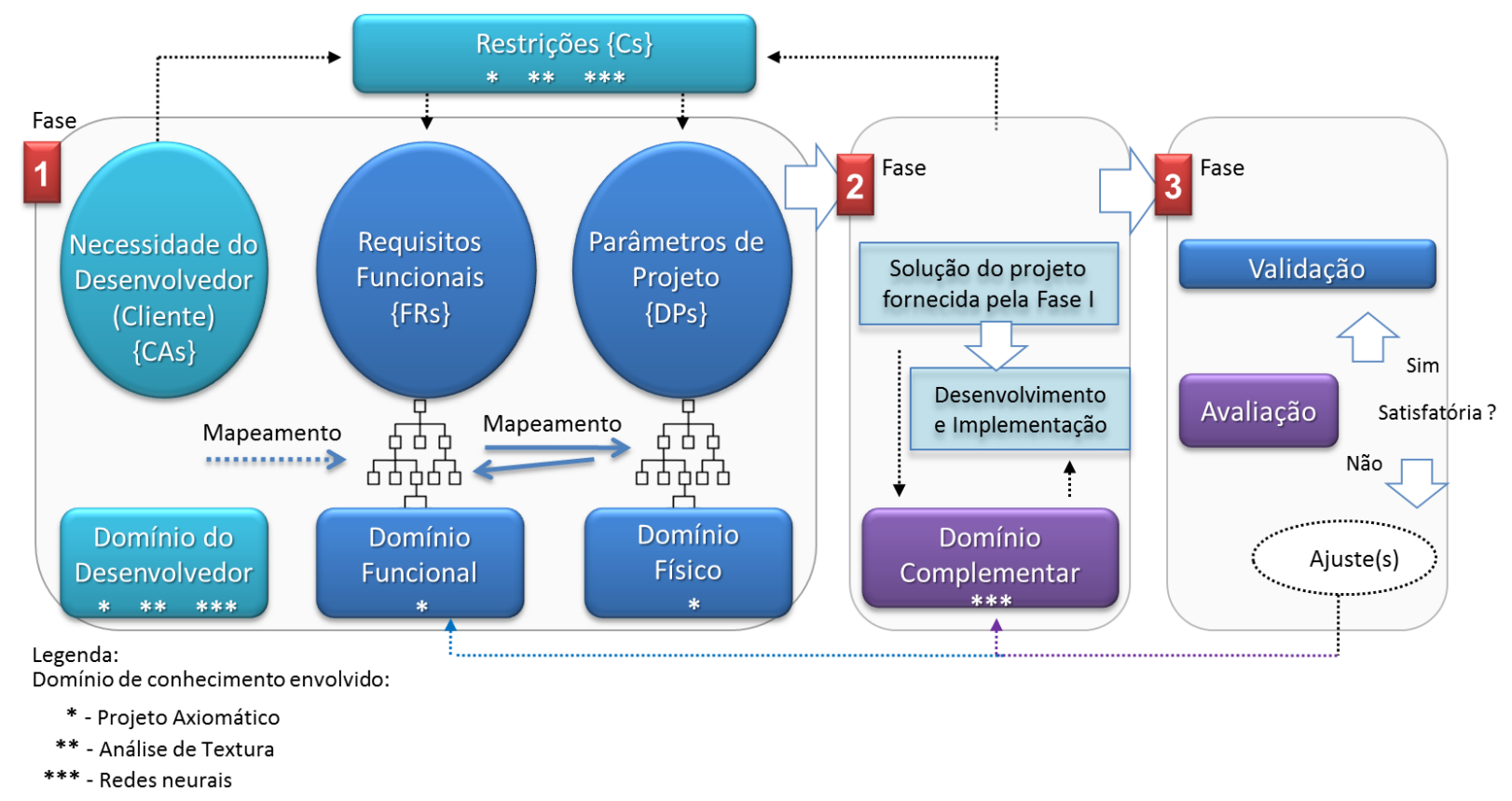

Figura 3.1: Processo proposto para o desenvolvimento do trabalho - Fase I, II e III

\subsubsection{Fase I - Definição do Problema}

A Fase I é responsável por definir (formalmente) o problema proposto, o que na abordagem axiomática consiste em especificar os domínios respectivos (do cliente/desenvolvedor, o domínio funcional e o domínio físico) e as restrições, bem como os mapeamentos entre estes domínios.

A mudança na denominação do domínio do cliente para domínio do desenvolvedor, como mostra a figura 3.1, se deve ao fato de que estamos tratando com casos onde o mundo do cliente e do desenvolvedor (responsável pelos demais domínios) são próximos, permitindo ao desenvolvedor assumir o papel do especialista (stakeholder). Assim, percepção/definição do problema, o estabelecimento das necessidades, desejos e restrições do projeto são propostas diretamente pelo desenvolvedor. Ou seja, a aquisição e tradução dos requisitos deixa de ter um enfoque prioritário no relacionamento, comunicação e transferência de conhecimento entre o cliente e desenvolvedor (QUEIROZ, 2007; QUEIROZ; SILVA, 2009) e passa a ser baseado nos conhecimentos explícitos expressos em documentos (artigo, livros, entre outros). Estes por sua vez podem ser encontrados de forma difusa, não só pela quantidade, mas pela diversidade de soluções existentes para um determinado problema, como é o caso da análise de textura apresentada no capitulo 2 deste trabalho.

Especificamente, algumas atividades são propostas para a determinação deste domí- 
nio:

1. Compreensão (por parte do especialista/desenvolvedor) das diferentes técnicas ou métodos presentes na literatura para a análise e reconhecimento de textura;

2. Percepção por parte do desenvolvedor das limitação(ões) ou problema(s) presente(s) no processo de análise em questão, bem como uma perfeita identificação e compreensão do(s) domínio(s) envolvidos. A inserção de justificativa (rationales) para inclusão ou priorização de um dado requisito também faz parte dessa atividade, uma vez que a proposta é estabelecida pelo especialista/desenvolvedor e não por uma necessidade abstrata de um cliente ou organização específica que estejam distantes da implementação;

3. Definição das necessidades ou atributos que o especialista/desenvolvedor deseja num dado produto para solucionar ou minimizar o problema (requisitos nãofuncionais). Neste caso o desenvolvedor deve agir como cliente, muito embora sua base de conhecimento sobre a necessidade seja mais dependente de estudos motivados pelo próprio projeto. Nesse caso, a definição dos requisitos pode deixar de ser abstrata, genérica e não organizada, uma vez que estes não são mais expressos pelo cliente de forma difusa e quase que puramente funcional. Além disto, estes requisitos podem ser estabelecidos já de forma estruturada. No entanto, o sucesso desta atividade depende de um bom desempenho nas atividades anteriores ( 1 e 2$)$.

4. Por fim, deve-se identificar as limitações do domínio em que a solução irá atuar, bem como restrições impostas pelo desenvolvedor ao projeto. Estas vão delimitar o universo onde devem ser buscados os parâmetros do processo \{DPs pertencentes à etapa posterior da abordagem axiomática.

As atividades descritas acima devem ser mapeadas em requisitos funcionais $\{\mathrm{FRs}\}$, ou seja, um conjunto mínimo de requisitos independentes que caracterizam as necessidades funcionais (ações a serem realizadas pelo produto/sistema) de uma solução de projeto.

As atividades dos demais domínios não são diretamente afetadas por este procedimento. No caso específico da proposta deste trabalho, adota-se como atividade principal o mapeamento entre o domínio funcional e físico, que relaciona "o que se deseja atingir" (objetivo) e “como se pode atingir tal objetivo" (processo). Na execução deste mapeamento, realiza-se uma decomposição top-down, em "zigue-zague" (seção 2.1.2), organizada em hierarquia e com um link entre o projeto de mais alto nível e 
o de mais de baixo nível. O resultado destes mapeamentos entre o domínio funcional e o físico fornece não só a definição formal do problema como um todo, como a(s) possível(s) solução(ões) do projeto a ser(em) implementada(s) na fase II (nesta caso, um estudo de caso - análise de textura, extração e classificação/reconhecimento, através de rede neural, em única fase).

Em projetos originais, isto é, projetos considerados como novas soluções, o conjunto de requisitos funcionais, segundo Suh (2001), deve ser traduzido diretamente das necessidades do cliente e de modo neutro (sem levar em consideração soluções préconcebidas). Já o processo de criatividade envolvido no mapeamento entre os $\{\mathrm{RFs}\} \mathrm{e}$ $\{\mathrm{DPs}\}$ do projeto depende fundamentalmente da base de conhecimento e do processo inventivo do projetista. Por ser subjetivo, pode existir um número infinito de soluções criativas que satisfaçam os mesmos requisitos. A abordagem adotada permite não só explorar a criatividade, no caso de novos desafios de textura, mas também formalizá-la através dos princípios do axioma, isto é, matrizes de projeto. Usando estas matrizes é possível fazer o descarte de idéias inadequadas (ditas ruins - projeto acoplado) de forma rápida, e auxiliar a procura de soluções novas mais adequadas ou aceitáveis (projeto desacoplado e semi-acoplado, respectivamente).

Como forma de reduzir o espaço de soluções envolvidos nesta proposta, utilizase as restrições (limitação de solução). Como mencionado no capitulo anterior, as restrições podem ser divididos em: restrições de entrada e restrições de sistema. $\mathrm{O}$ primeiro refere-se às restrições impostas como parte da especificação do projeto, enquanto que o segundo é imposto pelo sistema no qual a solução do projeto irá funcionar, isto é, ao domínio complementar. Em vista deste fato, verifica-se a necessidade da compreensão deste domínio, dado o seu impacto na solução do projeto, e consequentemente, na fase seguinte desta proposta, apresentada na próxima seção.

Para a geração de redes neurais à análise de textura, a construção do frame relacionada com a FASE 1 será feita usando basicamente o primeiro axioma - Axioma da Independência. Uma razão para isso é a ausência de métricas para o uso do segundo axioma, que reduz a quantidade de informação das especificações, orientando a tomada de decisão pela melhor solução (ou por um conjunto que mais se qualifique neste processo). Por esta razão, três premissas foram adotadas de acordo com os princípios do Axioma da Independência para o desenvolvimento da presente proposta:

1. A ordem de seleção da matriz de projeto deve ser realizada de acordo com a seguinte classificação: solução desacoplada (tido como adequada); semi-acoplada (tido como aceitável); e por último, o descarte e busca por nova solução para projetos acoplados (ruim ou que não funciona de forma adequada); 
2. A utilização dos parâmetros de restrição para delimitar o escopo das soluções (conceito ilustrado no exemplo 2 da seção 2.1.3).

3. Na existência de duas ou mais equações de projetos semi-acoplados ou desacoplados, adota-se o seguinte critério:

a. Projeto semi-acoplado: o cálculo da medida de Reangularidade (R) e Semangularidade $(\mathrm{S})$.

A relação entre $\{$ FRs $\}$ e $\{$ DPs $\}$ nas matrizes de projeto é estabelecida através de um valor unitário (constante). Assim, as medidas de $\mathrm{R}$ e $\mathrm{S}$ podem ser calculadas pelas equações 2.7 e 2.8. De acordo com (SUH, 2001), a equação que apresentar o menor grau de dependência funcional é tida como a melhor solução.

b. Projeto desacoplado: caso as restrições do domínio de aplicação e de projeto não seja suficiente para a escolha da melhor solução (através da redução do espaço de busca), a tomada de decisão poderá ser efetuada de forma subjetiva, isto é, associada à percepção do especialista/desenvolvedor.

Com o propósito de auxiliar a compreensão, apresenta-se de forma sucinta um esquema (Fig 3.2) indicando os critérios e as atividades adotadas para o desenvolvimento desta fase no caso específico da análise de textura.

O resultado da aplicação desta primeira fase (mapeamento e decomposição das necessidades do desenvolvedor na forma $\{\mathrm{RFs}\}$ e, conseqüentemente, $\{\mathrm{DPs}\}$ ) é o fornecimento de uma concepção formal (raciocínio envolvido no projeto) da análise entre os pixels a ser realizada pelo domínio complementar - Fase II da proposta, descrita na próxima seção.

Por fim, adota-se uma ferramenta computacional de auxílio ao desenvolvimento desta fase, denominada de ACCLARO DFSS (ACCLARODFSS, 2010). Ferramenta que ajuda na descrição das necessidades do desenvolvedor, requisitos funcionais, parâmetros, restrições e suas relações, auxílio ao processo de mapeamento e decomposição entre os domínios funcional e físico, criação de forma automática da matriz de projeto, auxílio à análise de projeto acoplamento, rastreamento e visualização do impacto nas mudanças, bem como a representação gráfica do projeto através do diagrama de fluxo, apresentado no capítulo 2 deste trabalho. 


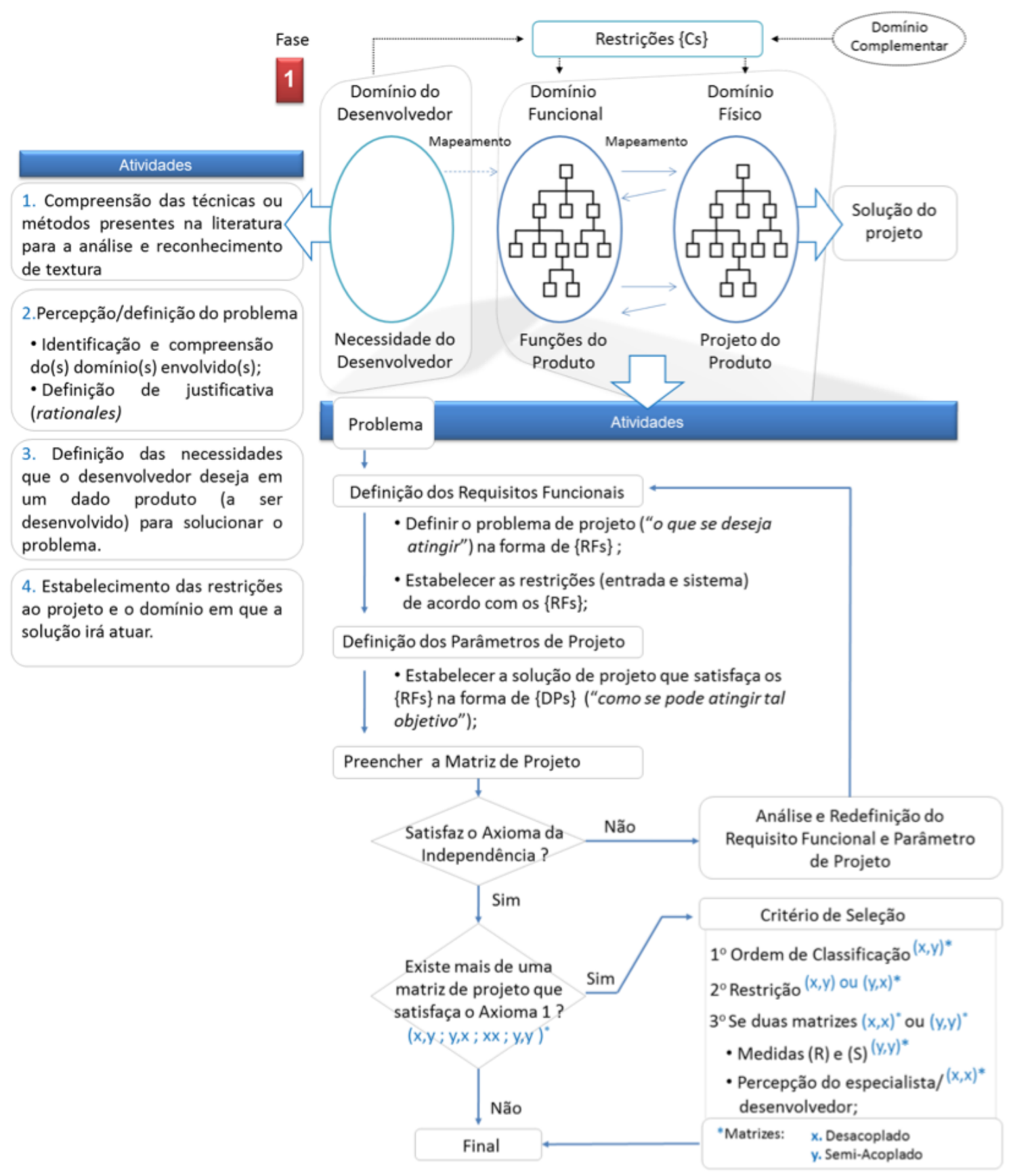

Figura 3.2: Atividades e escopo dos critérios adotados na primeira fase do processo proposto. 


\subsubsection{Fase II - Desenvolvimento e Implementação}

$\mathrm{Na}$ Fase I, descrita anteriormente, se elabora o framework de projeto segundo o método Axiomático. A informação que caracteriza a proximidade entre o mundo do cliente e do desenvolvedor é inserida, bem como as informações específicas da aplicação - a análise de textura com Redes Neurais Artificiais (RNA).

A Fase II é composta pelo domínio complementar (RNA), em que a solução do projeto fornecida pela Fase I deve ser desenvolvida e implementada. Esta por sua vez insere-se nas etapas/atividades propostas para a Fase II, como mostra a figura 3.3.

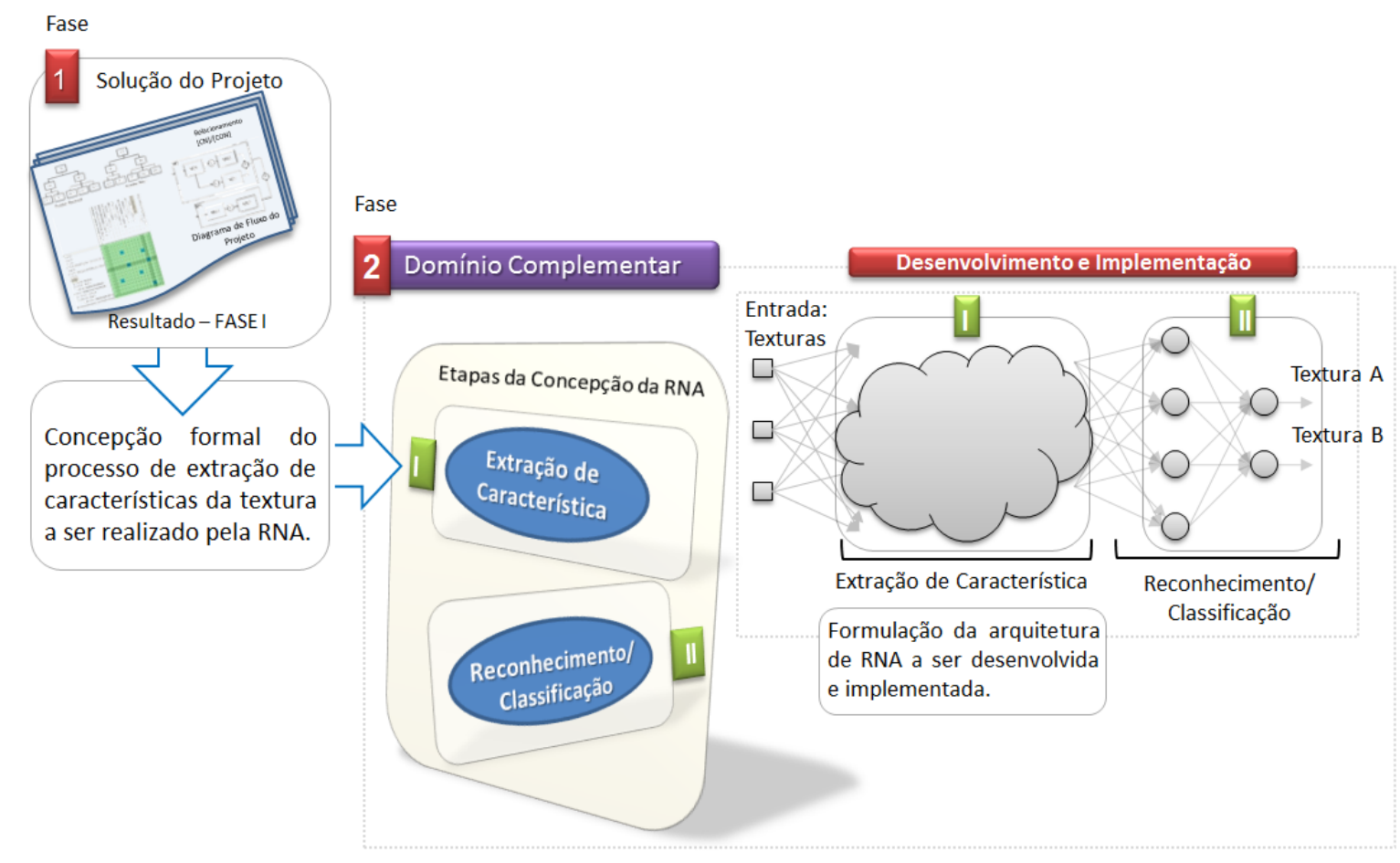

Figura 3.3: Escopo das etapas a ser realizada na Fase II do processo proposto.

O modelo de RNA a ser desenvolvido para análise e reconhecimento de textura tem o papel fundamental de extrair não só as características do padrão (detectar tendências complexas ou não), bem como classificá-las através de uma estrutura unificada, isto é, com apenas uma única fase de aprendizado. Todavia, deve-se ressaltar que o contexto de análise a ser tratado neste trabalho é delimitado à análise de texturas homogêneas.

A definição da topologia, conectividade, número de camadas, isto é, da arquitetura da RNA responsável tão só pela extração da característica local e não global da textura, baseia-se na concepção formal (fornecida pelo framework do projeto, segundo a proposta) da análise dos pixels a serem extraídos conforme a sua relação/distribuição espacial existente entre os vários graus de cinza presentes na textura. Logo, esta etapa implica no desenvolvimento da primeira parte da concepção da arquitetura de RNA. 
Com base na teoria do domínio complementar, etapa 2, à atividade de reconhecimento/ classificação pode ser realizada através de uma segunda rede acoplada a primeira. Uma rede, por exemplo, com topologia de propagação direta (feed-forward), duas camadas, totalmente conectadas e realizadas através de um processo competitivo entre os neurônios, em que o ganhador leva tudo ("winner take-all”) (HAYKIN, 1999)

Entretanto, como se pretende desenvolver uma RNA que englobe ambas as atividades em uma única fase de aprendizado, adota-se a premissa de se utilizar um único modelo de neurônio artificial, com algumas propriedades biológicas, descritas no decorrer desta seção.

A seguir ilustra-se (Fig 3.4 ) a unidade de processamento que forma a base para o desenvolvimento e implementação da atividade proposta à segunda fase.

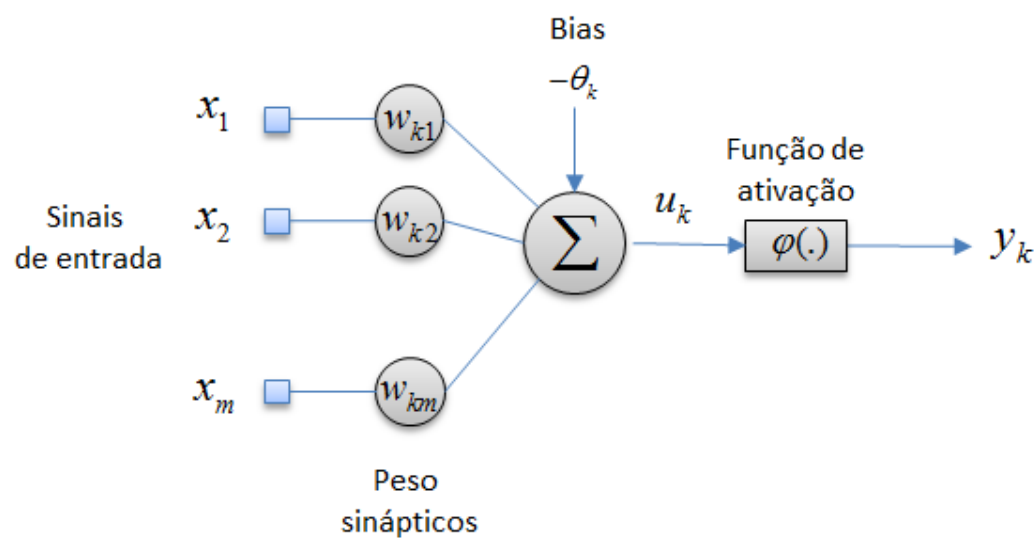

Figura 3.4: Modelo do neurônio artificial (HAYKIN, 1999).

Em termos matemático essa unidade pode ser escrita pelas equações 3.1 e 3.2.

$$
\begin{aligned}
& u_{k}=\sum_{j=1}^{m} w_{k j} x_{j} \\
& y_{k}=\varphi\left(u_{k}-\theta_{k}\right)
\end{aligned}
$$

em que: $u_{k}$ é o potencial de ativação; $w_{k j}$ são os pesos sinápticos do neurônio k; $x_{j}$ são os sinais de entrada; $y_{k}$ é o sinal de saída do neurônio; $\theta_{k}$ representa o bias associado ao neurônio k; e o $\varphi$ é a função de ativação.

Em relação à função de ativação $(\varphi)$ adota-se a função logística para ser utilizada 
em tal modelo. Esta sempre assume valores reais entre $[0,1]$ e pode ser expressa pela equação 3.3

$$
\varphi\left(u_{k}-\theta_{k}\right)=\frac{1}{1+\frac{1}{\exp \left(\frac{u_{k}-\theta_{k}}{T}\right)}}
$$

Os parâmetro $T$ e $\theta_{k}$ influenciam a sigmoide na inclinação e deslocamento, respectivamente, como mostra a figura 3.5

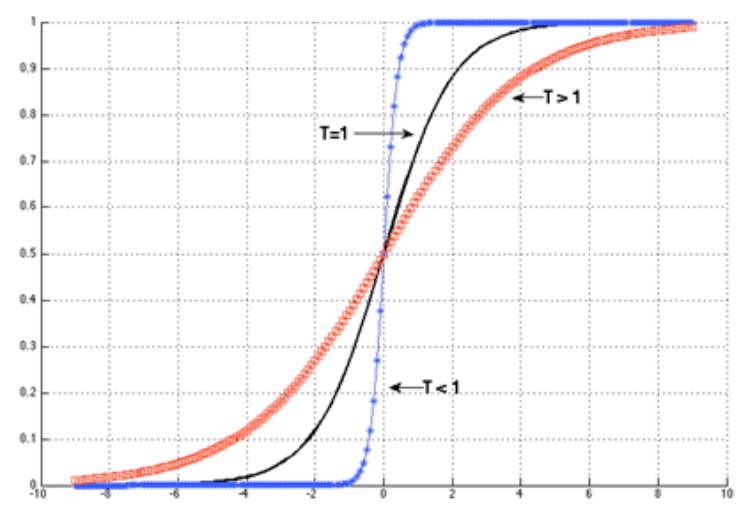

(a) Formato da curva sigmoide em função do parâmetro $T$

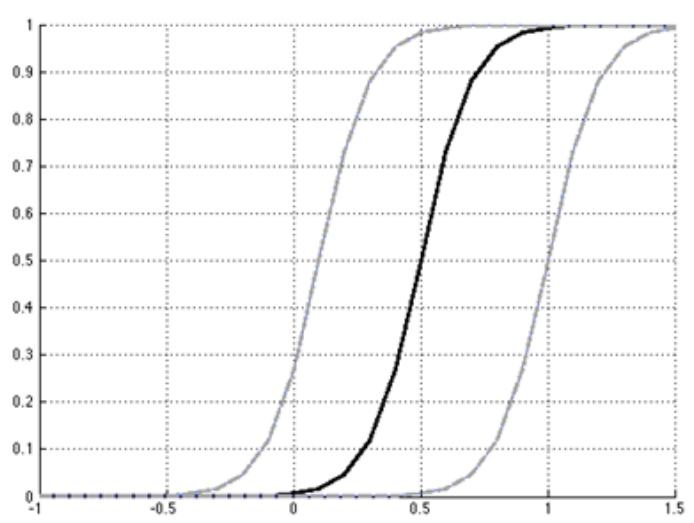

(b) Deslocamento da sigmoide em função da adição ou subtração do bias $\theta_{k}$

Figura 3.5: Influência dos parâmetros $T$ e $\theta_{k}$ na função logística.

Na literatura alguns autores (TRIESCH, 2005, 2007; SULLIVAN; SA, 2006; WILLIAMS; NOBLE, 2007; PELAEZ et al., 2008) utilizam tais parâmetro (ambos ou apenas um deles) para auxiliar a convergência da RNA. Justificam o seu uso por meio de propriedades homeostática/regulatórias do neurônio biológico, tais como: “escalonamento sináptico" (homeostatic synaptic scaling) ${ }^{1}$ (TURRIGIANO; NELSON, 2004; MAFFEI; NELSON; G.G, 2004) e a plasticidade intrínseca ${ }^{2}$ (intrinsic plasticity or intrinsic excitability) (DESAI; RUTHERFORD; TURRIGIANO, 1999; DAOUDAL; DEBANNE, 2003; DESAI, 2003).

Entretanto, o modelo aqui descrito adota o parâmetro $T$ como uma constante, enquanto que a variação de $\theta_{k}$ é fornecida pela equação 3.4 (PELAEZ et al., 2008).

\footnotetext{
${ }^{1}$ Mecanismos que altera a entrada das sinapses por um fator multiplicativo, que segundo Sullivan e Sa (2006), presume-se preservar a relação de forças das sinapses.

${ }^{2}$ Capacidade do neurônio mudar sua excitação em função da distribuição de estímulo que o mesmo é submetido.
} 


$$
\theta_{k}=\frac{\rho \cdot y_{k}(t-1)+\theta_{k}(t-1)}{1+\rho}
$$

em que: $\rho$ é uma constante (arbitrária) de velocidade de deslocamento, dentro do intervalo [0.001, 0.1] e $y_{k}(t-1)$ é a saída do neurônio $k$ em $(t-1)$;

Deve-se salientar que $\theta_{k}$ desloca a função de ativação do neurônio para esquerda ou direita livremente no eixo da abcissa com base no estímulo que este é submetido, diferenciando no mecanismo da plasticidade intrínseca (DESAI, 2003) utilizada por alguns autores, como mencionado anteriormente.

Com relação à regra de aprendizado, opta-se pela descrita na equação 3.5, uma vez que é baseada nos princípios de modificações/alterações sinápticas NMDA do neurônio biológico (KANDEL; SCHWARTS; JESSEL, 2000; BEAR; CONNORS; PARADISO, 2006). Maiores detalhes sobre definição/relação biológica podem ser encontrados em (O'REILLY; MUNAKATA, 2000).

$$
\Delta w=\sigma \cdot x_{j}\left(y_{k}-w_{i j}\right)
$$

em que: $\Delta w$ é o incremento de peso; $\sigma$ é a constante de aprendizado dentro de um intervalo [0.001 a 0.1$]$; $x_{j}$ é o valor do neurônio pré-sináptico; $y_{k}$ é o valor do neurônio pós-sináptico; $w_{i j}$ denota o peso sináptico.

Por fim, a atualização do peso do neurônio artificial descrito anteriormente é fornecida pela equação .

$$
w_{k j}(t+1)=w_{k j}(t)+\Delta_{t} w_{k j}
$$




\subsubsection{Fase III - Avaliação e Validação}

A Fase III é responsável pela avaliação da implementação, ajustes na fase II e I, bem como a validação do projeto desenvolvido na fase I. Esta seção apresenta a(s) atividade(s) a ser(em) realizada(s) em cada uma delas.

A fase de avaliação tem como objetivo verificar o funcionamento/desempenho da implementação. Isto é, avaliar a extração e reconhecimento/classificação do conjunto de dados (textura homogênea) submetida à rede. Conjunto este não utilizado na fase de aprendizado e que deve ser inserido na rede de forma aleatória para impedir quaisquer tendências associadas ou não à ordem de apresentação dos dados. Indiretamente essa fase avalia também o processo proposto como um todo.

A fase de avaliação também tem o papel de auxiliar o ajuste de parâmetros do domínio complementar. Como mencionado anteriormente, tal domínio não possui regras formais à definição/determinação de alguns dos seus parâmetros, tais como: valor inicial dos pesos sinápticos, número de unidades presentes não só na camada de reconhecimento/classificação, bem como na camada de extração de característica, ajuste no parâmetro de inicialização, entre outros. Estes por sua vez são empiricamente estabelecidos na implementação - fase II e, posteriormente ajustados com base na avaliação dos resultados experimentais - fase III. Sendo assim, existe a ocorrência do ciclo de ajuste (ida e vinda, Fig. 3.1) entre tais fases, responsável não só pela adequação dos parâmetros mencionados acima, bem como a aquisição da melhor avaliação/desempenho do modelo para a extração e reconhecimento/classificação das texturas homogêneas.

Caso o resultado da avaliação após a realização do ciclo de ajuste não seja satisfatório, modificações na concepção da definição da solução do problema (fase I) podem ser realizadas. Isto é, um ajuste, adaptação ou até mesmo uma nova proposta de solução à análise pode ser obtida. Estas por sua vez são conduzidas na recente experiência prática adquiridas das fases II e III, o que auxilia o desenvolvedor a tomar decisões mais conscientes e informadas em relação ao problema.

De acordo com o ciclo da proposta apresentada na figura 3.1, modificações realizadas na fase I devem retornar ao processo de desenvolvimento e implementação e, posteriormente, a nova fase de avaliação.

Por fim, a validação é realizada de acordo com a resposta da avaliação. Isto é, se for satisfatória, a análise proposta na fase I é coerente com a extração de texturas e, conseqüentemente, contempla as necessidades do especialista/desenvolvedor. Em outras palavras, mostra que a especificação dos requisitos $\{\mathrm{FRs}\}$ e parâmetros do projeto 
\{DPs $\}$ delineados no início do projeto, apresentam-se adequadas à implementação da solução.

\subsection{Resumo do Capítulo}

Neste capítulo foi apresentada a proposta de um processo de projeto (design) em domínios próximos a ser utilizado no desenvolvimento do trabalho.

Teve como base para sua formação duas premissas: a primeira, relacionada à importância do uso do projeto axiomático (um método sistemático eficaz e poderoso na aplicação de desenvolvimento de projetos nas mais diversas áreas do conhecimento humano (KULAKA; CEBIB; KAHRAMANC, 2010) como metodologia de auxílio ao desenvolvimento de projeto, capaz de antecipar a formalização e análise de requisitos, garantindo a primeira fase de validação; e a segunda, ao ajuste do mencionado método. Fato este ocasionado por não ter sido encontrado na literatura relatos de utilização da abordagem axiomática em projetos voltados à análise de textura em imagens digitais, bem como em rede neurais.

A proposta consta de três fases, apresentadas na figura 3.1. Na primeira delas define-se o problema e fornece uma concepção formal (raciocínio envolvido no projeto - estabelecido pela abordagem axiomática) do processo de análise entre os pixels a ser realizada pelo domínio complementar - Fase II.

O estabelecimento das necessidades, desejos e restrições de projeto definidas nesta primeira fase, são fornecidas diretamente pelo especialista/desenvolvedor, ao invés de um cliente. Ou seja, a aquisição e tradução dos requisitos deixa de ter um enfoque prioritário na relação transferência de conhecimento entre o cliente e desenvolvedor (QUEIROZ, 2007; QUEIROZ; SILVA, 2009) e passa a ser baseado nos conhecimentos expressos em documentos. Sendo assim, quatro atividades são propostas para tal etapa: a) compreensão das técnicas ou métodos presentes na literatura para a análise e reconhecimento de textura; b) percepção/definição do problema; c) estabelecimento das necessidades que o desenvolvedor deseja em um dado produto (a ser desenvolvido) para solucionar o problema; d) declaração das restrições do projeto e do domínio em que a solução irá atuar.

Após as atividades descritas acima, uma decomposição top-down, em zigue-zague, organizada em hierarquia do que se deseja atingir e, como se pode atingir tal objetivo (extração de características de textura homogênea) é realizada com a finalidade de formalizar a solução do projeto através dos princípios do primeiro axioma. Todavia, a ausência de métricas para o uso do segundo axioma, um dos responsáveis pelo pro- 
cesso de tomada de decisão da melhor solução, foi o motivo para o estabelecimento dos seguintes critérios usados na mencionada atividade: a) seleção da matriz de projeto a ser realizada de acordo com a classificação: solução desacoplada e semi-acoplada; b) a utilização de restrições como parâmetros decisivos na escolha da melhor equação de projeto; c) na existência de duas ou mais equações de projetos semi-acoplados ou desacoplados, adota-se para o primeiro caso as medidas de reangularidade (R) e Semangularidade (S), enquanto que para o segundo, a tomada de decisão é efetuada de forma subjetiva isto é, associada à percepção do especialista/desenvolvedor. Na Figura 3.2 encontra-se um esquemático que indica todas as atividades e critérios adotados para o desenvolvimento desta primeira fase no caso específico da análise de textura.

A segunda fase é orientada pela resposta da fase I, caracterizada por ser o domínio em que a solução do problema será desenvolvido e implementado. O contexto de Redes Neurais foi adotado para compor o domínio acima citado. Assim, a RNA tem o papel fundamental de extrair não só as características do padrão (delimitado neste trabalho como textura homogêneas), bem como classificá-las através de uma estrutura unificada.

Com relação à definição da topologia, conectividade e número de camadas para a extração de característica, esta se baseará no resultado da primeira fase, isto é, no fornecimento da concepção formal da análise a ser realizada entre os pixels, estabelecida no resultado do projeto axiomático. Já no reconhecimento/classificação é realizada com base na teoria do domínio complementar. Entretanto, como se pretende desenvolver uma RNA que englobe ambas as atividades em uma única fase de aprendizado, adota-se a premissa de se utilizar um único modelo de neurônio artificial, descrito na seção 3.2.2.

A terceira e última fase é responsável pela avaliação, ajustes na fase II e I, como a validação do projeto desenvolvido na fase I e, conseqüentemente, o processo proposto.

A avaliação tem como objetivo verificar o funcionamento/desempenho da fase II, bem como auxiliar no ajuste dos parâmetros do domínio complementar. Este não possui regras formais para seu estabelecimento, por exemplo: números de camadas e neurônios da rede. São empiricamente determinados na fase mencionada e, posteriormente, ajustados com base na avaliação dos resultados experimentais - fase III. Por este motivo, existe a ocorrência do ciclo de ajuste, como mostra figura 3.1. Todavia, caso a mesma não seja satisfatória, modificações na fase I podem ser realizadas para atender tal necessidade.

A validação finaliza o processo de modo que se a análise proposta na fase I for satisfatória e coerente com a extração de texturas, a especificação dos requisitos $\{$ FRs $\}$ 
e parâmetros de projeto $\{\mathrm{DPs}\}$ delineados no inicio da fase I, mostram-se adequados à implementação da proposta de solução.

Por fim, menciona-se neste capítulo que serão utilizadas duas ferramentas computacionais: a primeira, denominada de ACCLARO DFSS (ACCLARODFSS, 2010), ajuda o desenvolvimento do projeto axiomático, enquanto que a segunda MATLAB (MATHWORKS, 2010), auxilia a prototipagem rápida e a avaliação do modelo da RNA. 


\section{Estudo de Caso}

\subsection{Introdução}

Este capítulo apresenta a aplicação prática do processo proposto em um estudo de caso para análise e reconhecimento de textura. É dividido em duas seções principais, sendo a primeira responsável por fornecer a delimitação do contexto de análise e, a segunda, a aplicação/explanação da proposta - fase por fase.

Na delimitação do contexto, a abrangência de tal análise é estabelecida, bem como salientado o seu real propósito.

Em seguida, são apresentadas as três fases para o processo. Na primeira, responsável pelo fornecimento da solução, explana-se as premissas adotadas, as justificativas de cada uma delas, o levantamento das necessidades, das restrições/limitações dos domínios envolvidos, o estabelecimento dos requisitos funcionais, das especificações e da matriz de projeto - solução à extração da característica da textura.

A segunda, descreve como o diagrama de fluxo fornecido pela primeira fase (Projeto Axiomático) é interpretada para o domínio de desenvolvimento e implementação, bem como a junção à fase de reconhecimento/classificação. Ou seja, o desenvolvimento de uma arquitetura neural para análise e reconhecimento de textura em uma única fase de aprendizado.

Posteriormente, ilustram-se os resultados obtidos na terceira fase, os parâmetros adotados, a taxa de acerto, a imagem obtida em função da resposta da rede, a segmentação de duas ou mais texturas numa mesma imagem. Todas elas, em diferentes aplicações nos domínios da engenharia e medicina.

\subsection{Delimitação do Contexto de Análise}

De acordo com o objetivo delineado na seção 1.3, o estudo de caso escolhido para implementar o processo do projeto, baseia-se na análise de texturas homogêneas. Segundo alguns autores, tal terminologia pode ser definida como: 
1. “... grupo de elementos da imagem com níveis de cinza semelhantes...” (HARALICK, 1979);

2. “Uma região homogênea refere-se a um grupo de pixels conectados na imagem que compartilham uma característica em comum. Essa característica pode ser brilho, cor, textura, etc" (BOVIK, 2000);

3. “composto de partes ou elementos que são todos da mesma natureza” (MICHAELIS, 2011; OXFORD, 2011);

Logo, pode-se afirmar, por exemplo, que uma textura do tipo areia (Fig.4.1 - b), madeira (Fig. 4.1 - c), água (Fig 4.1 - d), é tida como homogênea, pois cada uma delas contém elementos da imagem com níveis de cinza semelhantes entre elas. Entretanto, isso não invalida, por exemplo, de serem classificadas com base no espectro de textura (estocástica, quase-estocástica, irregular, quase-regular, regular), como apresentado na figura 2.13 da seção 2.2.2.

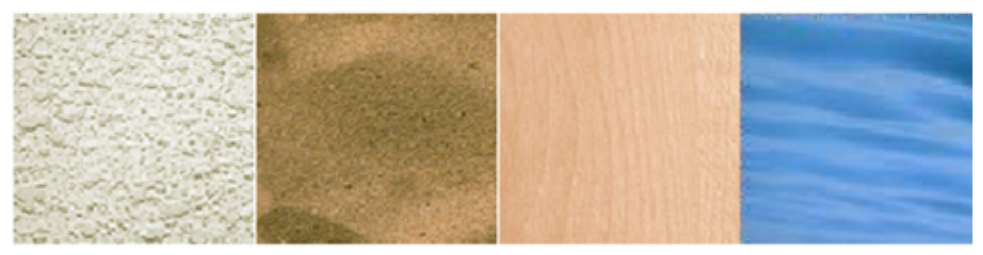
(a) parede
(b) areia
(c) madeira
(d) água

Figura 4.1: Exemplos de texturas homogêneas

Por existir uma gama extensa de texturas presentes na literatura (MIRMEHDI; XIE; SURI, 2009), optou-se em utilizar algumas que possuíssem certo grau de relevância para aplicações tanto na área da engenharia, como na da medicina.

Todavia, deve-se esclarecer que não faz parte do objetivo abordado nesta tese de doutorado, fornecer a análise completa de textura para uma determinada área/aplicação.

Convém salientar que o escopo principal aqui é explanar o processo descrito no capítulo anterior, bem como validá-lo através dos resultados práticos obtidos.

\subsection{Aplicação do Processo Proposto}

O processo é aplicado em três fases, sendo a primeira responsável pela definição do problema; a segunda pelo desenvolvimento e implementação da solução fornecida pela fase I; e a última, a fase de avaliação e validação. 
Nesta seção são descritos as considerações/premissas adotadas, suas respectivas justificativas e os resultados obtidos na aplicação de cada uma delas.

\subsubsection{FASE I - Definição do Problema}

Esta fase refere-se à utilização do Projeto Axiomático no contexto de domínios próximos, em que o desenvolvedor assume o papel do próprio cliente (especialista) no projeto. Assim, este se torna o responsável pela percepção/definição do problema, pelo estabelecimento das necessidades, desejos e restrições (explanação - seção 3.2.1).

Basicamente, esta fase é realizada neste trabalho em duas etapas: a primeira referente às definições anteriormente citadas; e a segunda, o estabelecimento/mapeamento top-down dos requisitos funcionais $\{\mathrm{FRs}\}$ e parâmetros de projeto $\{\mathrm{DPs}\}$, isto é, das etapas propriamente dita do Projeto Axiomático.

Entretanto, acredita-se que o sucesso da segunda etapa está fortemente vinculado a definição da primeira, ou seja, do levantamento cuidadoso (justificado) das necessidades/requisitos que o desenvolvedor deseja em um dado produto para solucionar uma determinada necessidade/problema por ele identificado.

A seguir apresentam-se tais etapas, onde se descrevem as premissas adotadas, as descrições das atividades realizadas e os resultados obtidos em cada uma delas.

\subsubsection{Etapa I - Domínio do Desenvolvedor}

Com base na compreensão das técnicas/métodos presentes na literatura para a análise e reconhecimento de textura (seção 2.2) e nas atividades do processo de projeto delineado para o domínio do desenvolvedor (seção 3.2.1), alguns critérios foram estabelecidos para sua realização. Estes por sua vez estão associados às atividades propostas à esta primeira etapa: aquisição/levantamento das necessidades e aquisição/levantamento das restrições, descritas no decorrer do texto respectivamente nesta ordem.

$\mathrm{Na}$ atividade do levantamento dos requisitos, o primeiro critério adotado referese a sua decomposição em categoria (geral) e subcategorias (específicas). Tal premissa foi adotada com a finalidade de proporcionar uma melhor compreensão no desenvolvimento do projeto, bem como no estabelecimento dos $\{$ FRs $\}$ e $\{$ DPs $\}$ - descrita posteriormente nesta seção.

A tabela 4.1 apresenta a organização da categoria e subcategorias dos requisitos para esta etapa e a sua correlação com as atividades anteriormente delineadas (capítulo 
$3)$.

Tabela 4.1: Correspondência com as atividades proposta (seção 3.2.1) e os grupos de requisitos estabelecidos para o domínio do desenvolvedor.

\begin{tabular}{l|c}
\hline Descrição da categoria e subcategorias & $\begin{array}{l}\text { Correspondência com as } \\
\text { atividades do método }\end{array}$ \\
\hline $\begin{array}{l}\text { 1. Produto/Sistema: requisitos ou atributos gerais almejados pelo } \\
\text { desenvolvedor com o intuito/objetivo de propor uma solução para } \\
\text { reduzir ou até mesmo eliminar o(s) possível (eis) problema(s) } \\
\text { encontrado(s)/identificado(s) no escopo do processo de análise em } \\
\text { questão. }\end{array}$ & 01 e 02 \\
\hline $\begin{array}{l}\text { 1.1 Requisitos de Entrada: levantamento das necessidades à entrada do } \\
\text { sistema. Refere-se às características que o desenvolvedor deve } \\
\text { ponderar/considerar à entrada, como exemplo, as propriedades de uma } \\
\text { imagem digital. }\end{array}$ & 01 e 03 \\
\hline $\begin{array}{l}\text { 1.2 Requisitos de Análise: estabelecimento dos requisitos para definição } \\
\text { da regra de análise a ser desenvolvida. Neste caso, baseia-se na extração } \\
\text { das características de textura presentes nos métodos ou técnicas } \\
\text { descritas neste trabalho, bem como nas definições das suas próprias } \\
\text { propriedades. }\end{array}$ & 01 e 03 \\
$\begin{array}{l}\text { 1.3 Requisitos de Saida: levantamento dos requisitos de saída do } \\
\text { Produto/Sistema a ser fornecida na fase posterior - II. }\end{array}$ & 01 e 03 \\
\hline
\end{tabular}

O segundo critério foi à adoção de uma nomenclatura/sigla para identificar os requisitos obtidos. É de grande relevância não só para sua organização no projeto, como no auxilio ao terceiro critério - indicação/estabelecimento da existência de uma relação/vínculo (qualquer) entre dois ou mais requisitos através de suas conexões: $(\rightarrow)$ entrada e saída $(\downarrow)$. Um exemplo hipotético entre quatro requisitos pode ser observado na tabela 4.2 .

Tabela 4.2: Relação/vínculo hipotético entre três requisitos quaisquer.

\begin{tabular}{|c|c|c|c|}
\hline Identificação & Requisito & $(\rightarrow)$ Entrada & Saida $(\downarrow)$ \\
\hline 0001 & A & & 0002 \\
\hline 0002 & B & 0001 & 0004 \\
\hline 0003 & C & & \\
\hline 0004 & D & 0002 & \\
\hline
\end{tabular}

O objetivo da premissa adotada é mapear a existência de relações entre todos os requisitos do projeto, mesmo numa fase tão inicial. Neste caso isso foi possível por causa da ênfase que a abordagem dos domínios próximos oferece. Ou seja, ao invés dos requisitos serem expressos de forma difusa pelo cliente (normalmente com idéias confusas e truncadas, etc), eles são estabelecidas pelo próprio desenvolvedor, que os estrutura com base na interpretação dos conhecimentos explícitos. 
Tal mapeamento contribui não só à compreensão das ações tomadas/realizadas em etapas posteriores do processo, bem como no auxílio ao desenvolvimento de uma documentação clara, objetiva e útil para rastrear os vínculos existentes (como um todo) no projeto.

O quarto e, último critério, desta atividade foi o acréscimo de uma nota adicional de informação para auxiliar a compreensão do requisito, bem como a razão, isto é, a sua justificativa.

Em vista da explanação acima descrita, apresenta-se o levantamento dos requisitos ${ }^{1}$ realizados nesta etapa através da tabela $4.3,4.4,4.5,4.6$.

Deve-se salientar que o levantamento mencionado descreve/indica as necessidades ou características que o sistema deve conter e, não fornecer uma solução específica para o problema. Esta será definida e desenvolvida no decorrer da seção 4.3.1.2.

Com relação ao campo denominado "restrição associada", presente nas tabelas acima citadas, será explanada a sua função posteriormente, pois esta faz parte do levantamento das restrições.

A próxima atividade a ser apresentada nesta seção refere-se à aquisição/ levantamento das restrições - item 4 do processo estabelecido (seção 3.2.1). Tem como finalidade identificar as limitações que ambos os domínios, tanto da aplicação (textura), como complementar (redes neurais), impõem a solução a ser desenvolvida/implementada no decorrer do projeto. Para tal, utilizam-se os mesmos critérios (adaptados a esse contexto) explanados na atividade anterior.

Assim, com base no primeiro deles, o levantamento das restrições foi dividido em duas categorias: a primeira, referente ao domínio da textura e, a segunda, ao domínio de redes neurais (ambas possuem características peculiares que limitam/restringem o universo de busca/atuação por uma determinada solução). Este critério tem a função de melhorar a compreensão do problema, bem como auxiliar o desenvolvedor na definição dos $\{$ FRs $\}$ e $\{$ DPs $\}$.

Com relação ao segundo, também foi adotada uma nomenclatura/sigla para cada uma das restrições. Já o terceiro, a relação de vínculo, $(\rightarrow)$ entrada e saída $(\downarrow)$, também foi mantida, pois o mapeamento entre elas são decisivas no estabelecimento e implementação da solução (Fase I e II, respectivamente do processo delineado). O quarto, nota e justificativa, também auxiliam a uma maior compreensão no estabeleci-

\footnotetext{
${ }^{1}$ Segundo David (1993), requisitos podem ser definidos como uma coleção de sentenças que devem descrever de modo claro, sem ambiguidades, conciso e consistente todos os aspectos significativos de um produto ou sistema. Devem conter informações suficientes para permitir que a equipe de projeto construa o sistema que satisfaça os clientes, e nada mais.
} 


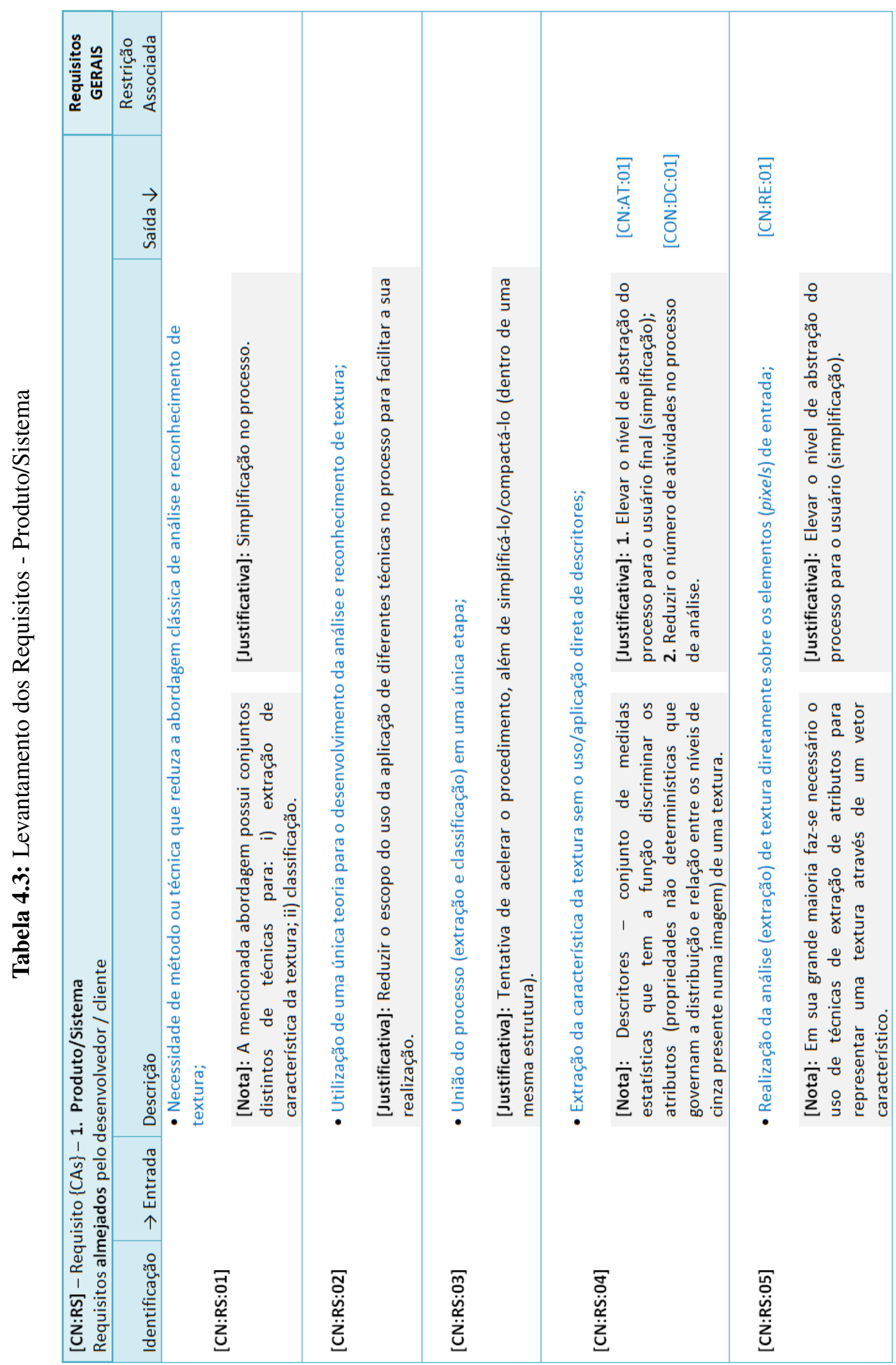




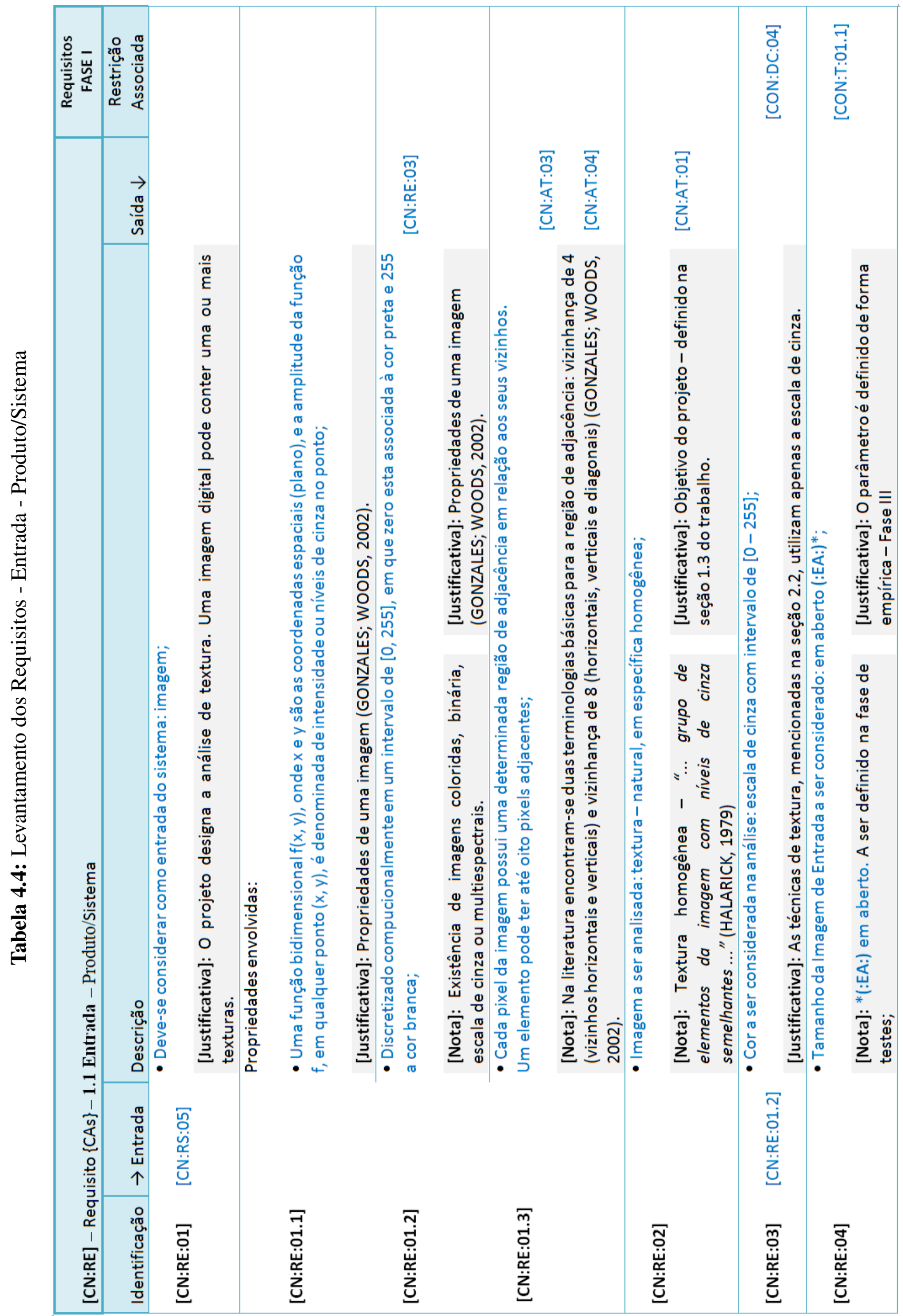




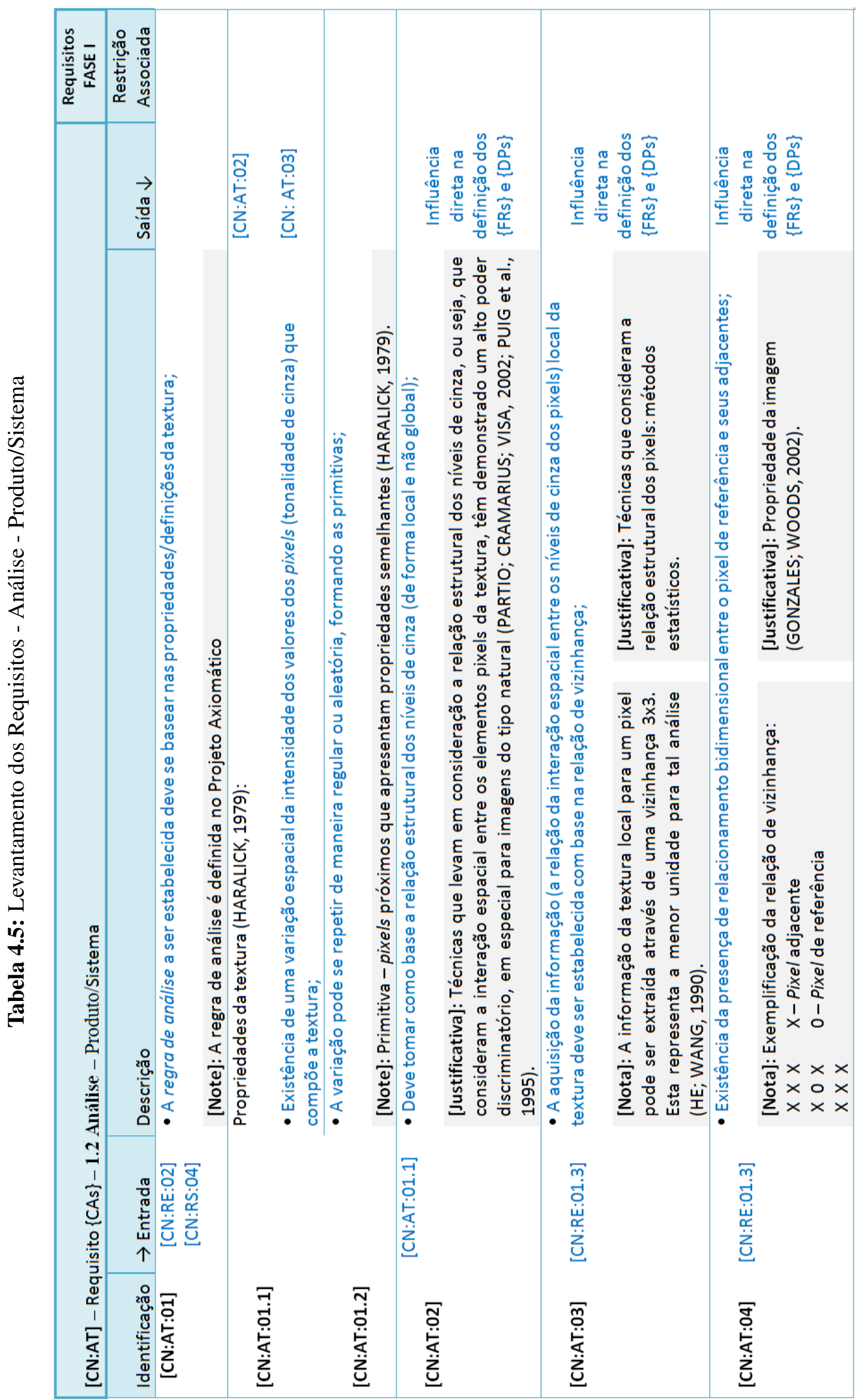




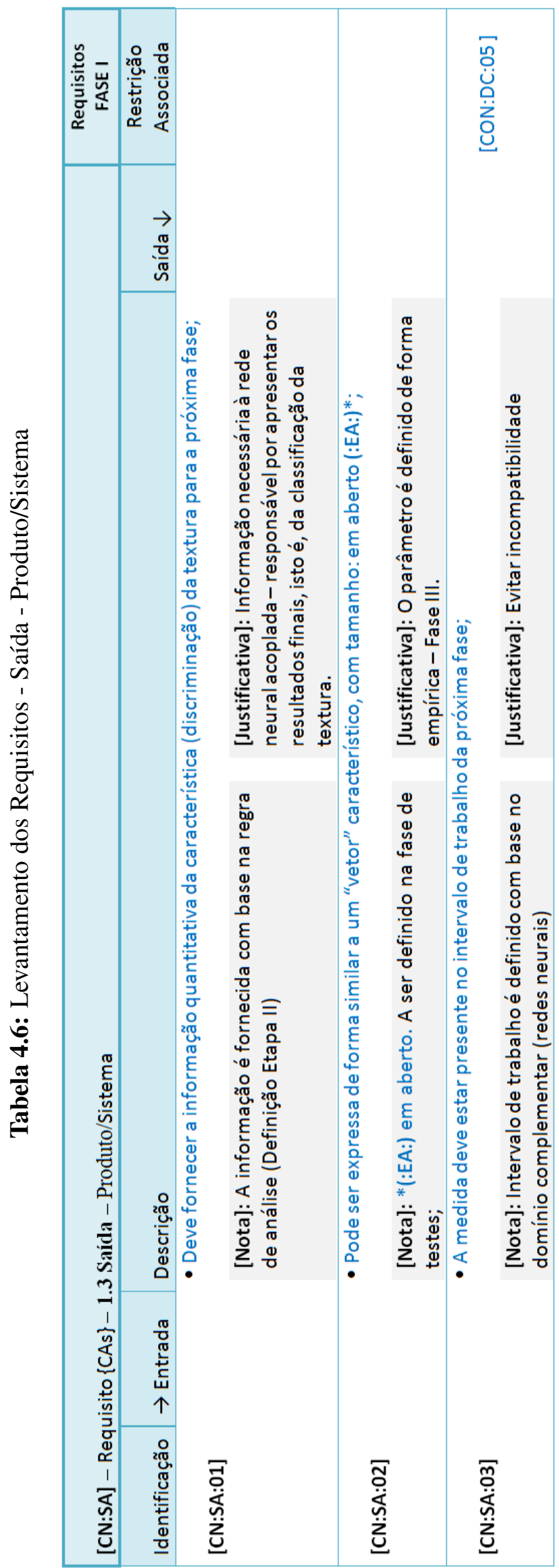


mento das restrições.

Entretanto, um quinto critério foi estabelecido para a atividade em questão. Referese ao campo denominado de "restrição associada", presentes nas tabelas 4.3, 4.4, 4.5, 4.6, e, que até o presente momento não foi explanado no texto. A função deste campo é permitir a identificação/mapeamento de algum vínculo existente entre um requisito e restrição(ões). Isto é, auxiliar o desenvolvedor a identificar quais as limitações que o domínio da aplicação ou complementar infere diretamente na necessidade. Fato de extrema relevância porque impacta diretamente na definição da solução.

Assim, com base no terceiro e quinto critério, o mapeamento nesta atividade pode ser de dois tipos: $\{$ restrição-restrição $\}$ e $\{$ requisito-restrição_associada $\}$.

No primeiro caso, uma restrição pode surgir em decorrência de outra restrição, enquanto que no segundo, um requisito sofre uma limitação dos domínios em questão (Textura e Rede Neurais). A figura 4.2 exemplifica ambos os relacionamentos de forma hipotética.

\begin{tabular}{|c|c|c|c|}
\hline Identificação & $(\rightarrow)$ Entrada & Descrição & Saída $(\downarrow)$ \\
\hline $001 \mathrm{R}$ & & $\mathrm{A}$ & \\
\hline $002 R^{*}$ & & $\mathrm{~B}$ & $003 R$ \\
\hline $003 \mathrm{R}$ & $002 R$ & $\mathrm{C}$ & \\
\hline $004 \mathrm{R}$ & & $\mathrm{D}$ & \\
\hline \multicolumn{4}{|c|}{ *indica a existência de um vínculo com um requisito }
\end{tabular}

(a) Lista de restrições

\begin{tabular}{|c|c|c|c|c|}
\hline Identificação & $(\rightarrow)$ Entrada & Descrição & Saída $(\downarrow)$ & Restrição Associada \\
\hline $001 \mathrm{~N}$ & & $\mathrm{~A}$ & $002 \mathrm{~N}$ & \\
\hline $002 \mathrm{~N}$ & $001 N$ & $\mathrm{~B}$ & & $002 R^{*}$ \\
\hline $003 \mathrm{~N}$ & \multicolumn{5}{|c|}{ *indica a existência de um vínculo com uma restrição }
\end{tabular}

(b) Lista de requisitos/necessidades

Figura 4.2: Relação/vínculo hipotético entre $\{$ restrição-restrição $\}$ e requisitos $\{$ requisito-restrição_associada $\}$.

Com o desenvolver do trabalho, também se observou a existência de outra relação/ vínculo que pode acontecer - um caso particular. Refere-se aos requisitos gerais (tabela 4.3) que expressam o desejo do desenvolvedor em relação ao Produto/Sistema a ser desenvolvido. Esse pode influenciar diretamente à definição de uma restrição, por exemplo: na análise de textura o uso de descritores tem a função de discriminar os atributos da textura. Sem o seu uso direto, a técnica a ser desenvolvida tem por obrigação encontrar sozinha a presença de regularidade existente no padrão de entrada 
para definição da sua característica. Isto impacta diretamente no domínio complementar e, por sua vez, influencia outras restrições (e assim sucessivamente).

A figura 4.3 exemplifica a forma usada para vincular tal relação $\{$ saída $(\downarrow)$ - restrição $\}$.

\begin{tabular}{|c|c|c|c|c|}
\hline Identificação & $(\rightarrow)$ Entrada & Descrição & Saída $(\downarrow)$ & Restrição Associada \\
\hline $001 \mathrm{~N}$ & & $\mathrm{~A}$ & $002 N$ & \\
\hline $002 \mathrm{~N}$ & $001 N$ & $\mathrm{~B}$ & & \\
\hline $003 \mathrm{~N}$ & & $\mathrm{C}$ & $002 R^{*}$ & \\
\hline \multicolumn{5}{|c|}{ *indica a existência de impacto sobre uma restrição }
\end{tabular}

(a) Lista de requisitos

\begin{tabular}{|c|c|c|c|}
\hline Identificação & $(\rightarrow)$ Entrada & Descrição & Saída $(\downarrow)$ \\
\hline $001 \mathrm{R}$ & & $\mathrm{A}$ & $003 R$ \\
\hline $002 \mathrm{R}$ & $003 N^{*}$ & $\mathrm{~B}$ & $\mathrm{C}$ \\
\hline $003 \mathrm{R}$ & $002 R$ & *indica a existência de influência sobre a restrição
\end{tabular}

(b) Lista de restrições

Figura 4.3: Relação/vínculo hipotético entre $\{$ saída $(\downarrow)$ - restrição $\}$

Em vista das explanações acima descritas, apresenta-se nas tabelas 4.7 e 4.8 o levantamento das restrições com base nos respectivos domínios da aplicação e complementar. Entretanto, deve-se salientar que no domínio complementar, as restrições baseiam-se no modelo matemático do neurônio estabelecido (seção 3.2.2) para o desenvolvimento do projeto.

De posse dos requisitos do domínio do desenvolvedor e do levantamento das restrições, a próxima atividade a ser apresentada refere-se ao estabelecimento de uma definição/solução de parte (mencionado na seção 3.2.2) do Produto/Sistema desejado. Esta por sua vez é realizada através do mapeamento entre os requisitos funcionais e parâmetros do projeto.

Com a finalidade de auxiliar a compreensão das atividades até aqui apresentadas e a demais na seção seguinte, ilustra-se a figura 4.4 . 


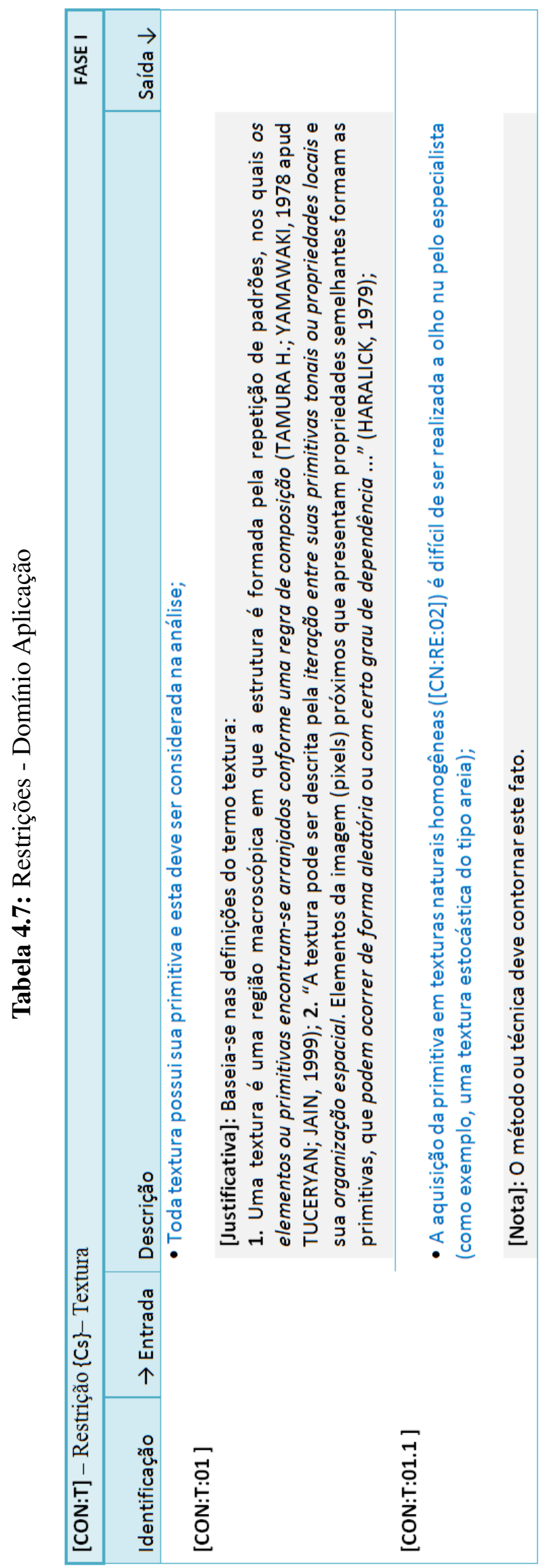




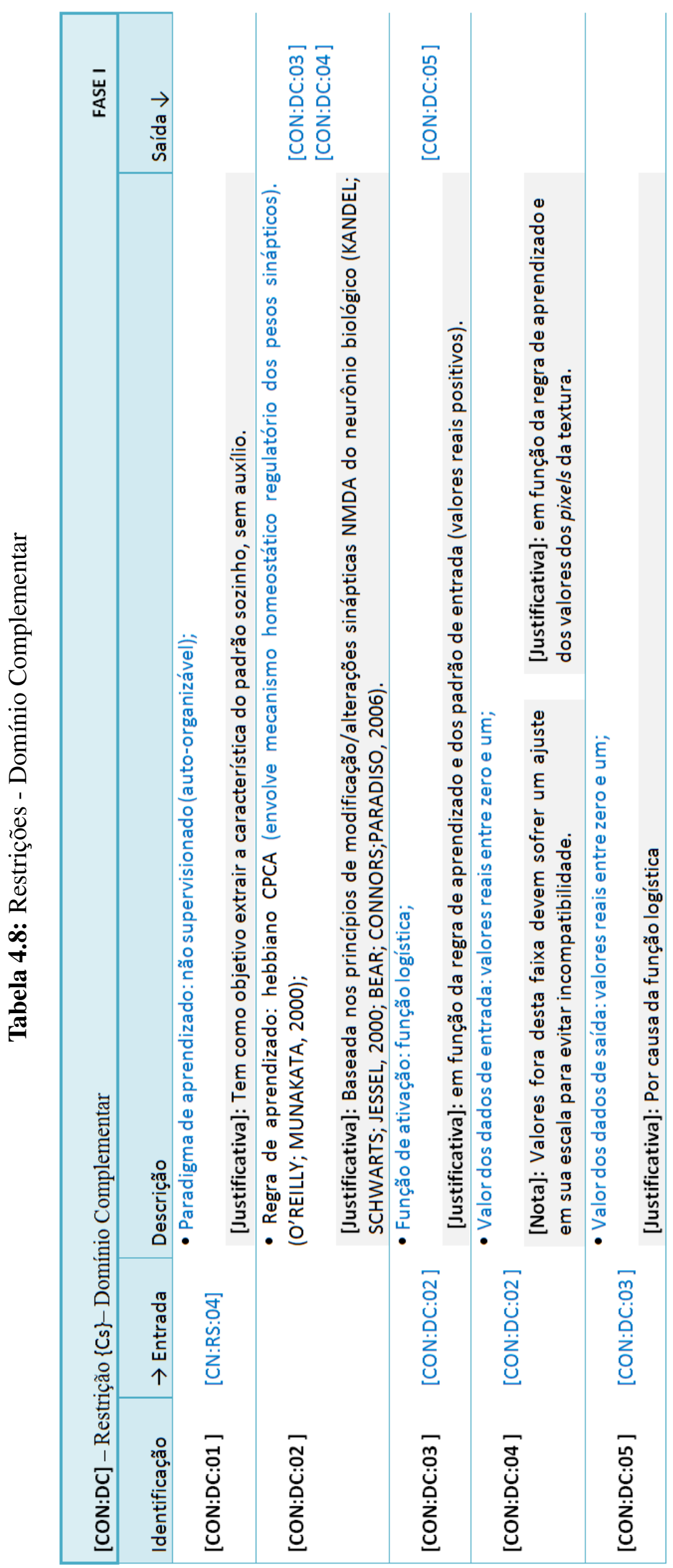


1 Fase

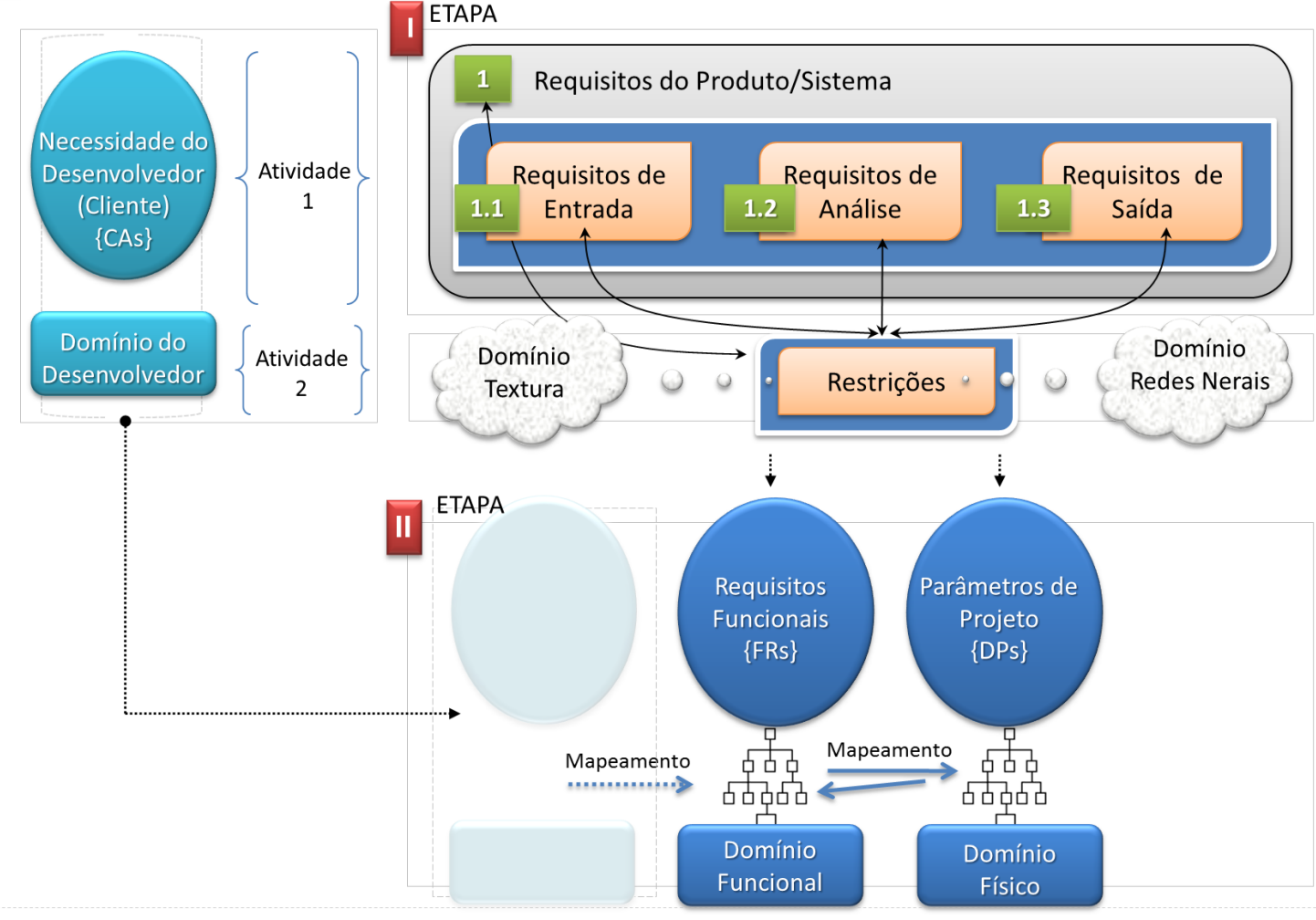

Figura 4.4: Atividades envolvidas na FASE I - Definição do Problema

Na próxima seção apresenta-se a segunda etapa corresponde à última atividade da Fase I.

\subsubsection{Etapa II - Domínio Funcional e Físico}

Os domínios funcional e o físico representam respectivamente os requisitos funcionais (ações a serem realizadas pelo produto a ser desenvolvido) e os parâmetros do projeto (os elementos de solução). O mapeamento entre esses domínios é uma atividade desenvolvida através da decomposição cima para baixo (top-down) e em "ziguezague" (seção 2.1.2), em que se pergunta ao domínio da esquerda "o que se deseja realizar" e, ao domínio da direita, "como alcançar tal objetivo/propósito".

Todavia, para se obter uma definição formal da solução do projeto, este processo deve respeitar os princípios do axioma (seção 2.1.3 e 2.1.4). Isto é, princípios que auxiliam o desenvolvedor/projetista a descartar idéias ditas ruins ou inadequadas no decorrer da definição da solução/mapeamento. É dependente da base de conhecimento e do processo inventivo do projetista/desenvolvedor e pode fornecer "inúmeras" soluções criativas que satisfaçam os mesmos requisitos.

Neste trabalho, em específico, deve-se salientar que a solução a ser fornecida é fortemente dependente do domínio complementar. Domínio que não possui regras 
formais bem estabelecidas e, que em sua grande maioria, a solução "pré-concebida" (com base na experiência do projetista) é realizada de forma empírica.

Em vista do fato acima mencionado (e descrito em capítulos anteriores), a solução a ser delineada nesta fase refere-se ao estabelecimento de uma regra de análise (à extração da característica da textura) a ser implementada no domínio complementar. Regra esta que será aplicada, testada, avaliada e validada no decorrer do trabalho e servirá de base (os resultados obtidos) para validar o processo aqui proposto. Com base nos resultados descritos na seção anterior, apresenta-se na tabela 4.9 a decomposição dos domínios funcional (“o que") e físico (“como"), bem como o link existente entre os $\{$ FRs $\}$ (requisitos funcionais) $\{\mathrm{CAs}\}$ (necessidades do desenvolvedor) e $\{$ DPs $\}$ (parâmetros do projeto) $\{\mathrm{Cs}\}$ (restrições). Já o relacionamento dos $\{\mathrm{FRs}\}$ e $\{\mathrm{DPs}\}$ é apresentada através da matriz de projeto na figura 4.5 .

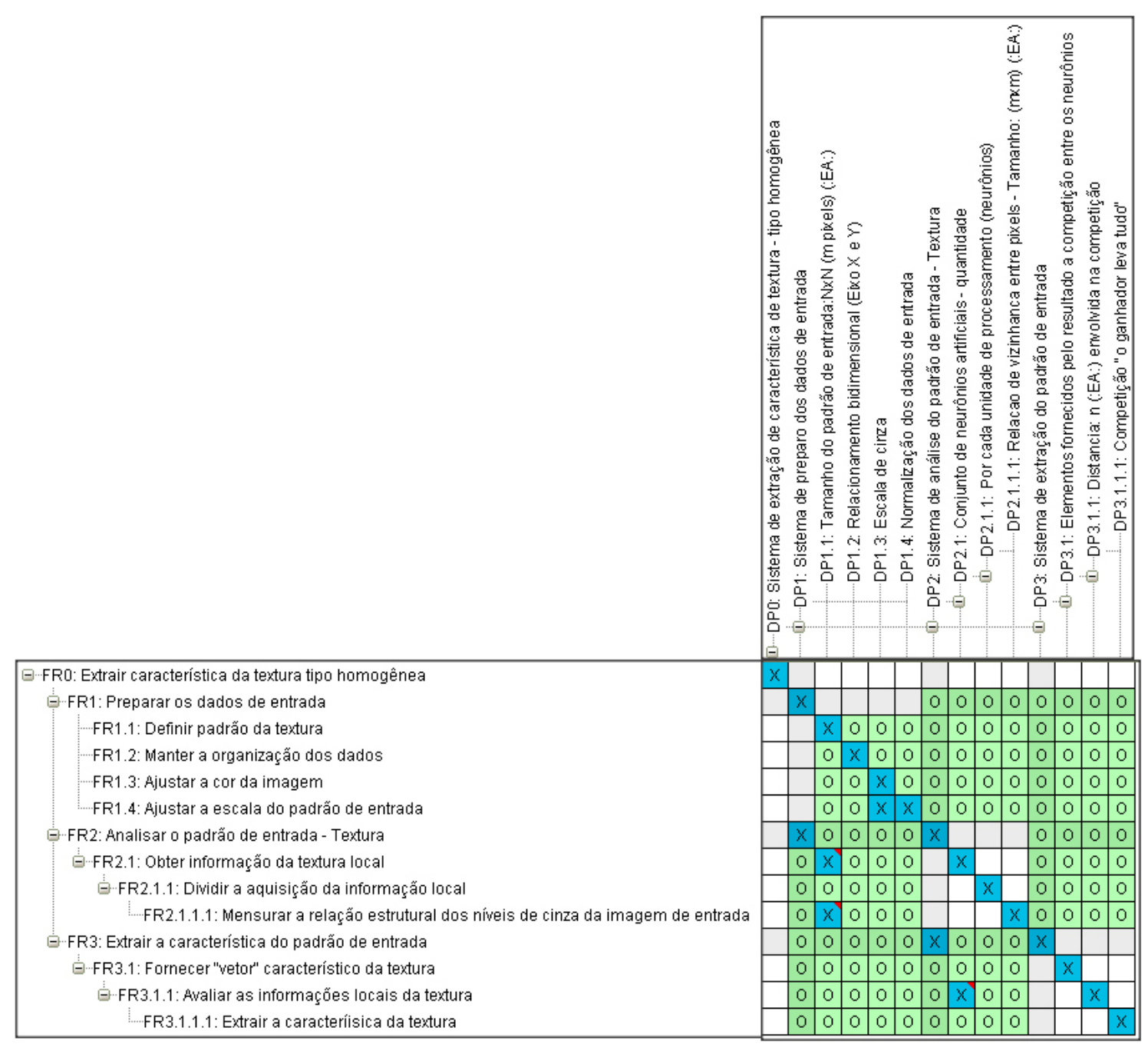

Figura 4.5: Matriz de Projeto da solução (regra de análise à extração de característica a ser desempenhada pelo domínio complementar.)

Como se pode observar na matriz de projeto (Fig. 4.5), trata-se de uma matriz tri- 


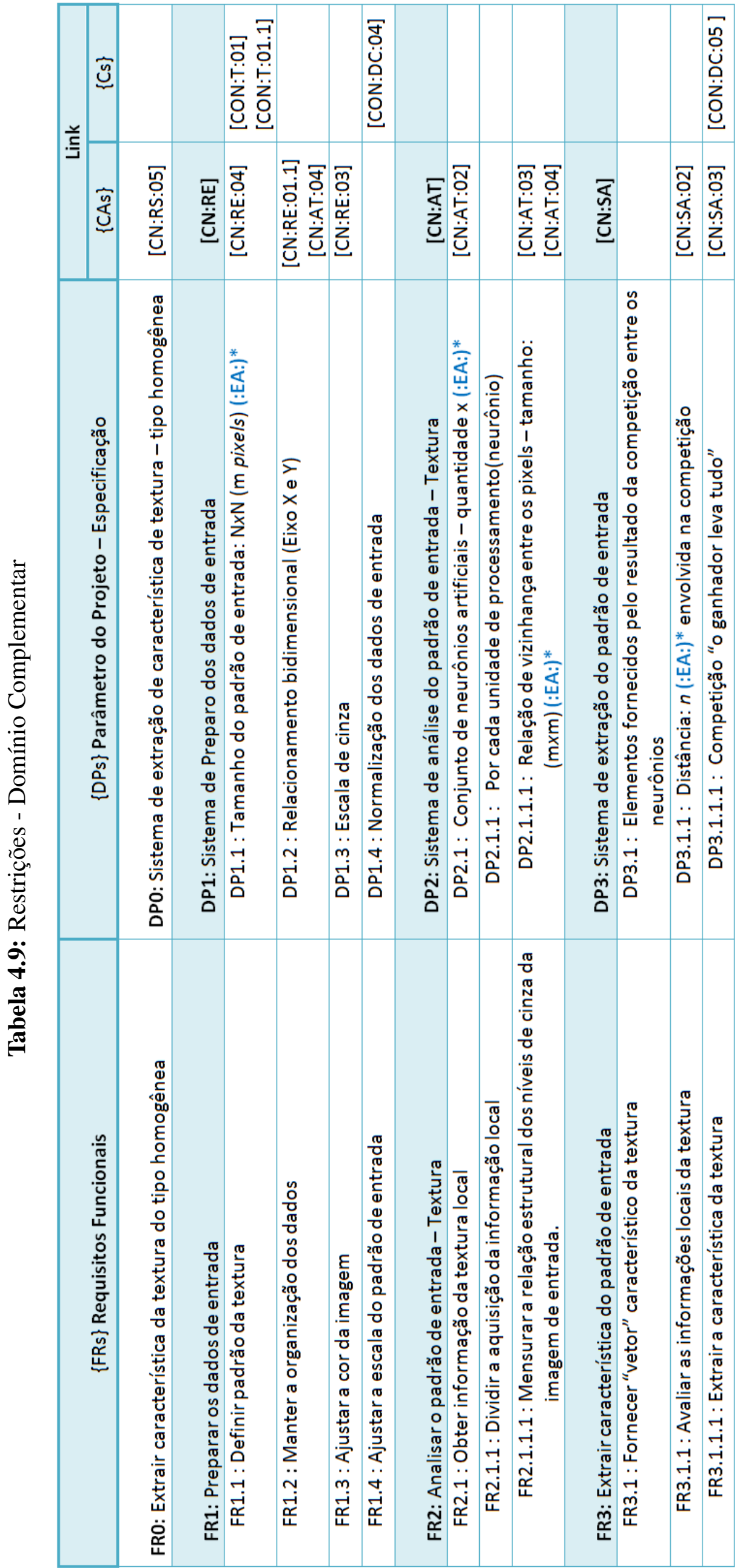


angular, isto é, um projeto do tipo semi-acoplado (decoupled), em que a independência dos $\{$ FRs $\}$ somente é atendida se os $\{$ DPs $\}$ estiverem numa determinada sequiência. Por exemplo: \{FR1.4:Ajustar a escala do padrão de entrada\} só pode ser realizado após o \{FR1.3:Ajustar a cor da imagem $\}$.

Entretanto, neste trabalho deve-se salientar algumas observações não só em relação à existência de dependência entre alguns $\{$ DPs $\}$, bem como os parâmetros sinalizados na tabela 4.9 pela sigla :EA: (em aberto).

O parâmetro $\{$ DP1.1:Tamanho do padrão de entrada:NxN (m pixels) $\}$, por exemplo, não tem o seu tamanho $N x N$ definido nesta fase por causa da restrição imposta pelo domínio da aplicação, indicado por: $\{[\mathrm{CON}: \mathrm{T}: 01]$ : Toda textura possui sua primitiva e esta deve ser considerada na análise $\}$ e $\{[\mathrm{CON}: \mathrm{T}: 01.1]$ : A aquisição da primitiva em texturas naturais homogêneas é difícil de ser realizada a olho nu pelo especialista (como exemplo, uma textura estocástica do tipo areia)\} (tabelas 4.7 e 4.9). Como o tamanho do padrão de entrada $N x N$ deve ser suficiente para conter a primitiva e, esta é difícil de ser estabelecida a olho nu, adota-se a premissa de especificar tal valor através de avaliações empíricas na Fase III. Esta por sua vez fornecerá indícios práticos do melhor tamanho a ser adotado à análise de texturas naturais homogêneas.

Já em relação aos \{DP2.1: Conjunto de neurônios artificiais-quantidade $\mathrm{x}\}$ e $\{$ DP2.1.1.1:Relação de vizinhança entre os pixels-tamanho: (mxm)\}, correspondente, respectivamente, aos requisitos funcionais $\{F R 2.1:$ obter informação da textura local $\}$ e $\{$ FR2.1.1.1: Mensurar a relação estrutural dos níveis de cinza da imagem de entrada\}, são parâmetros que também não podem ser definidos nesta fase de projeto porque ambos são dependentes do $\{\mathrm{DP} 1.1\}$, isto é, do tamanho do padrão de entrada, discutido anteriormente.

Por fim, o quarto e último, \{FR3.1.1:Avaliar as informações locais da textura $\}$, correspondente a \{DP3.1.1: Distância:n envolvida na competição\}, é dependente do parâmetro $\{\mathrm{DP} 2.1\}$ e este por sua vez do $\{\mathrm{DP} 1.1\}$, o que dificulta ainda mais o seu estabelecimento.

Logo, adota-se como premissa a avaliação de forma empírica desses parâmetros na fase III. Já a relação existente de dependências entre eles, esta é apresentada na própria matriz de projeto, como ilustrada na figura 4.5.

A próxima seção apresenta a fase de desenvolvimento e implementação da proposta. 


\subsubsection{FASE II - Desenvolvimento e Implementação}

A fase II tem como proposta o desenvolvimento e implementação da solução do projeto fornecido pela fase I - regra de análise à extração da característica de uma textura a ser realizada por uma rede neural artificial (RNA), bem como o acoplamento a uma segunda RNA para o reconhecimento/classificação da textura. Em vista disto, a explanação desta seção foi dividida em duas, sendo a primeira correspondente ao desenvolvimento da rede para extração da característica e, a segunda, ao reconhecimento/ classificação.

\section{I - Extração da Característica}

O desenvolvimento desta atividade baseia-se na resposta da matriz de projeto (Fig. 4.5). Matriz esta que através da sua representação em diagrama de fluxo (explanado na seção 2.1.5), auxilia a compreensão de como a informação deve fluir sobre a regra proposta, apresentado na figura 4.6.

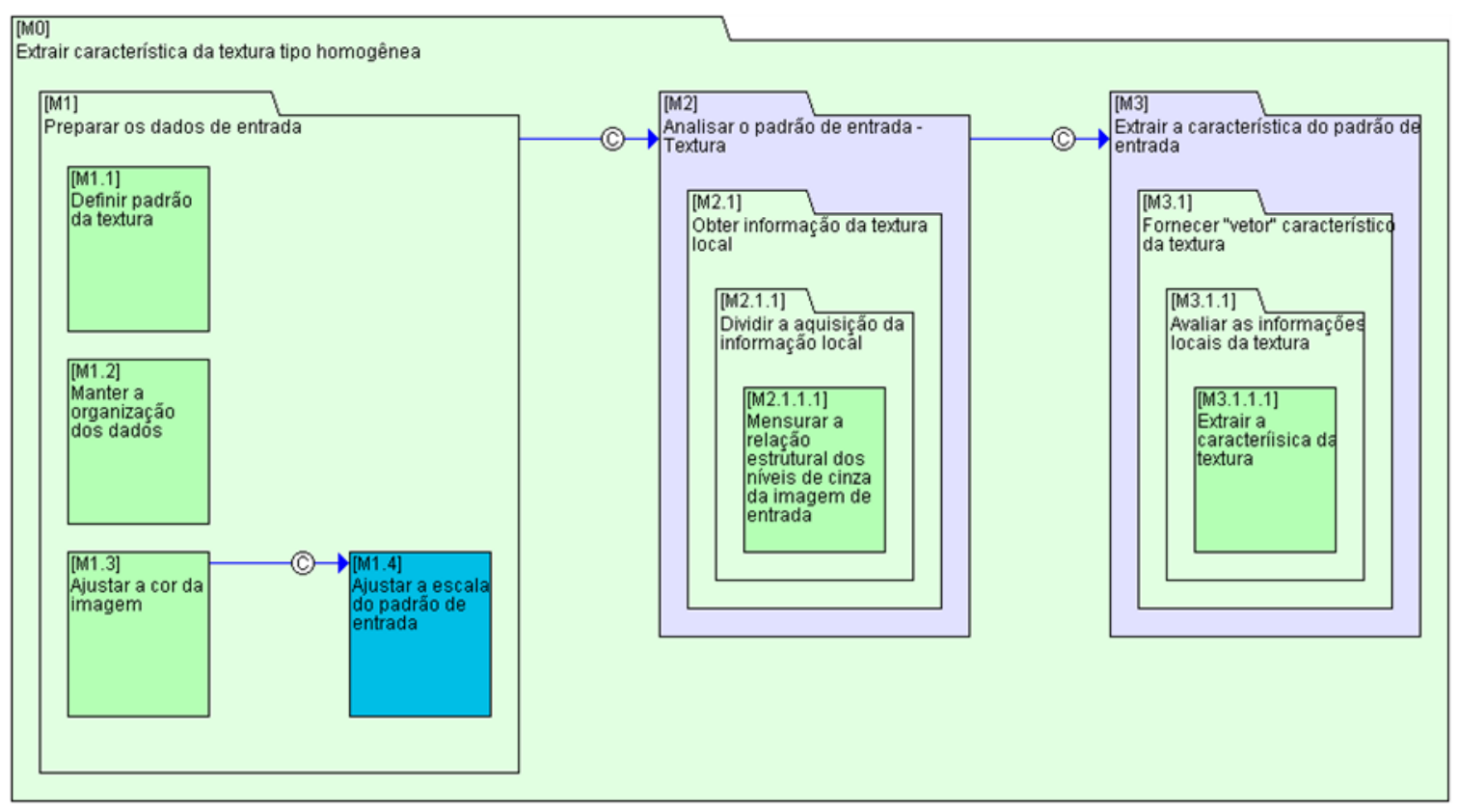

Figura 4.6: Diagrama de fluxo da matriz de projeto fornecida pela Fase I

Com base nas informações do fluxo e dos parâmetros $\{$ DPs $\}$, descrita na seção anterior, o diagrama é interpretado e desenvolvido no domínio de redes neurais, de acordo com a explanação a seguir. O parâmetro do projeto $\{$ DP1: Sistema de Preparo dos dados de entrada\} (tabela 4.9) indica o que deve se considerar em relação à camada de entrada da rede neural. Neste caso, um tamanho $N x N\{$ DP1.1 $\}$ em que se preserva 
a relação espacial bi-dimencional dos dados de entrada $\{$ DP1.2 $\}$ para efetuar a análise estrutural dos elementos que compõe a textura. Entretanto, esses dados devem ser convertidos primeiro a escala de cinza e, posteriormente, serem normalizados $\{$ DP1.4 $\}$, já que numa imagem, a tonalidade dos pixels pode variar num intervalo de 0 a 255 .

Já em relação ao parâmetro $\{$ DP2: Sistema de análise do padrão de entrada - Textura\}, este representa a formação da primeira camada neural. Ou seja, composta por um conjunto de neurônios artificiais $\{$ DP2.1\} responsáveis por obter a informação da textura local. Tal informação é obtida em parte por cada unidade de processamento/neurônio $\{\mathrm{DP} 2.1 .1\}$ que tem como função analisar a relação de vizinhança $(M x M)$ entre os pixels presentes na imagem/textura de entrada $\{\mathrm{DP} 2.1 .1 .1\}$. Ou seja, cada unidade analisa uma pequena região da textura.

Em virtude de tal configuração, a conexão presente entre os neurônios da $1^{o}$ camada neural e a camada de entrada (pixels) apresenta-se parcialmente conectada, delimitada pelo tamanho MxM. Por último, o parâmetro \{DP3: Sistema de extração do padrão de entrada\} representa a extração e, consequentemente, o fornecimento da descrição da característica da textura pelos neurônios pertencentes a $1^{o}$ camada neural.

A descrição é fornecida através da competição entre as unidades de processamento \{DP3.1\} e é realizada por uma distância $n$ entre seus vizinhos próximos $\{$ DP3.1.1\}. Tal parâmetro fornece a região em que os neurônios vão disputar entre si e, aquele que tiver maior vantagem em termos de valor será o ganhador da competição $\{$ DP3.1.1.1 $\}$ (“o ganhador leva tudo", segundo (HAYKIN, 1999)). Neste trabalho essa competição é denominada de regional.

Desta forma, o resultado final é apresentado por vários neurônios ganhadores que exprimem a característica da textura e pode ser representado, por exemplo, num vetor. A figura 4.7 ilustra graficamente a explanação acima descrita. 


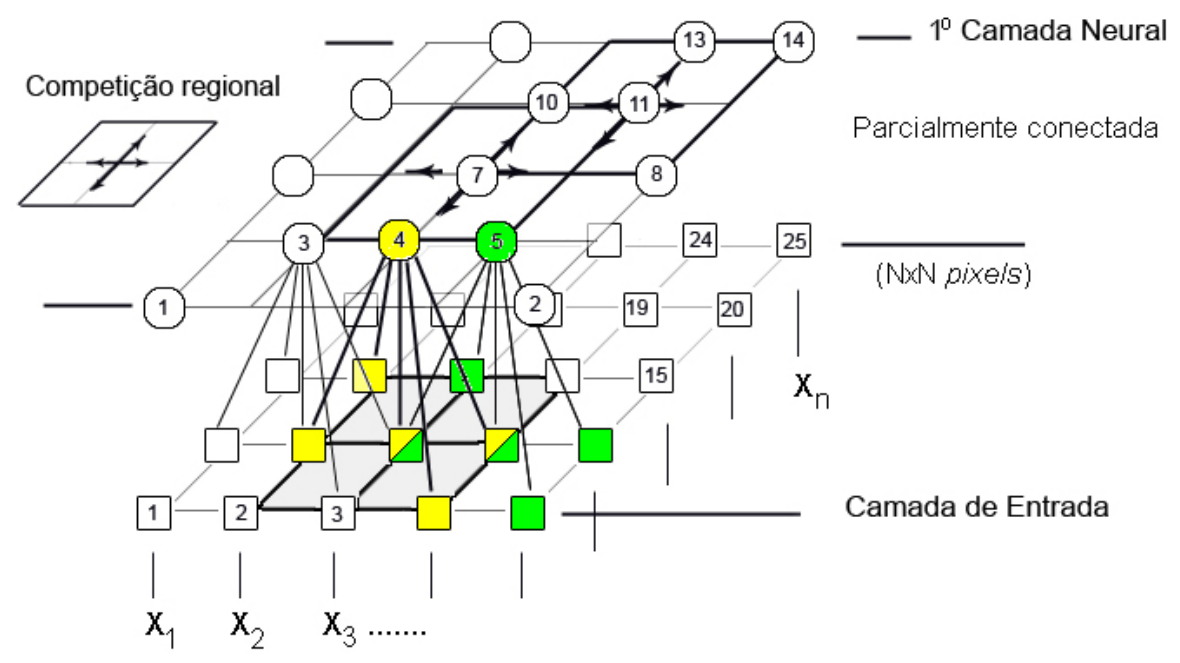

Figura 4.7: Representação em Rede Neural da solução proposta pela Fase I.

\section{II - Reconhecimento/Classificação}

Esta atividade refere-se à definição da segunda parte da RNA para a etapa do reconhecimento/classificação.

É composta de duas camadas, em que a primeira recebe os dados de entrada dos neurônios da atividade I, enquanto que a segunda, é responsável por classificar o padrão de entrada. Ambas são totalmente conectadas e empregam a competição global em que "o ganhador leva tudo". Já a quantidade de neurônios das camadas é definida respectivamente, de forma empírica e com base no número de classes desejadas. Diferentemente da parte I - Extração da Característica, que emprega um aprendizado não supervisionado, a parte II - Reconhecimento/Classificação utiliza-se do supervisionado ("auxílio de um professor"), muito embora a regra usada em todo o conjunto seja uma só, descrita na seção 3.2.2.

A figura 4.8 apresenta a rede neural artificial completa à análise (extração da característica) e reconhecimento/classificação de textura proposta para o estudo de caso.

Para o treinamento desta RNA propõe-se a sua realização em uma única fase de aprendizado e com o critério de parada baseado no número de iterações.

A sua construção é dependente de alguns parâmetros, sendo eles: tamanho do padrão de entrada $N x N$; quantidade de neurônios na primeira camada neural; determinação da relação de vizinhança $M x M$ (número de pixels que cada neurônio da $1^{o}$ camada é responsável em analisar a sua relação estrutural); distância $n$ (parâmetro que define as regiões de competição entre os neurônios); e o número de neurônios da segunda 


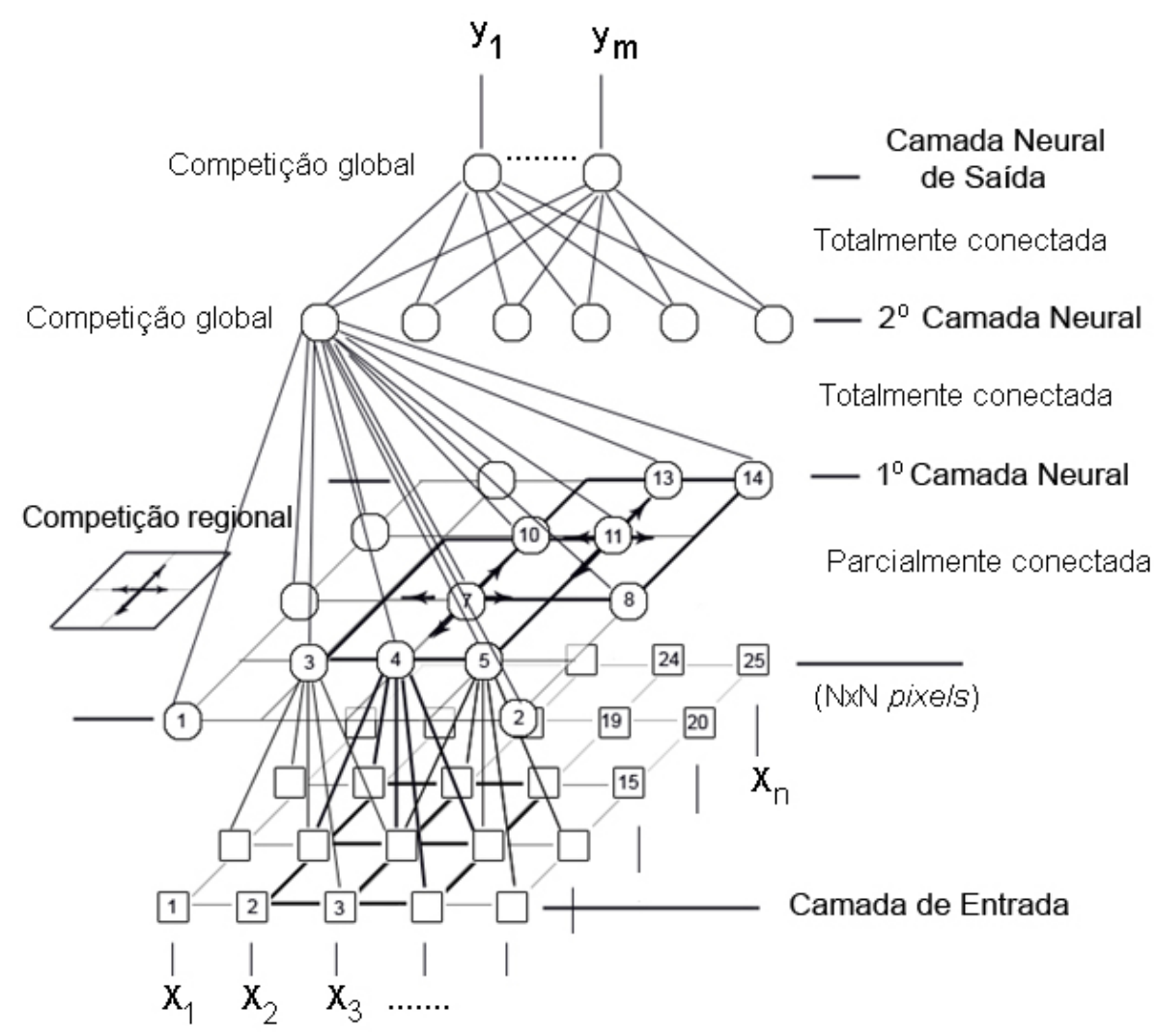

Figura 4.8: Arquitetura da rede neural proposta para a análise e reconhecimento de textura.

e da camada de saída. Todavia, opta-se por apresenta-los na seção 4.3.3 - Avaliação e Validação dos resultados.

Em relação à camada neural de saída e seu aprendizado (supervisionado) para distinguir as diferentes classes de texturas a serem apresentadas a RNA, a seguinte premissa é adotada: a adição de neurônios a cada unidade de processamento de saída, ativo ou não (com base na seqüência de padrões a ser apresentada), com o objetivo de auxiliar a RNA a ajustar seus pesos sinápticos em função da classe pertencente a textura.

Como a formulação matemática do neurônio artificial e da regra de aprendizado estabelecida para o mesmo foram descritas na seção 3.2.2, apresenta-se abaixo o algoritmo em pseudocódigo da fase de treinamento da RNA (Fig. 4.9).

A próxima seção mostra os resultados obtidos na fase de simulação.

\subsubsection{FASE III - Avaliação e Validação}

Sucintamente, esta fase tem como objetivo verificar o funcionamento/desempenho da RNA proposta com base nos resultados oriundos da fase I e II. Também são defini- 


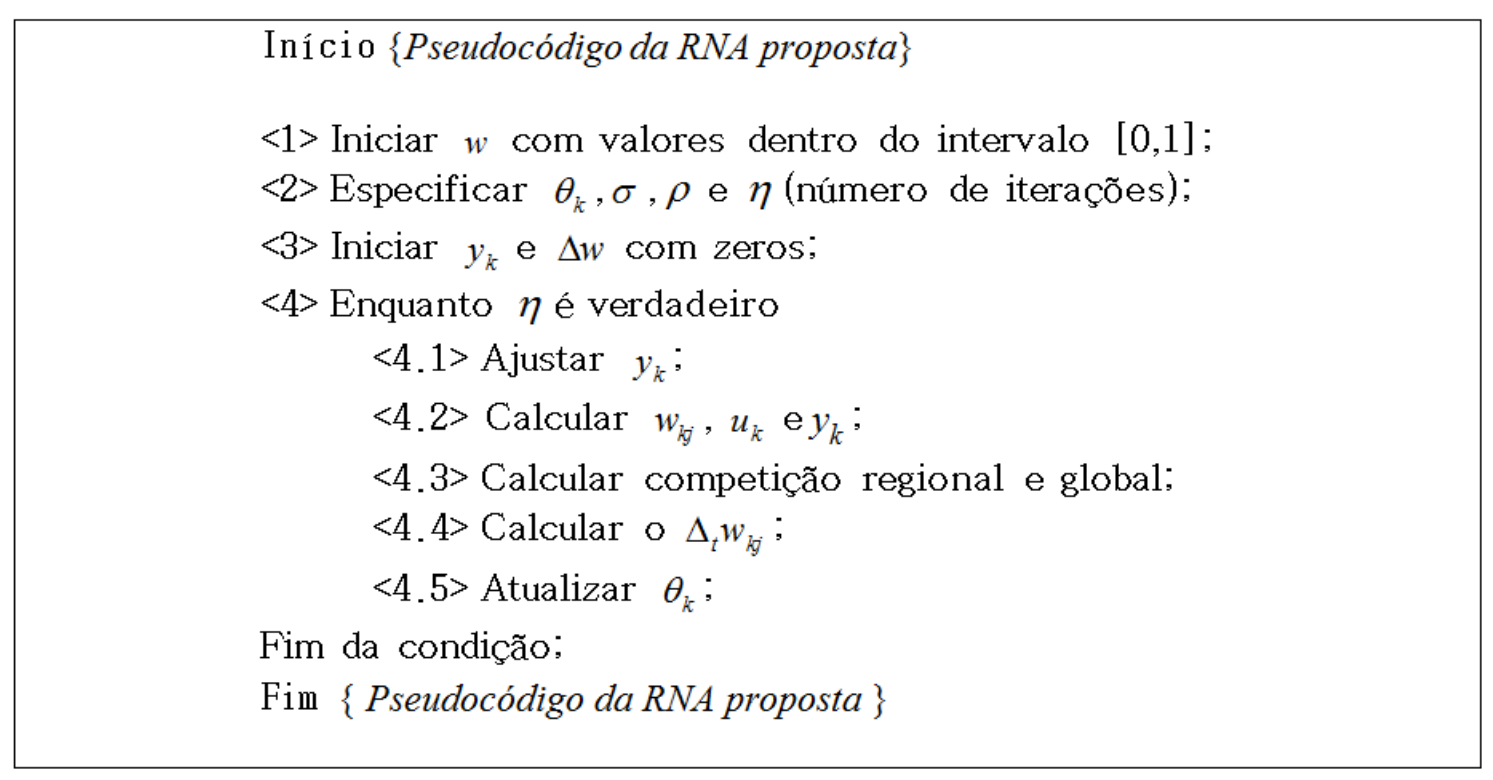

Figura 4.9: Pseudocódigo da RNA proposta

dos os parâmetros em aberto, mencionados nas seções anteriores, uma vez que são fortemente dependentes da avaliação dos resultados prático-experimentais.

Com a proposta de melhor elucidar tais resultados, opta-se nesta seção em apresentar a classificação das texturas, através do uso de segmentação. Ou seja, verificar se numa imagem digital, composta por duas texturas homogêneas, a RNA treinada identifica/particiona as respectivas regiões que a compõe. Para tal, utilizam-se dois tipos de texturas: sintética e natural, em que a primeira auxilia os primeiros testes realizados na RNA, enquanto que a segunda apresenta algumas (possíveis) aplicações práticas do domínio da engenharia e medicina. Todavia, deve-se salientar que os exemplos utilizados aqui nesta seção têm como escopo e foco principal a verificação do funcionamento da RNA e, conseqüentemente validação dos $\{$ FRs $\},\{$ DPs $\}$ e o processo aqui estabelecido.

A implementação e a obtenção dos resultados/simulações foi realizada com o auxílio da ferramenta computacional matemática (comercial) de prototipagem rápida, MATLAB 2011 a , versão Linux/MacOsx. Para a criação e manipulação de algumas texturas homogêneas (utilizadas em testes preliminares à RNA) utilizou-se a ferramenta de manipulação gráfica Adobe Photoshop CS4.

Já a fase de treinamento e operação da rede, o hardware utilizado foi um iMac 2.66 Mhz Quad-core 8 MB cache com 12 Gb RAM. A plataforma multicore permite a ferramenta computacional matemática acelerar (MATHWORKS, 2010) (de forma automática, sem a necessidade de se empregar um algoritmo específico de computação paralela) a fase de aprendizado da RNA. 


\subsubsection{Textura Homogênea Sintética}

A primeira simulação (preliminar) teve como objetivo verificar o funcionamento/aprendizado da RNA, bem como estabelecer a base para o comportamento/ajuste dos seus parâmetros.

Para isto, foi criada uma imagem (sintética) com a presença de suas regiões homogêneas (sem ruído, com duas tonalidades de cinza e características semelhantes), sendo elas: a primeira constituinte do fundo da imagem; e a segunda, um objeto, isto é, uma figura geométrica simples (um círculo), como mostra a figura 4.10 - a.

De posse da imagem, algumas sub-imagens foram selecionadas no tamanho 5x5 2 (25 pixels no total) para compor os dois grupos de treinamento: A e B. O primeiro, contém imagens da borda do objeto, enquanto que o segundo, as imagens foram selecionadas de forma aleatória, como mostra a figura 4.10 - b. Ou seja, dezoito imagens constituíram cada grupo/classe, totalizando 36 imagens (5x5) para a fase de treinamento da RNA.

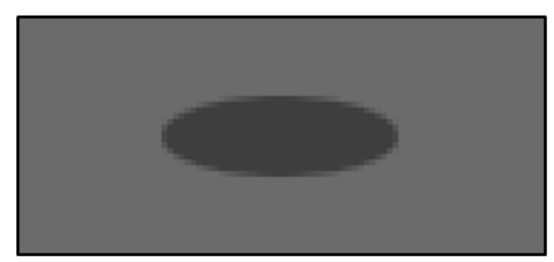

(a) Imagem sintética com duas tonalidades de cinza

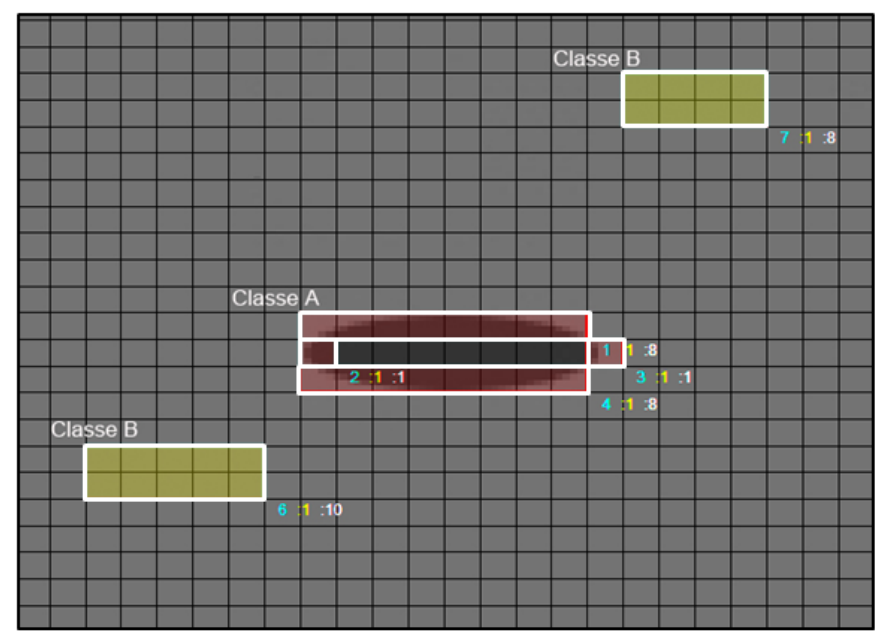

(b) Definição das sub-imagens para treinamento - Classe A e B

Figura 4.10: Textura homogênea sintética criada para a fase de aprendizado da RNA.

\footnotetext{
${ }^{2} \mathrm{O}$ tamanho do padrão de entrada de $(5 \times 5)$ foi baseada em função do custo computacional (quanto maior o tamanho, maior a quantidade de neurônios/pesos sinápticos e conseqüentemente, maior o volume de cálculo envolvido) e da complexidade da textura
} 
Para o conjunto de padrões de teste, duas imagens foram estabelecidas (a primeira com $360 \times 360$ pixels, a segunda com $520 \times 520$ pixels), onde se inseriram vários objetos de formatos diferentes (com mesmos tons de cinza da imagem de treinamento), como mostra a figura 4.11 - a e b. A seleção deste, tem como objetivo verificar a capacidade de generalização da rede perante os novos dados de entrada (não treinados).

Além disto, para identificar a porcentagem de acertos e erros do processo classificatório, duas imagens máscaras também foram estabelecidas (Fig. $4.11 \mathrm{c} \mathrm{e} \mathrm{d).}$ Elas apresentam a resposta ideal ao reconhecimento/classificação para o problema em questão.

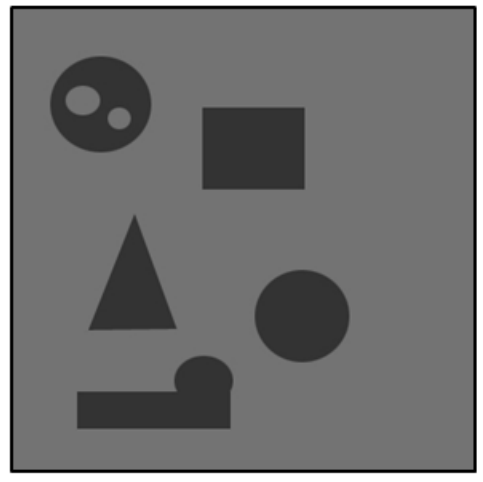

(a) Imagem teste 01

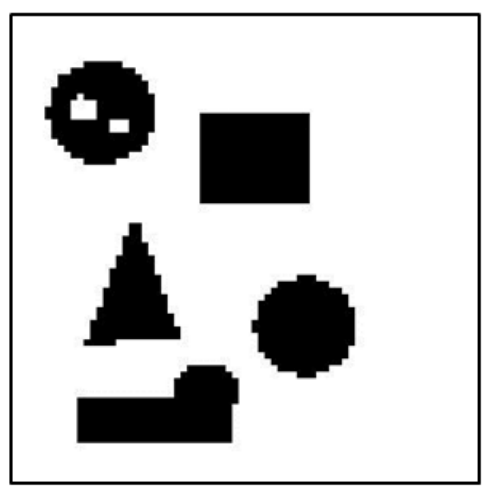

(c) Imagem máscara 01

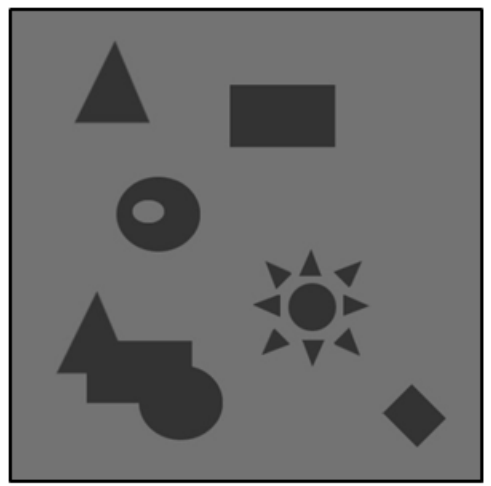

(b) Imagem teste 02

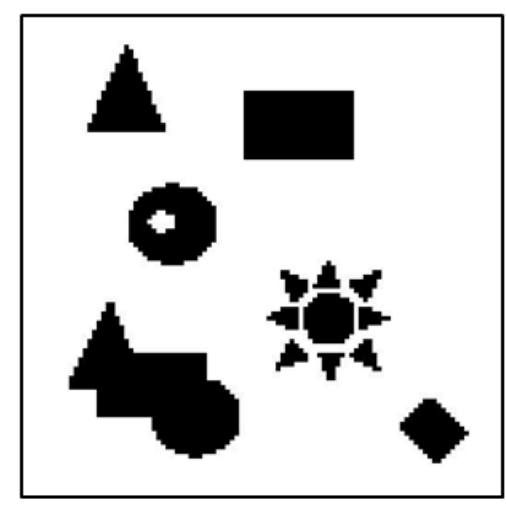

(d) Imagem máscara 02

Figura 4.11: Textura sintética criada para os testes preliminares com a RNA proposta.

De posse dos dados de entrada (treinamento) os seguintes parâmetros foram utilizados à fase de aprendizado: $\sigma$ (constante de aprendizado) $=0.005 ; \rho$ (constante de veloc. deslocamento $)=0.005 ; \theta_{k}($ deslocamento da função logística $)=0.5 ; \eta=100$ (iterações); tamanho do padrão de entrada: $5 \times 5(N x N)$; quantidade de neurônios - $1^{o}$ camada neural $=25 ; 2^{\circ}$ camada neural $=30$, camada de saída/classes $=2$; distância da relação de vizinhança $\mathrm{n}=1$ (correspondente à janela $M x M=3 \times 3$ ).

Já os resultados fornecidos pela resposta da rede para as imagens: teste 01 (Fig 4.11 - a) e 02 (Fig 4.11 - b) são apresentados na tabela 4.10 
Tabela 4.10: Taxas de acerto obtidas na fase de teste da RNA para análise e reconhecimento de textura - Simulação 01

\begin{tabular}{|c|c|c|c|c|c|}
\hline & Descrição & Total de Imagens $(5 \times 5)$ & Imagens Reconhecidas & Erro & Taxa de Acertos (\%) \\
\hline \multirow{2}{*}{ 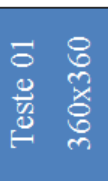 } & $\begin{array}{c}\text { Fundo } \\
\text { (Classe A) }\end{array}$ & 4203 & 4203 & 0 & 100 \\
\hline & $\begin{array}{c}\text { Objeto } \\
\text { (Classe B) }\end{array}$ & 981 & 963 & 18 & 98.1651 \\
\hline \multirow{2}{*}{ 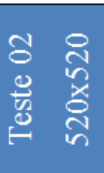 } & $\begin{array}{c}\text { Fundo } \\
\text { (Classe A) }\end{array}$ & 8998 & 8998 & $\overline{0}$ & 100 \\
\hline & $\begin{array}{c}\text { Objeto } \\
\text { (Classe B) }\end{array}$ & 1818 & 1796 & 22 & 98.7899 \\
\hline
\end{tabular}

Para uma melhor compreensão da taxa de acerto e erro apresentada na tabela 4.10, ilustra-se o resultado na figura 4.12.

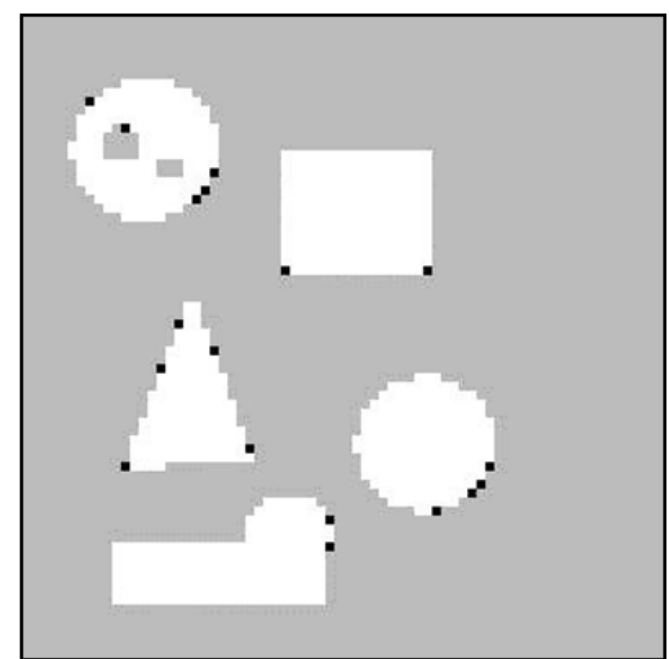

(a) Teste 01

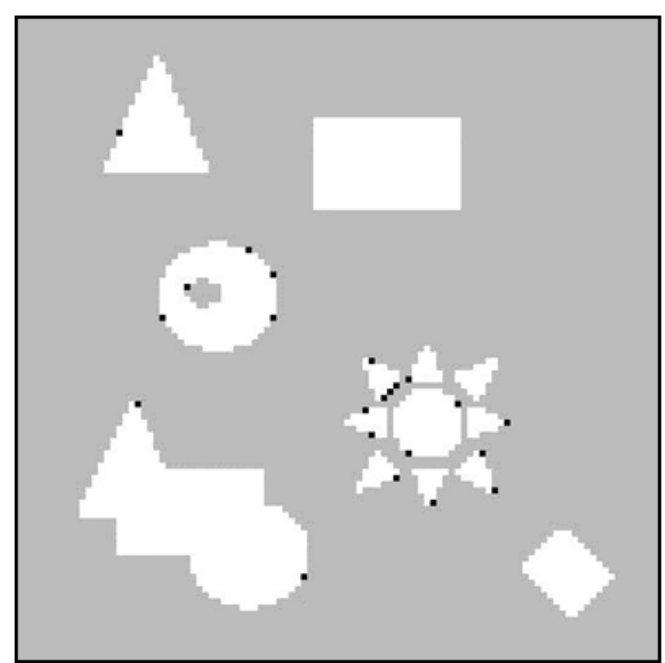

(b) Teste 02

Figura 4.12: Imagem em função da resposta da RNA. A cor cinza - representa o reconhecimento exato do fundo da imagem; a cor branca - representa o reconhecimento das imagens que compõe os objetos; cor preta - representa as imagens do objeto que foram reconhecidas de forma errônea pela RNA.

Os resultados aqui apresentados referem-se à análise e reconhecimento de duas texturas ditas homogêneas - sintéticas. Entretanto, testes em texturas naturais também são empregadas e descritas a seguir.

\subsubsection{Textura Homogênea Natural}

\section{Textura 01}

A próxima análise a ser efetuada engloba uma imagem clássica - Tijolo. É composta por duas texturas homogênea: o tijolo em sí e o material que une-os. Ambas são 
compostas de elementos com níveis de cinza semelhantes, como mostra a figura 4.13 a.

Uma área aleatória da figura 4.13 - a (tamanho 415×315) foi escolhida e selecionada para compor o segundo teste a ser realizado com a rede neural.

De forma similar ao teste anterior, grupos de imagens foram selecionados para compor o conjunto de treinamento: A - tijolo; e B ao material que os une (Fig 4.13 b). Ambas as classes tiveram 30 texturas, totalizando 60 à fase de treinamento.

Nesta simulação o padrão de entrada também foi mantido 5x5 (uma relação estrutural entre 25 pixels), e uma imagem máscara (Fig 4.13 - c) também foi definida para se estabelecer a porcentagem de acertos da RNA.

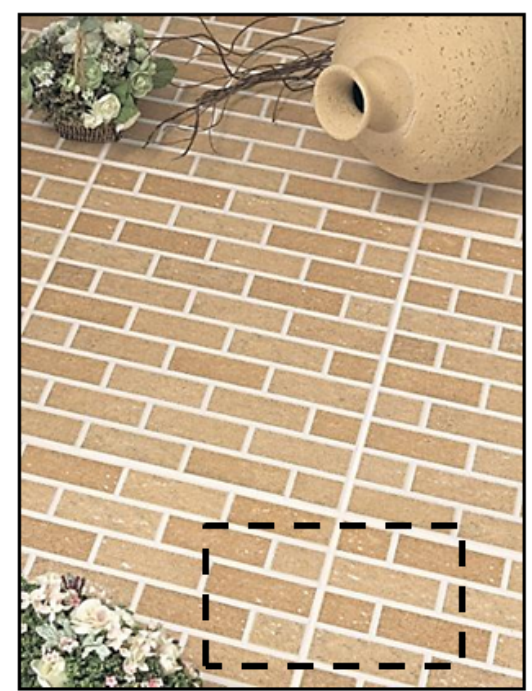

(a) Seleção da imagem original

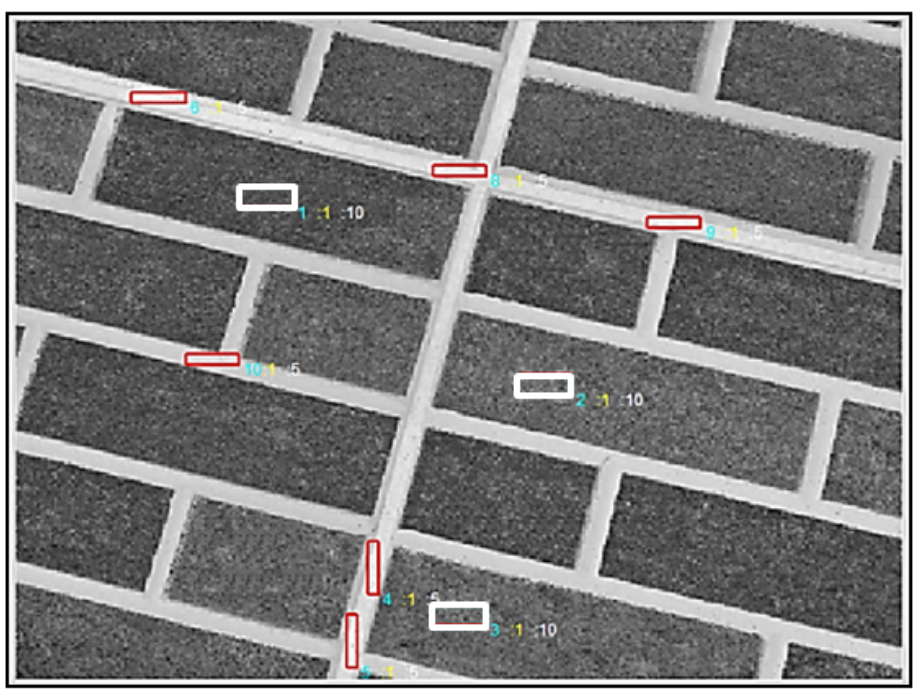

(b) Seleção das imagens de treinamento, classe A (tijolo) e B (material que une os tijolos)

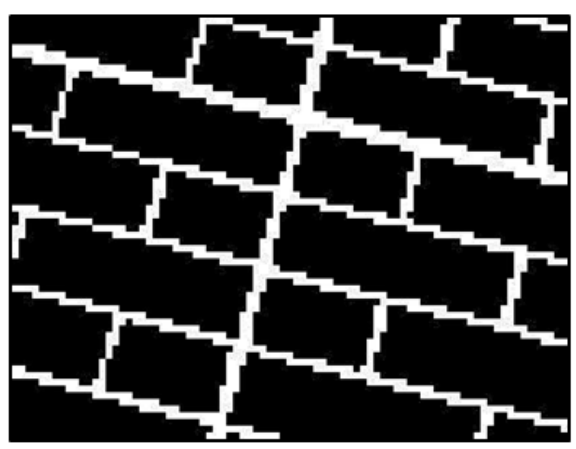

(c) Imagem máscara

Figura 4.13: Imagem clássica - Tijolo (LAMBERTI, 2011)

Os parâmetros usados nesta simulação foram: $\sigma=0.005 ; \rho=0.005 ; \theta_{k}=0.6 ; \eta=$ 100; tamanho do padrão de entrada: $5 \times 5(N x N)$; quantidade de neurônios - $1^{o}$ camada neural $=25 ; 2^{\circ}$ camada neural $=30$, camada de saída/classes $=2$; distância da relação 
de vizinhança $n=1$.

Já os resultados oriundos da classificação são apresentados na tabela 4.11, enquanto que a taxa de acerto e erro é ilustrada na figura 4.14.

Tabela 4.11: Taxas de acerto obtidas na fase de teste da RNA para análise e reconhecimento de textura - Simulação 02.

\begin{tabular}{|c|c|c|c|c|c|}
\hline & Descrição & Total de Imagens (5x5) & Imagens Reconhecidas & Erro & Taxa de Acertos (\%) \\
\hline \multirow{2}{*}{ 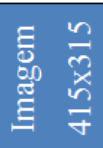 } & Classe A & 4301 & 4239 & 62 & 98.5585 \\
\hline & Classe B & 928 & 913 & 15 & 98.3836 \\
\hline
\end{tabular}

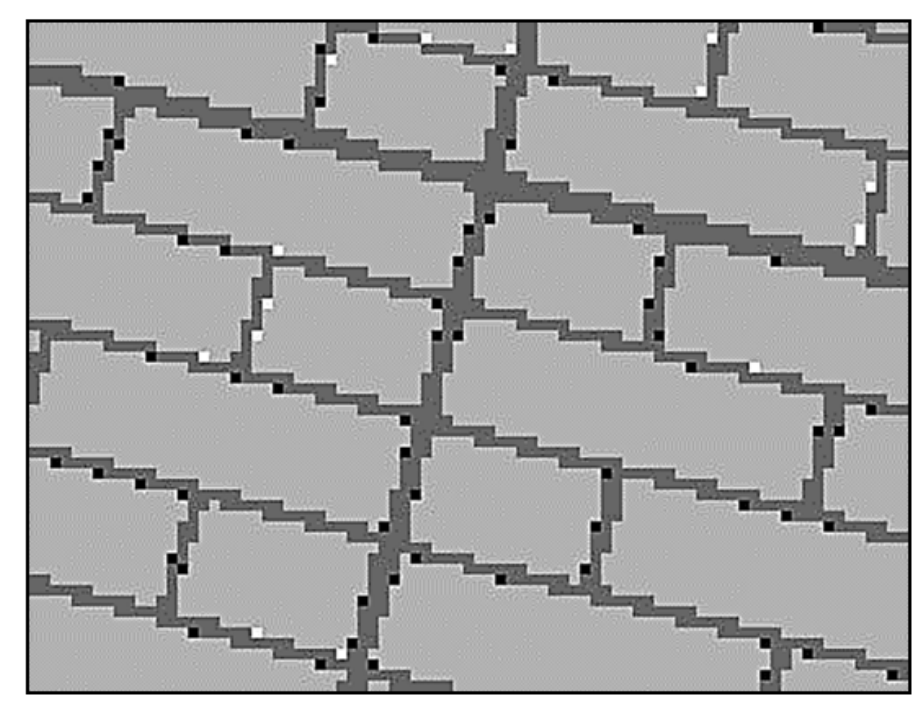

Figura 4.14: Imagem em função da resposta da RNA. A cor cinza escuro - representa o reconhecimento da classe B; cor cinza claro - representa a Classe A; cor preta pontos onde ocorreram erros na classe $\mathrm{A}$; cor branca - pontos onde ocorreram erros na classe B.

\section{Textura 02 e 03}

O próximo teste refere-se a duas aplicações de inspeção visual no domínio da engenharia, sendo elas: indústria têxtil e madeireira. A seguir apresenta-se respectivamente cada uma delas.

No primeiro caso, o objetivo é a detecção de falhas/defeitos na fabricação de tecidos. Uma imagem 500x360 foi adquirida (KUMAR, 2011) e, então, selecionadas as áreas de interesse para compor os padrões de treinamento, neste caso: A - tecido 
normal e B - tecido com falhas. O total de imagens foi de 60 , em que cada grupo é composto pela metade delas.

A figura 4.15 apresenta as cinco regiões estabelecidas, sendo a 1, 2 e 3 relacionada à classe $\mathrm{B}$, enquanto que a quarta e quinta refere-se à classe $\mathrm{A}$.

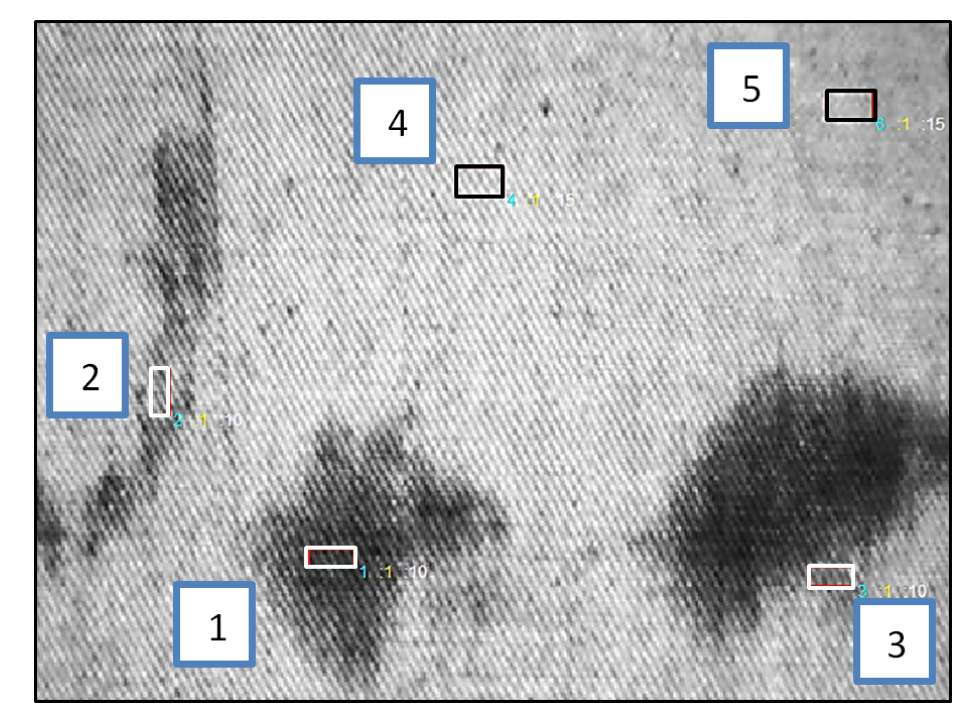

Figura 4.15: Tecido com falha na fabricação (KUMAR, 2011) e as respectivas áreas de interesse para compor o conjunto de treinamento.

Para estabelecer a porcentagem de acertos da RNA também foi definida uma máscara. Já em relação aos parâmetros de simulação para fase de aprendizado estes foram definidos como: $\sigma=0.005 ; \rho=0.005 ; \theta_{k}=0.3 ; \eta=100$; tamanho do padrão de entrada: $5 \times 5(N x N)$; quantidade de neurônios $-1^{o}$ camada neural $=25 ; 2^{\circ}$ camada neural $=30$, camada de saída/classes $=2$; distância da relação de vizinhança $n=1$.

Os resultados obtidos pela classificação são apresentados na tabela 4.12, enquanto que a taxa de acerto e erro é ilustrada na figura 4.16 .

Tabela 4.12: Taxas de acerto obtidas na fase de teste da RNA para análise e reconhecimento de textura - Simulação 03.

\begin{tabular}{|c|c|c|c|c|c|}
\hline & Descrição & Total de Imagens $(5 \times 5)$ & Imagens Reconhecidas & Erro & Taxa de Acertos (\%) \\
\hline \multirow{2}{*}{ 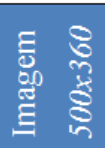 } & Classe A & 5820 & 5775 & 45 & 99.2268 \\
\hline & Classe B & 1380 & 1278 & 102 & 92.6087 \\
\hline
\end{tabular}




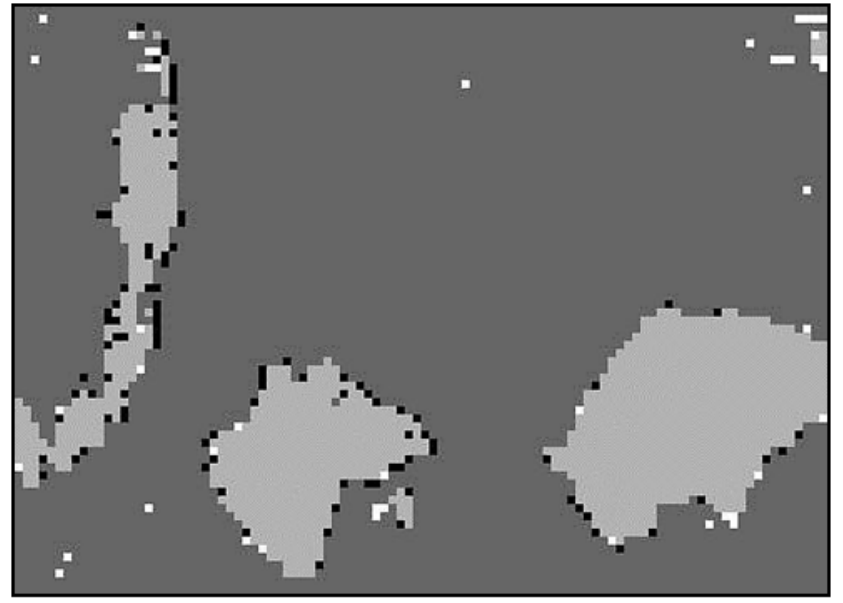

(a) Taxa de acerto e erro. A cor cinza escuro - representa o reconhecimento da classe A; a cor cinza claro - representa a Classe B; cor preta - pontos onde ocorreram erros na classe B; cor branca - pontos onde ocorreram erros na Classe A.

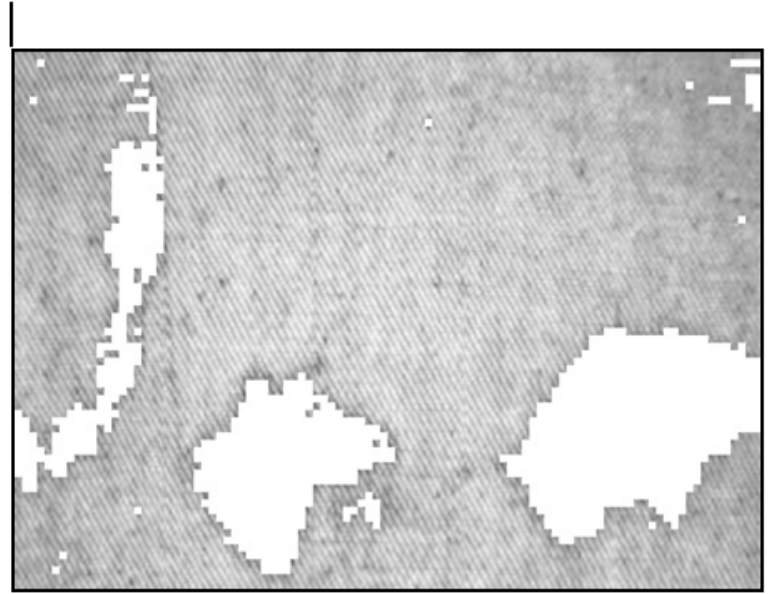

(b) Imagem segmentada - somente o tecido normal

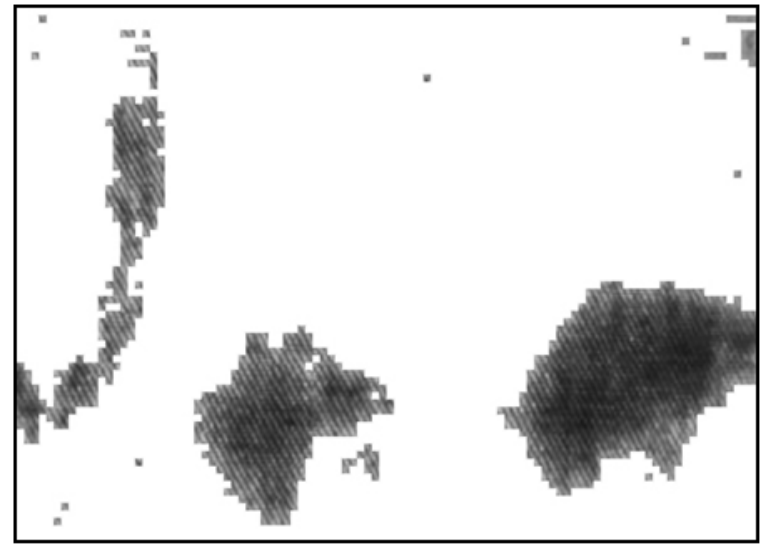

(c) Imagem segmentada - somente as falhas do tecido

Figura 4.16: Imagens em função da resposta da RNA

O segundo caso tem como objetivo detectar falhas/defeitos em placas de madeira (VTT; OULU, 2011). Todavia, como o objetivo aqui desta seção não é desenvolver uma análise completa de um problema específico (fora do escopo desde trabalho), simplifica-se o processo em classificar: madeira (Classe A) e falha/defeito (Classe B).

Sendo assim, dezoito texturas foram selecionadas para cada grupo, ou seja, um total de 36 (tamanho 5x5) à fase de treinamento da rede, como mostra a figura 4.17

Para testar o desempenho da RNA utiliza-se uma imagem teste (placa de madeira) com a presença de seis falhas, onde uma delas foi usada para treinar a rede, ilustrada respectivamente na figura 4.17 e 4.18 .

Para essas texturas a rede foi simulada com os seguintes parâmetros: $\sigma=0.005 ; \rho$ 


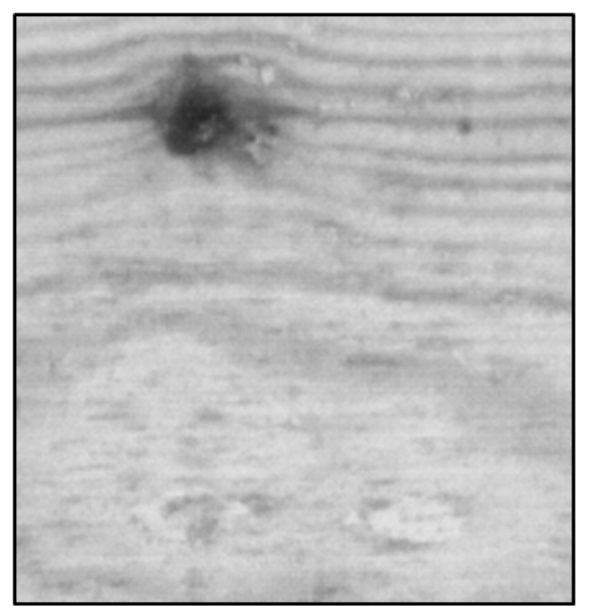

(a) Imagem original

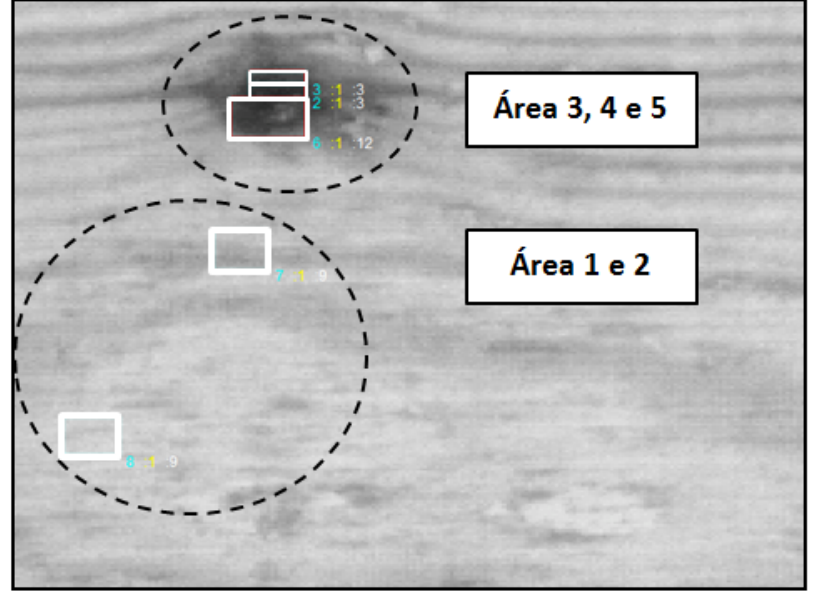

(b) Seleção dos padrões de treinamento

Figura 4.17: Imagem utilizada para o treinamento da RNA. (adaptado: (VTT; OULU, 2011))

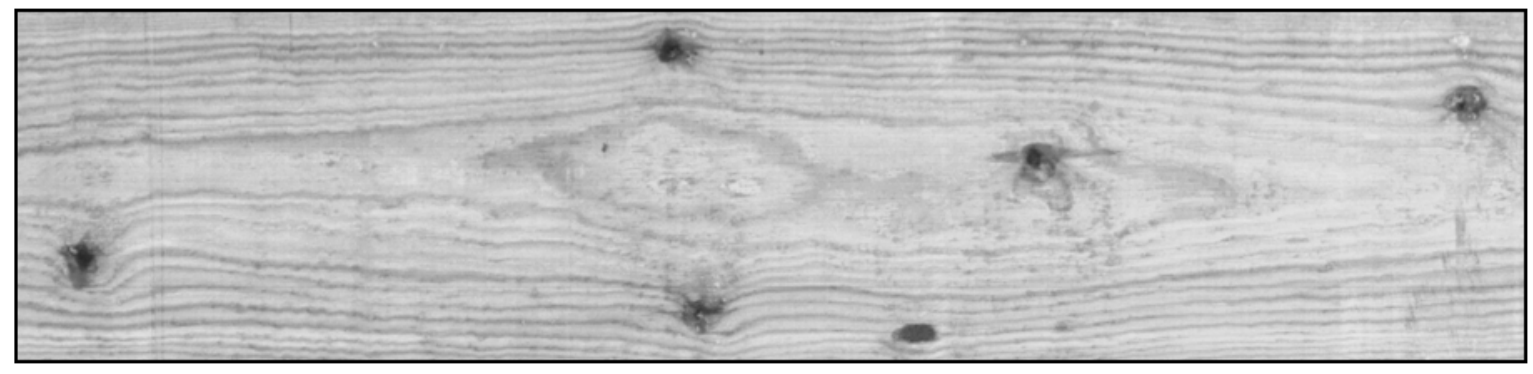

Figura 4.18: Imagem teste - tamanho 1710x395 pixels (adaptado: (VTT; OULU, 2011))

$=0.005 ; \theta_{k}=0.6 ; \eta=100 ;$ tamanho do padrão de entrada: $5 \times 5(N x N)$; quantidade de neurônios $-1^{o}$ camada neural $=25 ; 2^{\circ}$ camada neural $=18$, camada de saída/classes $=$ 2; distância da relação de vizinhança $n=1$.

A resposta na fase de reconhecimento/classificação é apresentada na tabela 4.13. Já a resposta em relação à segmentação pode ser vista na figura 4.19.

Tabela 4.13: Taxas de acerto obtidas na fase de teste da RNA para análise e reconhecimento de textura - Simulação 04.

\begin{tabular}{|c|c|c|c|c|c|}
\hline & Descrição & Total de Imagens $(5 \times 5)$ & Imagens Reconhecidas & Erro & Taxa de Acertos (\%) \\
\hline E & Classe A & 26648 & 26637 & 11 & 99.9587 \\
\hline 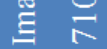 & Classe B & 370 & 370 & 0 & 100 \\
\hline
\end{tabular}




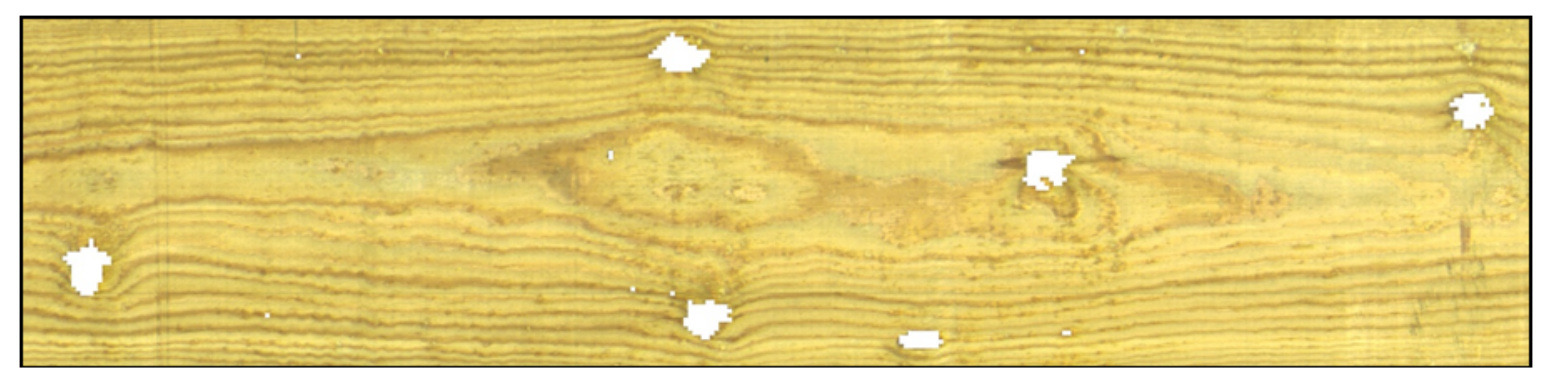

(a) Imagem segmentada - áreas correspondentes as falhas detectadas

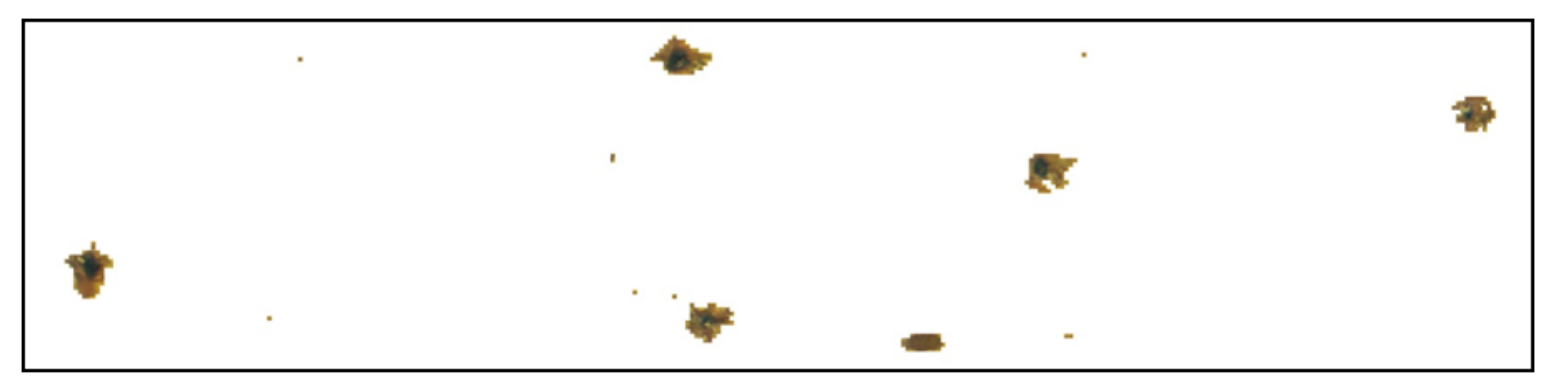

(b) Imagem segmentada - falhas da madeira

Figura 4.19: Imagem gerada em função da resposta da RNA - tamanho 1710x395 pixels

\section{Textura 04 e 05}

A quarta e quinta texturas, últimas a serem apresentadas neste capítulo, estão diretamente correlacionadas ao domínio da medicina. A primeira relacionada à doença de pele - identificação de um câncer; e a segunda, detecção da esclera, pupila e íris do olho de um ser humano. Todavia, este segundo exemplo teve com premissa a expansão da RNA na classificação de três grupos, bem como no aumento do número de imagens em relação às outras descritas.

No exemplo da doença de pele, uma imagem de 645x410 foi adquirida em (LCC, 2011). Esta foi utilizada tanto para selecionar o conjunto dos padrões de treinamento quanto para testar a RNA. Assim, 80 texturas (5x5) foram adquiridas, sendo 40 relacionadas à classe A - pele (áreas 5,6,7); e as demais ao grupo B - câncer (áreas 1,2,3,4), como mostra a figura 4.20. 


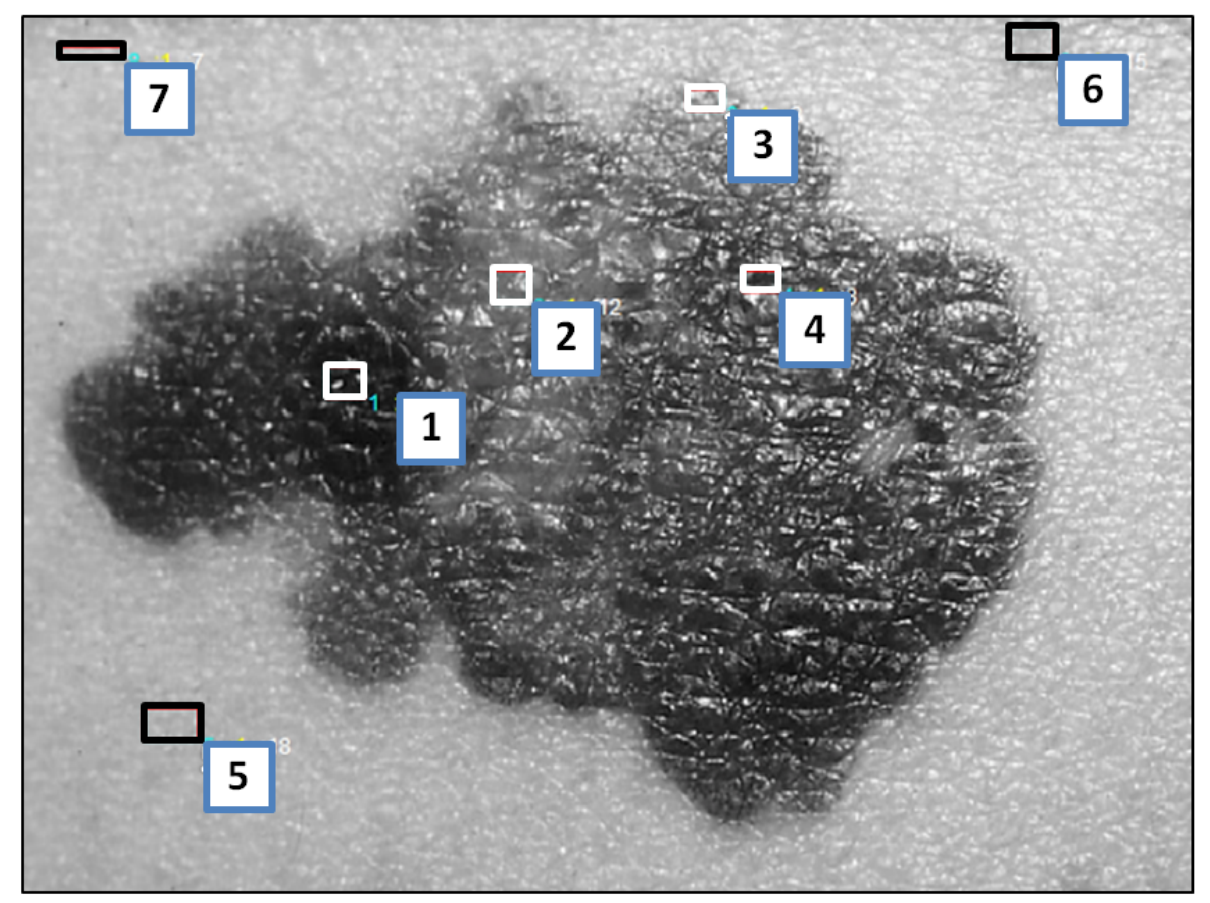

Figura 4.20: Imagem de câncer de pele (LCC, 2011) e as respectivas áreas/texturas consideradas no conjunto de treinamento à RNA.

Nesta simulação os parâmetros estabelecidos foram $\sigma=0.005 ; \rho=0.005 ; \theta_{k}=$ 0.6; $\eta=110$; tamanho do padrão de entrada: $5 \times 5(N x N)$; quantidade de neurônios $-1^{o}$ camada neural $=25 ; 2^{\circ}$ camada neural $=40$, camada de saída/classes $=2$; distância da relação de vizinhança $n=1$.

O resultado à fase de reconhecimento/classificação pode ser visto na tabela 4.14, enquanto que a resposta da taxa de acerto/erro e segmentação da imagem são ilustradas na figura 4.21.

Tabela 4.14: Taxas de acerto obtidas na fase de teste da RNA para análise e reconhecimento de textura - Simulação 05.

\begin{tabular}{|c|c|c|c|c|c|}
\hline & Descrição & Total de Imagens (5x5) & Imagens reconhecidas & Erro & Taxa de acertos (\%) \\
\hline $\bar{\Xi}$ & Classe A & 2763 & 2762 & 1 & 99.9638 \\
\hline & Classe B & 2367 & 2290 & 77 & 96.7469 \\
\hline
\end{tabular}




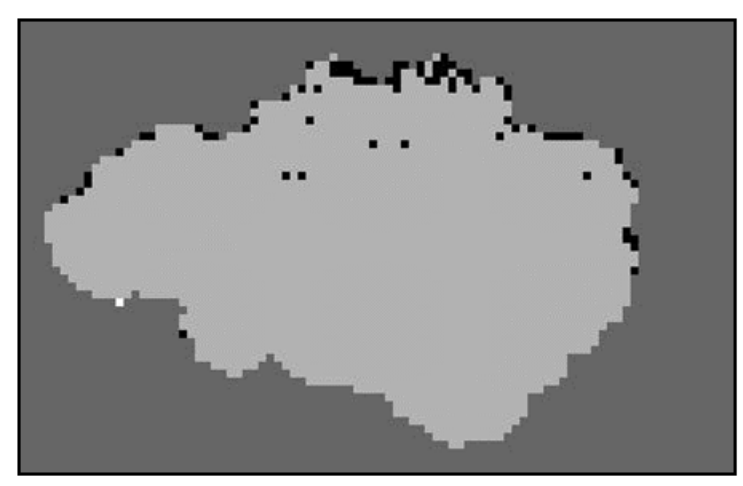

(a) Taxa de acerto e erro. A cor cinza escuro representa o reconhecimento da classe A; cor cinza claro - representa a classe B; cor preta - pontos onde ocorreram erros na classe B; cor branca - pontos onde ocorreram erros na classe A.

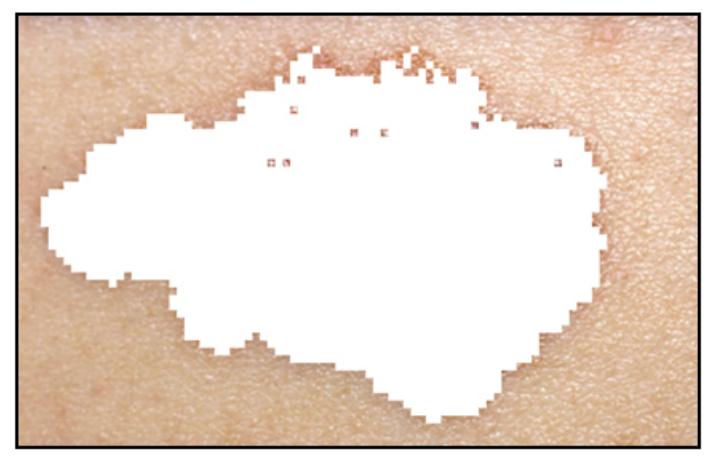

(b) Imagem segmentada - tecido saudável

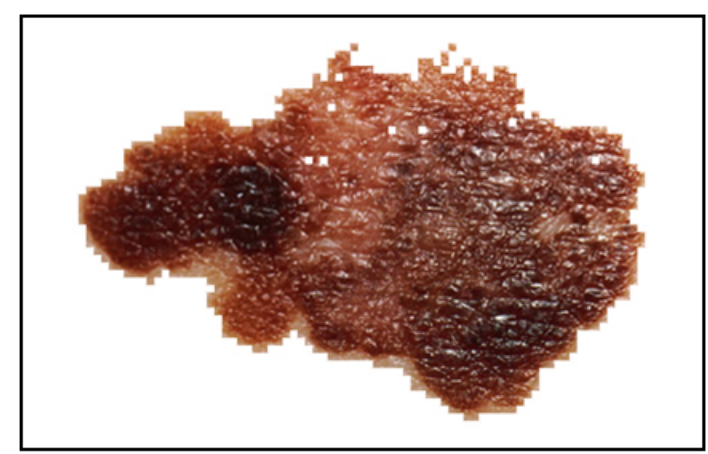

(c) Imagem segmentada - tecido com câncer

Figura 4.21: Imagens em função da resposta da RNA

A última simulação baseia-se na detecção da região da esclera (parte branca do olho), íris e pupila. Teve como premissa a expansão da RNA em três grupos de classificação, diferentemente das outras anteriormente descritas.

Uma imagem com foco no globo ocular foi adquirida no tamanho 440x430. Neste, os conjuntos dos padrões de treinamento/textura foram selecionados, sendo: 30 imagens (Classe A) da esclera; 30 imagens (Classe B) da íris; e 20 imagens correspondentes à pupila (Classe C), todas elas do mesmo tamanho: 5x5. Assim, um total de 80 imagens foi utilizado à fase de aprendizado e ilustrado as áreas com as respectivas classes na figura 4.22 - a. Entretanto, como as regiões das pálpebras não fazem parte do interesse deste contexto, estas foram removidas, como mostra a figura 4.22 - b.

Para esta simulação os seguintes parâmetros foram utilizados: $\sigma=0.005 ; \rho=$ 0.005; $\theta_{k}=0.3 ; \eta=300$; tamanho do padrão de entrada: $5 \times 5$ ( ); quantidade de neurônios $-1^{o}$ camada neural $=25 ; 2^{\circ}$ camada neural $=35$, camada de saída $/$ classes $=$ 3; distância da relação de vizinhança $n=1$.

O resultado do reconhecimento/classificação é fornecido na tabela 4.15, enquanto que o resultado da taxa/erro e segmentação é apresentado na figura 4.23. 


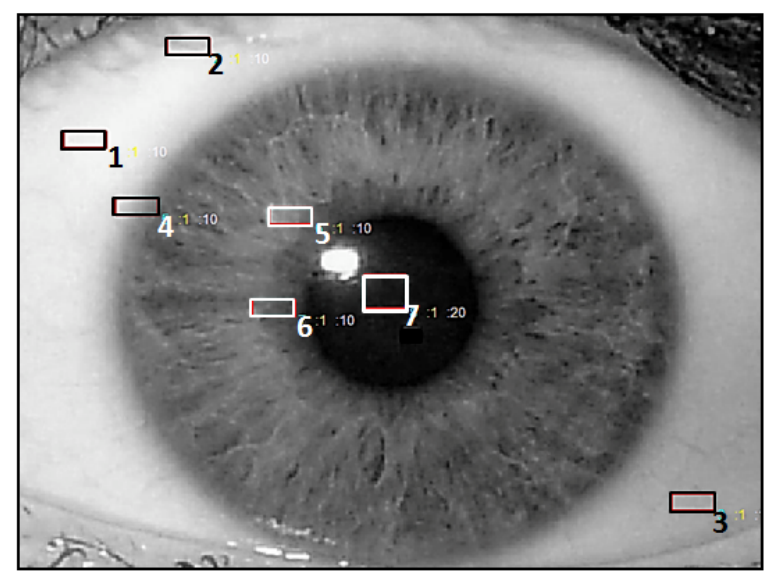

(a) áreas de interesse: 1,2,3 - Esclera; 4,5,6 - Íris; 7 pupila;

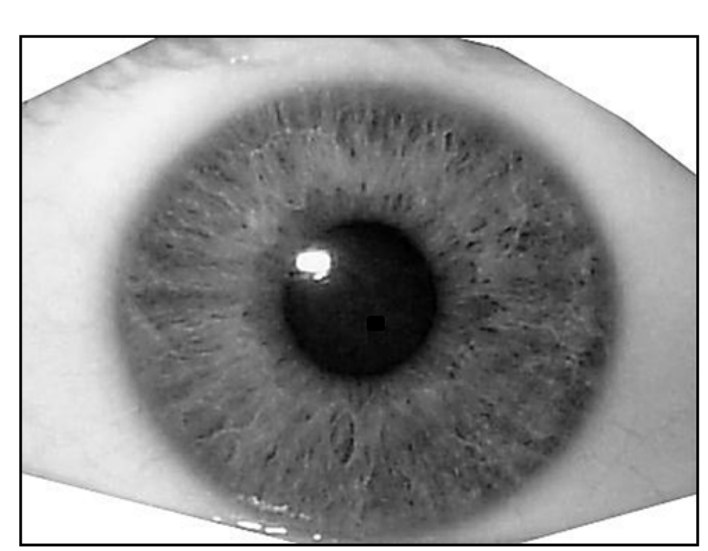

(b) Remoção das pálpebras - região fora do escopo de análise (imagem teste)

Figura 4.22: Imagem utilizada do globo ocular

Tabela 4.15: Taxas de acerto obtidas na fase de teste da RNA para análise e reconhecimento de textura - Simulação 06.

\begin{tabular}{|c|c|c|c|c|c|}
\hline & Descrição & Total de Imagens (5x5) & Imagens reconhecidas & Erro & Taxa de acertos (\%) \\
\hline \multirow{3}{*}{ 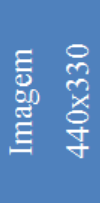 } & Classe A & 2674 & 2661 & 13 & 99.5138 \\
\hline & Classe B & 2855 & 2844 & 11 & 99.6147 \\
\hline & Classe $\mathrm{C}$ & 279 & 243 & 36 & 87.0968 \\
\hline
\end{tabular}

Por fim, a validação é discutida no próximo capítulo. 


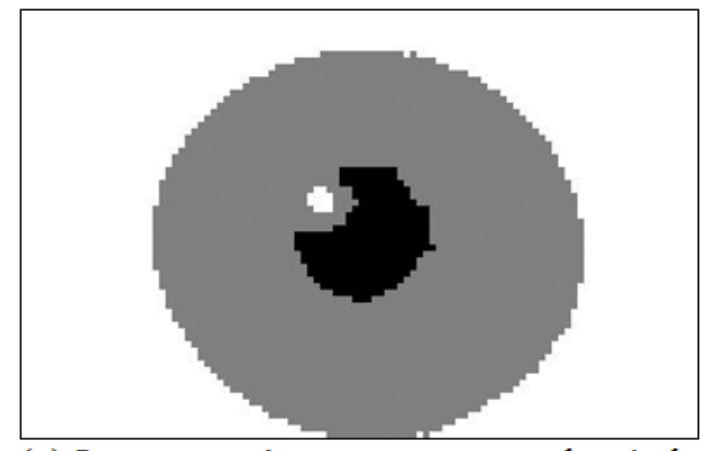

(a) Imagem máscara - resposta desejada

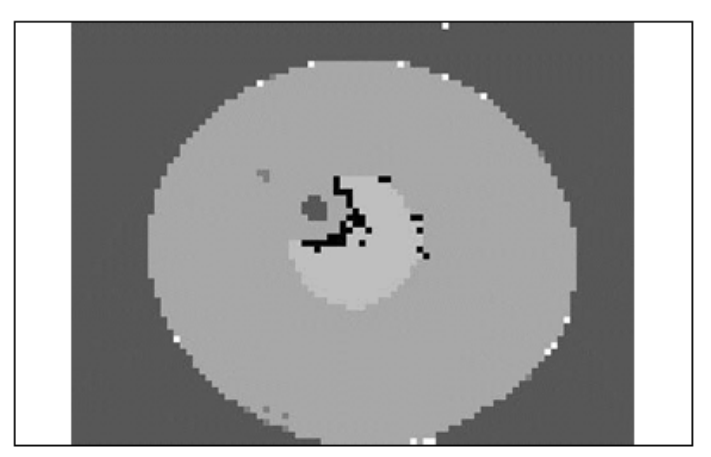

(c) Taxa de acerto e erro. A cor cinza escuro representa o reconhecimento da classe $\mathrm{A}$; a cor cinza claro representa a classe $\mathrm{B}$; a cor branca representa o reconhecimento da classe $\mathrm{C}$; a cor preta representa o erro na classe $\mathrm{C}$;

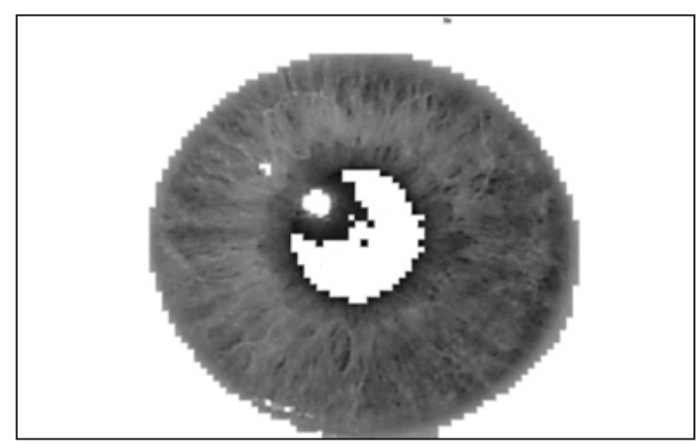

(e) Segmentação da íris

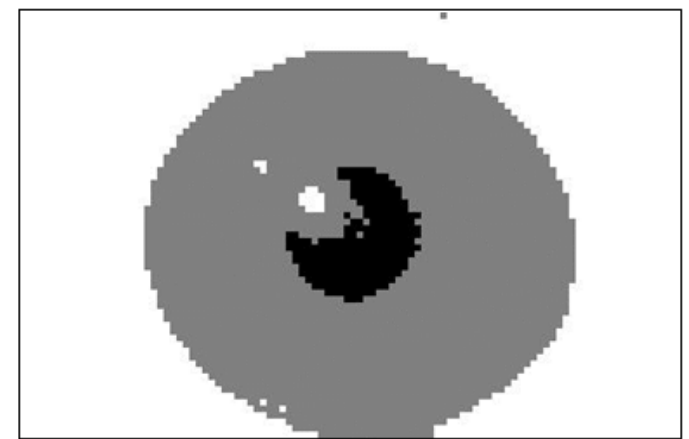

(b) Resposta da rede neural

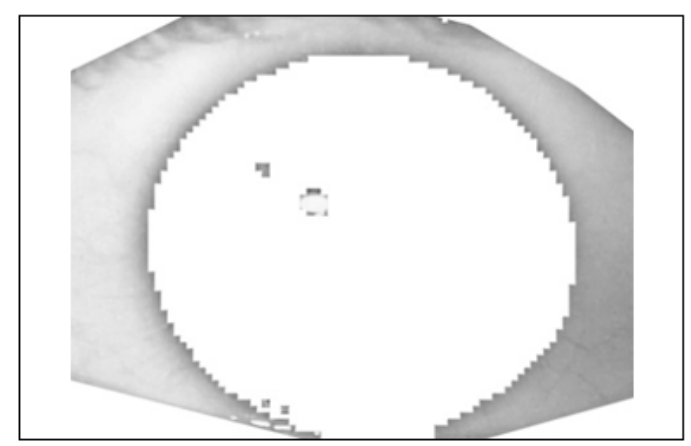

(d) Segmentação da esclera

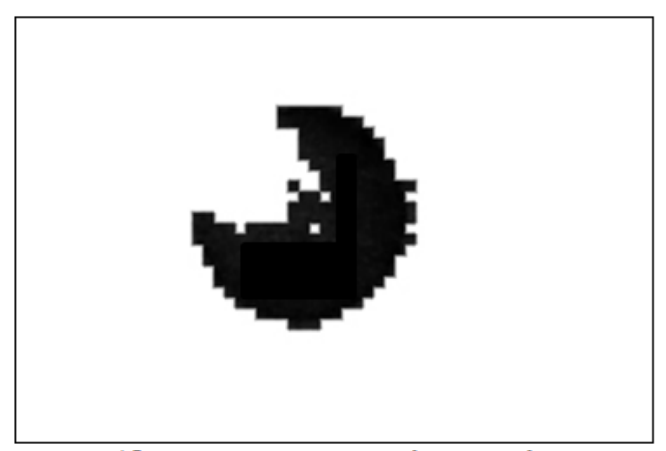

(f) Segmentação da pupila

Figura 4.23: Imagens em função da resposta da RNA 


\section{Discussões e Análise dos Resultados}

\subsection{Introdução}

Este capítulo tem como objetivo explanar tópicos pertinentes a proposta do trabalho, tais como: discussão e sua aplicação, validação e a análise dos resultados oriundos da rede neural artificial.

Sendo assim, primeiro se discute a aplicação prática do processo, suas vantagens, desvantagens, as execuções das fases mais onerosas, mais rápidas, a diferença em termos práticos do desenvolvedor e do cliente no domínio próximo, a recompensa na utilização da abordagem do projeto axiomático, a diferença de tal abordagem no estudo de caso proposto e as demais na literatura, a realização do ciclo de ajuste, os questionamentos levantados no mesmo, e etc.

Em seguida, explana-se o papel da validação, vantagens, os locais (fases) onde foram realizados, bem como algumas ressalvas sobre a solução estabelecida e validação em si. Por fim, apresenta-se as análises dos resultados obtidos pela fase de reconhecimento/classificação de textura oriundas da RNA. Ilustra-se graficamente os dados utilizados no treinamento da mesma e as justificativas em relação às taxas de acerto/erro.

\subsection{Discussões}

\subsubsection{Discussões sobre o Processo e sua Aplicação}

A eliciação de requisito é um processo eminentemente informal e, na abordagem clássica, intuitiva. É focada prioritariamente na relação de comunicação e transferência de conhecimento entre o cliente/especialista e desenvolvedor. Na literatura uma variedade de técnicas de auxílio a tal processo pode ser encontrada, bem como explanações sobre o uso prático das mesma (QUEIROZ, 2007; QUEIROZ; SILVA, 2009)

Neste trabalho, o fato do desenvolvedor assumir o papel do próprio cliente/ espe- 
cialista (domínios próximos, explanado em capítulos anteriores) faz com que o levantamento de requisitos deixe de ter um enfoque prioritário na transferência de conhecimento entre cliente e desenvolvedor e passe a se basear unicamente nas informações explicitas em documentos (neste caso: livros e artigos).

Na prática, o uso desse tipo de abordagem exige um esforço (em termos de tempo disponibilizado) por parte do desenvolvedor para ler, entender e compreender as informações contidas nos documentos. Entretanto, quando o problema a ser tratado relacionase com dois ou mais domínios próximos, como é o caso do trabalho, torna-se mais oneroso/custoso. Isto ocorre não só pelo aumento do volume de informações, bem como pela forma dispersa e não estruturada que estas se encontram na literatura (diferentes métodos, técnicas e soluções). Logo, uma atenção parcimoniosa por parte do desenvolvedor faz-se necessário à percepção do problema, identificação das reais necessidades (em potencial), desejos e restrições a serem estabelecidos no desenvolvimento do projeto.

Em contrapartida, a aplicação prática desse tipo de abordagem provê várias vantagens, por exemplo, fornece fortes subsídios (em termos de conhecimento sobre a aplicação) ao desenvolvedor para estabelecer as necessidades e restrições diferentemente de um cliente. Ou seja, enquanto este contribui de forma abstrata, genérica, não-organizada, expressa de forma difusa e quase que puramente funcional, o desenvolvedor (com base no conhecimento explícito) pode estabelecer de forma concisa, estruturada em categorias (mais gerais), subcategorias (mais específicas), justificados, com nota adicional de informações (para melhor compreensão do problema) e possíveis relações entre eles (isto é, cria um mapeamento das relações/vínculos existentes entre as necessidades).

Acredita-se que o critério de justificativa (fundamentado em documentos presentes na literatura) auxilia, se não a redução, mas a sinalização/identificação de que tal levantamento é induzido apenas pelo conhecimento do desenvolvedor (isto é, por uma autoconfiança no domínio da aplicação), ou se o processo é baseado numa solução existente (ou pré-concebida), já que os mesmos são justificados através de documentos.

Já o estabelecimento de relações entre requisitos e as restrições proporcionam um grande auxílio à fase de definição da solução (em específico: o domínio funcional $\{$ FRs $\}$ e físico $\{$ DPs $\}$ ), pois fornece uma compreensão ampla do problema em questão. Além disto, fornece características de rastreamento/identificação de possíveis falhas oriundas do estabelecimento dos requisitos e restrições (responsáveis pelos maiores erros ocasionados em projeto); criação de uma base de informação/conhecimento 
a outros projetos (reutilização de requisitos); compreensão das tomadas de ações em etapas posteriores; subsídios para uma documentação mais clara, lógica e objetiva; e etc. Todas elas características almejáveis/desejáveis à melhoria da qualidade do desenvolvimento do projeto.

A tabela 5.1 apresenta de forma sucinta as vantagens que a abordagem adotada fornece tanto para o projeto como para o desenvolvedor.

Tabela 5.1: Características fornecidas pela abordagem da busca de informações explícitas em documentos.

\begin{tabular}{|c|c|}
\hline Vantagens para o desenvolvedor & Vantagens para o projeto \\
\hline $\begin{array}{l}\text { - Compreensão das atividades/procedimentos } \\
\text { do domínio em análise; }\end{array}$ & $\begin{array}{l}\text { - Auxílio à identifícação das reais } \\
\text { necessidades; } \\
\text { - Discernir melhor sobre os requisitos em } \\
\text { potencial; }\end{array}$ \\
\hline $\begin{array}{l}\text { - Acréscimo a sua base de conhecimento } \\
\text { (experiência que pode ser utilizada em outros } \\
\text { projetos); Pode variar de um conhecimento } \\
\text { superficial a profundo; }\end{array}$ & $\begin{array}{l}\text { - Auxílio à criação/estabelecimento de } \\
\text { solução mais concisa; }\end{array}$ \\
\hline $\begin{array}{l}\text { - Ajuda a estabelecer o requisito de forma } \\
\text { estruturada; }\end{array}$ & $\begin{array}{l}\text { - Melhora o discernimento sobre os } \\
\text { requisitos; } \\
\text { - Fornece subsídios para uma documentação } \\
\text { mais clara, lógica e objetiva; }\end{array}$ \\
\hline $\begin{array}{l}\text { - Base (conhecimento) para justificar os } \\
\text { requisitos; }\end{array}$ & - Provê maior compreensão do projeto; \\
\hline $\begin{array}{l}\text { - Facilidade no estabelecimento do } \\
\text { relacionamento entre as necessidades e } \\
\text { restrições; }\end{array}$ & $\begin{array}{l}\text { - Auxílio ao mapeamento e rastreamento das } \\
\text { necessidades no projeto; }\end{array}$ \\
\hline
\end{tabular}

Com relação ao critério de parada, este é estabelecido quando as necessidades e restrições começam a se repetir. Caso o mesmo não esteja completo, observa-se certa dificuldade em etapas posteriores - estabelecimento dos $\{$ FRs $\}$ e $\{$ DPs $\}$.

Se por um lado a proposta exige na fase inicial um esforço elevado, por outro, a etapa posterior acelera a formalização (contemplada do informal ao formal) dos requisitos e, conseqüentemente, a concepção da solução de tal maneira que conforta o projetista visualizar o esforço empregado (anteriormente) em algo realístico (solução proposta) e bem fundamentado (através do axioma). É claro que a exeqüibilidade desta alternativa está diretamente vinculada ao método de projeto empregado, neste caso: Projeto Axiomático.

No processo, utiliza-se o primeiro axioma (seção 2.1.3) para a escolha da melhor solução. A vantagem desse axioma é o fato de mesmo que a solução esteja numa fase completamente abstrata, como é o caso (seção 4.3.1.2), este fornece meios formais 
(independente da aplicação) para estabelecer se a solução é aceitável, não aceitável ou ruim.

Além disto, mesmo o desenvolvedor agindo como o "senhor" do projeto (abordagem de domínios próximos), realizando o processo de tomada/escolha de decisão "por conta própria", o projeto axiomático não permite que o desenvolvedor venha a influenciá-lo. Isto ocorre porque este não é realizado de forma subjetiva, com critérios estabelecidos e avaliados pelo próprio projetista/desenvolvedor e, sim pelos conceitos formais envolvidos no primeiro axioma.

Já a definição da solução é estabelecida com base no comportamento do domínio da RNA. Domínio este que possui um fluxo de informações sempre dependente da resposta de suas entradas anteriores. Assim, considerando a ordem/seqüência que tais informações devem acontecer (baseado nas necessidades do domínio da textura - seção 4.3.1.1) para extrair a característica do padrão de entrada foi planejada/projetada à solução (o mapeamento dos requisitos funcionais e parâmetros do projeto). Isto é, a elaboração de uma matriz de projeto semi-acoplado em que a independência dos $\{$ FRs $\}$ somente é atendida se os $\{$ DPs $\}$ estiverem numa determinada seqüência.

Entretanto, o que diferencia o uso do Projeto Axiomático neste trabalho em relação aos demais exemplos encontrados na literatura (DESIGN, 2010) é o fato de atuar num domínio em que a definição das especificações é realizada de forma empírica. Ou seja, necessita de etapas posteriores tais como: a fase de teste/avaliação para o estabelecimentos de tais parâmetros.

No capítulo 3, menciona-se que caso o resultado do teste/avaliação não seja satisfatório, ajustes, modificações, adaptações ou até mesmo uma nova solução para a concepção pode ser realizada através do ciclo de ajuste (seção 3.2.3). Na prática isto ocorreu, mas de maneira diferente. Isto é, a concepção fornecida pelo desenvolvimento do projeto axiomático estava coerente com o levantamento das necessidades, mas a formulação matemática inicial estabelecida para a fase de desenvolvimento e implementação (Fase II) não era compatível com a solução proposta/fornecida. Fato considerado perfeitamente normal uma vez que a arquitetura envolvida na RNA (seção 4.3.2) difere das demais encontradas na literatura da área, principalmente no conceito da competição entre os neurônios - regional.

Assim, quando a primeira tentativa de aprendizado da RNA foi executada e, posteriormente efetuado o processo de reconhecimento/classificação, observou-se que a proposta implementada não funcionava, o que levou a um levantamento de algumas questões, tais como: 
1. Houve falha na solução proposta, isto é, no mapeamento entre o domínio funcional e físico ?

(a) tais falhas são oriundas de um levantamento de requisito e restrições errôneo?

(b) houve alguma distorção por parte do projetista/desenvolvedor na solução, isto é, propôs algo incompatível com o domínio complementar (RNA)?

2. O não funcionamento é ocasionado porque:

(a) existem falhas no código de implementação da RNA?

(b) as definições dos parâmetros iniciais para inicialização da RNA está correta?

(c) a formulação matemática estabelecida para a arquitetura é errônea?

Porém, a resposta para essas questões foi realizada de traz para frente, isto é, primeiro verificou-se se a causa está no domínio de desenvolvimento e implementação (questionamentos 02) e, posteriormente, no domínio da definição do problema (questionamentos 01).

O que dificultou a analise de tais questões foi o fato do domínio de RNA ser baseado em simulações/testes práticos. Demanda tempo e custo computacional. Todavia, quando os questionamentos retornam (ciclo de ajuste) a fase inicial da definição do problema, verifica-se claramente o quanto é importante para o rastreamento de erros/falhas à organização dos requisitos e restrições, o mapeamento/vínculo entre eles; a visualização rápida (diagrama de árvore e de fluxo) de como alterações em níveis mais elevados da solução pode afetar os mais baixos e etc.

A seguir é apresenta-se a discussão sobre a validação.

\subsubsection{Validação}

A validação é realizado de acordo com a resposta da avaliação da RNA à análise e reconhecimento de textura. Isto é, se sua resposta for satisfatória no reconhecimento da textura isso quer dizer que a especificação dos requisitos $\{F R s\}$ e parâmetros do projeto $\{$ DPs $\}$ delineados na fase I, bem como a formulação matemática utilizada para o desenvolvimento e implementação da proposta, mostram-se adequadas.

Na prática, observa-se a necessidade de checar, verificar e confirmar se as necessidades delineadas estão realmente coerentemente com os desejos do desenvolvedor e os resultados práticos obtidos. Se não existe inconsistência, omissão, ambiguidade, 
estabelecimento de relação/vínculo trocados ou falta de algum deles, bem como a definição dos parâmetros em aberto. Se existe a coerência dos $\{F R s\},\{D P s\}$ e a matriz do projeto, muito embora já exista um ciclo de ajuste responsável por tal atividade. A intenção é eliminar qualquer incoerência no projeto que por ventura possa ocorrer entre a solução implementada e as definições oriundas em fases anteriores.

A figura 5.1 ilustra de forma gráfica os locais em que tal verificação deve ocorrer.

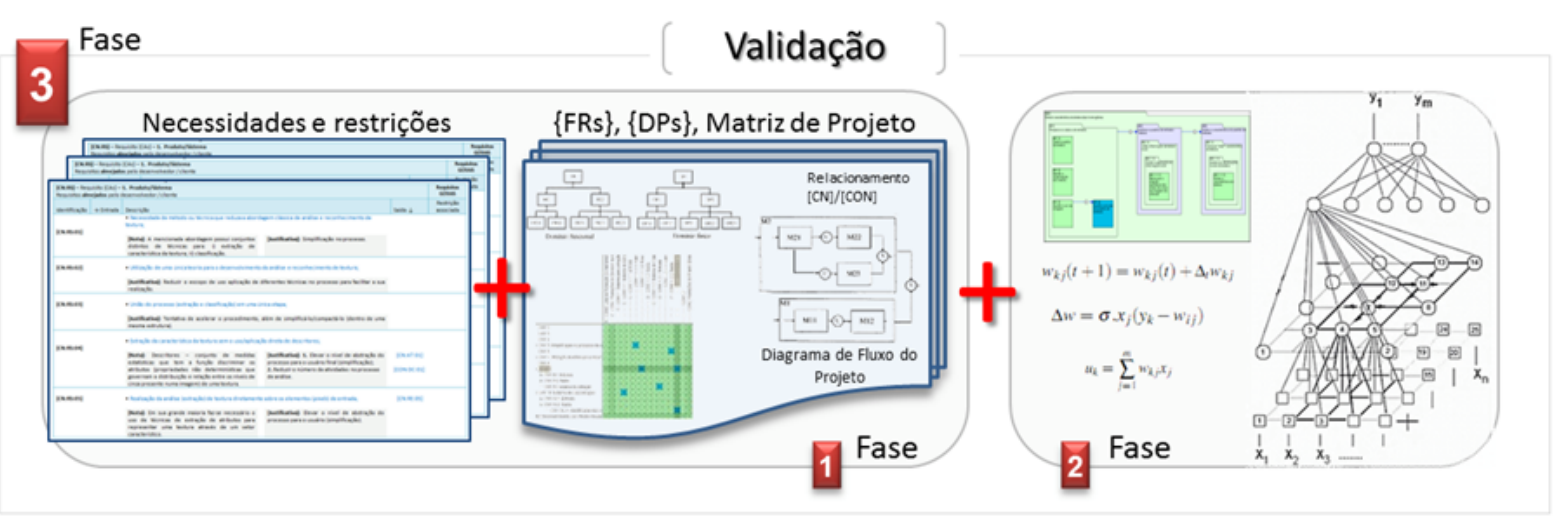

Figura 5.1: Fases envolvidas na validação da solução.

Entretanto, após a realização do funcionamento prático da solução, verifica-se claramente que o desenvolvedor/projetista possui um amadurecimento maior sobre o sistema/produto desenvolvido e, isto, facilita demasiadamente a realização/execução da validação.

Deve-se ressaltar que a mencionada atividade é de suma importância para a documentação do projeto, pois a mesma pode ser utilizada para outros fins, tais como: servir de base para sistema ou produtos subseqüentes; rastreamento e gerenciamento de requisito ao longo da evolução do produto/sistema; e etc.

Por fim, com o estudo de caso proposto, pode-se observar que a solução desenvolvida atende as necessidades/desejos gerais levantadas pelo projetista/desenvolvedor. Necessidade de método ou técnica que reduza a abordagem de análise e reconhecimento de textura; utilização de uma única teoria para o desenvolvimento de tal análise; união das atividades (extração e classificação) em uma única etapa; extração da característica da textura sem o uso/aplicação direta de descritores; realização da análise (extração) da textura diretamente sobre os elementos (pixels) de entrada são alguns dos requisitos/desejos para o sistema/projeto. Todas elas visam um único propósito: elevar o nível de abstração ao usuário final, minimizar o número de atividades envolvidas, bem como reduzir as diferentes técnicas presentes no processo de análise e reconhecimento de textura. 
Deve-se salientar que os fatos acima mencionados não indicam que a solução fornecida pelo estudo de caso aqui nesta tese de doutorado seja melhor do que os demais presentes na literatura (cada uma possui uma característica própria). Qualquer afirmativa a este nível exige análises mais densas (em termo de textura), bem como um estudo comparativo - alvo a ser explorado em trabalhos futuros.

No entanto, o estudo de caso apresentado neste trabalho tem como objetivo verificar se a proposta é factível de ser empregada/realizada. No estudo exposto, pode-se afirmar que foi satisfatório e com bons resultados. Todavia, para uma validação mais concreta do processo em si, acredita-se que seja necessário à aplicação deste em outros estudos de caso.

\subsection{Análise dos Resultados}

Esta seção tem como objetivo analisar e discutir alguns dos resultados obtidos pela análise e reconhecimento de textura fornecido pela RNA. Sendo assim, apresenta-se na tabela 5.2 o resumo das seis simulações que envolveram desde texturas homogêneas sintéticas até as naturais. Maiores detalhes sobre os parâmetros utilizados podem ser encontrados na seção 4.3.3.

Tabela 5.2: Resumo das seis simulações da RNA em relação a texturas homogêneas sintéticas e naturais.

\begin{tabular}{|c|c|c|c|c|c|c|}
\hline \multirow[t]{3}{*}{ Simulações } & \multirow[t]{3}{*}{ Tipo de Imagem } & \multirow{3}{*}{$\begin{array}{c}\text { Número de } \\
\text { Imagens para } \\
\text { Treinamento }(5 \times 5)\end{array}$} & \multirow{3}{*}{$\begin{array}{c}\text { Número } \\
\text { Total de } \\
\text { Neurônios }\end{array}$} & \multicolumn{3}{|c|}{ Taxa de Acertos (\%) } \\
\hline & & & & \multicolumn{3}{|c|}{ Classes } \\
\hline & & & & 01 & 02 & 03 \\
\hline 01 & Sintética & 36 & 57 & 100 & 98.1651 & \\
\hline 02 & Natural - tijolo & 60 & 57 & 98.5585 & 98.3836 & \\
\hline 03 & Natural - indústria têxtil & 60 & 57 & 99.2268 & 92.6087 & \\
\hline 04 & $\begin{array}{l}\text { Natural - defeitos em } \\
\text { madeira }\end{array}$ & 36 & 45 & 99.0587 & 100 & \\
\hline 05 & Natural - câncer de pele & 80 & 67 & 99.9638 & 96.7469 & \\
\hline 06 & Natural - globo ocular & 80 & 63 & 99.5138 & 99.6147 & 87.0968 \\
\hline
\end{tabular}

Dentre os resultados expostos discute-se aqui três deles - simulações 03, 05 e 06. A escolha dar-se-á em função da taxa de acerto.

A simulação 03 refere-se à análise da textura natural num caso específico para a indústria têxtil, em que foi considerada como falha as manchas pretas no tecido. Embora o resultado para tal identificação tenha sido de $92.6087 \%$, um resultado satisfatório quando se observa a segmentação final entre as falhas e o tecido bom, apresentados na figura 4.15 , pode-se observar alguns fatos que influenciam essa taxa. 
O primeiro refere-se a imagem base utilizada para efetuar os cálculos estatísticos. Foram consideradas apenas as manchas pretas grandes como falhas. Os pontos pequenos $(5 \times 5)$ foram rotulados como característicos do próprio tecido. Assim, por se tratar de uma imagem com tamanho 500x360, em que a análise é realizada de 5x5 em $5 \times 5$ pixels, os pontos pretos característicos dos tecidos que caírem dentro da região de análise da RNA, serão considerados como falha. Ou seja, o resultado da RNA é correto com base na sua aprendizagem, muito embora não seja para a aplicação.

Logo, o fato acima mencionado impacta no resultado estatístico final. Para minimizar tal efeito seria necessário um tratamento posterior, isto é, considerar um tamanho mínimo para a mancha do tecido de maneira a excluir os pequenos pontos aleatórios encontrados/reconhecimentos. Todavia, tal premissa não foi adotada nesta simulação.

O segundo motivo refere-se às regiões próximas à borda das manchas. Isto é, verifica-se no conjunto de treinamento que existe uma pequena sobreposição de dados entre os dois grupos. Esta pode ser observada através do histograma ${ }^{1}$ (Fig 5.3) da área 2 e 3 (considerado como mancha) e área 5 (considerado como tecido normal). No entanto, se for observada novamente à segmentação do tecido normal na figura 4.16 $\mathrm{b}$ verifica-se claramente que para a aplicação, tal fato não ocasiona problemas, pois a análise $5 \times 5$ é bem minuciosa/meticulosa.

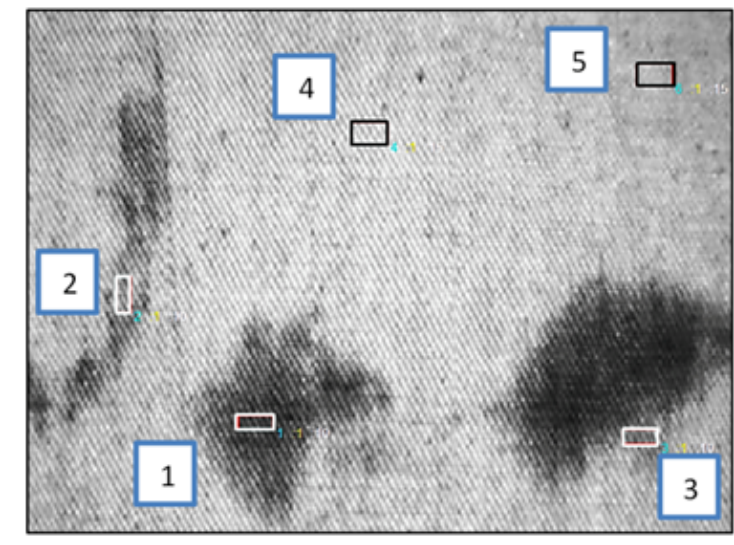

(a) Tecido com manchas (500x360) - as áreas $1,2,3$ representam a classe $\mathrm{A}$ com manchas e as áreas: 4,5 representa a classe $B$ com tecido normal.

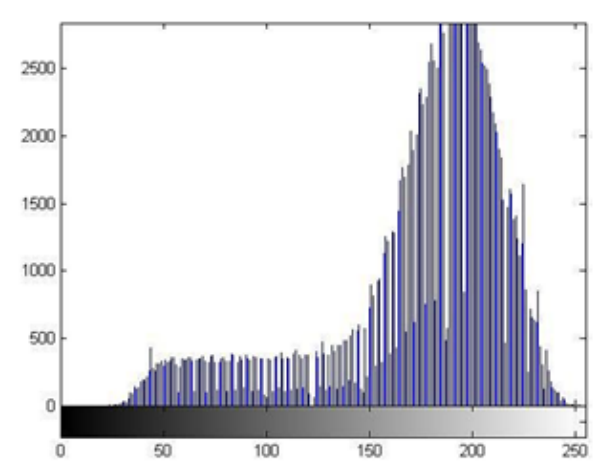

(b) Histograma da imagem

Figura 5.2: Histograma da imagem utilizada na simulação 03 .

A simulação 04 refere-se à análise da textura natural num caso específico para a área médica - câncer de pele, em que foi considerado a classificação de dois tipos de

\footnotetext{
${ }^{1}$ Uma representação da distribuição de freqüência dos níveis de cinza de uma imagem. No entanto, estima somente a propriedade individual de tais elementos e não a relação de vizinhança (arranjo estrutural) entre os mesmos.
} 


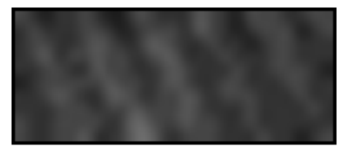

(a) Área $1(25 \times 10)$

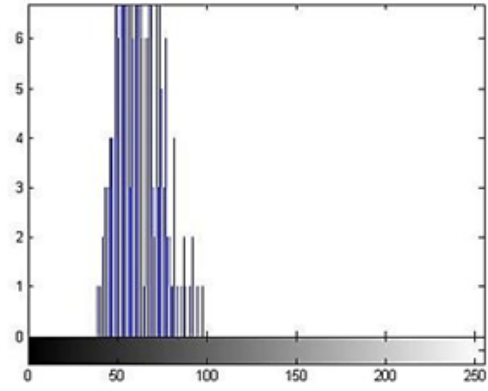

(d) Histograma área 1

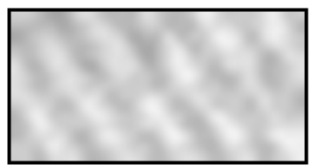

(g) Área 4 (25x15)

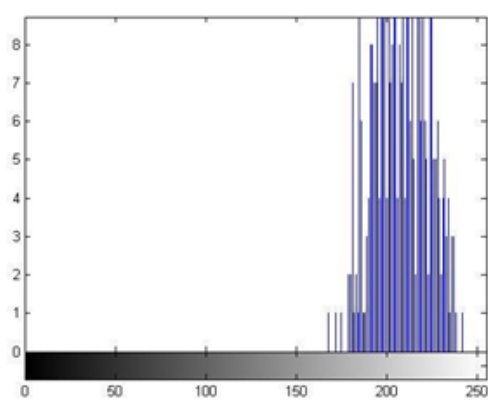

(1) Histograma área 4

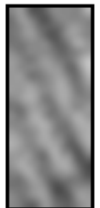

(b) Área 2 (10x25)

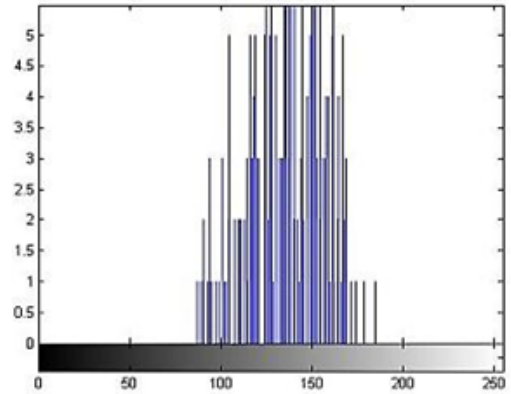

(e) Histograma área 2

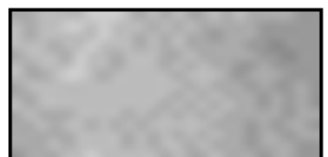

(h) Área $5(25 \times 15)$

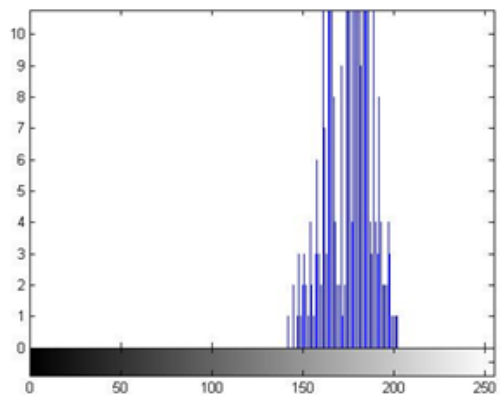

(m) Histograma área 5

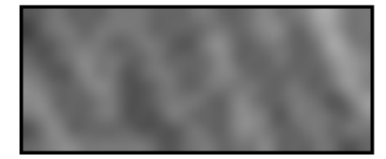

(c) Área $3(25 \times 10)$

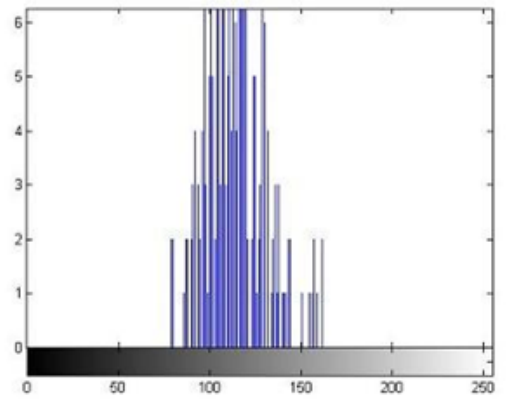

(f) Histograma área 3

Figura 5.3: Histograma do conjunto de dados utilizados para o treinamento da RNA (áreas:1,2,3 - Classe A; áreas 4,5 - Classe B).

texturas: o primeiro - tecido normal; e o segundo - tecido com câncer. De acordo com o resultado da tabela 5.2, 96.77469\% foi à taxa de acerto para a identificação de tecido com câncer. Um resultado satisfatório, muito embora tenha se observado que a maior taxa de erro ocorre na região superior da imagem, como mostra a figura 4.16 - a.

Em vista do fato acima descrito, os histogramas foram levantados e apresentados na figuras 5.4 e 5.5 . Mostram claramente que a RNA desenvolvida não analisa somente a distribuição da intensidade dos pixels (falsa sensação que se pode ter ao visualizar os histogramas do exemplo anterior - simulação 03) que compõe a imagem e, sim a relação estrutural (bi-dimensional) presente entre os mesmos (definido no levantamento de requisitos). 
Com relação ao erro, observa-se que a tal ocorrência é numa região entre a pele saudável e o inicio da doença na pele. Esta possui tonalidade e relação entre os pixels bem próximas da pele sem doença (vista na comparação entre os histogramas da Fig 5.5 - m, referente à pele normal, e Fig 5.5 - p, pele com indício de câncer). Acredita-se que esse seja o motivo para tal fato (generalização).

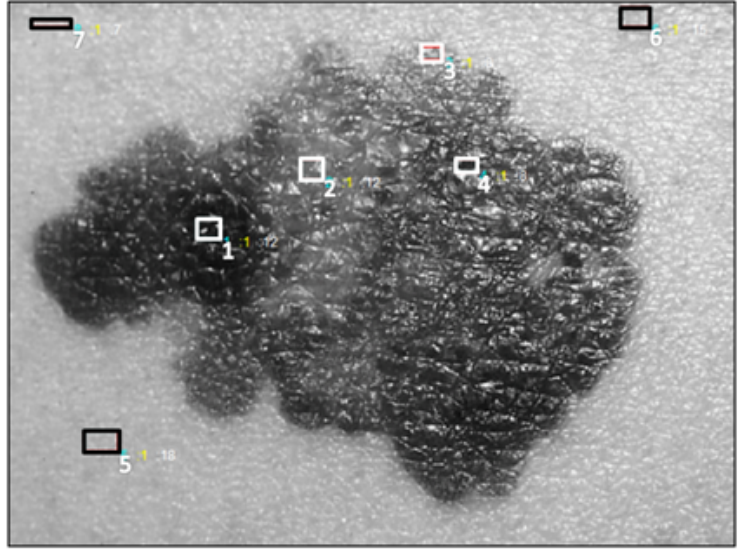

(a) Câncer de pele e as respectivas áreas/texturas consideradas no conjunto de treinamento à RNA (áreas 1, 2, 3 e 4 - pele com câncer; áreas 5,6 e 7 pele normal).

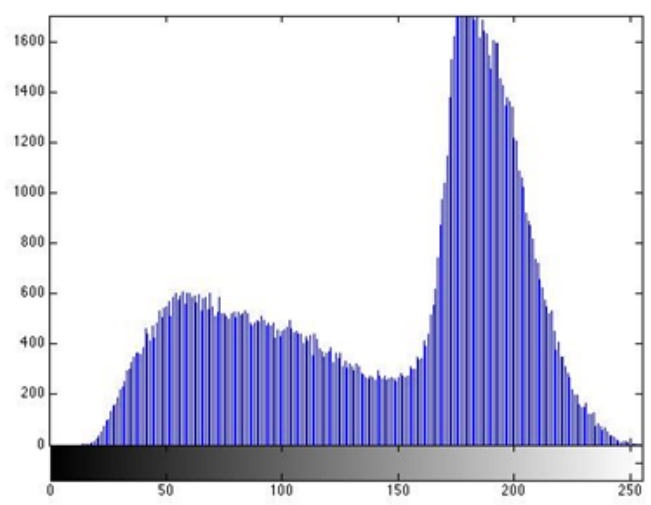

(b) Histograma da imagem - a

Figura 5.4: Histograma da imagem utilizada na simulação 04. 

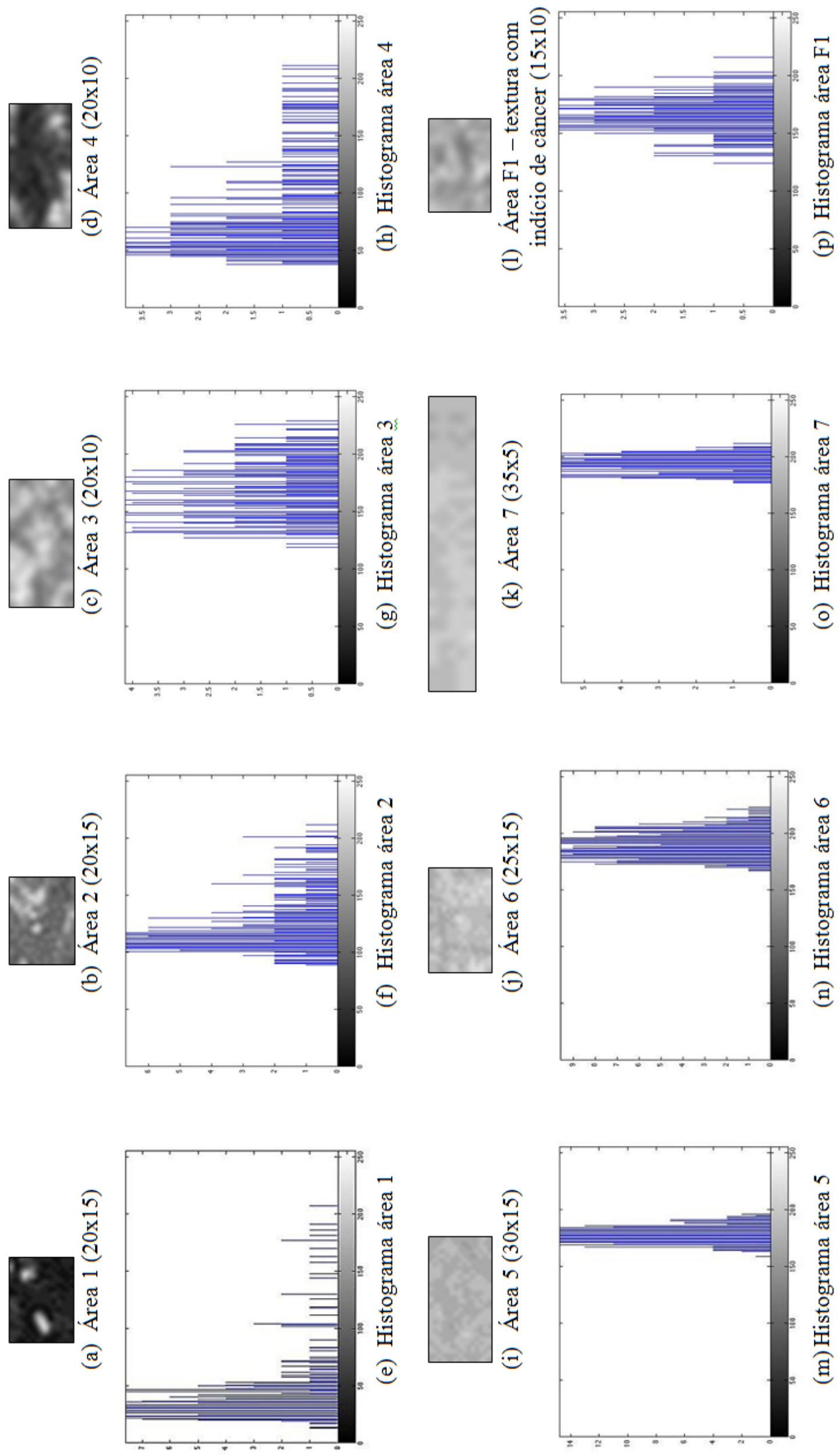

Figura 5.5: Histograma do conjunto de dados utilizado na RNA - Câncer de pele (áreas 1, 2, 3 e 4 - textura de câncer; áreas 5, 6 e 7 textura da pele normal). 
Já a simulação 06 foi estabelecida com o objetivo de testar a capacidade da rede classificar três diferentes tipos de texturas naturais. Da mesma forma que a análise anterior, foram levantados os histogramas dos dados de treinamento da RNA, apresentados nas figuras 5.6 e 5.7. No entanto, verifica-se que a taxa de erro ocorrido na classe C (íris) é afetada diretamente pelo reflexo da luz na córnea do globo ocular. Ou seja, impacta na mudança da tonalidade dos pixels pretos e, conseqüentemente, na textura daquela região (apresentada na Fig. 4.23 - c).

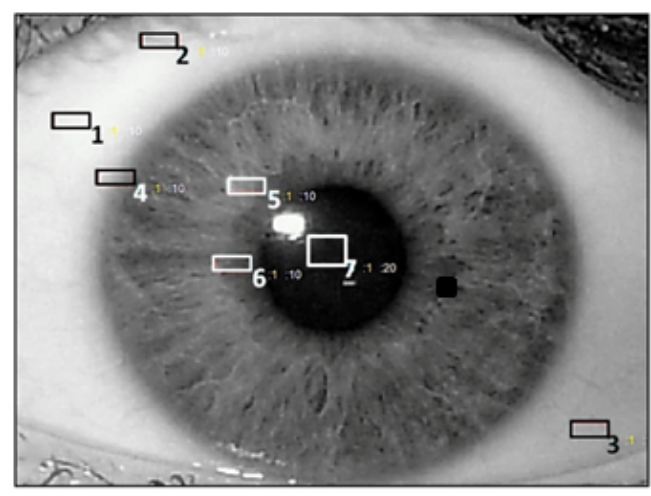

(a) Globo ocular e as respetivas áreas de interesse para o treinamento da RNA $(1,2,3$ esclera - classe A; 4,5,6 - íris - classe B, 7 pupila - classe C)

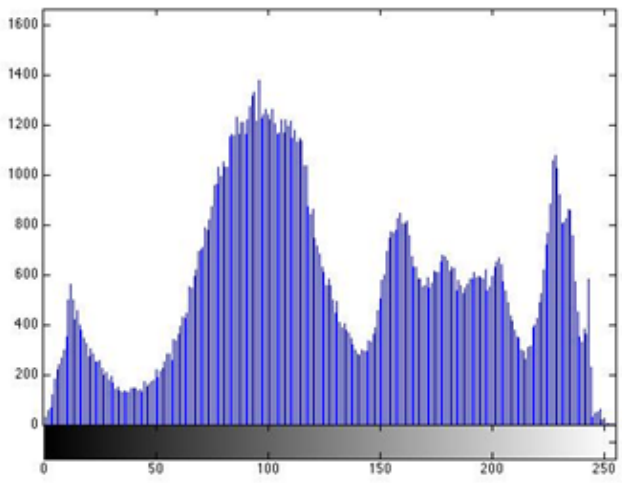

(b) Histograma do globo ocular

Figura 5.6: Histograma da imagem utilizada na simulação 06. 
(a) Área 1

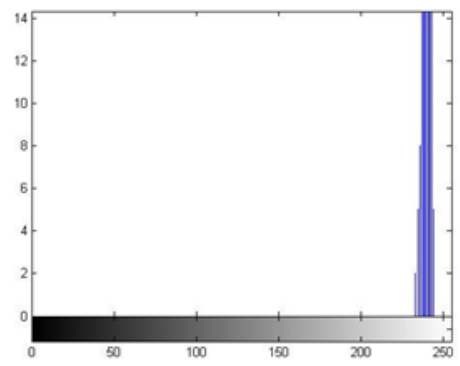

(d) Histograma área 01

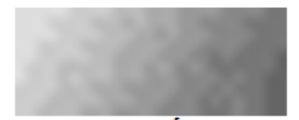

(g) Área 4

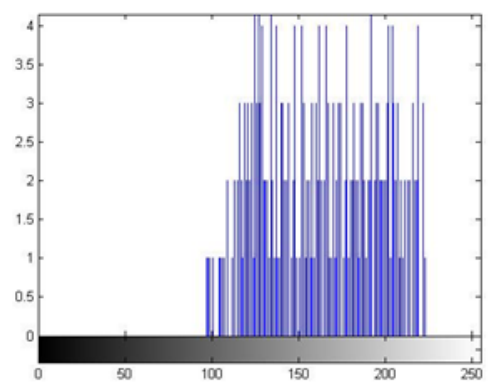

(j) Histograma área 04

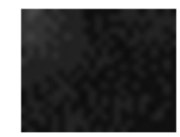

(m) Área 7

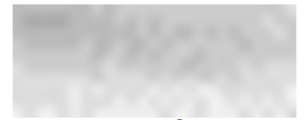

(b) Área 2

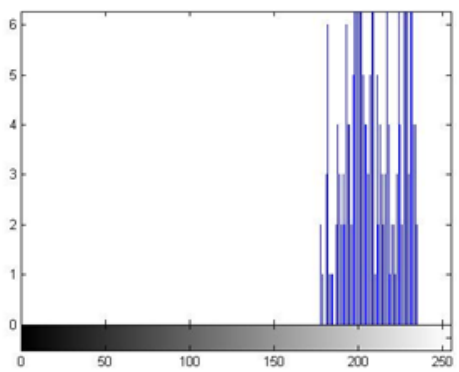

(e) Histograma área 02

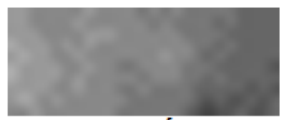

(h) Área 5

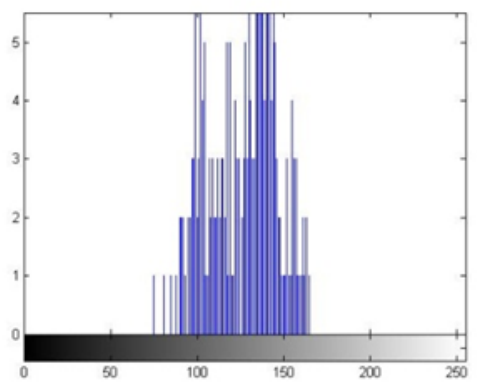

(k) Histograma área 05

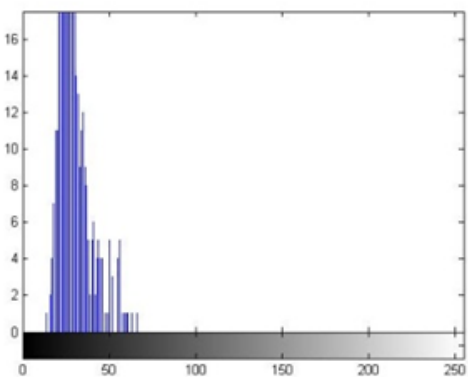

(n) Histograma área 07

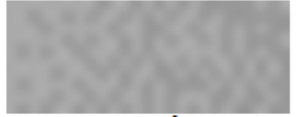

(c) Área 3

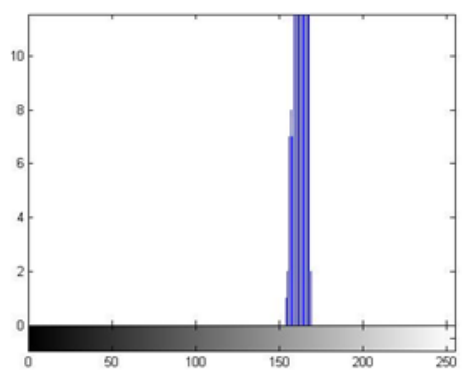

(f) Histograma área 03

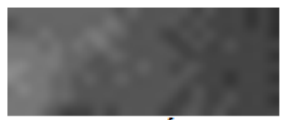

(i) Área 6

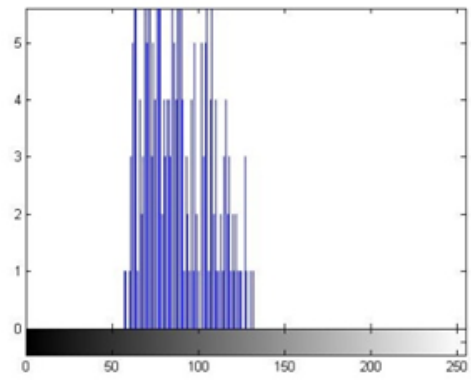

(1) Histograma área 06

Figura 5.7: Histograma do conjunto de dados utilizado no treinamento da na RNA simulação 06.

\subsection{Resumo do Capítulo}

Neste capítulo foram apresentadas as discussões sobre o processo e sua aplicação, a validação e as análises dos resultados.

Foi discutida a abordagem empregada na eliciação em vista do desenvolvedor assumir o papel do próprio cliente/especialista. Ou seja, o processo de levantamento de 
requisitos foi baseado nas informações explícitas em documentos (livros e artigos).

Na prática, esse tipo de abordagem exige um esforço elevado por parte do desenvolvedor para a aquisição, leitura, entendimento e compreensão das informações/ necessidades. Entretanto, por se encontrarem de forma dispersa e não estruturada, como é o caso neste trabalho, exige uma atenção parcimoniosa para a percepção/estabelecimento do problema, identificação das reais necessidades (em potencial), desejos e restrições.

Em contrapartida, tal abordagem também fornece várias vantagens (descritas na tabela 5.1), por exemplo, enquanto um cliente contribui de forma abstrata, genérica, não-organizada, expressa de forma difusa e quase que puramente funcional para os requisitos, o desenvolvedor baseado no conhecimento explícito pode estabelecer de forma concisa, estruturada em categorias, subcategorias, justificados, com nota adicional de informações e possíveis relações entre eles.

Também são apresentadas as vantagens de se utilizar o critério de justificativa, bem como a relação entre os requisitos e restrições, ou seja, um mapeamento de auxílio à compreensão das decisões a serem tomadas em etapas posteriores.

Discute-se também que, se por um lado o processo proposto exige na fase inicial um esforço elevado, por outro, a etapa posterior acelera a formalização dos requisitos, e consequentemente, a concepção da solução. Para tal se utiliza da abordagem de Projeto Axiomático, que através do primeiro axioma permite que mesmo numa fase completamente abstrata do projeto, meios formais possam (axiomas) ser utilizados para distinguir entre uma solução aceitável, não aceitável ou ruim.

Além disto, mesmo que o desenvolvedor aja como o "senhor"do projeto, abordagem dos domínios próximos, a tomada/escolha de decisão possa ser efetuada sem que o projetista/desenvolvedor a influencie.

Já em relação à solução, esta foi definida com base na ordem/seqüencia que as informações aconteceram no domínio complementar. Ou seja, através de uma matriz de projeto semi-acoplado. Também foi mencionado que a diferença do uso do Projeto Axiomático neste trabalho para as demais presentes na literatura, está no fato de atuar num domínio em que a definição das especificações é realizada de forma empírica. Isto é, exigindo a execução de etapas posteriores para o seu estabelecimento real e concreto.

Discute-se também o ciclo de ajuste proposto, levantando-se alguns questionamentos em relação à forma de análise tanto para a fase de desenvolvimento e implementação, quanto para a da definição do problema. Foram levantados os pontos críticos e positivos delas. 
Posteriormente, explana-se sobre a validação, uma atividade que tem por objetivo checar, verificar e confirmar se as necessidades delineadas estão realmente coerentemente com os desejos do desenvolvedor e os resultados práticos obtidos. Na prática o objetivo é eliminar qualquer incoerência que por ventura possa ter ocorrido no projeto. A importância desta dar-se-á em vista da documentação. Isto é, um documento que pode ser utilizado para outros fins, tais como: servir de base para sistema ou produtos subseqüentes; rastreamento e gerenciamento de requisito ao longo da evolução do produto/sistema; e etc. Em seguida salienta-se que os desejos/requisitos gerais delineados no projeto não indicam que a solução fornecida pelo estudo de caso aqui nesta tese de doutorado, seja melhor do que os demais presentes na literatura. Isto ocorre porque qualquer afirmativa a este nível faz-se necessário um estudo comparativo - alvo para trabalhos futuros.

No entanto, afirma-se que o resultado obtido pelo processo proposto foi satisfatório e com bons resultados, muito embora para uma validação concreta deste, em si, seja necessário a sua aplicação em outros estudos.

Por último, discute-se a análise dos resultados. Foi apresentada na tabela 5.2 os resultados sucintos de todas as seis simulações desenvolvidas neste trabalho, em que se explanam algumas delas em vista da taxa de erro. Além disto, apresentam-se justificativas e elementos gráficos que auxiliam a interpretação do funcionamento da RNA desenvolvida. 


\section{Conclusões e Trabalhos Futuros}

Neste trabalho foi apresentada a proposta de um processo de projeto, que leva em consideração a proximidade dos domínios, para orientar o especialista/projetista da área, a desenvolver soluções mais rápidas à abordagem clássica da análise e reconhecimento de textura.

Uma proposta efetiva foi realizada e os resultados de um estudo de caso especialmente escolhido para investigar a análise e reconhecimento de textura foram registrados, explanados e apresentados no decorrer do trabalho. Esta por sua vez auxiliou o estabelecimento das seguintes conclusões:

- Foi apresentado um único estudo de caso, portanto a importância deste está ligada à validação do processo de forma geral. O domínio de aplicação não pode ser generalizado, naturalmente, mas note-se que este foi escolhido exatamente por ser bastante sensível ao processo, especialmente no que diz respeito à velocidade de desenvolvimento. O importante porém é a proximidade de domínios que o exemplo pressupõe.

- Embora a composição das técnicas utilizadas na proposta forneçam subsídios para estabelecer uma solução formal e fundamentada em documentos, reduzindo o processo de tentativa e erro, isto não garante que soluções errôneas sejam fornecidas em função do pouco conhecimento do domínio de aplicação. Sendo assim, pode-se concluir que há um fluxo semântico entre as fases I, II e III e um processo evolutivo crescente (além dos requisitos de coerência) exigindo do desenvolvedor o conhecimento das áreas envolvidas no projeto;

- A fase inicial de levantamento das necessidades e restrições, por outro acelera rapidamente o estabelecimento da solução. Naturalmente este efeito é tão maior quanto melhor a análise dos requisitos, especialmente se métodos mais formais puderem ser utilizados. A possibilidade do uso destes métodos depende do domínio de aplicação;

- No caso de domínios próximos é possível o uso de conhecimento explícito, expresso em documentos, o que representa uma vantagens no processo de eliciação 
e análise, em relação ao processo tradicional, característico dos domínios distantes (que depende de relacionamento, comunicação e transferência de conhecimento entre o cliente e desenvolvedor). No estudo de caso foi possível detectar uma melhora no discernimento sobre os requisitos contraditórios ou redundantes, auxiliando o estabelecimento de soluções mais consistentes; maior facilidade no rastreamento dos requisitos; melhoria na determinação de vínculos entre requisitos e restrições.

- O desenvolvimento de conhecimento específico (associado ao domínio de aplicação) foi representado no estudo de caso, pela proposição de uma nova arquitetura de rede neural artificial para extração e classificação de características locais e não globais dos padrões de entrada, cuja atividade é realizada diretamente na representação espacial bidimensional da imagem/textura de entrada. Assim, a análise e reconhecimento/classificação de texturas é realizado em uma única fase de aprendizado;

- Uma nova abordagem, fruto do desenvolvimento do estudo de caso, foi apresentada para a competição entre os neurônios, denominada de competição regional. $\mathrm{Na}$ literatura não se encontra relatos sobre tal definição. No entanto, faz-se a ressalva de que um estudo mais detalhado sobre o resultado dessa modalidade de competição deve ainda ser realizado;

- Em relação ao processo proposto, as vantagens da aplicação do método axiomático a domínios próximos (com relação à mesma aplicação a domínios distantes) ficaram bastante claras, permitindo a sua extensão a outros domínios semelhantes, muito embora seja necessário sempre o desenvolvimento de conhecimento específico do domínio - o que é facilitado também pelo processo e pelo sistemático do conhecimento explícito;

- A proposta forneceu resultados promissores a todas as áreas envolvidas, sendo elas: Engenharia de Projeto, Redes Neurais Artificiais e Processamento Digital de Imagens, em específico, análise de textura. Além disto, proporcionou a multidisciplinaridade entre as três grandes áreas mencionadas;

Assim, o objetivo de estabelecer as devidas diferenças entre processos de projeto associados a domínios distantes e domínios próximos foi plenamente atingido, onde um estudo minucioso sobre o primeiro foi objeto da dissertação de mestrado do autor e um estudo mais extenso, com desenvolvimento associado de conhecimento específico ao domínio, foi realizado nesta tese. Isto mostra que na Engenharia de Projeto existe 
por vezes uma confusão entre métodos e técnicas válidas em uma das situações estudadas e usadas na outra sem a devida análise de validade. Mostra ainda que um certo preconceito desenvolvido por desenvolvedores de projetos em domínios próximos com respeito a técnicas de eliciação de requisitos em domínios distantes se justifica formalmente, e aponta novamente para o uso indevido de técnicas, pertinentes em um caso, no outro. Entretanto dado a dificuldade de tratar formalmente a fase inicial, estes resultados dependeram muito de um esforço na aplicação da técnica etnográfica na dissertação, e agora, de um desenvolvimento que além de se concentrar no processo de projeto, precisou avançar sobre as técnicas especificas usadas no domínio de aplicação a até trazer uma contribuição neste exercício.

Como trabalho futuro esse se estende à:

- Aplicar tal proposta em outros estudos de caso para avaliar o processo de generalização da abordagem apresentada e desenvolver uma representação simbólica que explore mais a rastreabilidade de requisitos em domínios próximos, onde esta parece mais factível;

- Ampliar o escopo de texturas usadas na RNA desenvolvida, bem como elaborar um estudo comparativo entre ela e as demais técnicas presentes na literatura para a análise e reconhecimento de textura;

- Um estudo mais detalhado, em termos da representação dos dados, em relação à competição regional desenvolvida na arquitetura da rede neural artificial implementada.

- Ampliar o estudo e o proceso para domínios próximos para o caso de sistemas complexos e de maior porte, de grande interesse acadêmico e comercial. 


\section{Referências Bibliográficas}

ACCLARODFSS. Ferramenta computacional para desenvolvimento de projeto utilizando a abordagem de projeto axiomático. April 2010. Disponível em: $<$ http://www.dfss-software.com/>.

ALBREGTSEN, F. Statistical Texture Measures Computed From Gray Level Run Length Matrices. University of Oslo,Department of Informatics, Image Processing Laboratory. [S.1.], 1995. Disponível em: <http://www.ifi.uio.no/in384/info/glrlm.ps $>$.

ALBREGTSEN, F.; NIELSEN, B.; DANIELSEN, H. E. Adaptive gray level run length features from class distance matrices. In: Proc. 15th Int Pattern Recognition Conf. [S.1.: s.n.], 2000. v. 3, p. 738-741.

ALEXANDER, I.; ROBERTSON, S. Understanding project sociology by modeling stakeholders. IEEE Software, v. 21, n. 1, p. 23-27, 2004.

AMADASUN, M.; KING, R. Textural features corresponding to textural properties. IEEE Trans. System, v. 19, n. 5, p. 1264-1274, 1989.

ANYS, H.; HE, D.-C. Evaluation of textural and multipolarization radar features for crop classification. IEEE Transactions on Geoscience and Remote Sensing, vol. 33, n. 5, p. pp. 1170-1181, 1995.

ARCIDIACONO, G.; CITTI, P.; FONTANA, V.; MARTELLI, T. Reliability improvement of car sliding door using axiomatic approach. In: Proceedings of ICAD 2004 - the 3rd International Conference on Axiomatic Design. [S.1.: s.n.], 2004.

AULAKH, S. S.; GILL, J. Lean manufacturing using axiomatic design. In: Proceedings of the World Congress on Engineering. [S.1.: s.n.], 2009.

BABIC, B. Axiomatic design of flexible manufacturing systems. International Journal of Production Research,, v. 37, n. 5, p. 1159-1173, 1999.

BAEA, S.; LEEB, J. M.; CHUB, C. N. Axiomatic design of automotive suspension systems. CIRP Annals - Manufacturing Technology, v. 51, n. 1, p. 115-118, 2002.

BALLARD, D. H. E.; BALLARD, C. M. Computer Vision. [S.1.]: Prentice-Hall, Englewood Cliffs NJ, 1982.

BANG, I. C.; HEO, G. An axiomatic design approach in development of nanofluid coolants. Applied Thermal Engineering, v. 29, n. 1, p. 75-90, 2009.

BARALDI, A.; PARMIGGIANI, F. An investigation of the textural characteristics associated with gray level cooccurrence matrix statistical parameters. IEEE Transactions on Geoscience and Remote Sensing, vol. 33, n. 2, p. pp. 293-304, 1995.

BARRONS, G.; BUTLER, F. Statistical and spectral texture analysis methods for discrimination of bread crumb images. In: IUFOST - World Congress of Food Sciences Technology. [S.1.: s.n.], 2006. 
BEAR, M.; CONNORS, B.; PARADISO, M. Neuroscience: Exploring the Brain. [S.1.]: Lippincott Williams \& Wilkins; third edition, 2006.

BEAR, M. F.; CONNORS, B. W.; PARADISO, M. Neurociências - Desvendando o Sistema Nervoso. [S.1.]: Editora Artmed,3 edição, 2008.

BEYER, H.; HOLTZBLATT, K. Apprenticing with the customer: A collaborative approach to requirements definition. Communications of the ACM, v. 38, n. 5, p. 45-52, 1995.

BEYMER, D. J. Face recognition under varying pose. In: Proc. CVPR '94. IEEE Computer Society Conf Computer Vision and Pattern Recognition. [S.1.: s.n.], 1994. p. $756-761$.

BHARATHI, V. S.; VIJILIOUS, M. A. L.; GANESAN, L. Orthogonal moments based texture analysis of ct liver images. Pattern Recognition Letters, v. 29, p. 1868-1872, 2008.

BLAXTER, J.; MCKAY, A.; PENNINGTON, A.; AGOURIDAS, V. Supply chain design: An application of axiomatic design. In: Proceedings of ICAD2002 - Second International Conference on Axiomatic Design. [S.1.: s.n.], 2002.

BORCHANI, M.; CLOPPET, F.; ATALAY, V.; STAMON, G. Change detection in aerial images. In: Proceedings of the First Canadian Conference on Computer and Robot Vision. [S.1.: s.n.], 2004. p. 7695-2127.

BOVIK, A. Handbook of Image and Video Processing. [S.1.]: Academic Press, 2000. $367 \mathrm{p}$.

BOVIK, A. C.; CLARK, M.; GEISLER, W. S. Multichannel texture analysis using localized spatial filters. IEEE Trans, v. 12, n. 1, p. 55-73, 1990.

BRODATZ, P. Brodatz Texture. September 2009. Disponível em: $<$ http://www.ux.uis.no/ tranden/ brodatz.html $>$.

BROWN, C. Elements of Axiomatic Design - a simple and practical approach to engineering design, Materials of the course from Axiomatic Design Workshop. May 2010. Disponível em: < http://www.axiomaticdesign.org/>.

CALARGE, F. A. Uma proposta de um Modelamento de Gestão Sistêmica de Qualidade Baseada na Abordagem do Axiomatic Design. Tese (Doutorado) Universidade Estadual de Campinas, 2000.

CASTELLANO, G.; BONILHA, L.; LI, L.; CENDES, F. Texture analysis of medical images. Clinical Radiology, v. 59, p. 1061-1069, 2004.

CHAN, C.; PAND, G. K. H. Fabric defect detection by fourier analysis. IEEE Transactions on Industry Application, v. 36, n. 5, 2000.

CHANDLER, R. C.; ARROYO, A. A.; NECHYBA, M.; SCHWARTZ, E. M. Robot navigation and textural analysis. In: Conference on Recent Advances in Robotic. [S.1.: s.n.], 2003.

CHANDRARATNE, M.; SAMARASINGHE, S.; KULASIR, D.; BICKERSTAFFE, R. Prediction of lamb tenderness using image surface texture features. Journal of Food Engineering, v. 77, n. 3, p. 492-499, 2006. 
CHANG, T.; KUO, C.-C. J. Texture analysis and classification with tree-structured wavelet transform. IEEE Transactions on Image Processing, Vol. 2, n. 4, p. pp. 429-441, 1993.

CHAUDHURI, B. B.; SARKAR, N. Texture segmentation ysing fractal dimensions. IEEE Transactions and Pattern Analysis and Machine Intelligence, v. 17, p. 72-77, 1995.

CHEN, C.; PAUL, F.; WANG, S. Handbook of pattern recognition \& computer vision. [S.1.]: World Scientific Publishing Company, 3rd edition, 2005.

CHO, C.-S.; CHUNG, B.-M.; PARK, M.-J. Development of real-time vision-based fabric inspection system. IEEE Transactions on Industrial Electronics, v. 52, n. 4, p. 1073-1079, 2005.

CHU, A.; SEHGAL, C.; GREENLEAF, J. Use of gray value distribution of run lengths for texture analysis. Pattern Recognition Letters, v. 11, p. 415-420, 1990.

CIOCCA, G.; SCHETTINI R., Z. V. Open-ended search in high quality image catalogues. In: International Conference on Advances in Infrastructure for Electronic Business, Science, and Education on the Internet, L'Aquila 31 Luglio. [S.1.: s.n.], 2000.

CLAUSI, D. A.; JERNIGAN, M. E. Designing gabor filters for optimal texture separability. Pattern Recognition Society, v. 33, p. 1835-1849, 2000.

COBURN, C. A.; ROBERTS, A. C. B. A multiscale texture analysis procedure for improved forest stand classification. International Journal of Remote Sensing, v. 25, p. 4287-4308, 2004.

COCHRAN, D. S.; REYNAL, V. A. Axiomatic Design of Manufacturing Systems. Massachesetts Insttitute of Technology, The Lean Aircraft Initiative Report Series RP96-05-14 November. [S.1.], 1996.

COOPER, G. The textural analysis of gravity data using cooccurrence-matrices. Computers Geosciences, v. 30, p. 107-115, 2004.

COSSU, R. Segmentation by means of textural analysis. Pixel, v. 1, p. 21-24, 1998.

CROSS, G.; JAIN, A. K. Markov random field texture models. IEEE Transactions on Pattern Analysis and Machine Intelligence, v. 5, p. 25-39, 1983.

DAOUDAL, G.; DEBANNE, D. Long-term plasticity of intrinsic excitability:

Learning rules and mechanisms. Learning and Memory, v. 10, p. 456-465, 2003.

DAUBECHIES, I. Ten Lectures on Wavelets. [S.1.]: SIAM: Society for Industrial and Applied Mathematics, 1 edition, 1992.

DAUGMAN, J. G. Uncertainty relation for resolution in space, spatial frequency and orientation optimized by two-dimensional visual cortical filters. Journal of Optical Society of America, v. 7, p. 1160-1169, 1985.

DAUGMAN, J. G. Complete discrete 2-d gabor transforms by neural networks for image analysis and compression. IEEE Transactions on Acoustics, Speech and Signal Processing, v. 36, n. 7, p. 1169-1179, 1988. 
DELENNE, C.; RABATEL, G.; AGURTO, V.; DESHAYES, M. Vine plot detection in aerial images using fourier analysis. In: 1st International Conference on Object-based Image Analysis - OBIA. [S.1.: s.n.], 2006.

DESAI, N. Homeostatic plasticity in the cns: synaptic and intrinsic forms. Journal of Physiology, v. 97, p. 391-402, 2003.

DESAI, N. S.; RUTHERFORD, L. C.; TURRIGIANO, G. Plasticity in the intrinsic excitability of cortical pyramidal neurons. Nature Neuroscience, v. 2, p. 515-520, 1999.

DESIGN, A. Axiomatic Design Solutions Inc. April 2010. Disponível em: $<$ http://www.axiomaticdesign.com/technology/papers.asp $>$.

DO, S.; SUH, N. P. Axiomatic design of software systems. CIRP Annals Manufacturing Technology, v. 49, n. 1, 2000.

DO, S. H.; PARK, G. J. Application of design axioms for glass bulb design and software development for design automation. Journal of Mechanical Design of the $A S M E$, v. 123, p. 322-329, 2001.

DUDA, R.; HART, P. Pattern Classification. [S.1.]: John Wiley \& Sons, New York, 2nd edition, 2001.

DURMUSOGLUA, M.; KULAKB, O. A methodology for the design of office cells using axiomatic design principles. Omega - The International Journal of Management Science, v. 36, p. 633-652, 2008.

EL-HANIK, B. Axiomatic Quality: Integrating Axiomatic Design with Six-Sigma, Reliability, and Quality Engineering. [S.1.]: Wiley, ISBN: 978-0-471-68273-8, 2005.

FAGAN, C.; DU, C. J.; DONNEL, C. Relations between radiograph texture analysis and microcomputed tomography in two rat models of bone. Journal of Food Science, v. 73, 2008.

FAUSETT, L. Fundamentals of Neural Networks: Architectures, Algorithms and Applications. [S.1.]: Prentice-Hall, Inc., Upper Saddle River, NJ, USA, ISBN: 0-13-334186-0, 1994.

FERREIRA, M. J.; SANTOS, C. Tracking system using texture cue based on wavelet transform. In: In 7th Portuguese Conference on Automatic Control, Lisboa, Portugal. [S.l.: s.n.], 2006.

FOGEL, D. S. Gabor filters as texture discriminator. Biological Cybernetics, v. 61, p. 103-113, 1989.

FREEBOROUGH, P. A.; FOX, N. C. Mr image texture analysis applied to the diagnosis and tracking of alzheimer's disease. IEEE Transactions on Medical Imaging, Vol. 17, n. 3, p. pp. 475-478, 1998.

FREY, D. D.; DYM, C. L. Validation of design methods: lessons from medicine. Research in Engineering Design, v. 17, 2006.

FREY, D. D.; JAHANGIR, E.; ENGELHARDT, F. Computing the information content of decoupled designs. Research in Engineering Design, v. 12, n. 2, p. 90-102, 2000. 
GABOR, D. Theory of communication. Journal of the Institute of Electrical Engineers, v. 93, p. 429-457, 1946.

GALLOWAY, M. M. Texture analysis using gray level run lengths. Computer Graphics Image Processing, v. 4, p. 172-179, 1975.

GIL, L. D. Axiomatic Design and Fabrication of Composite Structures. [S.1.]: Oxford University Press, 2006.

GLATARD, T.; MONTAGNAT, J.; MAGNIN, I. E. Texture based medical image indexing and retrieval: application to cardiac imaging. In: Proceeding MIR '04 Proceedings of the 6th ACM SIGMM international workshop on Multimedia information retrieval. [S.1.: s.n.], 2004.

GOGUEN, J.; LINDE, C. Techniques for requirements elicitation. 1st IEEE International Symposium on Requirements Engineering (RE'93), San Diego, USA, p. 152-164, 1993.

GONZALES, R. C.; WOODS, R. E. Digital Image Processing. [S.1.]: Prentice Hall, New Jersey, 2 edition, 2002.

GYUNG-JIN, P. Analytic Methods for Design Practice. [S.1.]: Springer, ISBN: 978-1-84628-472-4, 2007.

HANDMANN, U.; KALINKE, T. Fusion of texture and contour based methods for object recognition. In: Proc. IEEE Conf. Intelligent Transportation System ITSC 97. [S.1.: s.n.], 1997. p. 876-881.

HANN, D. B.; SMITH, A. M. S.; POWELL, A. K. Classification of off-diagonal points in a co-occurrence matrix. International Journal of Remote Sensing, v. 24, p. 1949-1956, 2003.

HARALICK, R.; SHAPIRO, L. Computer and Robot Vision. [S.1.]: Addison-Wesley Publishing Company, 1992.

HARALICK, R. M. Statistical and structural approaches to texture. IEEE Transactions Proc., v. 67, n. 5, p. 786-804, 1979.

HARALICK, R. M.; SHANMUGAM, K.; DINSTEIN, I. Textural features for image classification. IEEE Trans Systems Man Cybernetics, v. 3, n. 6, p. 610-621, 1973.

HAWKINS, J. K. Picture processing and psychopictorics. In: [S.1.]: Eds., Academic Press, New York, 1970. cap. Textural Properties for Pattern Recognition, p. 347-370.

HAYKIN, S. Neural Networks - a comprehensive foundation. [S.1.]: Prentice-Hall, 2nd edition, 1999.

HE, D. chen; WANG, L. Texture unit, texture spectrum, and texture analysis. IEEE Transactions on Geoscience and Remote Sensing, Vol. 28, n. 4, p. pp. 509-512, 1990.

HEO, G.; LEE, S. K. Design evaluation of emergency core cooling systems using axiomatic design. Nuclear Engineering and Design, v. 237, p. 38-46, 2007.

HICKEY, A. M.; DAVIS, A. M. Elicitation technique selection: how do experts do it? In: Proc. 11th IEEE Int. Requirements Engineering Conf. [S.1.: s.n.], 2003. p. 169-178. 
HOU, L.; WEN, Z.; HAN, D. Axiomatic design of an integrated automatic welding system for the handle of motorcycle. In: Proc. IEEE Int. Conf. Control and Automation ICCA 2007. [S.1.: s.n.], 2007. p. 1245-1249.

HOUSHMAND, M.; JAMSHIDNEZHAD, B. Redesigning of an automotive body assembly line through an axiomatic design approach. In: Conference Proceedings at Downing College, Cambridge, UK. [S.1.: s.n.], 2002.

HUYNH, V. M.; KURADA, S.; NORTH, W. Texture analysis of rough surfaces using optical fourier transform. Measurement Science and Technology, v. 2, p. 831-837, 1991.

ISLAM, A.; AKHTER, S.; MURSALIN, T. E. Automated textile defect recognition system using computer vision and artificial neural networks. World Academy of Science, Engineering and Technology, v. 13, 2006.

JAHNE, B. Digital Image Processing. [S.1.]: Springer-Verlag Berlin Heidelberb New York, 2002.

JAIN, A.; FARROKHNIA, F. Unsupervised texture segmentation using gabor . filters. Pattern Recognition, v. 24, n. 12, p. 1167-1186, 1991.

JAIN, A.; ROSS, A.; PRABHAKAR, S. Fingerprint Matching using Minutiae and Texture Features. [S.1.], 2001.

JI, Q.; ENGEL, J.; CRAINE, E. Classifying cervix tissue patterns with texture analysis. Pattern Recognition, v. 33, p. 1561-1573, 1999.

JUNG, C.; CATEN, C. S. T.; ECHEVESTE, M. E. S.; RIBERITO, J. L. D. Análise estrutural e síntese das características lineares e sistêmicas de modelos de desenvolvimento de produto. Revista Liberato, Novo Hamburgo, v. 10, p. 103-114, 2009.

KAIZER, H. A quantification of textures on aerial photographs, Technical Note 121, AD 69484, Boston. University Research Laboratory. [S.1.], 1955.

KANDEL, E.; SCHWARTS, J.; JESSEL, T. Principles of Neural Science. [S.1.]: McGraw-Hill, Fourth Edition, 2000.

KANG, Y.; HASEGAWA, O.; NAGAHASHI, H. Texture structure classification and depth estimation using multi-scale local autocorrelation features. In: Proc. Conf. Computer Vision and Pattern Recognition Workshop CVPRW '03. [S.1.: s.n.], 2003. v. 6.

KOTONYA, G.; SOMMERVILLE, I. Requirements engineering: processes and techniques. [S.1.]: Chichester: J. Wiley., 1998.

KRAMER, D.; AGHDASI, F. Texture analysis techniques for the classification of microcalcifications in digitised mammograms. In: Proc. IEEE AFRICON. [S.l.: s.n.], 1999. v. 1, p. 395-400.

KRUIZINGA, P.; PETKOV, N.; GRIGORESCU, S. E. Comparison of texture features based on gabor filters. In: Proc. Int Image Analysis and Processing Conf. [S.l.: s.n.], 1999. p. 142-147. 
KULAKA, O.; CEBIB, S.; KAHRAMANC, C. Applications of axiomatic design principles: A literature review. Expert Systems with Applications, Vol. 37, p. pp. 6705-6717, 2010.

KULKARNI, S.; VERMA, B. An auto-associator for automatic texture feature extraction. In: Proceedings of the 4 International Conference on Computational Intelligence and Multimedia Applications. [S.1.: s.n.], 2001. p. 328-332.

KUMAR, A. Web inspection using multi-scale wavelet decomposition. August 2011. Disponível em:

$<$ http://www4.comp.polyu.edu.hk/ csajaykr/myhome/research/wavelets.html $>$.

LAMBERTI, C. Design Cerâmico. August 2011. Disponível em:

$<$ http://designceramico.com.br/wp-content/uploads/2010/04/62270.jpg >.

LCC. Site Liga contra o cancer. August 2011. Disponível em:

$<$ http://www.ligacontraocancer.com.br/>.

LEE, J.; SHIN, H. Parameter design of water jet nozzle utilizing independence axiom. In: Proceedings of the Institution of Mechanical Engineers, (Part E: Journal of Process Mechanical Engineering). [S.1.: s.n.], 2008. v. 222, n. 3, p. 157-169.

LEEA, K. D.; SUHA, N. P.; OHB, J.-H. Axiomatic design of machine control system. CIRP Annals - Manufacturing Technology, v. 50, n. 1, p. 109-114, 2001.

LENDARIS, G. G.; STANLEY, G. L. Diffraction-pattern sampling for automatic pattern recognition. Proc. IEEE, v. 58, n. 2, p. 198-216, 1970.

LIU, C.; WECHSLER, H. A shape- and texture-based enhanced fisher classifier for face recognition. IEEE Transactions on Image Processing, v. 10, n. 4, p. 598-608, 2001.

LIU, Y.; WU, S.; ZHOU, X. Texture segmentation based on features in wavelet domain for image retrieval. In: Visual Communications and Image Processing. [S.1.: s.n.], 2003. p. 2026-2034.

LOH, H.-H.; LEU, J.-G.; LUO, R. C. The analysis of natural textures using run length features. IEEE Transactions on industrial electronics, v. 35, n. 2, p. 323-328, 1988.

LORETTE, A.; DESCOMBES, X.; ZERUBIA, J. Texture analysis through a markovian modelling and fuzzy classification: Application to urban area extraction from satellite images. International Journal of Computer Vision, v. 36(3), p. 221-236, 2000 .

LUERKENS, D. W. Theory and Application of Morphological Analysis: Fine Particles and Surfaces. [S.1.]: CRC Press, 1991.

MAFFEI, S.; NELSON; G.G, T. Selective reconfiguration of layer 4 visual cortical circuitry by visual deprivation. Nature Neuroscience 7, v. 12, p. 1353-1359, 2004.

MAILLARD, P. Developing methods of texture analysis in high resolution images of the earth. X Simpósio Brasileiro de Sensoriamento Remoto, p. 1309-1319, 21-26 Abril 2001.

MALLAT, S. Multiresolution approximations and wavelet orthonormal bases of 12(r). Transactions of the American Mathematical Society, v. 315, n. 1, p. 69-87, 1989. 
MALLAT, S. G. A theory for multiresolution signal decomposition: the wavelet representation. IEEE Transactions on Pattern Analysis and Machine Intelligence, v. 11, n. 7, p. 674-693, 1989.

MANJUNATH, B. S.; CHELLAPPA, R.; MALSBURG, C. von der. A feature based approach to face recognition. In: Proc. CVPR '92. IEEE Computer Society Conf Computer Vision and Pattern Recognition. [S.1.: s.n.], 1992. p. 373-378.

MANJUNATH, B. S.; MA, W. Y. Texture features for browsing and retrieval of image data. IEEE Transaction on Pattern Analysis and Machine Intelligence, v. 18, n. 8, p. 837-842, 1996.

MARTINS, M. P.; GUIMARAES, L. N. F.; FONSECA, L. M. G. Texture feature neural classifier for remote sensing image retrieval systems. In: Proc. XV Brazilian Symp. Computer Graphics and Image Processing. [S.1.: s.n.], 2002. p. 90-96.

MATERKA, A.; STRZELECKI, M. Texture Analysis Methods - A Review, Technical University of Lodz, Institute of Electronics, COST B11 report, Brussels. [S.1.], 1998.

MATHER, P.; TSO, B. Classification Methods for Remotely Sensed Data. [S.1.]: Taylor \& Francis Group, LLC, 2nd ed., 2009.

MATHWORKS. MATLAB - The Language of Technical Computing. October 2010. Disponível em: <http://www.mathworks.com/products/matlab/>.

MELVIN, J. W.; SUH, N. P. Simulation within the axiomatic design framework. CIRP Annals - Manufacturing Technology, v. 51, p. 107-110, 2002.

MICHAELIS. Dicionario Michaelis. August 2011.

MILTON, N. R. Knowledge Acquisition in Practice, A Step-by-step Guide. [S.1.]: Springer, first edition, 2007.

MIRMEHDI, M.; XIE, X.; SURI, J. Handbook of Texture Analysis. [S.1.]: Imperial College Press, 2009.

MUDIGONDA, N. R.; RANGAYYAN, R.; DESAUTELS, J. E. L. Gradient and texture analysis for the classification of mammographic masses. IEEE Transaction on Medical Imaging, v. 19, n. 10, p. 1032-1043, 2000.

MUNEESWARAN, K.; GANESAN, L.; ARUMUGAMC, S.; SOUNDAR, K. R. Texture classi?cation with combined rotation and scale invariant wavelet features. Pattern Recognition Society, v. 38, p. 1495-1506, 2005.

MURATA, S.; HERMANAND, P.; LAKOWICZ, J. Texture analysis of fluorescence lifetime images of at- and gc-rich regions in nuclei. Journal of Histochemistry and Cytochemistry, v. 49, p. 1443-1452, 2001.

NAE. National Academy of Engineering. April 2010. Disponível em: $<$ http://www.nae.edu $>$.

NORDLUND, M. An Information Framework for Engineering Design based on Axiomatic Design. Tese (Doutorado) - Dept. of Manufacturing Systems, Royal Institute of Technology (KTH), Stockholm, Sweden., 1996.

NSF. Axiomatic Design Workshop for Professors, MIT, Cambridge, MA. [S.1.], 1998. 
ODOM, E.; BEYERLEIN, S.; BROWN, C. A.; D.DREW; L.GALLUP; S.ZIMMERMAN; J.OLBERDING. Role of axiomatic design in teaching capstone courses. In: Proceeding of the 2005 American Society for Engineering Education Annual conference \& Exposition. [S.1.: s.n.], 2005.

O'REILLY, R. C.; MUNAKATA, Y. Computational Explorations in Cognitive Neuroscience - Understanding the Mind by Simulating the Brain. [S.1.]: The MIT Press, 2000. ISBN 0-262-15052-2.

OTTO, K.; WOOD, K. Product Design: Techniques in Reverse Engineering and New Product Development. [S.1.]: New Jersey: Prentice Hall, 2001.

OXFORD. Oxford Dictionary. August 2011.

PAHL, G.; BEITZ, W. Engineering Design: A Systematic Approach. [S.1.]: London: Springer, $3^{\text {a }}$ edição, 2007.

PARTIO, M.; CRAMARIUS, B.; VISA, A. Rock texture retrieval using gray level co-occurrence matrix. In: Proc. of the 5th Nordic Signal Processing Symposium (NORSIG). [S.1.: s.n.], 2002.

PASQUALI, A. L.; RODRIGUES, R. B.; VIANA, R. H. da R.; PISTORI, H. Extração de características utilizando filtro de gabor aplicado à identificação de defeitos no couro bovino. Revista Hífen, v. 31, n. 59, p. 99-105, 2007. Disponível em: $<$ http://revistaseletronicas.pucrs.br/fo/ojs/index.php/hifen/article/view/3882/2950>.

PEARLSTINE, L.; PORTIER, L.; SMITH, S. E. Textural discrimination of an invasive plant, schinus terebinthifolius, from low altitude aerial digital imagery. Photogrammetric Engineering and Remote Sensing, v. 1, n. 3, p. 289-298, 2005.

PELAEZ, F.; RANVAUD, R.; SZAFIR, S.; RAMIREZ-FERNANDEZ, R. J. The illusion of movement in static images analyzed with a biologically plausible unsupervised neural network model. In: Proceeding of Brain Inspired Cognitive Systems - BICS. [S.1.: s.n.], 2008.

PETKOV, N.; KRUIZINGA, P. Computational models of visual neurons specialised in the detection of periodic and aperiodic oriented visual stimuli: bar and grating cells. Biological Cybernetics, v. 76, n. 2, p. 83-96, 1997.

PORTER, R.; CANAGARAJAH, N. A robust automatic clustering scheme for image segmentation using wavelets. IEEE Trans. Image Processing, v. 5, n. 4, p. 662-665, 1996.

PRATT, W. Digital Image Processing. [S.1.]: Wiley Interscience, New York, 3 ed, 2001.

PUGH, S. Total Design: Integrate Methods for Successful Product Engineering. [S.1.]: London: Addison-Wesley, 1990.

QUEIROZ, R.; SILVA, J. Requirements elicitation and communication in disjoint domains: case study in automation to surgical processes. Sba: Controle \& Automação Sociedade Brasileira de Automática, ISSN 0103-1759, v. 20, n. 4, 2009.

QUEIROZ, R. A. A. Eliciação e Comunicação de Requisitos em Domínios Disjuntos: Um estudo de Caso na Área Médica. Dissertação (Mestrado) - Universidade São Paulo - USP, Departamento de Engenharia Mecatrônica, 2007. 
RAGHU, P. P.; POONGODI, R.; YEGNANARAYANA, B. A combined neural network approach for texture classification. Neural Networks, v. 8, n. 6, p. 976-987, 1995.

REED, R. D.; MARKS, R. J. Neural Smithing - Supervised Learning in Feedforward Artificial Neural Network. [S.1.]: The MIT Press, 1999.

REIS, M.; BAUER, A. Wavelet texture analysis of on-line acquired images for paper formation assessment and monitoring. Chemometrics and Intelligent Laboratory Systems 95, v. 95, n. 2, p. 129-137, February 2009.

ROBERTSON, S.; ROBERTSON, J. Mastering the Requirements Process. [S.1.]: Addison-Wesley, 2006.

RUBNER, Y.; TOMASI, C. Perceptual Metrics for Image Database Navigation (The Kluwer International Series in Engineering and Computer Science, Volume 594). [S.1.]: Springer-Verlag, 2001.

RUIZ, L.; FDEZ-SARRA, A.; RECIO, J. Texture feature extraction for classification of remote sensing data using wavelet decomposition: A comparative study. In: Proceedings of XXth ISPRS Congress. [S.1.: s.n.], 2004. p. 1109.

RUSS, J. The Image Processing Handbook. [S.1.]: CRC Press, ISBN: 0-8493-2532-3, 1998.

RUSSELL, S.; NORVIG, P. Artificial Intelligence: A Modern Approach. [S.1.]: Prentice Hall. Edition. 2 nd edition, 2003.

SAMPAIO, J. R. G. Uma abordagem multi-escala para a geração de mosaicos. Dissertação (Mestrado) - Instituto de Ciências Matemáticas e de Computação ICMC, Universidade São Paulo - USP, 2007.

SCHETTINI., R.; B., C. B.; AC, C. C.; AC., G. C. On the detection of pornographic digital images. In: VCIP. [S.1.: s.n.], 2003. p. 2105-2113.

SEBE, N.; LEW, M. Principles of visual information retrieval. In: [S.1.]: Springer-Verlag Berlin Heidelberb New York, 2001. cap. Texture Features for Content-based Retrieval, p. 51-86.

SHABAN, M. A.; DIKSHIT, O. Textural classification of high resolution digital satellite imagery. In: Proc. IEEE Int. Geoscience and Remote Sensing Symp IGARSS '98. [S.1.: s.n.], 1998. v. 5, p. 2590-2592.

SHELDON, F. T.; KAVI, K. M.; TAUSWORTHE, R. C.; YU, J. T.; BRETTSCHNEIDER, R.; EVERETT, W. W. Reliability measurement: from theory to practice. IEEE Software, v. 9, n. 4, p. 13-20, 1992.

SIEW, L. H.; HODGSON, R. M.; WOOD, E. J. Texture measures for carpet wear assessment. IEEE Transactions on Pattern Analysis and Machine Intelligence, v. 10, n. 1, p. 92-105, 1988.

SILVA, I. N. da; SPATTI, D. H.; FLAUZINO, R. A. Redes Neurais Artificiais para engenharia e ciência aplicadas. [S.1.]: Artliber Editora, 2010. 
SILVA, L. A. Categorização de Imagens Médicas baseada em Transformada Wavelet e Mapas Auto-Organizáveis. Tese (Doutorado) — Universidade de São Paulo Departamento de Engenharia Elétrica, 2009.

SKLANSKY, J. Image segmentation and feature extraction. IEEE Transactions on Systems, Man, and Cybernetics, SMC-8, p. 237-247, 1978.

SONKA, M.; HLAVAC, V.; BOYLE, R. Image Processing, Analysis and Machine Vision. [S.1.]: CL-Engineering, 2 edition, 1998.

STRAND, J.; TAXT, T. Local frequency features for texture classification. Pattern Recognition, v. 27, n. 10, p. 1397-1406, 1994.

SUH, N. P. The Principles of Design. [S.1.]: Oxford University Press, New York, 1990.

SUH, N. P. Designing-in of quality through axiomatic design. IEEE Transactions on Reliability, v. 44, n. 2, p. 256-264, 1995.

SUH, N. P. Axiomatic design theory for systems. Research in Engineering Design, v. 10, n. 4, p. 189-209, 1998.

SUH, N. P. Axiomatic Design: advances and applications. [S.1.]: Oxford University Press. New York, EUA, 2001.

SULLIVAN, T. J.; SA, V. R. de. Homeostatic synaptic scaling in self-organizing maps. Neural Networks, v. 19, n. 6-7, p. 734 - 743, 2006. ISSN 08936080. Advances in Self Organising Maps - WSOM'05. Disponível em: $<$ http://www.sciencedirect.com/science/article/pii/S0893608006000712>.

TAMURA H., S. M.; YAMAWAKI, Y. Textural features corresponding to visual perception. IEEE Transactions on Systems, Man, and Cybernetics, SMC-8, p. 460-473, 1978.

TANG, X. Texture information in run-length matrices. IEEE Transactions on Image Processing, v. 7, n. 11, p. 1602-1609, 1998.

TATE, D. A. A Roadmap for Decomposition: Activities, Theories, and Tools for System Design. Tese (Doutorado) - Massachusetts Institute of Technology (MIT), 1999.

TITIVE, F. H. C.; BOUZERDOUM, A. Texture classification using convolutional neural network. IEEE Tencon, v. 1, 2006.

TIVIVE, F. H. C.; BOUZERDOUM, A. Efficient training algorithms for a class of shunting inhibitory convolutional neural networks. IEEE Transaction on Neural Networks, v. 16, n. 3, p. 541-556, 2005.

TIVIVE, F. H. C.; BOUZERDOUM, A. Texture classification using convolutional neural networks. In: Proc.IEEE Region 10 Conference TENCON. [S.l.: s.n.], 2006. p. $1-4$.

TOGAY, C.; DOGRU, A.; TANIK, J. Systematic component-oriented development with axiomatic design. Journal of Systems and Software, 2008. 
TOU, J. Y.; TAY, Y. H.; LAU, P. Y. Recent trends in texture classification: A review. In: Proceedings Symposium on Progress in Information and Communication Technology, SPICT 2009. [S.1.: s.n.], 2009. p. 63-68.

TRIESCH, J. A gradiente rule for the plasticity of a neuron's intrinsic excitability. ICANN, LNCS 3696, p. 65-70, 2005.

TRIESCH, J. Synergies between intrinsic and synaptic plasticity mechanisms. Neural Computation, v. 19, p. 885-909, 2007.

TUCERYAN, M.; JAIN, A. K. Handbook of pattern recognition and computer vision. In: __ [S.1.]: River Edge, NJ: World Scientific Publishing Company, 1999. cap. Texture analysis, p. 207-248.

TUCERYAN, M.; JAIN, A. K.; LEE, Y. Texture segmentation using voronoi polygons. In: Proc. CVPR '88. Computer Society Conf Computer Vision and Pattern Recognition. [S.1.: s.n.], 1988. p. 94-99.

TURRIGIANO; NELSON. Homeostatic plasticity in the developing nervous system. Nature Reviews Neuroscience 5, v. 5, p. 97-107, 2004.

ULLMAN, D. G. The Mechanical Design Process. [S.1.]: Singapore: McGraw-Hill, 1997.

ULRICH, K. T.; EPINGER, S. D. Product Design and Development. [S.1.]: New York: McGraw-Hill, 1995.

USHIZIMA, D. M.; MAYUMI, D.; SABINO, U.; COSTA, L. D. F.; RIZZATTI, E. G.; ZAGO, M. A. A texture approach to leukocyte recognition. RealTime Imaging, v. 10, n. 4, p. 205-216, 2004. Disponível em: $<$ http://www.vision.ime.usp.br/ cesar/programa/pdf/77.pdf $>$.

VERMA, B.; KULKARNI, S. Texture feature extraction and classification. Computer Analysis of Images and Patterns, Lecture Notes in Computer Sciense, v. 2124, p. 228-235, 2001.

VTT; OULU. Lumber Board Images. August 2011. University of Oulu and VTT Building Technology. Disponível em: $<$ http://www.ee.oulu.fi/ olli/Projects/Boards/Lumber.Boards.html $>$.

VYAS, V. S.; REGE, P. Automated texture analysis with gabor filter. GVIP Journal, v. 6, n. 1, July 2006. Disponível em: $<$ http://www.icgst.com/gvip/Volume6/Issue1/P1150614003.pdf $>$.

WAN, Y.-Y.; DU, J.-X.; HUANG, D.-S.; CHI, Z.; CHEUNG, Y.-M.; WANG, X.-F.; ZHANG, G.-J. Bark texture feature extraction based on statistical texture analysis. In: Proc. Int Intelligent Multimedia, Video and Speech Processing Symp. [S.l.: s.n.], 2004. p. 482-485.

WECHSLER, H. Texture analysis - a survey. Signal Processing, v. 2, p. 271-282, 1980.

WESZKA, J.; ROSENFELD, A. An application of texture analysis to materials inspection. Pattern Recognition, v. 8, p. 195-200, 1976. 
WHITCOMB, C. A.; SZATKOWSKI, J. J. Concept level naval surface combatant design in the axiomatic approach todesign framework. In: Proceedings of ICAD 2000, First International Conference on Axiomatic Design, Cambridge, EUA. [S.1.: s.n.], 2000. p. pp 21-23.

WILLIAMS, H.; NOBLE, J. Homeostatic plasticity improves signal propagation in continuous-time recurrent neural networks. Biosystems, v. 87, n. 2-3, p. 252 - 259, 2007. ISSN 0303-2647. Papers presented at the Sixth International Workshop on Information Processing in Cells and Tissues, York, UK, 2005 - IPCAT 2005, Information Processing in Cells and Tissues. Disponível em: $<$ http://www.sciencedirect.com/science/article/pii/S0303264706001729>.

WOUWER, G. Van de; SCHEUNDERS, P.; DYCK, D. V. Statistical texture characterization from discrete wavelet representations. IEEE Transactions on Image Processing, v. 8, n. 4, p. 592-598, 1999.

ZHANG, J.; TIENIU, T. Brief review of invariant texture analysis methods. Pattern Recognition, v. 35, p. 735-747, 2002.

ZHANG, X.; GAO, Y.; LEUNG, M. K. H. Automatic texture synthesis for face recognition from single views. In: Proc. 18th Int. Conf. Pattern Recognition ICPR 2006. [S.1.: s.n.], 2006. v. 3, p. 1151-1154. 